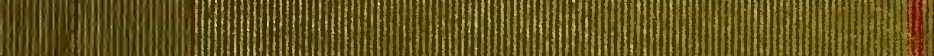
THE POTAT
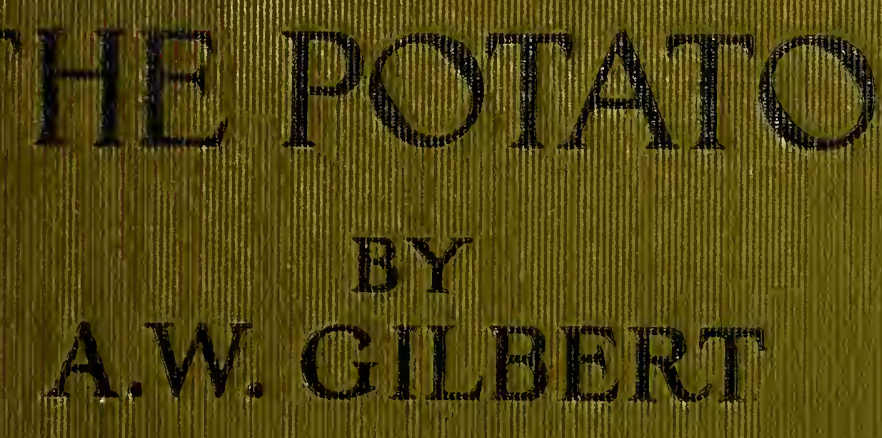

\title{
A.W. GILBERT
}




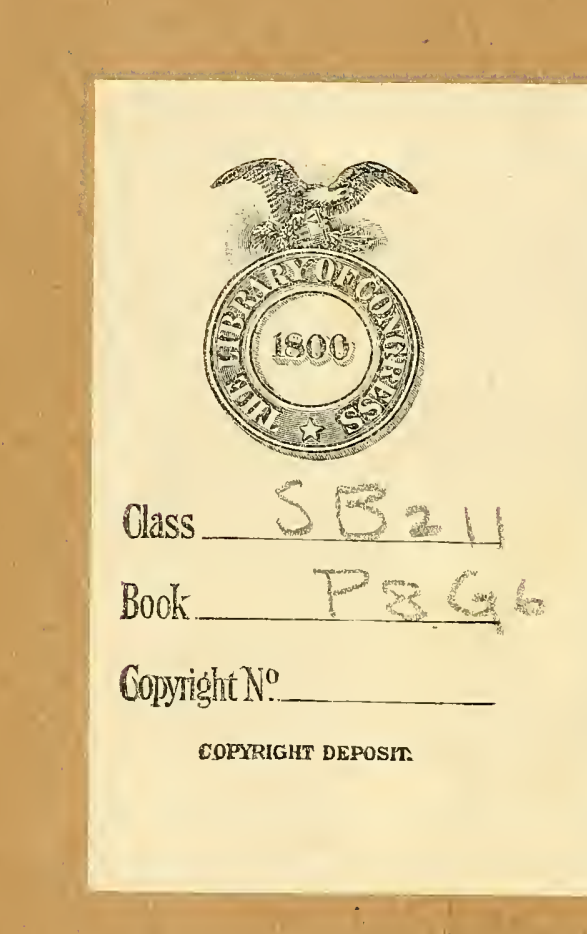


!

$y \quad z \quad \therefore$

30 in

(x)

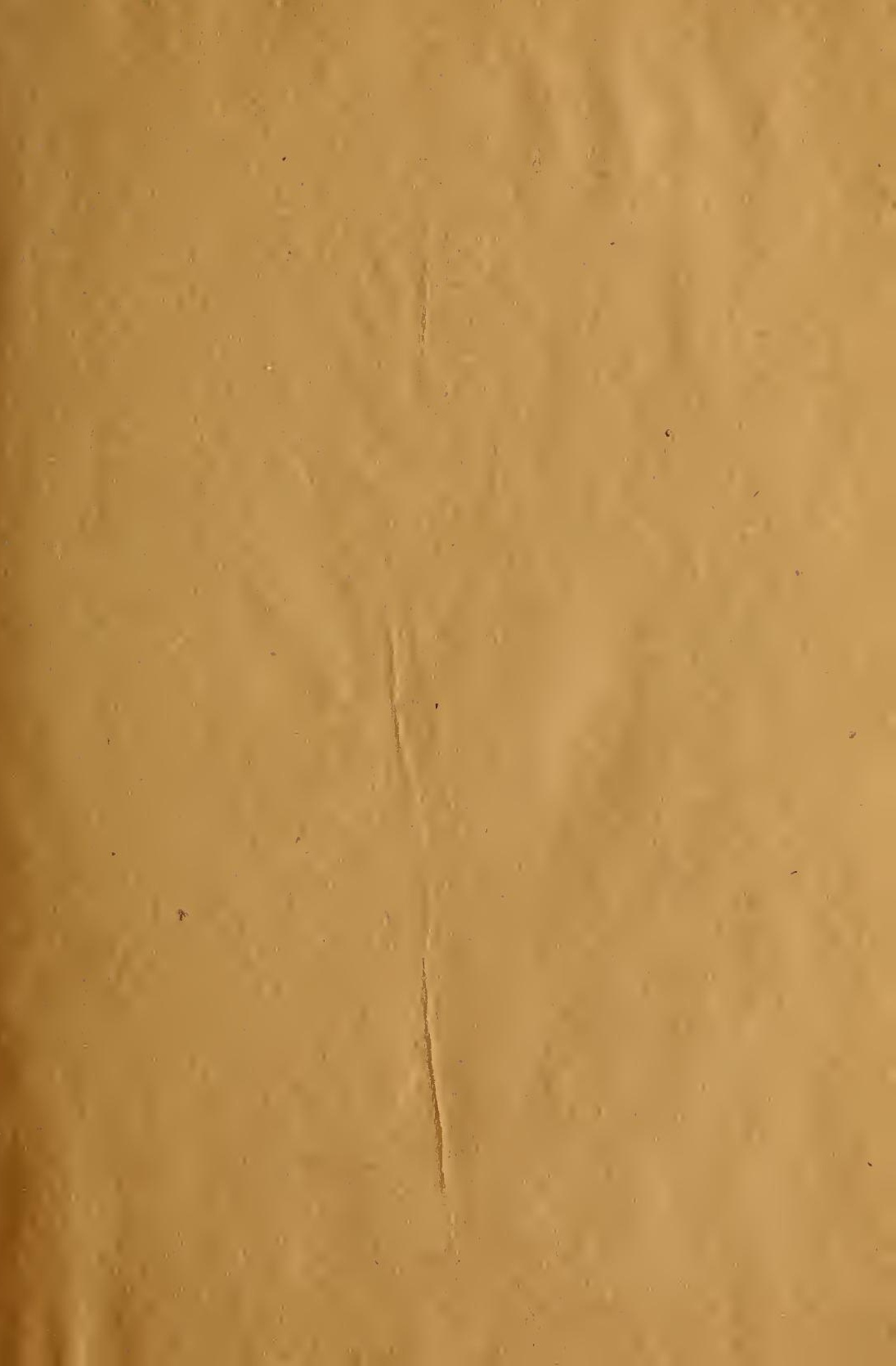


$+10$ 




\title{
Tbe TRural Icience \$erícs
}

\author{
EdITED BY L. H. BAILEY
}

\section{THE POTATO}




\section{The Litural Srimce Series}

Edited by L. H. Bailey

THE SoIL. King.

The Spraying of Plants. Lodeman.

Milk and its Products. Wing. Enlarged and Revised.

The Fertility of the Land. Roberts.

The Principles of Fruit-growing. Bailey. 20th Edition, Revised.

Bush-Fruits. Card. Revised.

Fertilizers. Toorhees. Revised.

The Principles of Agriculture. Bailey. Revised.

Irrigation and Drainage. King.

The Farmstead, Roberts.

Rural Wealth axd Welfare, Fairchild.

The Principles of Vegetable-gardenixg. Bailey.

Farm Poultry. Watson. Enlarged and Revised.

The Feeding of Animals. Jordan. (Now Rural Text-Book.)

The Farmer's Business Handbook. Roberts.

The Diseases of Animals. Mayo.

The Horse, Roberts.

How to Choose a Farir. Hunt.

Forage Crops. Voorhees.

Bacteria in Relation to Country life. Lipman.

The Nursery-book. Bailey.

Plant-breeding. Bailey and Gilbert. Revised.

The Forcing-воок. Bailey.

The Pruning-Book. Bailey. (Now Rural Manual Series.)

Fruit-growing in Arid Regions. Paddock and Whipple.

Rural Hrgiene. Ogden.

DrY-FARMING. Widtsoe.

LAW FOR THE AMERICAN FARMER. Green.

Farm Boys and Girls. Mcheever.

The Training and Breaking of Horses. Harper.

Shenp-farming in North America. Craig.

Coöperation in Agriculture. Powell.

The Farm Woonlot. Cheyney and Wentling.

Household Insects. Herrick.

Citrus Fruits. Coit.

Principles of Rural Credits. Morman.

Beekenping. Phillips.

Subtropical Vegetable-gardening. Rolfs.

Turf for Golf Courses. Piper and Oakley.

The Potato. Gilbert. 


\section{THE POTATO}

BY

ARTHUR W. GILBERT, PH.D.

PROFESSOR OF PLANT-BREEDING, NEW YORK STATE COLLEGE

OF AGRICULTURE AT CORNELL UNIVERSITY

ASSISTED BY

MORTIER F. BARRUS, Рн.D.

PROFESSOR OF PLANT PATHOLOGY, NEW YORK STATE COLLEGE OF AGRICULTURE AT CORNELL UNIVERSITY

AND

DANIEL DEAN

FORMERLY PRESIDENT OF THE NEW YORK STATE

POTATO ASSOCIATION

Trem 1 Gark

THE MACMILLAN COMPANY

1917

All rights reserved 


\section{$5 B 211$}

COPYRight, 1917,

BY THE MACMILLAN COMPANY.

Set up and electrotyped. Published March, 1917.

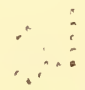

\section{MAR 291917}

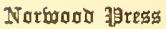

J. S. Cushing Co. - Berwick \& Smith Co. Norwood, Mass., U.S.A.

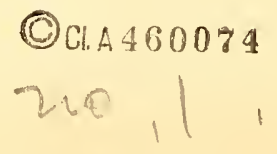




\section{PREFACE}

THIs book is intended to give brief and practical suggestions on the growing, breeding and marketing of potatoes. It is written especially for the practical farmer and the student who may wish concise information on the potato without having to read many miscellaneous sources of information, especially experiment station bulletins which, although highly valuable, are likely to contain much detail.

The chapters on breeding and varieties occupy an unusually large proportion of the book. This is for the reason that these subjects have been treated in potato literature much less than methods of culture, and the general interest in them has called for this extended discussion to meet not only the necessities of the case but also the public demand.

I have been glad to place in the hands of Doctor Barrus and $\mathrm{Mr}$. Dean the chapter's on Diseases and Field Methods respectively. These men have had broad experience in their lines and are thoroughly competent to discuss them.

The author wishes, also, to acknowledge the valuable aid of Professor Herrick in reading the manuscript on Potato Insects, and Mr. A. C. Fraser and Mr. J. J. Pollock for valuable assistance.

ARTHUR W. GILBERT.

ITHACA, New York,

January, 1917. 



\section{CONTENTS}

CHAPTER

PAGES

I. Acreage, Distribution, Production and ValuATION . . . . . . . . . . 1-13

II. History . . . . . . . . . 14-20

III. Classification and Botanical Characteristics . 21-46

Description of the Irish potato - Classification of varieties - Important varieties of Iowa and the Central West - Tabulation of varieties Synonyms - Description of typical varieties.

IV. Potato Breeding . . . . . .

Ideals for the potato crop - Use of score card - Possibilities of improving the potato - Methods of improvement - Improvement of the potato by selection - Running out of varieties - Appearance of bud sports - Improvement by hybridization.

V. Clmate, Sorls and Ronation . $\cdot$.
Factors influencing potato culture - Heat $86-112$ Water requirements - Soil texture - Available plant-food - Drainage and soil air-Critical period - Type, variety and strain - Diseases General types of potato-growing in the United States - Soils - Rotation - Hay plants.

VI. Manures and Fertilizers . . . . . $113-132$ tilizers - Nitrogen - Phosphorus - Potassium - Calcium - Sulphur - Applying fertilizers —. Farm manures. 
CHAPTEF

VII. Planting

Tillage tools - Results of tillage - Planting Hill and drill planting - Planting tools - Hand planting - Seed potatoes - Cutting seed.

VIII. Care of the Growing Crop . . . . . 160-169

IX. Potato Insects and Their Control . . . 170-182

The Colorado potato-beetle - Flea-beetle Blister-beetle - The three-lined leaf-beetle Tortoise-beetles - The potato plant-louse Leaf-hoppers - The potato-stalk weevil — The stalk-borer - White grubs - Wire-worms.

$X$. Diseases of the Potato

$183-205$

Classification of causes of disease - Early blight - Late blight - Rhizoctoniose - Fusarium wilt - Verticillium wilt - Fusarium dry rot - Silver scurf - Potato wart - Common scab - Black-leg - Bacteria wilt - Powdery scab - Tip-burn - Arsenical injury - Spindling sprout - Net-necrosis - Curly dwarf - Mosaic leaf-roll — Constitutional degeneracy and other weakened conditions of plants.

XI. Control Measures against Diseases

Control of curly-dwarf, mosaic and leaf-roll - Field inspection - Seed treatment to prevent disease - Disease from organisms already in soil - Treatment for potato blight - Preparation of bordeaux mixture - Other remedies - Diseaseresistant varieties - Summary.

XII. Harvesting the Potato

$226-236$

Time to harvest - Methods of digging - Picking and sorting - Labor and cost of harvesting.

XIII. Markets, Marketing and Storage

Marketing through local dealers - Marketing the crop — Grading - Packages — Shipping Early and late potatoes - Markets - Range and prices. 
Use for human food - Quality when cooked Use for starch - Process of starch manufacture - Uses of potato starch - Uses for industrial alcohol - The manufacture of alcohol from potatoes - Use as stock food - Alcohol slops or residue - Potato pomace - Poultry food - Dried or desiccated potatoes - Potato flour.

XV. Cost of Growing Potatoes .

Results of a survey in New York state - Other survey results - Cost of hauling. 



\section{LIST OF PLATES}

PLATE

I. The potato as first grown in Europe

II. Types of potato tubers, as illustrated by the Wisconsin Experiment Station . . . . 32

III. A plate of smooth potatoes with few and shallow eyes - the breeder's ideal . . . . 48

(Photo by Farm Crops Dept., Cornell University)

IV. Illustration of good shaped potato for table use. Variety, Green Mountain

(Photo by Farm Crops Dept., Cornell University)

V. Typical early and late potatoes. Top, Irish Cobbler (early). Bottom, Rural New Yorker (late) . . . . . . . . .

(Photo by Farm Crops Dept., Cornell University)

VI. Breeding. Each group of four plates represents the progeny of a tuber, and each plate is the product of a single hill

VII. Tubers with histories. Upper, influence of growing season, showing the second-growth tubers on the right compared with the normal uniform tubers on the left. Lower, breeding. - The immunity and susceptibility of two tuber progenies . . . . . . . .

VIII. Seed potatoes. Top, different ways of eutting. Bottom, good and bad types for seed . . 
PLATE

FACING PAGE

IX. Potato diseases. Upper tuber, lot caused by late blight; two bottom tubers, net necrosis. Leaf, under surface, showing effect of late blight

(Tuber cuts - Courtesy of Dept. of Plant Pathology, College of Agriculture, Cornell University)

(Leaf cut - Courtesy of the Geneva Agricultural Experiment Station Bulletin 241, Plate XII) ,

X. Potato diseases. Top, part of a potato leaf, showing spots of early blight. Bottom, rhizoctoniose . . . . . .

(Courtesy Dept. of Plant Pathology, College of Agriculture, Comell University)

XI. Potato diseases. Left, powdery scab. Right, fusarium dry rot . . . . . . .

(Courtesy Dept. of Plant Pathology, College of Agriculture, Cornell University)

XII. Spindling potato sprouts. Upper picture, rhizoctoniose . . . . . . 198

(Courtesy Dept. of Plant Pathology, College of Agriculture, Cornell University)

XIII. Preparing the bordeaux mixture

(Courtesy Dept. of Plant Pathology, College of Agriculture, Cornell University)

XIV. The potato harvest. View in an eastern field . 232

XV. Combined potato digger and loader . . . . 233

(Photo by W. C. Blake)

XVI. Potato products . . . . . . 259 
THE POTATO 



\section{THE POTATO}

CHAPTER I

ACREAGE, DISTRIBUTION, PRODUCTION AND VALUATION

THE potato is one of the most widely cultivated of the agricultural plants. The esculent tubers, which are developed underground on slender leafless shoots or stems, are used for food and also industrially. The plant is allied botanically to several powerful narcotics, such as tobacco, henbane and belladonna, and also to the tomato, eggplant and capsicum.

The potato comprises about 25 per cent of the food of European and English-speaking peoples. Only the Oriental peoples exist without it. A greater weight of potatoes can be produced to a unit area than any other food crop.

The yield in millions of tons of the world's most important plants is shown in the following table:

Table I. - World's Crops of the Most Important Food Plants, in Million Tons. Average for 5 Years, 19081912

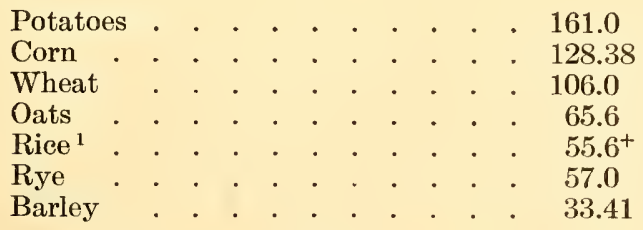

${ }^{1}$ This figure does not represent the rice crop of the world, as statistics from certain sections of China are lacking. 
The average annual production of potatoes in the world for the last ten years has been over 5,000,000,000 bushels. The production of wheat, corn and oats has been approximately 4,000,000,000 bushels each. Potatoes, therefore, lead the other crops in total production.

This immense total world production is generally and widely distributed. The six leading countries and their average anmual production for the years 1911-1913, and the average yields an acre for the years 1904-1913, are as follows (see Fig. 1):

\section{TABLE II}

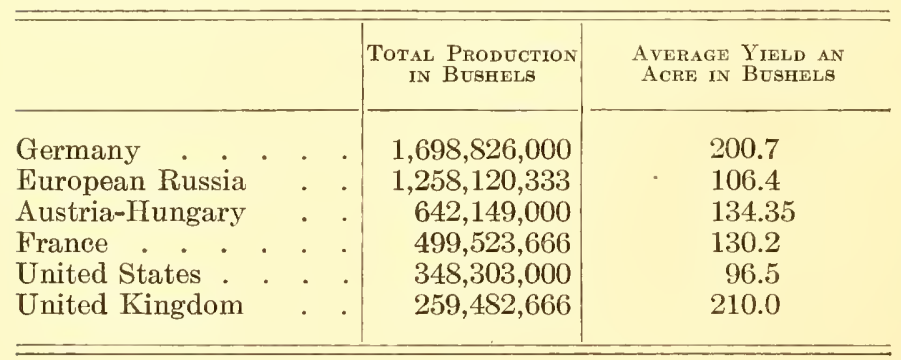

About 90 per cent of the world's crop is grown in Europe, Germany and Russia producing more than half of the total crop. The United States produces only about one-fifth as much as Germany. This is largely due to the fact that the German consumption per capita is about two and one-half times as great as ours, and that more than 50 per cent of the German crop is used either for stock food or for conversion into starch, alcohol or other industrial by-products. Potatoes, at present, are used very little for these purposes in this country, less than 1 per cent being so employed. 
Table III. - Percentage of World's Potato Crop ${ }^{1}$ Produced by the Continents, and Principal Potato-producing Countries. For the Years 1908-1912

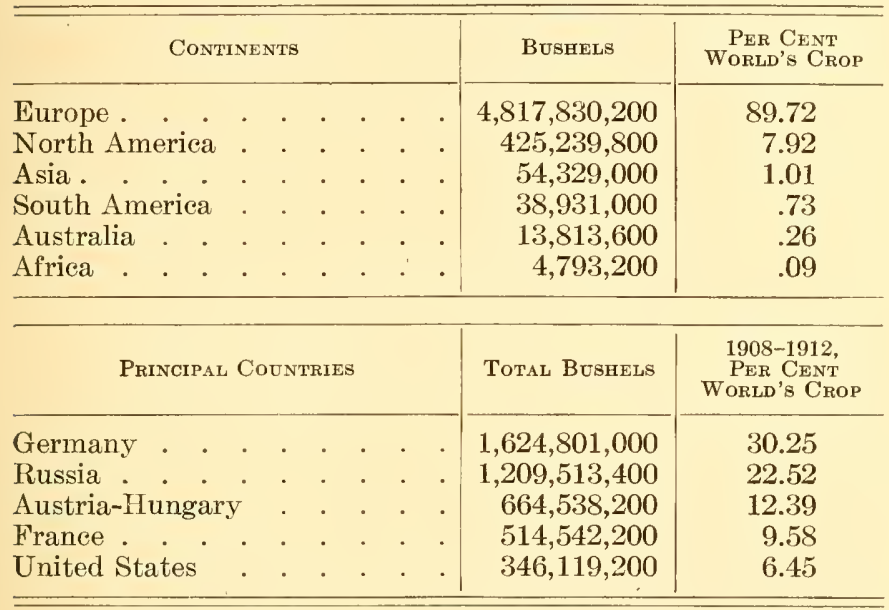

The cultivation of the potato is now extended over most of the agricultural sections of the United States and Canada and it is becoming increasingly important as an article of human food in this country. It ranks sixth in agricultural importance in the United States.

Table IV. - Relative Value of Crops in the United States IN Dollars (1908-1912)

\begin{tabular}{|c|c|c|c|c|c|c|c|c|}
\hline Corn & & & & . & & & & $1,512,780,000$ \\
\hline Hay & & & • & . & & . & & $768,330,000$ \\
\hline Cotton & . & & . & . & . & . & . & $724,710,000$ \\
\hline Wheat & & & . & . & . & . & & $666,940,000$ \\
\hline Oats & . & & . & . & . & . & & $412,360,000$ \\
\hline Potatoes & & & & . & . & . & • & $209,720,000$ \\
\hline Barley. & & & & & & & & $107,710,000$ \\
\hline Tobacco & & & & & & & & $94,429,000$ \\
\hline
\end{tabular}

${ }^{1}$ Average of world's crop for 1908-1912 = 5,369,590,000 bushels. 
The Potato

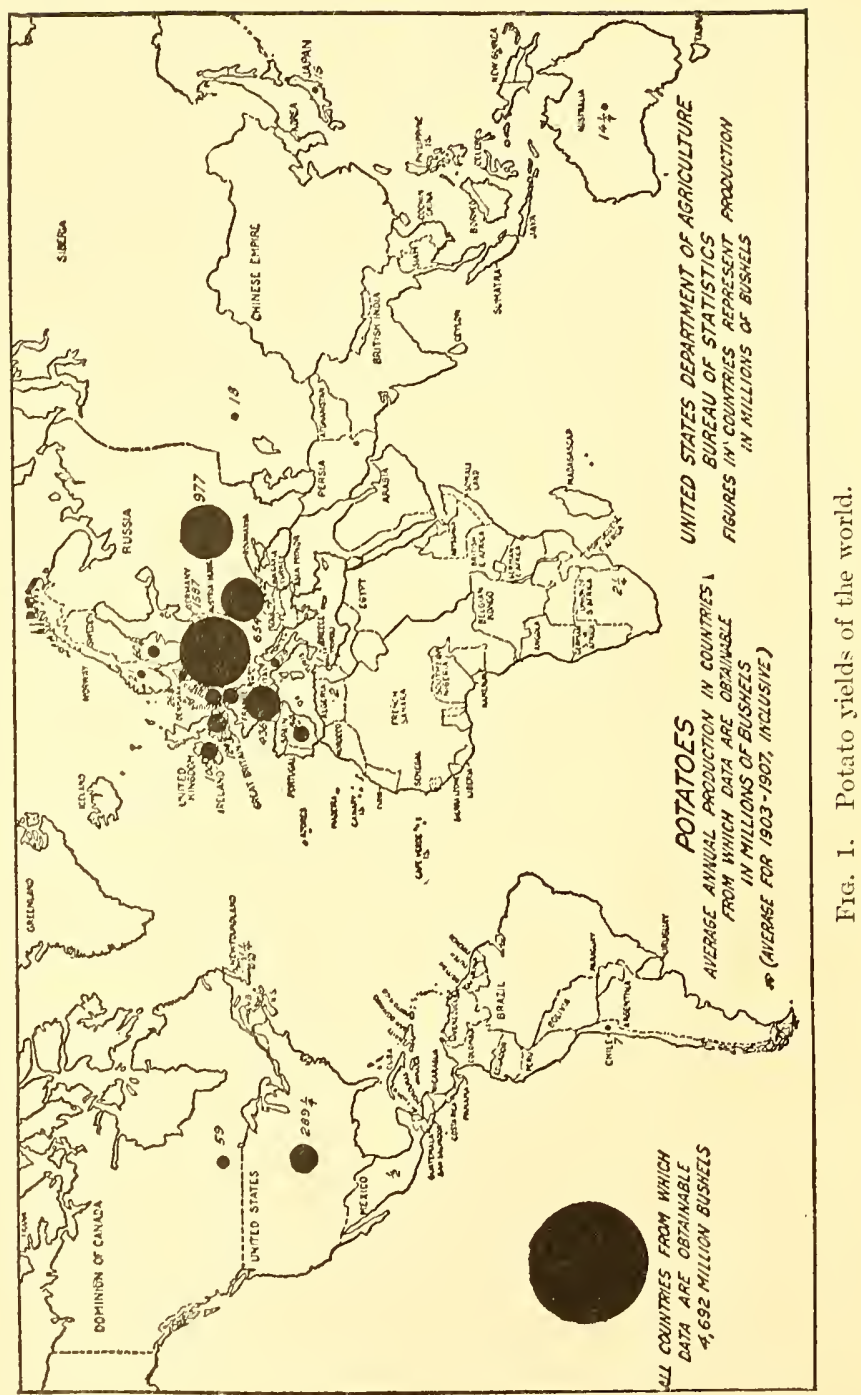


The following table illustrates graphically the distribution of potato-growing in the Uniter States (see Fig. 2).

In the United States, New York has led in potato production for the last twenty-five years. The learling states and yickl to the acre are as follows: ${ }^{1}$

TABLE V

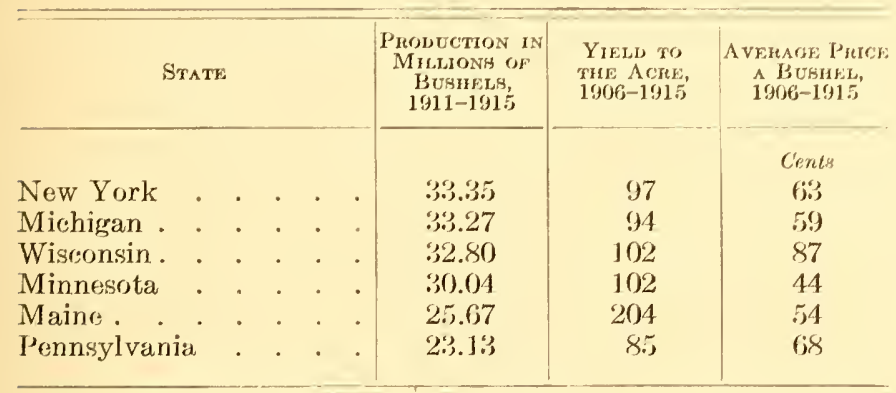

In the last few years, Michigan, Wisconsin, Maine and Minnesota have been rapidly gaining in production, and are now all close rivals of New York.

For the ten years 1902-1911 inclusive, an average of $3,230,000$ acres was devoted to the potato erop in the United States, from which $304,158,000$ bushels were producer, worth $\$ 177,503,000$. This comprises only about one-sixth of the world's crop.

Ten states along the northern border, where the climate is cooler and the erop is supplied with more moisture, produced nearly two-thirds of the potato crop of the United States (see Figs. 3 arıd 4). Potatoes are grown, however, in more or less quantity in every state of the Union.

As the agriculture in the United States becomes more

${ }^{1}$ After Montgomery. 


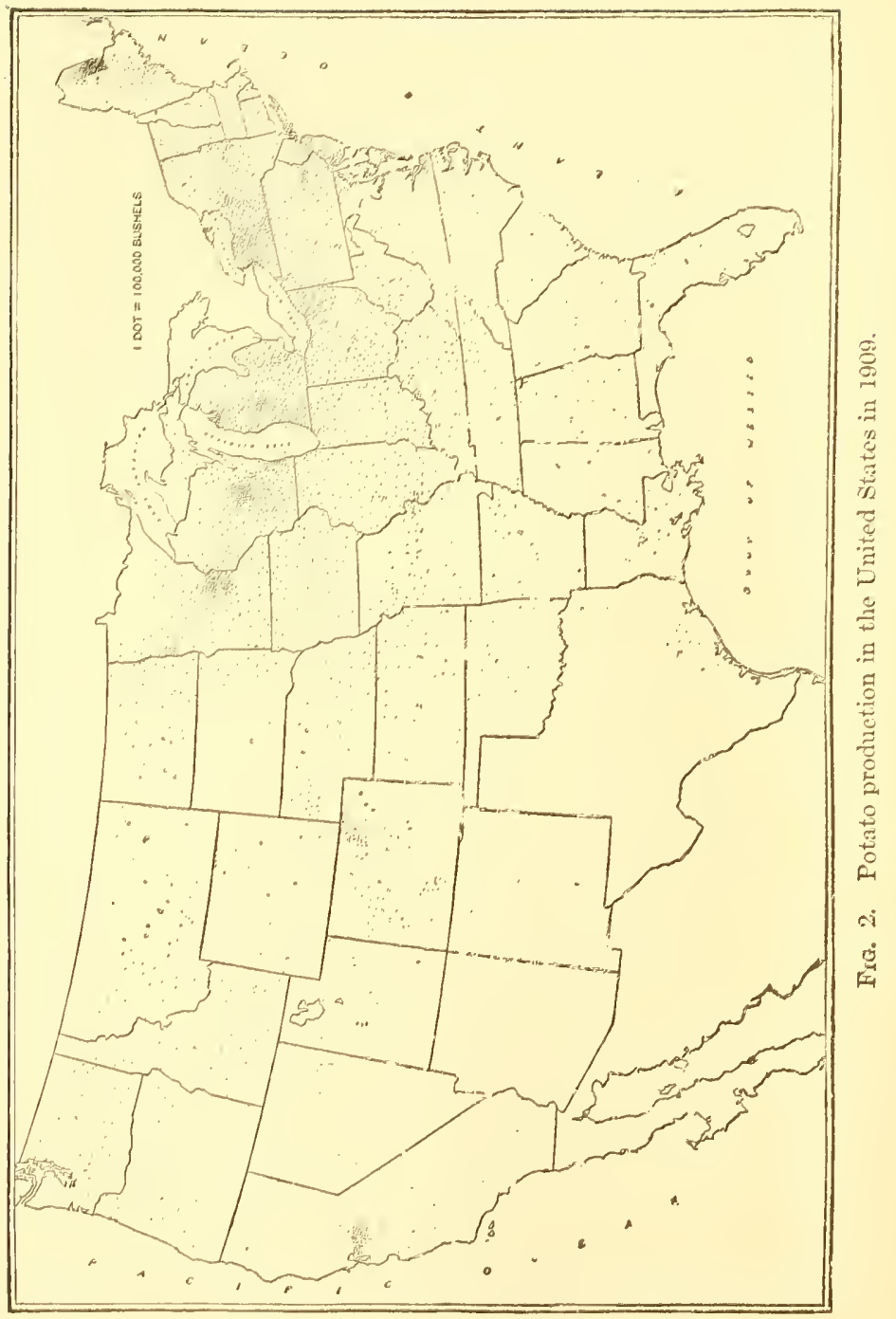


stable and railroad facilities develop, there is more and more of a tendency for farm crops to be intensively grown in certain areas where soil, climate and other fartors are hest suited tr, them. This is esperially tmue of a crop like com or wheat which is neither perishable nor very bulky and can be easily shipred. This is becoming

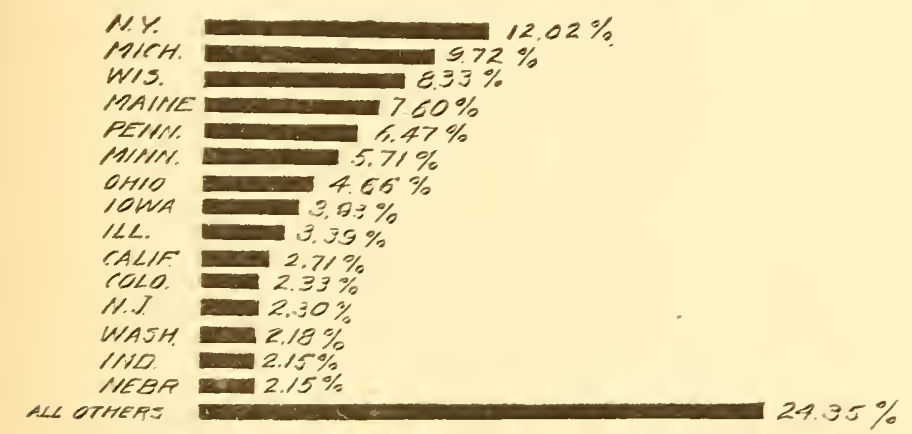

Els.3. Percertage of the protate, erop of the Trited States which is

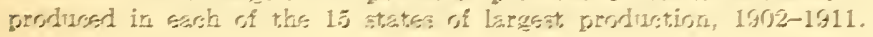

increasingly true of protatofs kfecause of their bulkiness and partial perishableness.

Jrost rof the protatoes raised in the Cnited States are still grown as a rash crop in relatively small parrels on many farms. There is a tendency, however, troward the development rof potatr-growing centers in widely separated sertions of the Cnited States. By a rareful inspertion of the map on page fine can sef that these areas are Irorated in Arorstrork County, Maine, the Norfolk and Eastem Shrore tmucking regions of Virginia and VIaryland, the Pied River Valley of Minnesota and Vorth Dakota, the Kaw Talley of Kansas, the Greely and Carbondale districts rf Corlorardo, and the San Joaquin and Sacramento valleve of California. 


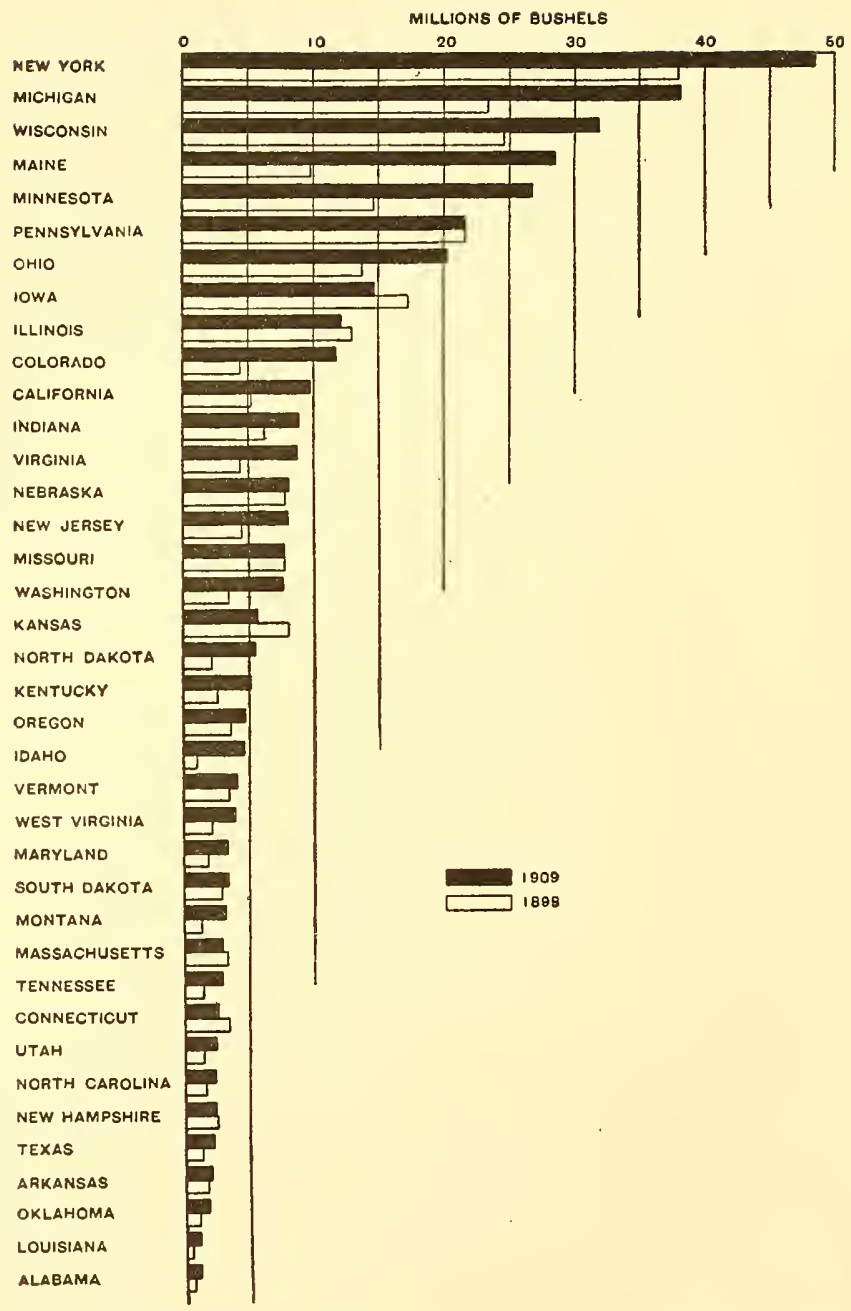

FIG 4. Production of potatoes in the different states, 1909 and 1899. 
The following tables from the thirteenth census indicate the total number of farms in certain states where potatoes were grown, the total yield and the total amount to each farm. The latter figure shows that the total production on most farms is in excess of the family consumption :

TABLE VI

\begin{tabular}{|c|c|c|c|c|c|c|}
\hline State & County & $\begin{array}{c}\text { BUSHELS } \\
\text { TO A } \\
\text { FARM }\end{array}$ & Codnty & $\begin{array}{c}\text { BUSHELS } \\
\text { TO A } \\
\text { FARM }\end{array}$ & County & $\begin{array}{c}\text { BUSHELS } \\
\text { TO A } \\
\text { FARM }\end{array}$ \\
\hline Mass. & Berkshire & 128.5 & Hampshire & 112.3 & Hampden & 119.9 \\
\hline Vt. & Bennington & 169.2 & Chittenden & 154.5 & Addison & 116.1 \\
\hline N. J. & Salem & 636.8 & Monmouth & 643.8 & Gloucester & 389.1 \\
\hline Del. & Kent & 44.3 & New Castle & 83.8 & Sussex & 101.4 \\
\hline W. Va. & Jackson & 42.9 & Wood & 48.1 & Preston & 43.4 \\
\hline S. C. & Beaufort & 39.9 & Charleston & 33.0 & Colleton & 29.4 \\
\hline Ga. & Chatham & 189.4 & Thomas & 9.7 & Union & 11.0 \\
\hline Fla. & St. John & 183.4 & Hillsboro & 22.1 & Gadsden & 13.7 \\
\hline Ill. & Cook & 161.7 & Madison & 188.6 & St. Clair & 260.9 \\
\hline Ia. & Blackhawk & 92.5 & Grundy & 489.8 & Scott & 358.5 \\
\hline Mo. & St. Louis & 167.2 & Buchanan & 127.9 & Ray & 135.6 \\
\hline Neb. & Sioux & 134.5 & Douglass & 134.2 & Cherry & 68.6 \\
\hline Ky. & Jefferson & 386.5 & Pike & 25.0 & Campbell & 98.9 \\
\hline Ala. & Mobile & 109.7 & Jefferson & 20.9 & Dallas & 3.8 \\
\hline Tex. & Harris & 58.7 & Cherokee & 32.0 & Cass & 15.3 \\
\hline Wash. & Yakima & 365.5 & King & 203.4 & Pierce & 166.7 \\
\hline Id. & Ada & 89.6 & Bingham & 802.4 & Lincoln & 120.7 \\
\hline
\end{tabular}

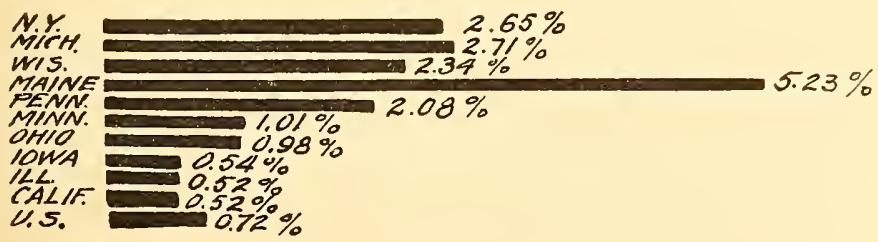

FIG. 5. Percentage of the improved farm land that was annually planted to potatoes in the ten leading states of the United States, 1902-1911. 


\section{TABLE VII}

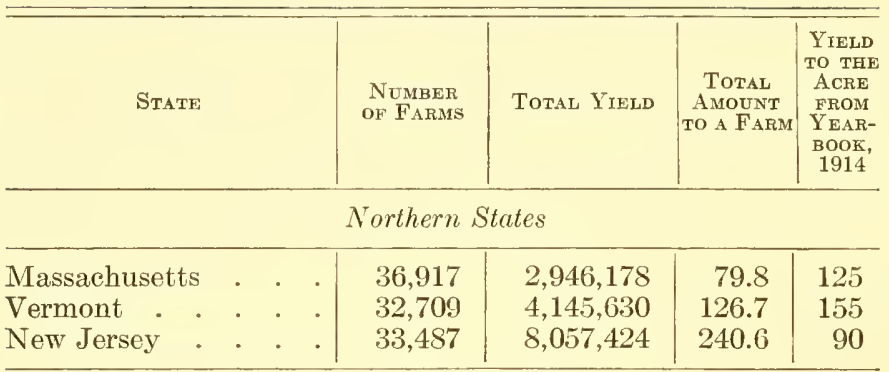

Southern States

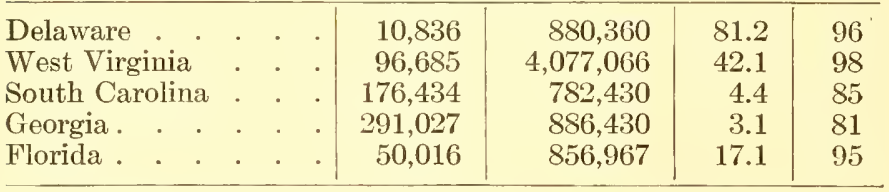

Northern Central States East of the Mississippi River

\begin{tabular}{llllll|l|l|l|l}
\hline Ohio : &. &. &. &. &. & 272,045 & $20,322,984$ & 74.7 & 93 \\
Illinois &. &. &. &. &. & 251,872 & $12,166,091$ & 48.3 & 91 \\
\hline
\end{tabular}

Northern Central States West of the Mississippi River

\begin{tabular}{|c|c|c|c|c|c|c|c|c|}
\hline Iowa & • & • & • & . & 217,044 & $14,710,247$ & 67.7 & 89 \\
\hline Missouri & . & . & . & . & 277,244 & $7,796,410$ & 20.8 & 85 \\
\hline Nebraska & . & - & . & . & 129,678 & $8,117,775$ & 62.5 & 78 \\
\hline
\end{tabular}

Southern Central States

\begin{tabular}{|c|c|c|c|c|c|c|c|c|}
\hline Kentucky & . & . & & . & 259,185 & $5,120,141$ & 19.7 & 92 \\
\hline Alabama & & . & & . & 262,901 & $1,128,564$ & 4.2 & 80 \\
\hline Texas. & . & . & . & . & 417,770 & $2,235,983$ & 5.3 & 50 \\
\hline
\end{tabular}

Far Western States

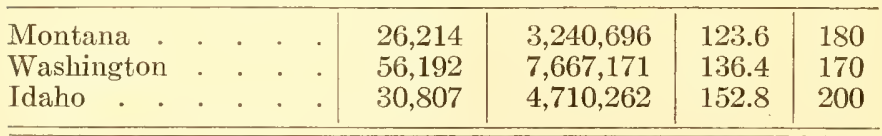


It is not easy to determine the amount of the family consumption of potatoes. It varies with different regions. In a survey of 483 farm families quite widely scattered, Funk found the average quantities and values of Irish potatoes consumed annually to a person in the following table :

\section{TABLE VIII}

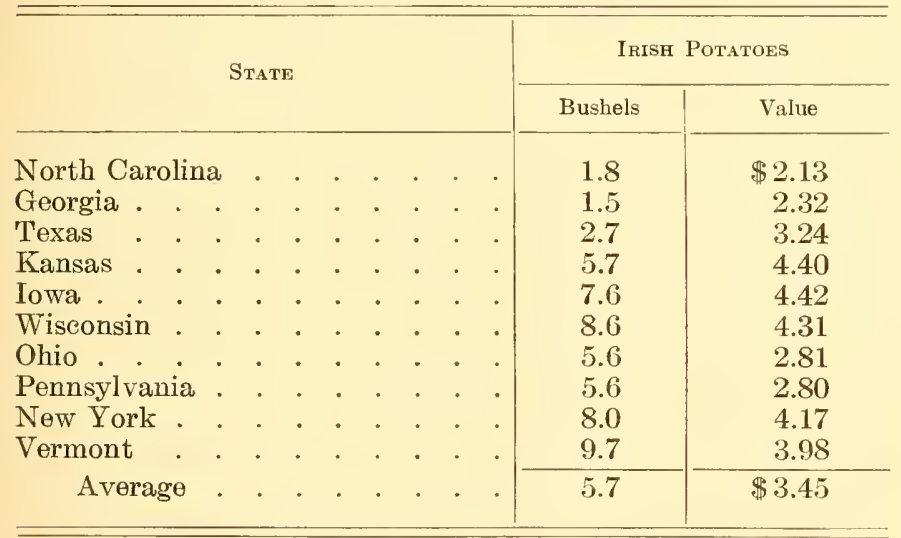

The average, it will be seen, was 5.7 bushels to a person. In the same survey was found an average of 4.6 persons in the family, making a total of 26.22 bushels of potatoes consumed to a family. Warren ${ }^{1}$ gives the average quantity of potatoes raised on the farm and used in the house on 106 farms in Livingston County, New York, in 1909 as 50.3 bushels and the average amount to an individual as 10.1 bushels. This is much higher than the figures Funk obtained in his survey, but even at this high figure, it is clearly seen that most farmers have at least a few bushels of potatoes to sell.

${ }^{1}$ Warren, G. F. “Farm Management," p. 24. 
In a farm management survey of Chester County, Pennsylvania, by Spillman ${ }^{1}$ it was found that the proportion of income from potatoes on 378 farms in that county was 8.9 per cent. On these farms, 6 per cent of the crop area was devoted to potatoes. "They were found on 366 of the 378 farms operated by owners. This crop is, therefore, very general in this region, though the acreage of potatoes is usually small. On only seven farms was the percentage of potato acreage found to exceed 20 (or 12 acres)." The farmers of this region grow at least enough for home use and usually some for sale.

The yields to the acre are dependent upon many factors, the most important of which seem to be climate and soil moisture. Yields to the acre in the United States are low as compared with England or Germany. The average yields of potatoes to the acre for the years 1901-1910 inclusive in the United States, Germany and Great Britain were 92.7, 200.8 and 200 respectively. European countries often grow the large, coarse, heavyyielding sorts for stock-feeding or for use in the arts, which accounts for some of the difference in average yields.

In the United States, the average yield to the acre is higher in Maine than in any other state. The average yield in the other states is usually 90 bushels or less.

Very large yields in the United States, however, are not unheard of. A yield of 700 bushels to the acre in Maine and the other potato-producing areas is not uncommon in very favorable seasons. Macoun, in speaking of the possibilities of the potato, makes note of the highest recorded yield of potatoes in this country. These were grown by Mrs. Selinda E. Jones of Chautauqua

1 Spillman, Dixon and Billings. "Farm Management Practice of Chester Co., Pa.," p. 26. 
County, New York, in the Women's National Potato Contest of 1888. She grew the White Elephant variety on one-twentieth of an acre at the rate of 1061 bushels to the acre.

In the United States the average yield of potatoes from one plant is about one-half pound. Some plants of Early Ohio have been known to yield thirteen tubers weighing $2 \frac{1}{2}$ pounds, and others of the same variety to produce three tubers weighing $\frac{1}{2}$ an ounce. The former yield is 80 times the latter. Some English experiments have produced twenty pounds of tubers to a plant, as many as 150 tubers being set on one plant.

The climate of Canada is well suited to the production of potatoes. The cool summers produce a yield to the acre that compares very favorably with the best regions of the United States. The average number of acres devoted to this crop for the years 1910-13 was 476,000 , upon which an average yield of 152.46 bushels to the acre was secured, making an average total yield for the four years of 72,569,000 bushels.

In the five fiscal years 1910-14, Canada exported an average of 1,451,990 bushels of potatoes each year, of which 376,406 bushels were sent to the United States. 


\section{CHAPTER II}

\section{HISTORY}

The early history of the potato is a matter of some doubt among historians, but all are agreed that it came originally from the high lands of Peru and Chile, where it is still found growing wild.

The Spaniards first discovered the potato in the neighborhood of Quito, Ecuador, where it was cultivated by the natives. According to Pedro Cieça de Léon, who seems to have made first written mention of the potato in his "Spanish Chronicles of Peru" (1550), the inhabitants subsisted largely on maize and what they called "papas" and "quinua:" The former is the Indian name for potato and the latter "is a plant about the height of a man and has leaves like the blite of Mauritania, and a small seed either red or white in color, from which is prepared a drink, and a food comparable to our rice."

Potatoes were used by the aborigines in place of bread, and were also dried in the sun to preserve them. They were usually cooked, but often made into flour. There was evidence of long-continued practice of cultivation, however crude. The potato, however, was and still is wild in the mountainous regions of Chile and Peru.

The potato was probably earried to Spain by explorers in the sixteenth century. There is no definite record of this first importation, but Rose believes that it was as 14 
early as 1533 or 1535 , at the time of the conquest of Peru by the Spaniards. Hieronymus Cardan, a monk, is supposed to have been the first to introduce it from Peru into Spain, and from thence it passed quickly into Italy, Austria, Germany, Switzerland, Belgium and France. The first figures and detailed description of it in its new home in continental Europe are those of Clusius in 1601 in his " Rariorum Plantarum Historia," although Bauhin in his "Phytopinax," printed in Basel in 1596, described it and gave it the Latin name or characterization, Solanum tuberosum esculentum.. (See Plate I.)

The date and method of introduction of the potato into North America are not definitely known, but it was probably introduced by Spanish voyagers and at sometime before 1585 , for it is clearly recorded that its first introduction was made into England by colonists from Virginia in 1586 under the patronage of Sir Walter Raleigh.

"It seems to me most likely," says De Candolle, "that some inhabitants of Virginia - perhaps English colonists - received tubers from Spanish or other travelers, traders or adventurers, during the ninety years which had elapsed since the discovery of America. Evidently, dating from the conquest of Peru and Chile, in 1535 to 1585, many vessels could have carried tubers of the potato as provisions, and Sir Walter Raleigh, making war on the Spaniards as a privateer, may have pillaged some vessel which contained them. This is the less improbable, since the Spaniards had introduced the plant into Europe before 1585."

At the discovery of America, we are told by Humboldt, the plant was cultivated in parts of western South America from Chile to Colombia but not in Mexico, and 
there is no account of its being found wild in other parts of North America.

From 1585 or 1586 , potato tubers were hrought from what is now North Carolina to Ircland on the return of the eolonists sent ont by Sir Walter Raleigh, and were first cultivated on Sir Walter's estate ncar Cork. This was some years later than their introduction into contimental Enirope.

In 1629, Parkinson in his "Paralisus," in which he gives an indifferent figure of the potato under the name of Papas seu Battatas Virginianorum, adds details as to the method of rooking the tubers which seems to indicate that they were still huxurics.

"The cultivation of the potato in Fingland made little progress for many years. It is said that in the time of James the first, they were so rare as to cost two shillings a pound, and are mentioned in 1619 among the articles provided for the royal houselodd. In 16i3:3, when their valuable properties had become more generally known, they were deemed worthy of notice by the Royal Socicty, which took measures to encourage their coltivation and for introduction into Ireland, especially as a safeguard aganst lamine, but their cultivation las become general only within the last one hundred years.

John Gerard received some tubers of the potato from Virginia and planted them in his garken. Ie gave a atureful alescription of then in his "Ilerbal," the first edition of which was published in London in 1597. In a later edition (163i) he pictures them by means of a woodcut (see Fig. 6). Me was so proul of these plants that he was represented in his portrait at the beginning of the work holding a flowering brancls of the plant in his hand. 
It should be noticed how closely the description of the potato at this early date corresponds with the plant as grown to-day. He says: "Virginia potato hath many hollow, flexible branches trailing upon the ground; these are square, uneven, knotted or kneed in sundry places at certaine distances: from the which knots cometh forth one great leafe made of divers leaves, some smaller and other greater, set together upon a fat midrlle rib by couples, of a swart green colour tending to redness; the whole leaf resembling those of the Winter-Cresses, but much larger; in taste at the first like grasse, but afterwards sharp and nipping the tongue.
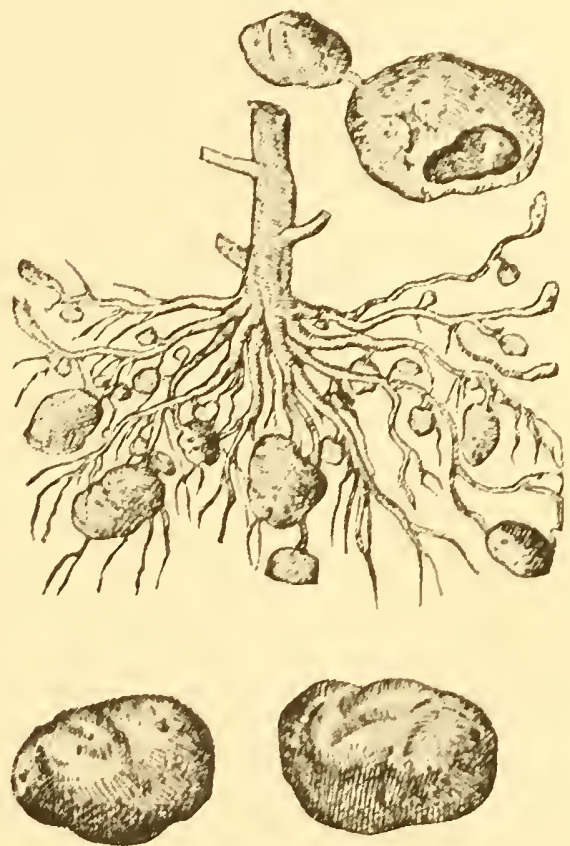

FiG. 6. Copy of the engraving of the Virginian protato in Gerard's "Herbal" - printed in 1636.

From the bosome of which leaves come forth long round slender foot stalkes, whereon grew very faire and pleasant floures, made of one entire whole leafe, which is folded or plaited in such strange sort, that it seems to be a floure made of five sundry small leaves, which cannot easily be 
perceived, except the same be pulled open. The whole floure is of a light purple colour, striped downe the middle of every fold or welt with a light show of yellownesse, as if purple and yellow were mixed together. In the middle of the floure thrusteth forth a thicke flat point all yellow as gold, with a small sharpe greene pricke or point in the midst thereof. The fruit succeeds the floures, round as a ball, of the bigness of a little Bullesse or wild plumme, green at first, and blacke when it is ripe, wherein is contained small white seed lesser than those of mustard; the root is thick, fat, and tuberous, not much differing either in shape, colour or taste from the common potatoes, saving that the roots hereof are not so great nor long; some of them are as round as a ball, some oval or eggefashion, some longer and others shorter; the knobby roots are fastened unto the stalkes with an infinite number of threddy strings. It groweth naturally in Americus where it was first discovered, as reporteth Clusia, since which time I have received roots hereof from Virginia, otherwise called Norembega, which grow and prosper in my garden as in their own native country. The leaves thrust forth on the ground in the beginning of May; the floures bud forth in August, the fruit is ripe in September. The Indians call this plant pappas, meaning roots, by which name also the common potatoes are called in those Indian countries. We have its proper name mentioned in the title 'Potatoes of Virginia.' Because it hath not only the shape and proportion of potatoes but also the pleasant taste and vertues of the same, we may call it in English, Potatoes of America or Virginia."

In 1769, the grain crops of France were a failure, threatening a national famine. Parmentier, a Parisian chemist, recommended the use of potatoes as food to take the 


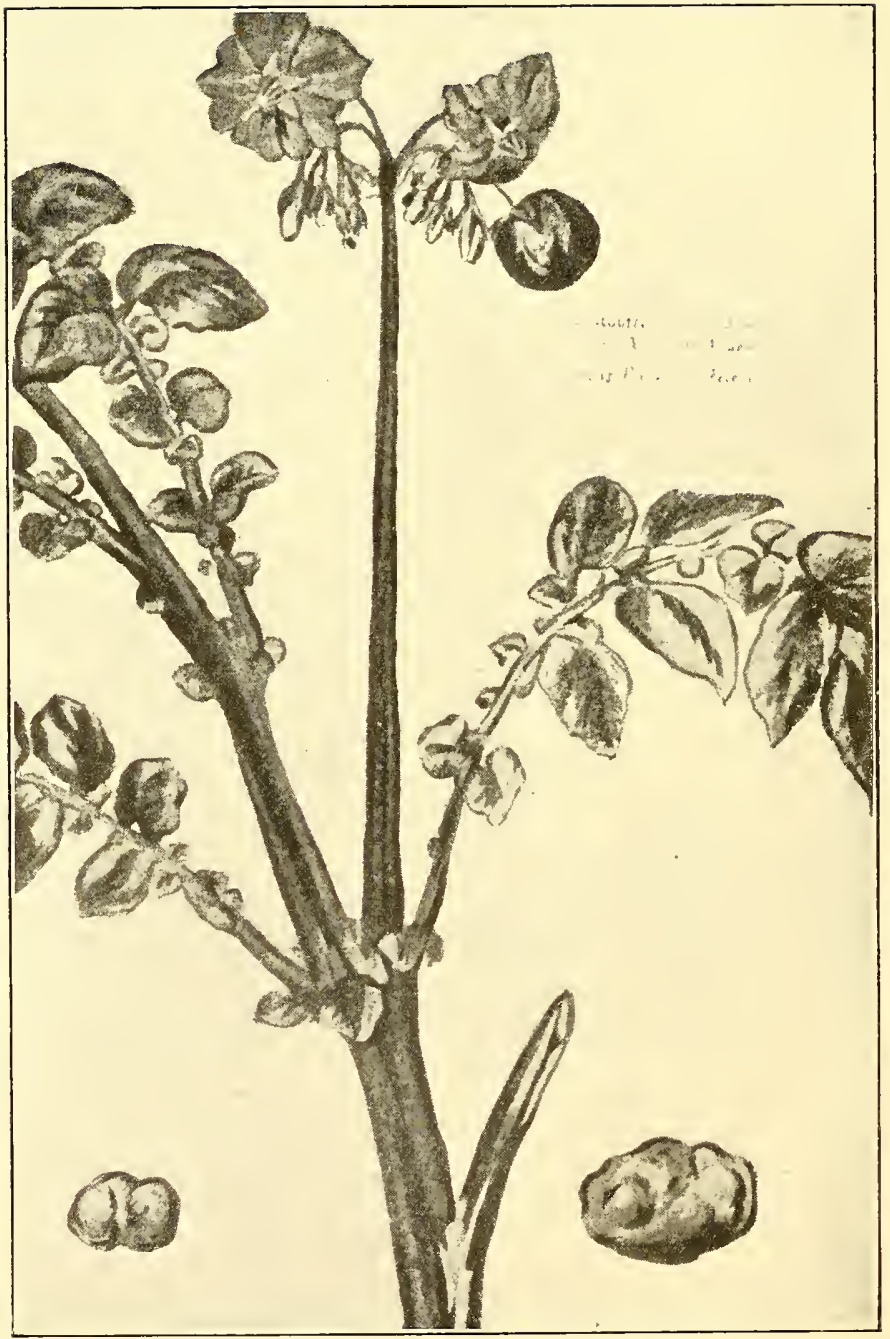

Plate I. - The potato as first grown in Europe. 
place of the grain crops. He had been a member of the medical staff of the French army in 1758, during the war in Hanover, and had been taken prisoner. During his five years in prison his principal food consisted of potatoes, which were then grown almost exclusively as food for animals. The dire need of food in France inspired him to write a book called a "Treatise on Certain Vegetables that in Times of Necessity can be substituted for Ordinary Food." This book was received with ridicule even though it received a certain amount of support from the Paris Agricultural Society. By persistent efforts, Parmentier was granted a small patch of land on which to experiment with his potatoes. The king ordered the plot to be guarded by a cordon of troops which excited the curiosity of the people. On August 24th, the king's fête-day, he presented the king with a basket of tubers and a bouquet of the blossoms. These were worn by the king and queen, who also ate the cooked tubers. They were found to be very palatable and soon became one of the foods of the French people.

During the seventeenth century, the potato gradually became, from a botanical curiosity cultivated only by collectors of new plants, one of the staple garden and field crops. Its cultivation as a field crop became somewhat common in Germany soon after 1772, when the grain crops failed and potatoes were used as a substitute. The quality was very poor, however, and even though they were enormously productive, their use was restricted largely as food for domestic animals and they were used as human food only when necessary as a substitute. By the latter half of the eighteenth century, it was extensively cultivated and recognized as one of the regular crops throughout the temperate regions of Europe and 
America, so that Henry Phillips (1822), who published a detailed account of the potato and its culture, was able to cite a single grower who planted 300 acres annually.

In Ireland, they were used very extensively as human food. By 1840 they had largely replaced the cereals and similar food crops because their yield in weight exceeded by twenty to thirty times the yield of wheat, barley or oats on an equal amount of land. Dependence upon a single crop for food, however, became disastrous for the Irish. The potato blight which appeared in the United States in 1845 devastated Ireland in 1846 and caused a widespread famine. It is conservatively estimated that 600,000 persons died during the two years 1846 and 1847 for want of food or from diseases caused by a meager diet of unhealthy and unnutritious food. By 1848 the plague had practically ceased.

\section{REFERENCES}

Campbell, W. H. W. The Father of the Potato. Cosmopolitan, Vol. II, pp. 191-192. 1886.

De Candolle, Alphonse. Origin of Cultivated Plants. 1-468, N. Y., 1892.

De l'Ecluse (or Clusius). Rariorum Plantarum Historiae, 1601, lib. Gerard. Herbal. 1597, p. 781, with illustration.

Heckel, E. The Origin of the Cultivated Varieties of the Potato. Rev. Sci. (Paris), 50: 1912, II, No. 21, pp. 641-646.

Henslow, Geo. The Origin and History of Our Garden Vegetables and Their Dietetic Values. II. Roots + tubers (cont.). Roy. Hort. Soc. Journ., 36: pp. 345-346, Figs. 120121 (1910-1911).

Rose, ERnest. Histoire de la pomme de terre traitée aux points de vue historique, cultural et utilitaire. 1-464 Par. 1898.

Sabine, J. On the Native Country of the Wild Potatoes. Trans. Hort. Soc. London, Vol. V, pp. 249-259. 1824. 


\section{CHAPTER III}

\section{CLASSIFICATION AND BOTANICAL CHARAC- TERISTICS}

The common or Irish potato is known botanically as Solanum tuberosum. This name was first applied to it by Bauhin in his "Phytopinax" in 1596 (page 15) and later adopted by Linnæus. In the same family (Solanaceæ) are many other plants of economic importance, as tomato, eggplant, tobacco, belladonna, henbane and capsicum or red-pepper.

Baker has reviewed the tuber-bearing species of Solanum from a systematic point of view as well as that of geographic distribution. Out of twenty so-called species he considers six to be really distinct, while the others are synonymous or trifling variations. The six admitted tuber-bearing species are S. tuberosum, S. Maglia, S. Commersonii, S. Cardiophyllum, S. Jamesii and S. oxycarpum. See also "Standard Cyclo. Hort." VI, 3181.

The following descriptions of species have been taken from Baker's "A Review of Tuber-bearing Species of Solanum" - Linnæan Soc. Journ. Bot., XX : pp. 489507 , pls.

Solanum tuberosum, Linn. - Stems stout, erect, much branched, 1-2 feet long, slightly hairy, distinctly winged on the angles. Leaves 1-2 feet long, slightly hairy, with 7-9 finely pilose oblong acute leaflets, the side ones stalked and unequally cordate at the base, the 1-2 lowest pairs much dwarfed, petiole about 1 inch long. Numerous small leaflets between larger ones. Flowers in compound terminal cymes with long peduncles. Corolla wheel shaped, dark lilac, 
nearly 1 inch in diameter. Calyx hairy, $\frac{1}{4}-\frac{1}{3}$ inch long, with teeth as long as or a little longer than the campanulate tube. Berry globose, less than an inch in diameter, smooth. Native of Chile and Ecuador.

Solanum Maglia, Schlecht. - Stems stout, erect, much branched, 1-2 feet long, strongly winged on angles, slightly hairy. Leaves 6-9 inches long, larger leaflets $5-7$, ovate acute, $2-3$ inches long, side ones stalked, unequally cordate at base. Flowers in compound cymes; pedicles downy. Corolla white, subrotate, $\frac{3}{4}$ to 1 inch in diameter. Style twice as long as the stamens. Fruit not seen.

Solanum Commersonii, Dunal. - Stems shorter and more slender than in S. tuberosum. Leaves 5-6 inches long, with a naked petiole 1-1 $\frac{1}{2}$ inches long; $5-9$ oblong acute leaflets, the terminal one much the longest; the rachis entirely without any of the small leaflets interspersed among the large ones. Flowers in lax compound cymes. Calyx $\frac{1}{6}-\frac{1}{4}$ inch long. Corolla pale lilac or white. Anthers orangeyellow. Style distinctly exserted beyond the anthers. South America.

Solanum cardiophyllum, Lindley. - Of the same general habit as S. tuberosum. No small leaflets interspersed amongst the large ones. Whole plant quite glabrous. Foliage very dark green. Leaflets 5, large, ovate acute. Flowers in compound cymes. Calyx glabrous. Style scarcely longer than the stamens. Mountains of Central Mexico at an elevation of 8000-9000 feet.

Solainum Jamesii, Torrey. - Minute globose tubers. Leaves distinctly petiolate, with 5-9 oblong acute leaflets; no smaller leaflets interspersed amongst the longer ones. Cymes few flowered. Corolla white. Fruit globose. Mountains of southwestern United States and Mexico.

Solanum oxycarpum, Schiede. - Tubers minute. Leaflets 5-9, oblong lanceolate, with no smaller leaflets interspersed amongst the larger ones. Cymes few flowered. Fruit ellipsoidal.

\section{DESCRIPTION OF THE IRISH POTATO}

The common potato owes its value to the peculiar habit of developing underground slender leafless shoots or branches which differ in character and office from the true roots, and gradually swelling at the free end 
produce the tubers (potatoes), which are the common vegetable food. The nature of these tubers is further rendered evident by the presence of "eyes" or leafbuds, which in due time lengthen into shoots and form the haulm or stems of the plant. Such buds are not, under ordinary circumstances, formed on roots. This budding of the tubers furnishes an efficient method of propagation, independent of seed production. Starch and other matters are stored up in the tubers, as in the seed, and are rendered available for the nutrition of the young shoots. When grown under natural circumstances, the tubers are relatively small, and close to the surface of the soil, or even lie upon it. In the latter case, they become green and have an acrid taste, which renders them unpalatable to human beings, and as poisonous qualities are produced similar to those of many Solanaceæ, they are unwholesome. Hence the recommendation to keep the tubers in cellars or pits not exposed to the light. Among the 900 species of Solanum, less than a dozen have this property of forming tubers. The production of small green tubers on the haulm, in the axils of the leaves of the potato, is not very infrequent, and affords an interesting proof of the true morphological nature of the underground shoots and tubers. This phenomenon follows injury to the phloëm in the lower parts of the stem, preventing the downward flow of the elaborated sap.

CLASSIFICATION OF VARIETIES. PLATE II

For the sake of convenience, the many varieties which are now on the market may be classified. No one classification, however, will be adequate to cover all conditions. Varieties differ somewhat from one part of the country 
to another. Most standard varieties have many synonyms which make the whole matter more confusing. The frequent appearance of new names for old varieties is as much the fault of the grower as it is of the seedsman. There is a strong demand for new things. The seedsman attempts to meet this, but most of our seedsmen are professedly not originators of new varieties, and the supply of strictly new varieties must, of necessity, be very limited, hence the demand is met by changing the name of some old variety and giving extensive advertising under its new name. The gullible grower accepts the dose, pays the price for the supposedly new article and is satisfied until he learns that it is nothing new and then he turns around and repeats the process again.

The number of named varieties is so large that the chances of finding something far superior are very slight. However, it is not at all impossible to find such a variety if one has the patience to look for it or the skill to produce it. However, for the average grower, it is much better to stick to the old standard sorts which are recognized in the market. If better varieties are demanded, it is wiser, in general, to start with standard varieties which have already reached some degree of perfection and improve them.

The potato is very susceptible to differences in soil and climate, and varieties often lose their distinguishing characteristics when grown under what might be considered unusual environment. There has also grown up, of course, a wide range of opinion as to what the standards of certain varieties are. The standard of a variety in one locality may be very different from the accepted standard of that same variety in another locality. The introduction of new varieties which may be but slight variations from the old sorts has still further complicated 
the situation. Moreover, many so-called new varieties are merely the old varieties under a new name. But on the whole, the old standard varieties may be recognized fairly accurately.

Potatoes may be classified according to the shape of the tubers. "Tubers are not always of the same form; three moderately distinct and fairly constant types are prevalent, namely, (1) round, (2) oval and (3) kidney shapes. The round type is somewhat spherical and has fewer internodes and 'eyes' than the oval or kidneyshaped potatoes. 'The kidney potatoes are thickest at the stem or basal end and taper gradually at the apex or seed end, while the oval varieties are thickest in the middle and taper towards both ends (see Fig. 7). These differences are sufficiently marked and constant for a comparison of the varieties in cultivation." - Percival.

Important varieties of Iowa and the Central West

C. L. Fitch, ${ }^{1}$ of the Iowa State College, made a thorough trial for a series of years of all varieties of commercial importance in the United States and Europe. He made also a canvass in person and by letter of the markets of the United States. The result was that only a few varieties were found to be of much commercial importance. He lists the following varieties as being the most valuable in the United States in order of their importance:

1. Rural

2. Green Mountain

3. Early Ohio

4. Burbank
5. Irish Cobbler

6. Bliss Triumph

7. Peerless (Pearl)

1 Fitch, C. L. "Identification of Potato Varieties." Iowa Extension Bul. 20 (1914). 

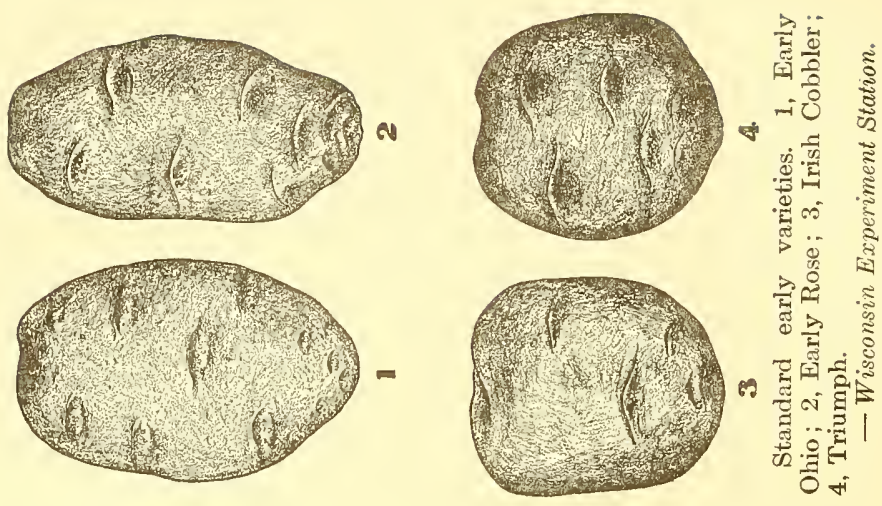

它
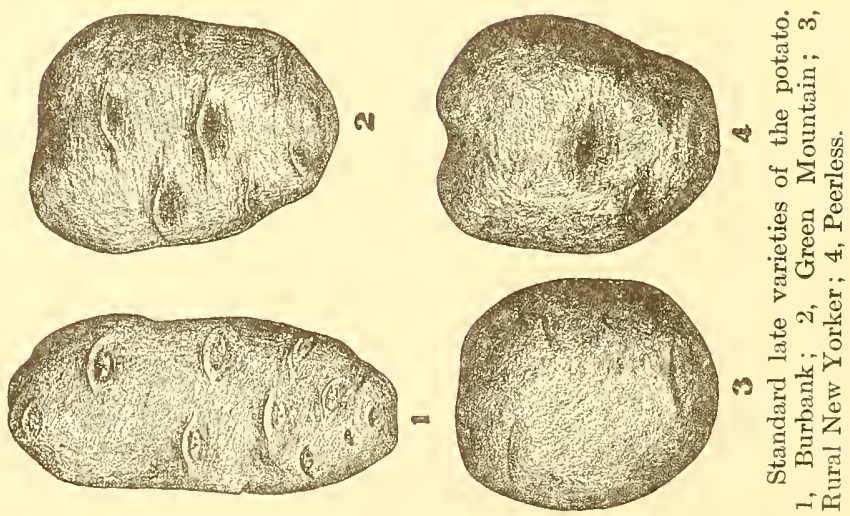
Fitch says that the varieties Rural, Early Ohio and Irish Cobbler are the outstanding varieties of Iowa. In regard to the others, he makes the following comments:

"The following are grown in Iowa to a greater or less degree or reach our markets.

"Green Mountain, the second most important variety in the United States, and a second best late sort for Iowa.

"Burbank, still the standard of the U. S. Government for market quotations, formerly important in Iowa, and at some seasons still important in the supply of her cities.

"Peerless or Pearl, by test at Ames, ranking among the best late sorts, and often coming into her markets from Colorado or Wisconsin.

"Bliss Triumph, sometimes grown in Iowa for very early use, and extensively grown in the South for the supply of the early markets of Iowa and the northern states."

William Stuart of the United States Department of Agriculture has recently made a very comprehensive and admirably arranged classification of potatoes. His bulletin contains not only a valuable key, but a careful description of our standard varieties of potatoes and points out many unnecessary synonyms. The reader is referred to this bulletin for this storehouse of information on potato varieties.

Stuart gives the following classification key:

\section{Stuart's classification}

\section{Group 1. - Cobbler.}

Tubers: Roundish; skin creamy white.

Sprouts: Base, leaf scales and tips slightly or distinctly tinged with reddish violet or magenta. In many cases the color is absent.

Flowers: Light rose-purple; under intense heat may be almost white. 
Group 2. - Triumph.

Tubers: Roundish; skin creamy white, with more or less numerous splashes of red, or carmine, or solid red; maturing very early.

Sprouts: Base, leaf scales and tips more or less deeply suffused with reddish violet.

Flowers: Very light rose-purple.

\section{Group 3. - Early Michigan.}

Tubers: Oblong or elongate-flattened; skin white or creamy white, occasionally suffused with pink around bud-eye cluster in Early Albino.

Sprouts : Base light rose-purple ; tips creamy or light rose-purple.

Flowers: White.

Group 4. - Rose Group.

Tubers: Elongated or oblong, usually flattish at the center and tapering gradually toward each end ; stem and seed end rather blunt. Skin smooth, flesh color. Flesh creamy white, sometimes streaked with red.

Sprouts: Rather long, medium thick, and usually clearly tinted with rose-lilac.

\section{Group 5. - Early Ohio Group.}

Tubers: Round-oblong with full, rounded seed and stem ends. Eyes numerous and rather shallow. Skin or flesh light pink with a deeper color around the eyes.

Sprouts: Short, much enlarged at the base, color varying from carmine-violet to violet-lilac or magenta-lilac.

\section{Group 6. - Hebron Group.}

Tubers: Elongated, somewhat flattened, with rather blunt ends, occasionally spindle shape. Eyes numerous. Skin creamy white, more or less clouded with flesh color or light pink.

Sprouts: Very similar to those of the Early Rose Group. 


\section{Group 7. - Burbank Group.}

Tubers: Long, cylindrical or slightly flattened in shape. Eyes numerous and rather shallow. Skin white to dull white, smooth to glistening, or sometimes russeted.

Sprouts: Base creamy white or faintly tinged with magenta.

Flowers: White.

\section{Group 8. - Green Mountain Group.}

Tubers: Broadly roundish-flattened to distinctly oblong-flattened; ends usually blunt, especially the seed end. Eyes rather shallow. Skin dull creamy white, more or less netted.

Sprouts: Rather short and stubby. White or faintly tinged.

Flowers: White.

\section{Group 9. - Rural Group.}

Tubers: Round-flattened to broadly roundish - oblong or distinctly oblong. Eyes few; very shallow. Skin creamy white and occasionally netted.

Sprouts : Short, base enlarged, dull white.

Flowers: Of fair size. Central portion of corolla deep violetpurple, shading to a lighter tone toward outside edge.

\section{Group 10. - Pearl.}

'Tubers: Round-flattened to heart-shape flattened, usually heavily shouldered; skin dull white, dull russet, or brownish white in section 1 or a deep bluish purple in section 2.

Sprouts: Section 1 - base, leaf scales and tips usually faintly tinged with lilac; section 2 - base, leaf seales and tips vinous mauve.

Flowers: White.

Group 11. - Peachblow.

Tubers : Round to round-flattened or round-oblong ; skin creamy white, splashed with crimson or solid pink; eves usually bright carmine. Includes some early-maturing varieties.

Sprouts: Base, leaf scales and tips more or less suffused with reddish violet.

Flowers: Purple. 


\section{Group types according to Fitch}

\section{Group 1. - Rural.}

Tuber shape: Wide and flat types when at best. Ends rounded much like stem and usually not recessed. (See Fig. 7.)

Tuber and eye color: Blinds, white. First sprouts yellow or waxy white with bluish violet tips which change, on exposure to light, to dark or dull purple.

Root stubs: Yellowish white; free from purple.

Stem: Erect and touched with brownish purple.

Foliage: Green, darkened by the purple, and in state much more acrid than "all-green" foliage.

Blossom : Bluish violet-white.

\section{Group 2. - Early OHio.}

Tuber shape: Somewhat flattened and slightly tapering, with stem end a least bit recessed. Eyes are unevenly distributed and numerous. (See Fig. 7.)

Tuber and eye color: Skin brownish pink, almost white to red, changing, on long exposure to light, to a weathered gray brown. First sprouts are white or greenish white with lilac tips.

Foliage: Medium green.

Blossoms : Lilac-white.

\section{Group 3. - Irish Cobbler.}

Tuber shape: The finest type is flat and wide like good Rurals but there is a very distinct round, rough, deep-eyed type formed in poorer conditions. In some cases large types are pear shaped and rough like the largest Rurals and may combine the pear shape with the heavy eyebrow types of the Rural.

Tuber and eye color: Skin smooth yellowish white, changing in the light to dull olive-green with a suggestion of blue. Blinds, white. Sprout-leaves, hairy, light green.

Blossoms: Pink with white tips on petals. White blossoms not found on Cobblers.

\section{Group 4. - Green Mountain.}

Tuber shape: The waisted or dumb-bell type is characteristic. Stem end somewhat recessed. (See Fig. 7.) 
Tuber and eye color : A fine smooth and quite brown netting is a feature of many of the tubers. An "all-white" variety.

Foliage: Bright green.

Blossoms: White. Buds yellow.

\section{Group 5. - Burbank.}

Tuber shape: Long, largest at center. Best type, shorter, wide, and flattened. Poor type, spindle shaped. Stem end flush. Eyes shallow or flush. In poor conditions very subject to knots. (See Fig. 7.)

Tuber and eye color: Blinds, white. Skin white changing in light to greenish gray brown. First sprouts white with light green tips.

Foliage: Bright green.

Blossoms: White. Buds yellow.

\section{Group 6. - Peerless or Pearl.}

Tuber and eye color: Skin, white, or if ripened well, brownish white, coarsely cracked. Skin turns dull green in light. (See Fig. 7.)

Blossoms: White, when borne. Buds, white or greenish white.

Stem and foliage: Vigorous, bright green.

\section{Group 7. - Bliss Triumph.}

Tuber shape: More or less roughly globular, recessed stem. Large tubers somewhat oval or nosy. (See Fig. 7.)

Tuber and eye color: Pink to red-brown skin changing in light to grayish red brown. Blinds, pink to red brown. Sproutleaves, dark apple-green.

\section{Groups according to Kohler}

Group 1. - Tuberosum Group.

Characterized by foliage of the wild Solanum type. Tubers of varying shape, usually with rather deep eyes; below medium in size.

Foliage relatively resistant to disease. 
Group 2. - Rural Group.

Rural New Yorker is the type of the group. Tubers characteristically short, smooth and flattened. Skin white. Eyes generally shallow.

Group 3. - Ime Group.

Plants upright in habit; little or no purple in stems. Tubers roundish or somewhat elongated with uneven surface.

Group 4. - Woltuan Group.

Plants medium erect; foliage fairly dense. Tubers similar to those of Leo group. Group not very well defined.

Group 5. - Endurance Group.

Plants very recumbent; leaves pure green. Tubers light in color ; elongated to medium in length.

Group 6. - Factor Group.

Plants fairly erect, with dense foliage. Tubers generally roundish or short elliptical; comparatively even surface.

Group 7. - Sharpe's Express.

Plants moderately erect; foliage dark green. Tubers rounded or slightly elongated and surface comparatively even. Flowers white.

\section{Group 8. - Green Mountain Group.}

Plants medium upright; stem free from purple. Tubers medium in length with a tendency toward oblong form; white and slightly netted skin. Eyes sunken somewhat. 


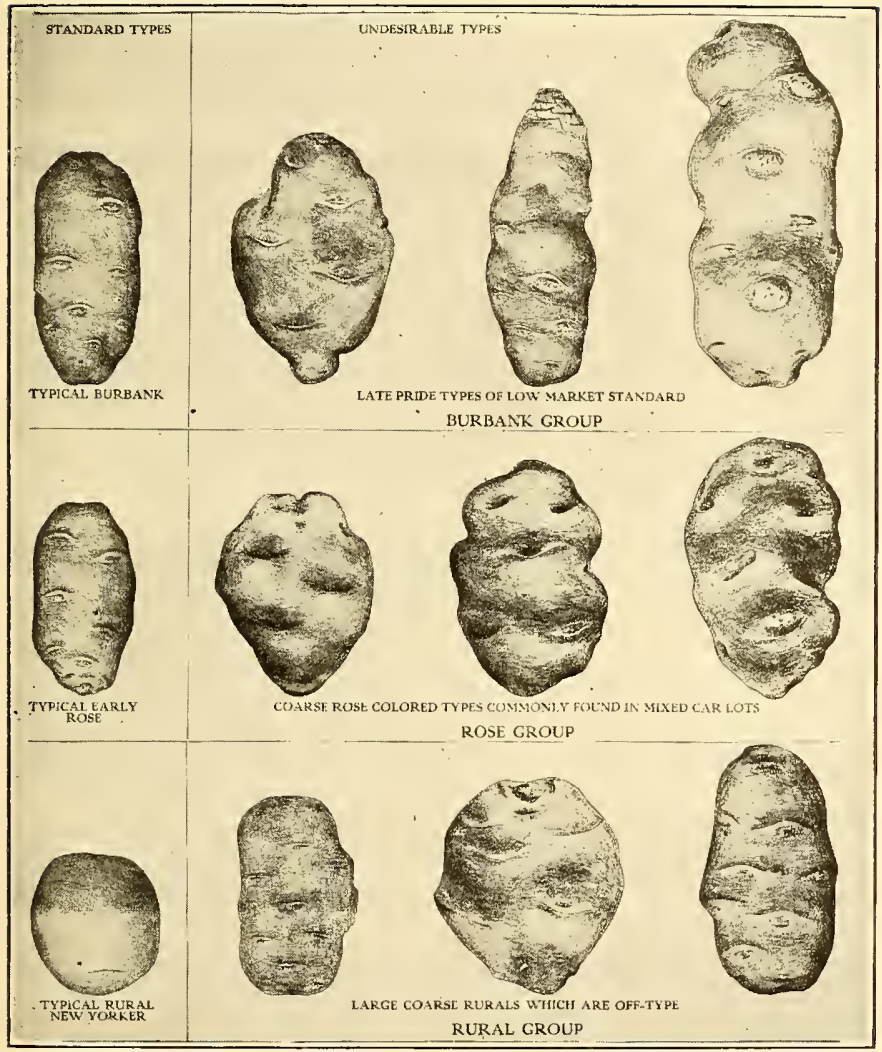

Plate II. - Types of potato tubers, as illustrated by the Wisconsin Experiment Station.

A careful selection of seed for a few years will gradually eliminate these undesirable types. 

Group 9. - Michigan Group.

Michigan variety typical of the group. Tubers somewhat elongated; skin fairly smooth. A composite group with characters not well defined.

Group 10. - Ohio Group.

The Early Ohio is typical of this group. Tubers oval in shape and only slightly compressed; eyes numerous and usually shallow. Surface quite even.

Group 11. - Cobbler Group.

Plants upright in habit. Tubers white, pink or red; variable in shape and size.

\section{Groups according to Milward}

Group 1. - Round White Group.

Tubers: round to oval and slightly flattened. Surface generally netted. Skin white and flesh white.

Flowers: white or purple.

Group 2. - Long White Group.

Tubers: Long oblong in shape and sometimes flattened. Skin and flesh white.

\section{Tabulation of varieties}

The varieties of potatoes mentioned and described by Stuart, Milward, Kohler and Fitch have been brought together in one table for convenience. Each variety so far as possible has been classified by naming the group into which it has been placed by one or more of the authors named. In this way, it is easy for any person to get an idea of a variety if he is unfamiliar with it by referring to the description of the group into which the variety is placed : 


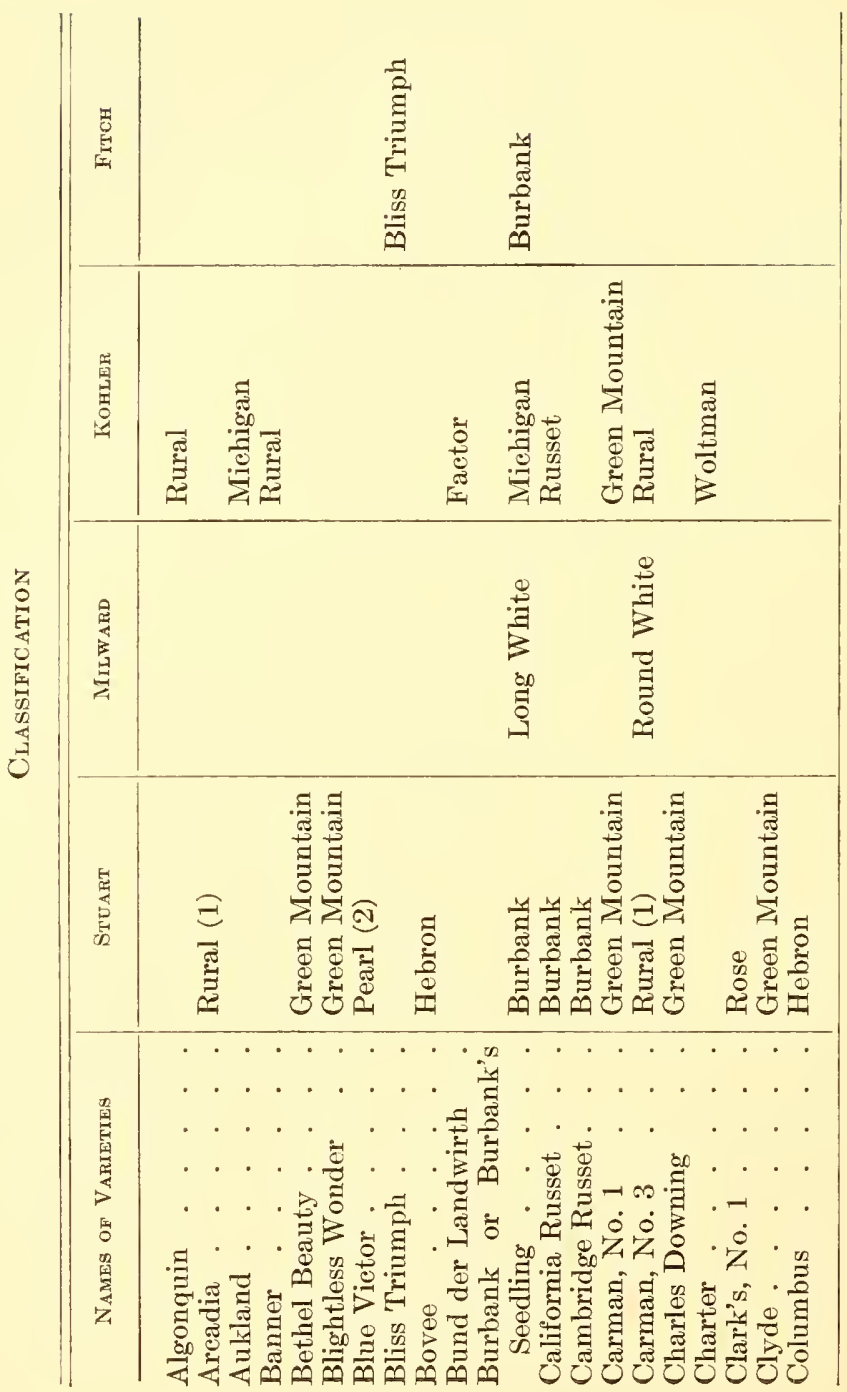




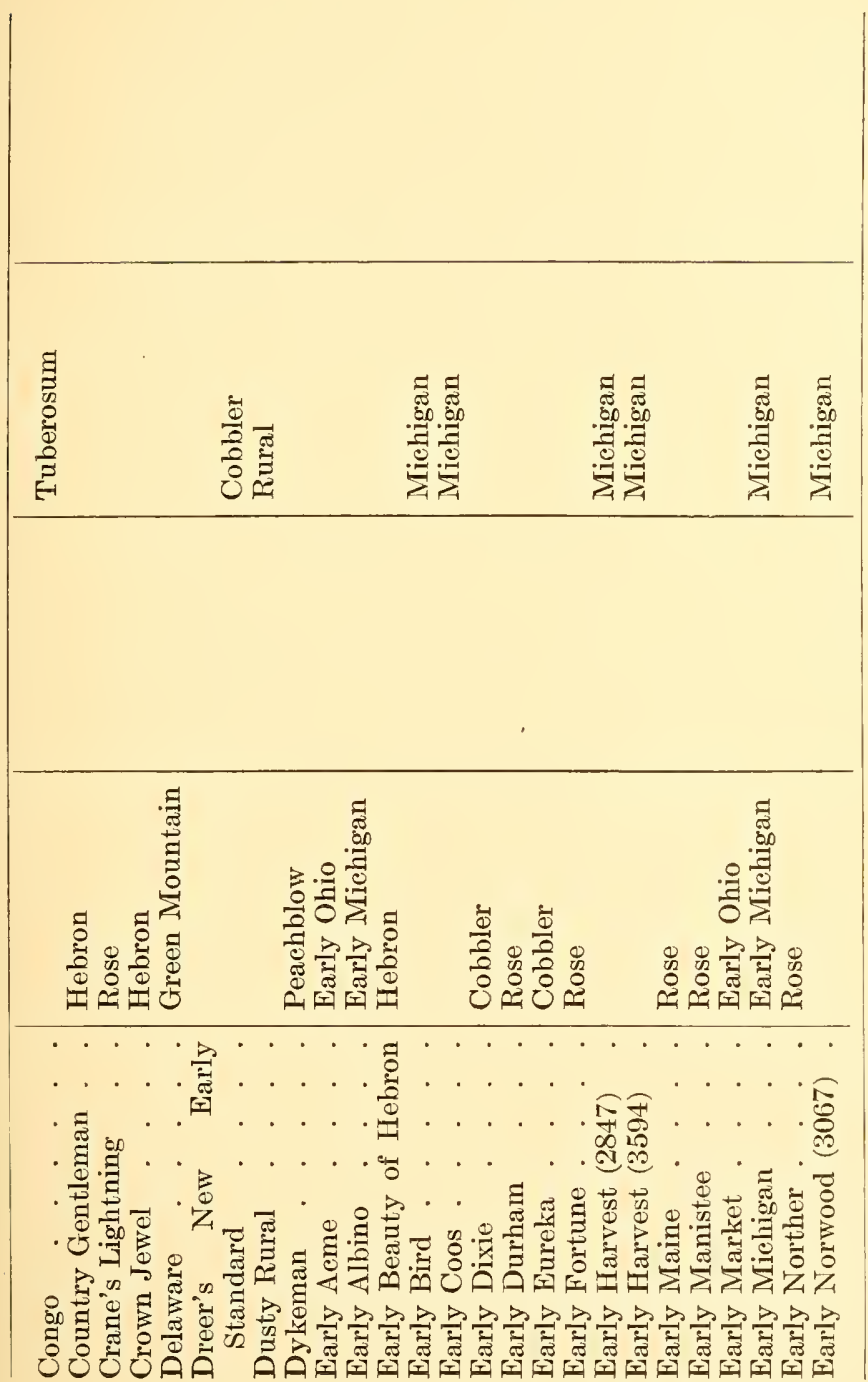




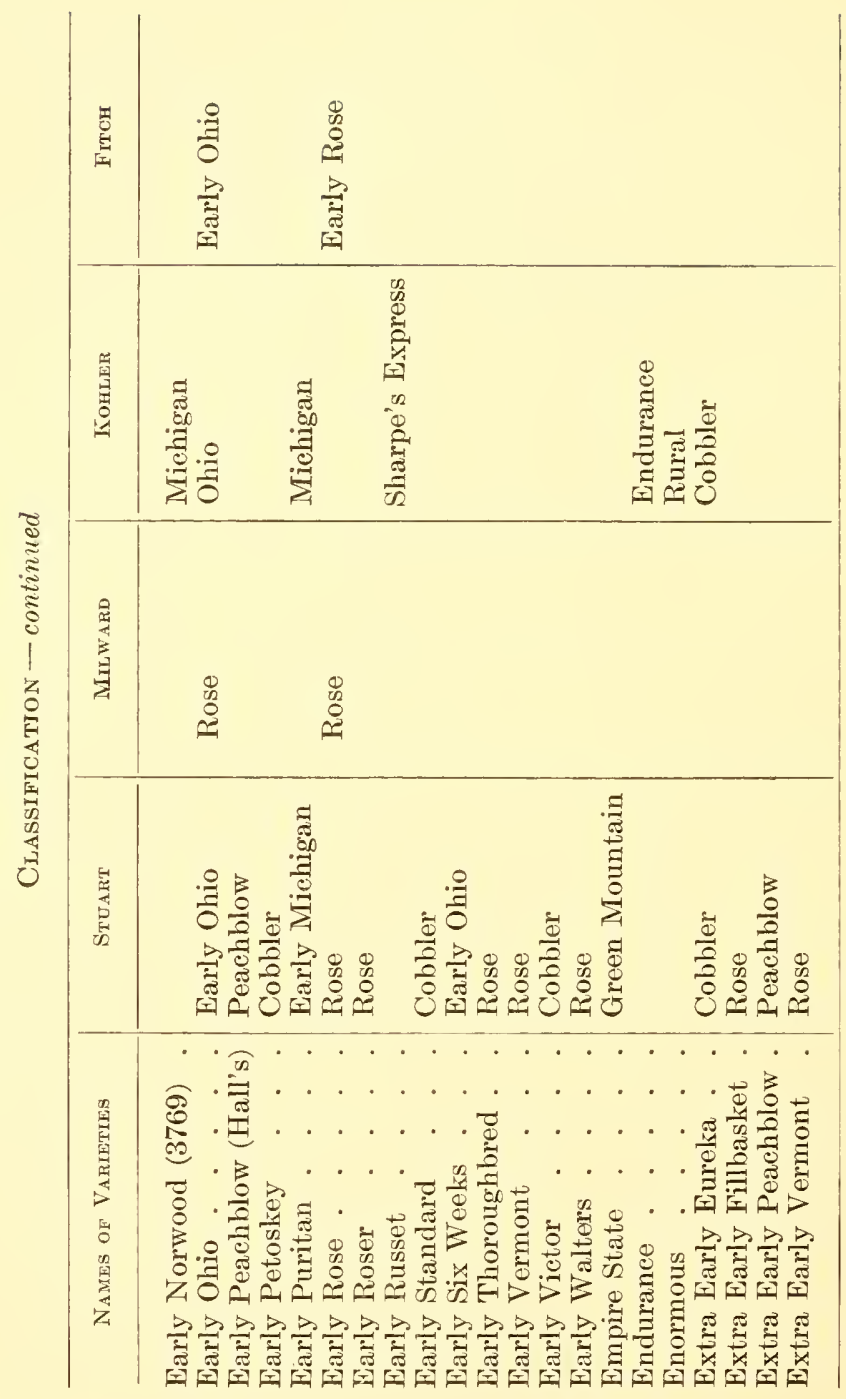




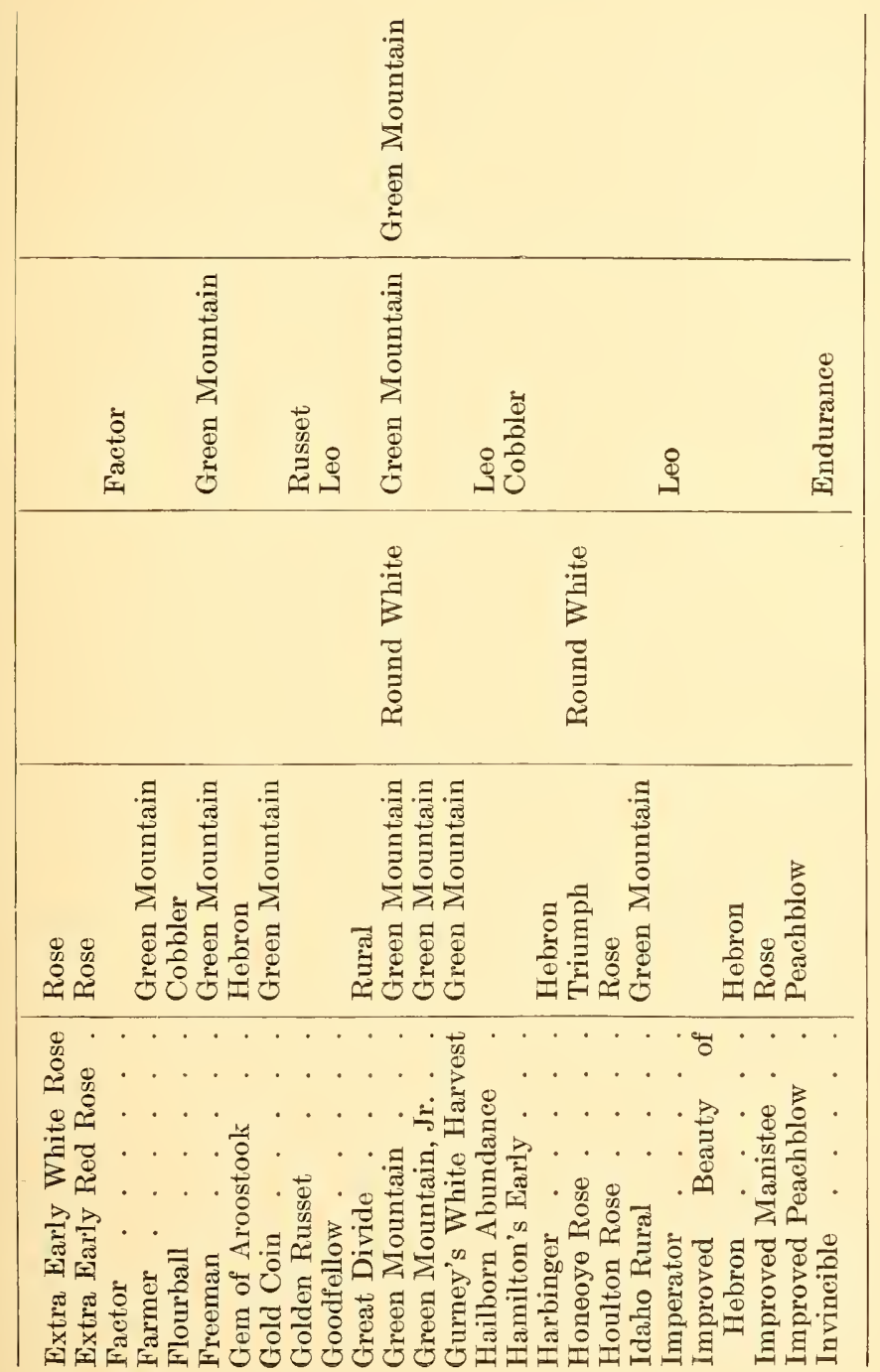




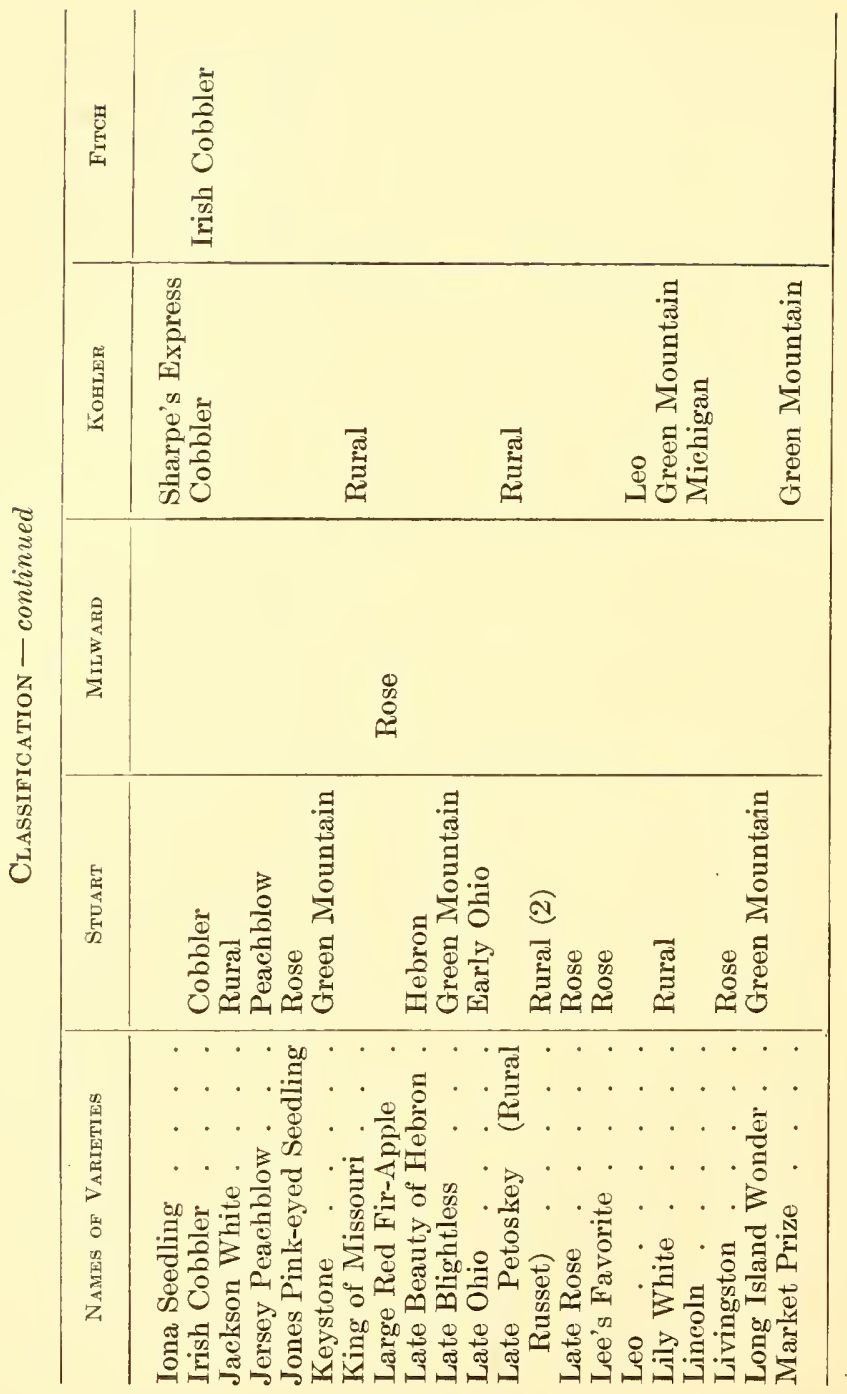




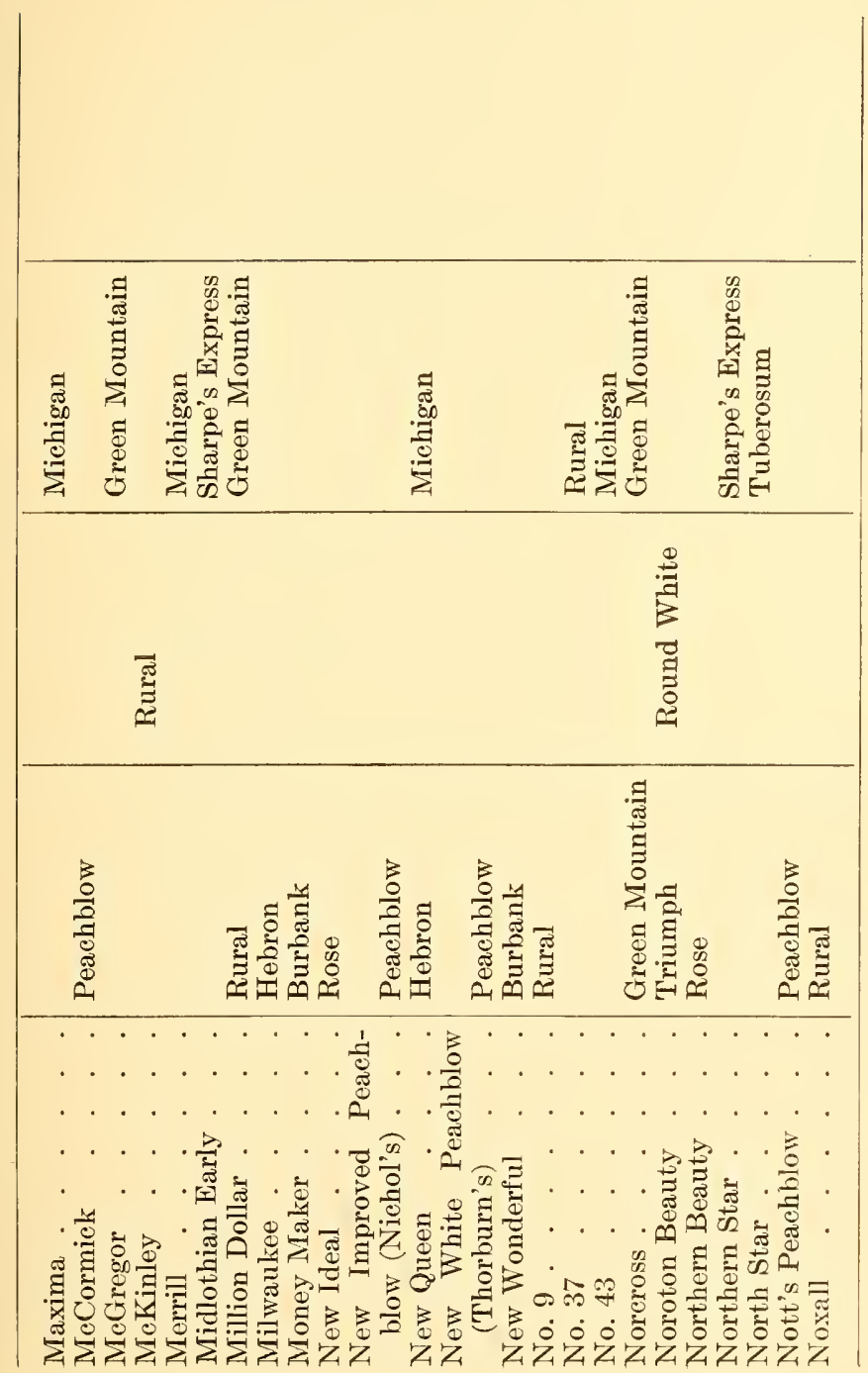




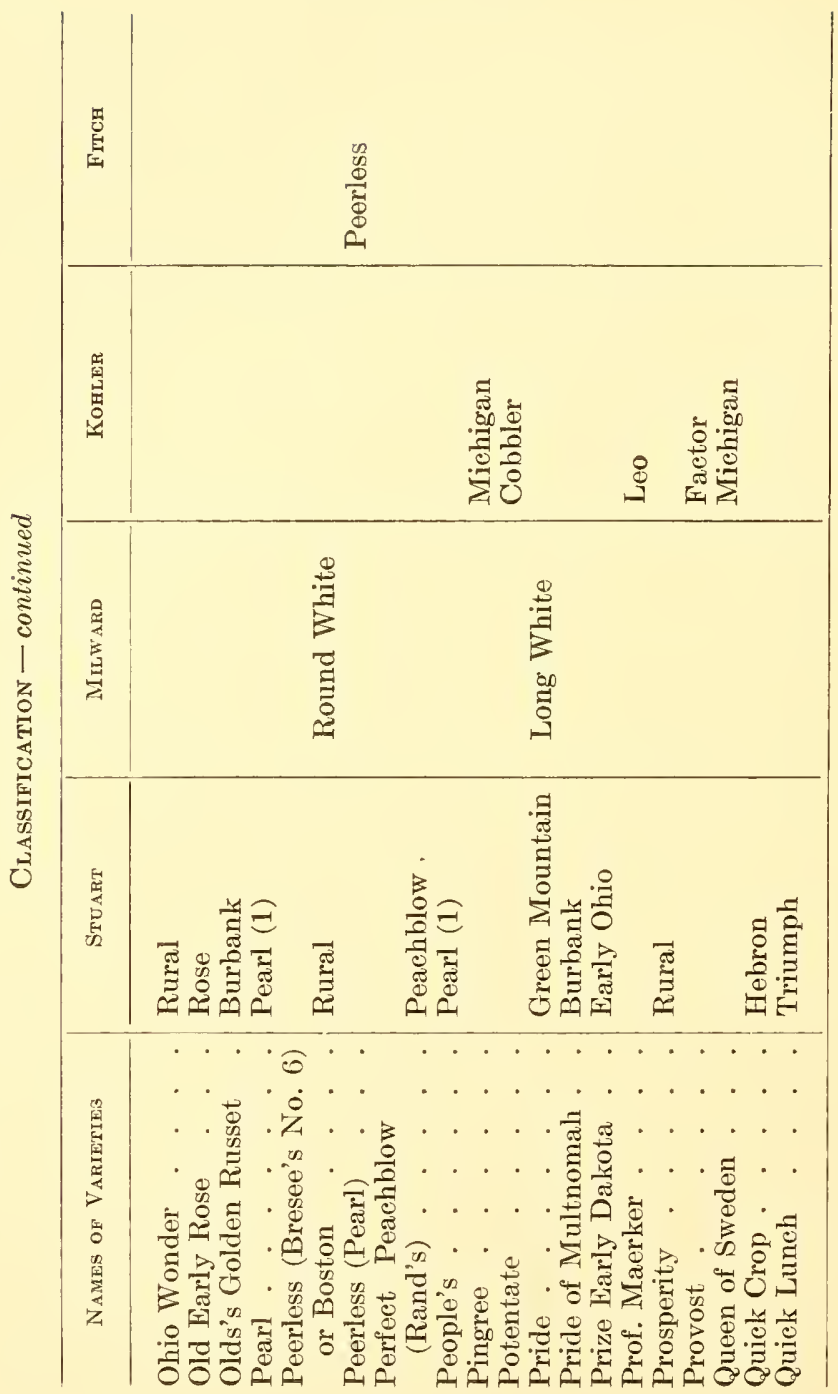




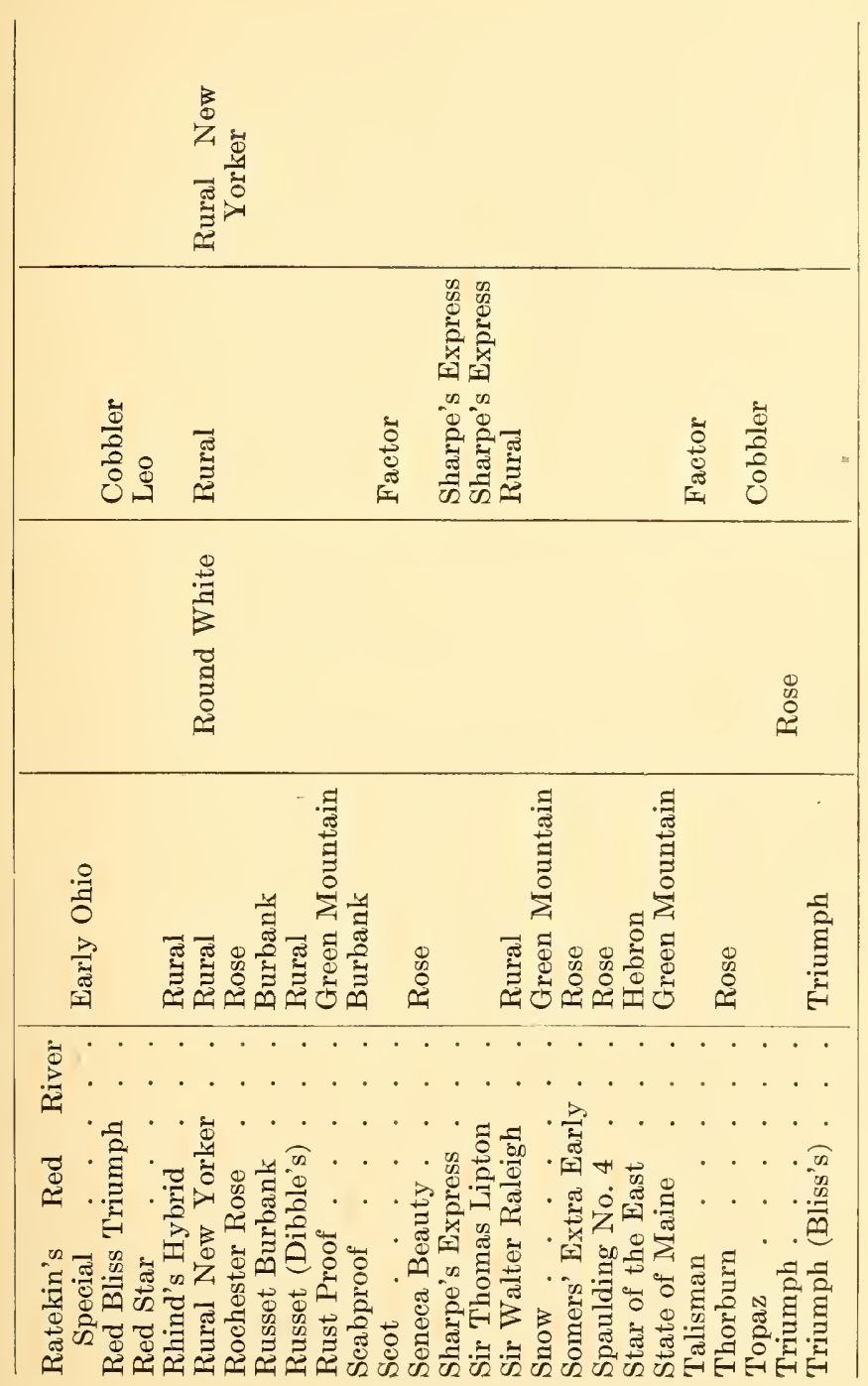




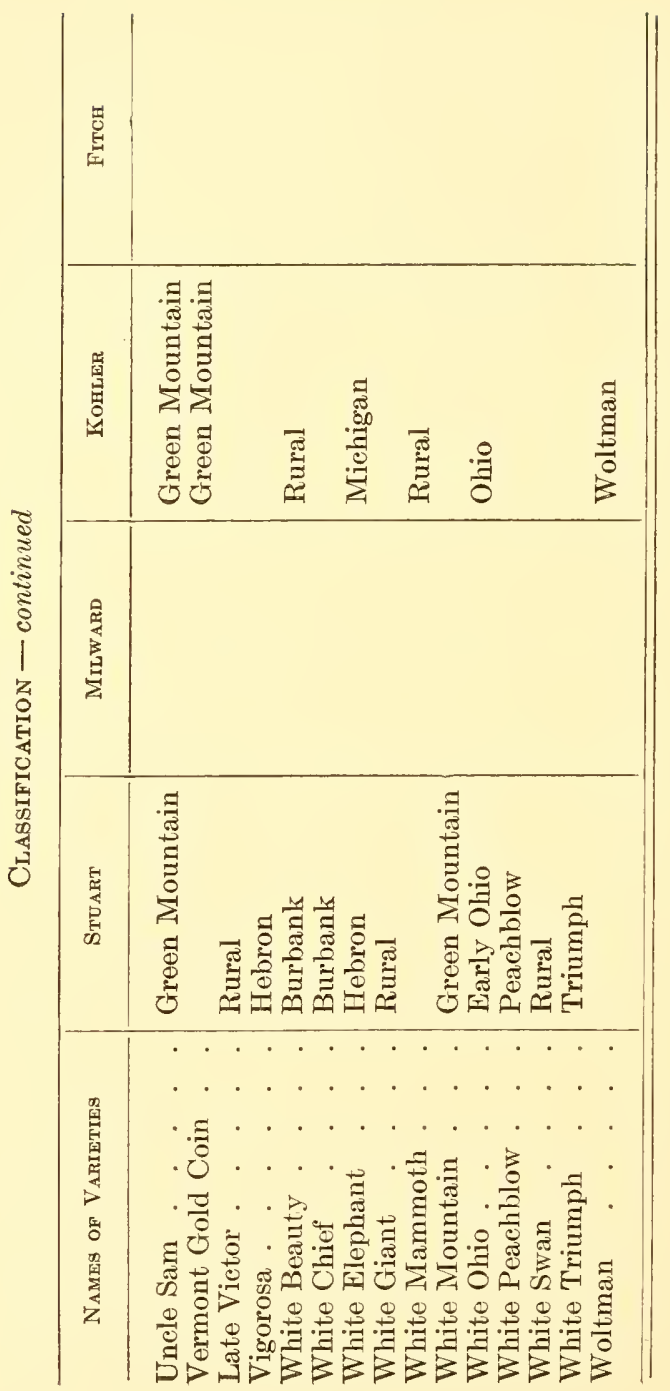




\section{Synonyms}

Frequently potatoes belonging to well-recognized varieties are renamed and sold as distinctly new sorts. This practice may be due to the fact that the seedsman, or the grower, is not familiar with all the standard varieties; or it may be a fraudulent attempt to induce the farmer to pay a high price for seed of a supposedly new and superior variety. Then, too, the same type may arise in different parts of the country at about the same time and be given different names in each locality. Because of these conditions we often have one variety masquerading under a number of different trade names. It is desirable that a single name be chosen for each distinct type, and that that name alone be used to designate tubers of the standardized type. The following list of synonyms, adapted from Stuart, may be found helpful in straightening out variety names:

\section{Synonym}

Acme

Black Mercer

Bliss Triumph

Blue Noses

Boston Market

Bresee's No. 2

Bresee's No. 4

Bresee's No. 6

Bruce's White Beauty

California Russet

Chenango

Chenango White

Early Bovee

Early Henry

Early Hunt

Early Pinkeye
Preferred Name

Early Acme

Black Chenango

Triumph

Mercer

Early Sebec

Bresee's Prolific

King of the Earlies

Peerless

White Beauty

Russet Burbank

Mercer

Mercer

Bovee

Early Shaw

Triumph

Dykeman 


\section{Synonym}

Early Sunlight

Early Victor

Early Wenwell

Ensign Bagley

Farmer Hasting

Improved Early Rose

Improved Manistee

Junior Pride

Knowles's Big Cropper

La Plata Red

Late Hoosier

Lookout Mountain

Maine Rose

Merino

Meshanock

Mashannocks

Nephannocks "

Neshannocks

New Blush

New Minister

Nishenock

Page's Extra Early Surprise

Peachblow

Peachblow

Philadelphia

Pride of the South

Queen of the West

Red Bliss

Red Mercer

Red Six Weeks

Rose No. 4

Round Pinkeye

Rural New Yorker (No. 1)

Rural Russet

Six Weeks

Spanish

Stray Beauty

Vermont Champion
Preferred Name

Sunlight

Victor

Wendell

Clark's Pride

Farmer

Early Rose

Early Manistee

White Triumph

Knowles

Long Red

McCormick

McCormick

Farly Maine

Long Red

Mercer

Mercer

Mercer

Mercer

Rural Blush

Minister

Mercer

Early Surprise

Jersey Peachblow

Western Red

Mercer

White Triumph

Maggie Murphy

Triumph

Long Red

Triumph

Spaulding No. 4

Dykeman

Carman No. 1

Late Petoskey

Early Six Weeks

Long Red

Triumph

Champion 
Synonym

Weld's Jumbo

White Bliss

White Chenango

White Early Ohio

White Elephant

White Meshannock

White Triumph

Willard Seedling
Preferred Name

Jumbo

Pride of the South

Mercer

White Ohio

Late Beauty of Hebron

White Mercer

Pride of the South

Willard

\section{DESCRIPTION OF TYPICAL VARIETIES}

Below are given brief descriptions of the more popular varieties. These descriptions have been taken largely from Stuart: ${ }^{1}$

Burbank. - Originated by Luther Burbank in 1873; claimed to be a seedling of the Early Rose. Season medium late. Tubers large, round, long; eyes shallow, but rather numerous; skin nearly smooth, white; flesh firm, fine grained, of excellent flavor when cooked.

Carman No. 1 (Rural New Yorker No. 1), - Originated by E. S. Carman in 1889. Seedling of other seedlings. Season medium. Very few, shallow eyes; quality excellent; flesh white. Vines very stocky.

Country Gentleman. - Originated by G. W. P. Jerrard Co. Season medium late. Vines of medium vigor and spreading habit; flowers white. Tubers long, cylindrical; eyes medium; skin light buff; flesh white.

Early Rose. - Originated by Albert Bresee in 1861. Season early. Vines stout, erect; leaves large. Tubers quite smooth; nearly cylindrical, tapering toward each end; eyes shallow; skin thin, tough, and of a dull blush color; flesh white, solid, brittle.

Green Mountain.- Originated by O. H. Alexander in 1878. Claimed to be a seedling for a cross between Dunmore and Excelsior. Season medium late. Vines vigorous, with dark green foliage. Tubers short and chunky, flattened, not very regular;

${ }^{1}$ Stuart, Wm. U. S. D. A., Prof. Paper, Bul. 176, 1915. 
eyes sometimes considerably depressed; skin nearly white; flesh fine grained.

Irish Cobbler. - Of unknown origin. Season extra early. Tubers nearly round, large; eyes good; skin russet, finely netted; flesh white. Similar or identical with variety Eureka.

Pearl, Midseason. - Vines strong, medium to large; stems medium dark green, rather stocky; erect at first, bending over as the season advances. Leaves large, flat, medium dark green. Flowers white. Tubers medium to large, round-flattened to heart-shaped, flattened, usually broader at the stem end; pinkish tinge about the eyes, especially when freshly dug; skin dull white or light russet, usually roughened or cracked; flesh solid and quite heavy.

Rural New Yorker No. 2. - Originated by E. S. Carman. Introduced into trade about 1889 . Season medium late. Vines thrifty and strong. Tubers oblong, inclined to round or round-oval, rather flattened; eyes few, shallow; slin pure white netted; flesh white.

Sir Walter Raleigh. - Originated by E. S. Carman. Claimed to be a seedling of Rural New Yorker No. 2. Introduced into trade in 1897. Vines similar in habit and color of flowers to those of Rural New Yorker, No. 2, but color of stems not as pronounced. Color of flesh and skin of tubers is the same;" quality better than that of Rural New Yorker No. 2.

\section{REFERENCES}

BaKer. A Review of Tuber-bearing Species of Solanum. Linn. Fitch, C. L. Soc. Journal Bot., 20: pp. 489-507, pls.

Identification of Potato Varieties. Iowa Extension Bul. 20. 1914. Kohler, A. R.

Potato Experiments and Studies at University Farm in 1909. University of Minnesota Bul. 118. April, 1910.

Milward, J. G.

Commercial Varieties of Potatoes for Wisconsin. University of Wisconsin Bul. 225. July, 1912.

Percival, John. Agricultural Botany, pp. 439-451. Stuart, Wh.

Group Classification and Varietal Descriptions of Some American Potatoes. U. S. D. A. Bul. 176. March 27th, 1915. 


\section{CHAPTER IV}

\section{POTATO BREEDING}

THE cultivated potato of to-day has undergone a remarkable change since its first introduction into Europe by the Spaniards. Some of this change has been brought about by better cultivation, but most of it is due to breeding. The tubers of the wild $S$. tuberosum were small and attracted little attention. Heriot, in his report on Virginia, describes the plant "with roots as large as a walnut and others much larger; they grow in damp soil, many hanging together as if tied on ropes." The potato as we know it has been developed by means of conscious and unconscious selection and by hybridization with other species. The modern potato has not only been much changed by breeding, but it is now grown in widely different surroundings which produce various changes in the tubers.

There are three foundations on which the increased productivity of crops rests - the enrichment of the land; its tillage and care; and the production of better varieties and strains. The first two are concerned with the environment of the crop, such as cultivation, fertilization, freedom from insects, disease and so forth, and the last with its heredity. We have long given attention to environment; now we are studying heredity with new enthusiasm and purpose. One of the "signs of the 
times" is the attention that is being given to the practical breeding of crops. We have learned that good seed is a necessary accompaniment to high fertility and good care and also the desirability of different varieties adapted to varying needs of soil, climate and man.

These wild forms have been taken, in most cases, from their original habitats and placed under conditions of soil, temperature and moisture to which they are not accustomed. Here selection must not only modify the plants better to meet the wants of man, but they must become adapted to their new environment. Most plants are very flexible and finally become adapted to a variety of conditions. This is evidenced by the very large number of varieties of which most of our cultivated plants consist.

Results of careful and systematic breeding are accumulating rapidly with very many kinds of plants. The results of all this work will probably enable us, eventually, to formulate somewhat definite statements as to how to proceed to secure desired results. Considerable evidence is already at hand, but on the whole the methods of breeding are still somewhat empirical.

All of our cultivated plants have come from wild forms. Man has seen in them possibilities of usefulness, and he has chosen year after year the ones which better serve his purpose. This constant selection has in the course of time produced profound changes in our plants.

\section{IDEALS FOR THE POTATO CROP}

Plant-breeding is worthy of the name only as it sets definite ideals and is able to attain them. Merely to produce new varieties is of no merit. We must give up 


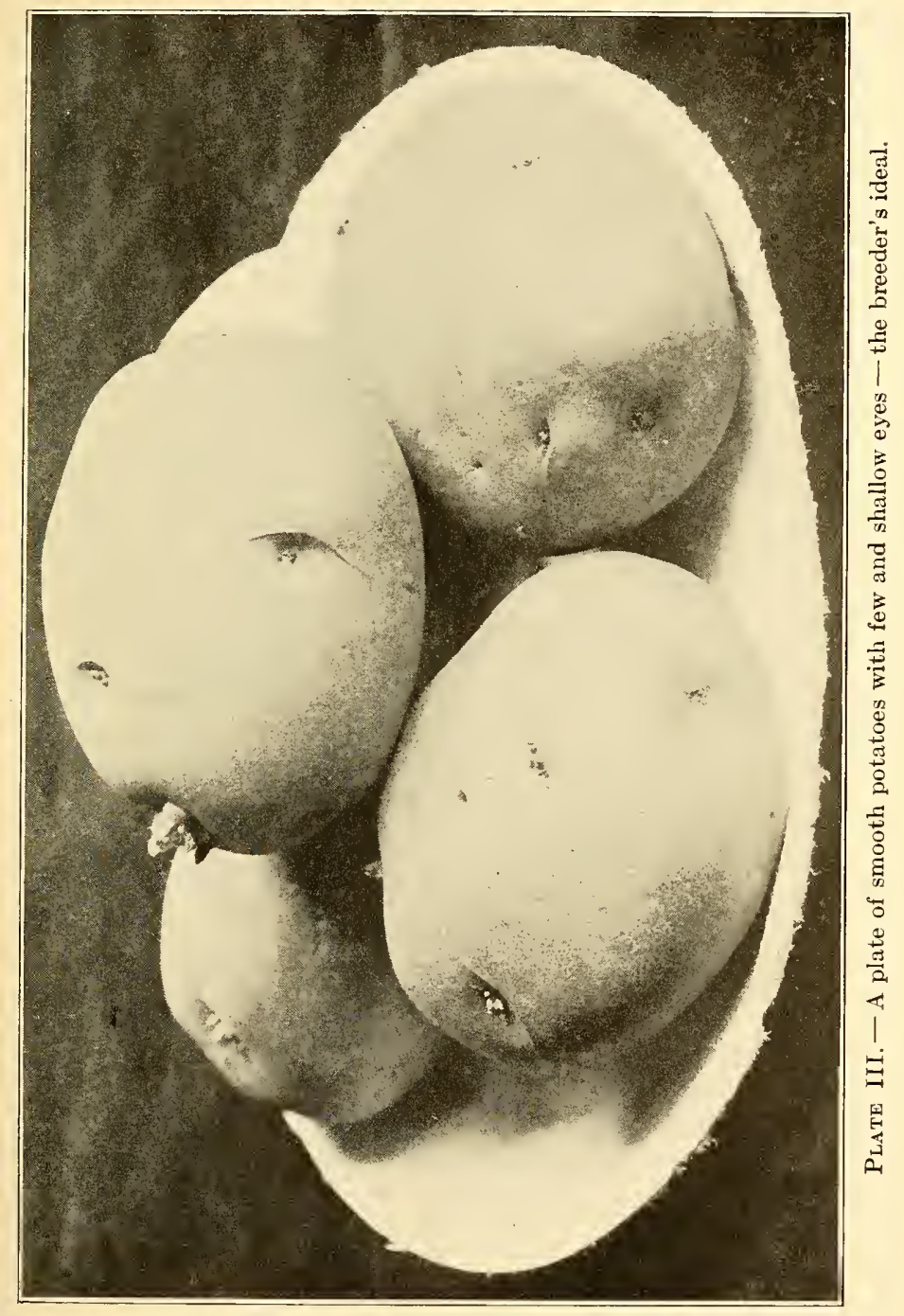



the production of mere novelties unless the new variety possesses some property which makes a real contribution to our present varieties.

It is unfair and dishonest consciously to rename old varieties under the pretense of producing something new. Our list of varieties contains many synonyms, and these should not be consciously increased.

In general, the improvement of our present standard varieties offers greater opportunities for the increased efficiency of the new generation of plants than the production of entirely new varieties.

Ideals for the perfect potato will change in the different localities. Certain attributes, however, are universally desired. These are as follows:

(1) High yield.

(2) Good quality.

(3) Disease-resisting capabilities.

(4) Good keeping qualities.

(5) Good color of flesh and skin.

(6) Skin of desirable texture.

(7) Tubers of good shape.

(8) Shallow eyes, relatively few in number.

(9) Maturing in season common to the variety.

(10) Upright, vigorous plants.

(11) Heavy leaf cuticle.

(12) No tendency to make second growth.

(13) Trueness to type of variety grown.

High yield is essential if the grower expects to continue raising potatoes for market. In aiming to secure high yield, however, we should remember that there are many other factors which determine the marketability and price of the product. Tubers of inferior quality, size 
and the like are not of great value even in large quantities.

From the consumer's point of view, quality is highly important. The grower would do well to keep his potatoes up to standard in this respect. Potatoes intended for human consumption should have a mealy flesh when boiled or baked. Up to a certain limit the quality improves with an increase in starch content. Potatoes to be used for the production of alcohol need be of no particular quality from the culinary standpoint.

There are no disease-proof varieties, but some are more resistant than others. Resistance is more important in the East than in the Mississippi Valley.

It is necessary to store potatoes for a long period, to supply the demands between crops. If the keeping qualities of a strain are poor, there are fewer potatoes which can be sold in the spring. In a sense, then, poor keeping quality is a factor which decreases yield.

The ideal color of skin and flesh will depend largely upon market preferences. In general a yellow skin and white flesh are desired. In the South, the red- or pinkskinned varieties are in favor. Because of the red color of some weak varieties, growers are likely to be skeptical of all colored varieties.

The skin may be thick, medium, or thin. When grown in sandy soil, the skin is usually smoother than when grown in heavy loams. A netted and slightly rough skin is preferred, many believing that it indicates proper maturity and good quality.

Flat-round or flat-oval tubers are better than the spherical, as the cortical and outer medullary layers, containing the starch, are relatively larger. Also a flat tuber bakes better, because the center is not too far from the outside. 



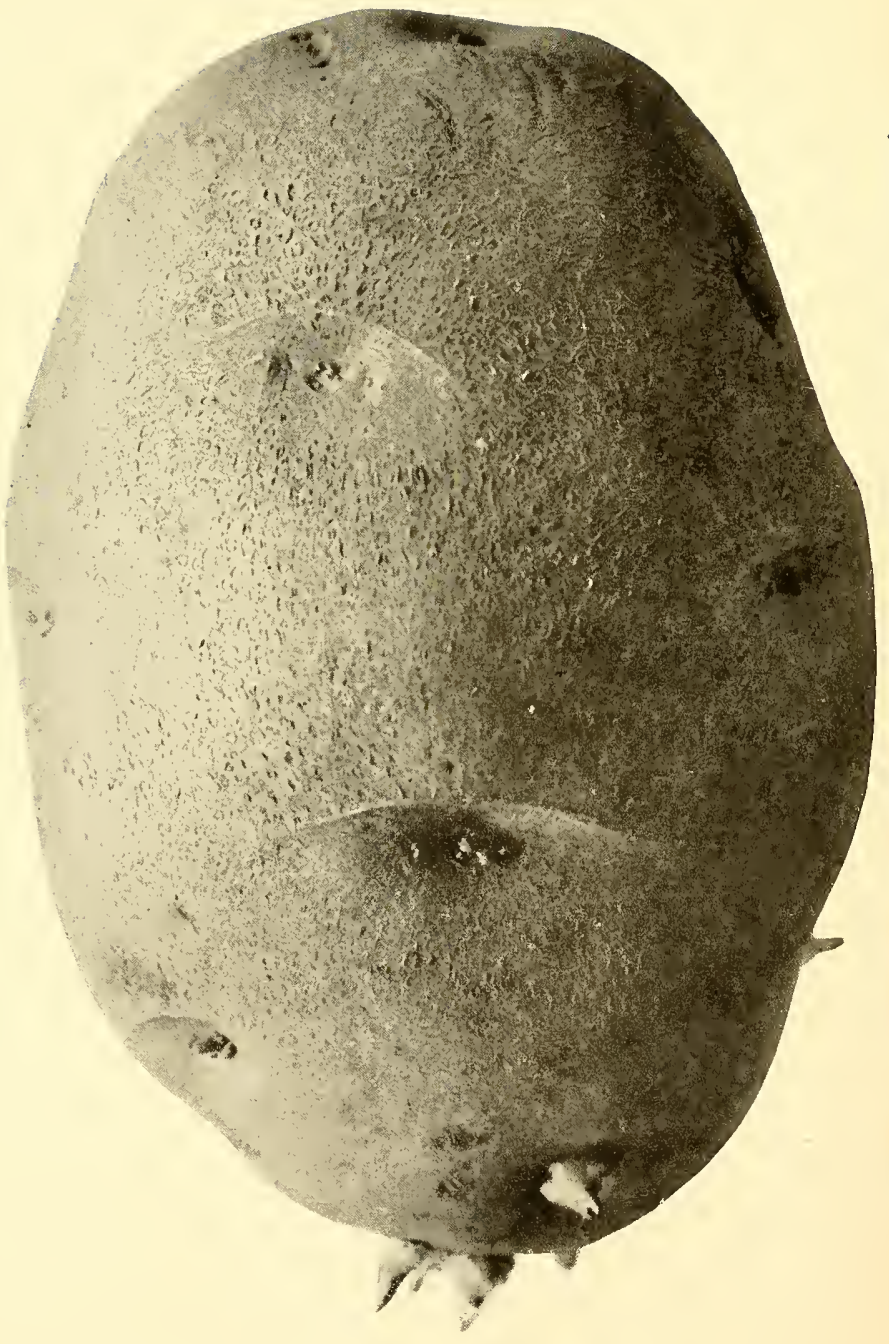

苟

$\stackrel{\oplus}{\stackrel{0}{2}}$

$\frac{9}{0}$

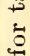

过

D

$\frac{2}{3}$

क

8

岇

焉 
Deep eyes cause waste in peeling. They hold moisture, thereby causing decay in storage. The tuber should have enough eyes to make good seed, but not so many as to make peeling difficult.

Early varieties may mature in 70 to 90 days after planting; second-earlier in 90 to 130 days; and late varieties may continue to grow for 200 days. It is important to choose a variety adapted to the locality.

The haulm and leaf are considered more important than formerly. Large haulms require wider spacing of plants and greater expense for spraying. Short-haulmed, upright, heavy-leafed tops are not as susceptible to disease as the prostrate types. The upright types are more likely to suffer during very dry spells, however, because the tops do not prevent the evaporation of moisture from the soil as do those of the more prone types. Care should be exercised to select a variety which is well suited to local conditions and which will grow vigorously. Differences in vigor will be noted in different strains of the same variety.

Leaves with thick cuticles are not as easily penetrated by disease spores.

When a period of drought is followed by a wet spell, second growth is likely to begin. The dry weather checks growth and the tubers begin to mature. Subsequent wet weather restarts growth. Such abnormalities should be discarded in selecting seed.

It is essential that the seed be as represented. None but experts can tell the different varieties apart, so seed should be obtained from a reliable source.

The half-tone illustrations in Plates III to VII show some of the desirable potato forms, and also results in breeding. 


\section{Use of score-card}

A score-card presents in a logically arranged, tabular form the different factors which make up an ideal potato. These factors are given relative importance or weight by means of percentage numbers, the sum of which is 100 . One should make frequent use of a score card to familiarize himself with all details and to compare his product with the theoretical ideal product, which it describes.

The score-card should be studied so as to establish the ideal of the desired variety firmly in mind before any attempt is made at improvement.

When breeding a crop, special attention should be paid to the details. The proper combination of the little and usually overlooked points makes the perfect crop.

It is important, further, to bear in mind the fact that a variety which is merely as good as any other in cultivation is not worth introducing. It should be better in some particular than any other in existence. The operator must know the points of his plant, as an expert stockbreeder knows the points of an animal, and he must possess the rare judgment to determine which characters are most likely to reappear in the offspring. Inasmuch as a person can be an expert in only a few plants, it follows that he cannot expect satisfactory results in breeding any species which may chance to come before him. Persistent and uniform effort, continued over a series of years, is generally demanded for the production of really valuable varieties. Thus it often happens that one man excels all competitors in breeding a particular class of plants. If the operator-himself an expert judge of the plant with which he deals - chooses his seeds with care and discrimination, and then proposes, 


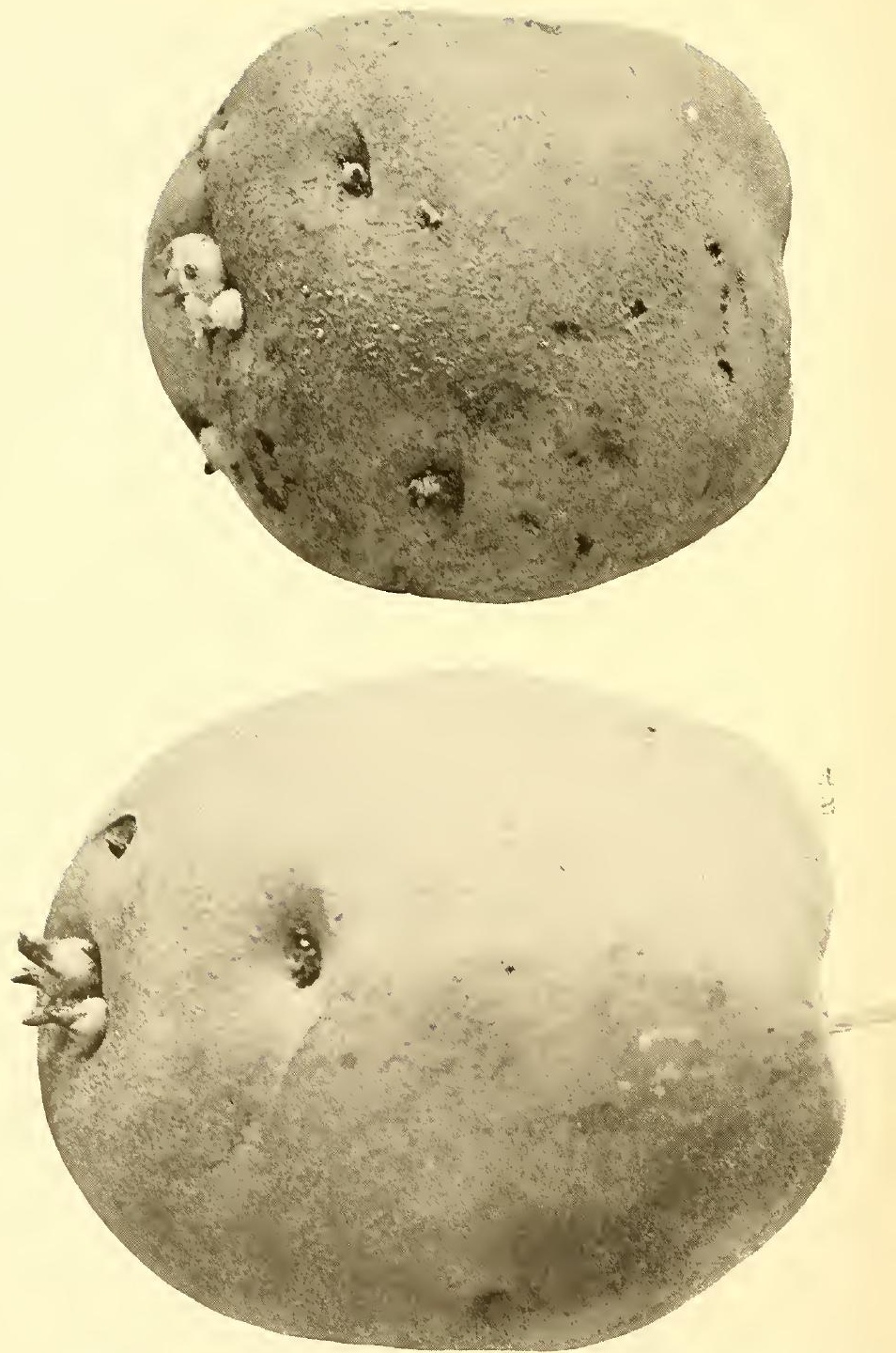

Phite Y.- Typieal early and late potatoes. Top. Irish Cobbler (early). Bottom, Rural New Iorker (late). 
if need be, to follow up his work generation after generation by means of selection, the work becomes plantbreeding of the highest type.

First of all, therefore, the operator must know what he is likely to secure, and what will probably be worth securing. Most persons, however, hegin at the other end of the problem, - they get what they ean, and then let the public judge whether the effort his been worth the while.

The following score-card has been adopted by the New York State Potato Association:

\section{Potato Score-caro}

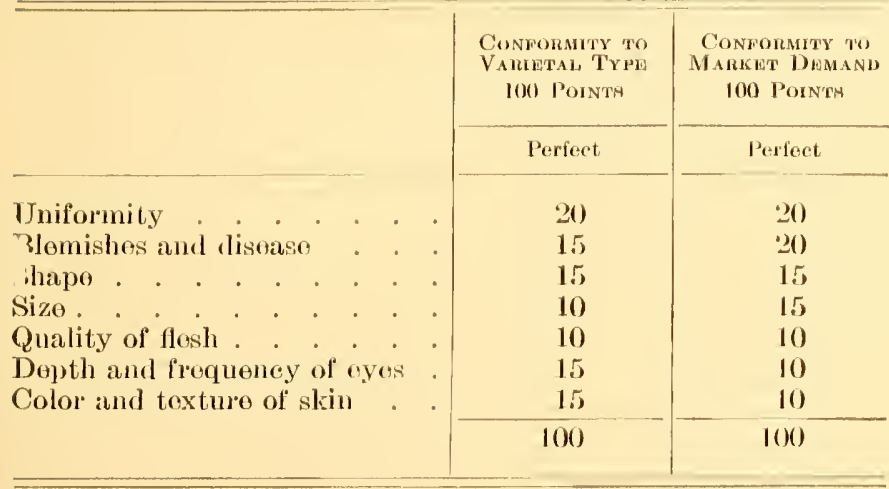

This score-eard is arranged with the idea of emphiasizing the more important characteristies to be eonsidered in selecting potatoes both true to varietal type and in aecordance with market demands. These two sets of qualifications are in many eases quite distinct. It is, therefore, true that the variety which fulfills both of these requirements is the one that scores highest and of which production should be encouraged. 
Uniformity. - Exhibit should be uniform in all physical characteristics.

Blemishes and disease. - Should be no evidence of blight, rot, grubs, rhizoctonia, sunburn, or injury from rough handling.

Shape. - Should be typical of the variety. Market demands a moderately oval-flat or round-flat shape.

Size. - Should be typical of the variety. Market demands a medium-sized potato.

Quality of flesh. - Should be true of the variety. Market requires a fine-textured flesh of light color, free from excess moisture and from hollow or dark spots.

Depth and frequency of eyes. - Should be typical of the variety. Market demands few and shallow eyes.

Color and texture of skin. - Should be typical of the variety. Market demands a thin, smooth skin. Whiteskinned varieties are preferable in most markets.

\section{POSSIBILITIES OF IMPROVING THE POTATO}

Even though the potato has been in cultivation for centuries, further improvement is by no means impossible. It responds very quickly to breeding. Most varieties are very impure and contain various types. The first task of the breeder is to become thoroughly acquainted with his plants so as to discard the poor plants and save the good ones for future planting. If this is done for a few years, the average yield of the crop and its uniformity will be greatly benefited.

The hill selection of potatoes is not generally practiced and as a consequence the varieties soon deteriorate and run out. This deterioration could be easily prevented by paying careful attention to planting seed from the best hills. 
It must not be forgotten that potatoes are now grown in regions where the climate is not entirely congenial to them. This constant action of a somewhat unfavorable climate will also cause them to degenerate if not counteracted by seed selection.

Careful experiments have been conducted with potatoes in which the offspring of different tubers are planted and recorded separately. Many of these progenies seem to degenerate completely, indicating that some degenerative factor, still unknown, is constantly at work. This deterioration is partially due to disease, without doubt, but some of it also is of a physiological nature.

The yields of any field or the average yields of any locality or of an entire state are far below what they should be. This is due to two causes: the conditions surrounding the crop have not been the best - perhaps insufficient food supply or water or poor soil; and secondly, the absence of seed selection has produced a poor stand of plants, many of which probably give low yields. By proper attention to fertilization, spraying and seed selection, the yield may often be doubled or trebled. Perhaps we can never expect the high yields to the acre obtained in Europe because of our hot dry climate (see Chapter I).

If seed selection becomes generally practiced, with its accompanying increase in yields, vast consequences may be looked for. If all of the hills on an acre of potatoes planted in the ordinary manner weigh one-half a pound, there will be a yield of 78 bushels to the acre. A half-pound hill, however, is very small. One ordinarysized tuber will weigh more than that. If, by means of breeding, the average yield to a hill is increased to one, two or three pounds, which is not at all impossible, the 
yields to the acre will be increased to 156,312 and 468 bushels respectively. If this reasoning were applied to all of the potato fields in the United States, the result would be almost unbelievable. Burbank has made the conservative estimate that if one tuber were added to each hill, the total resulting increase in the United States would be $21,000,000$ bushels yearly.

The following table gives the yields to the acre from hills of certain weights. It is assumed that the hills were 18 inches apart in the rows and the latter were 3 feet apart. This rate of planting gives 9372 hills on an acre:

\section{TABLE IX}

\begin{tabular}{c|c|c}
\hline Yield to the Hiul & Perfect Stand & 90 Per Cent Stand \\
\cline { 1 - 2 } Pounds & Bushels to the Acre & Bushels to the Acre \\
.5 & 78.1 & 70.29 \\
1.0 & 156.2 & 140.58 \\
1.5 & 234.3 & 210.87 \\
2.0 & 312.4 & 281.16 \\
2.5 & 390.5 & 351.45 \\
3.0 & 468.6 & 421.74 \\
3.5 & 546.7 & 492.03 \\
4.0 & 624.8 & 562.32 \\
\hline
\end{tabular}

\section{METHODS OF IMPROVEMENT}

Plants are improved in three ways: first, by simple selection, that is, breeding from the best, the object being to improve the present varieties rather than the production of new ones; second, to conduct extensive plantings for the purpose of discovering some unusually good individuals or mutants, which may become the foundation of improved varieties and which subsequently 


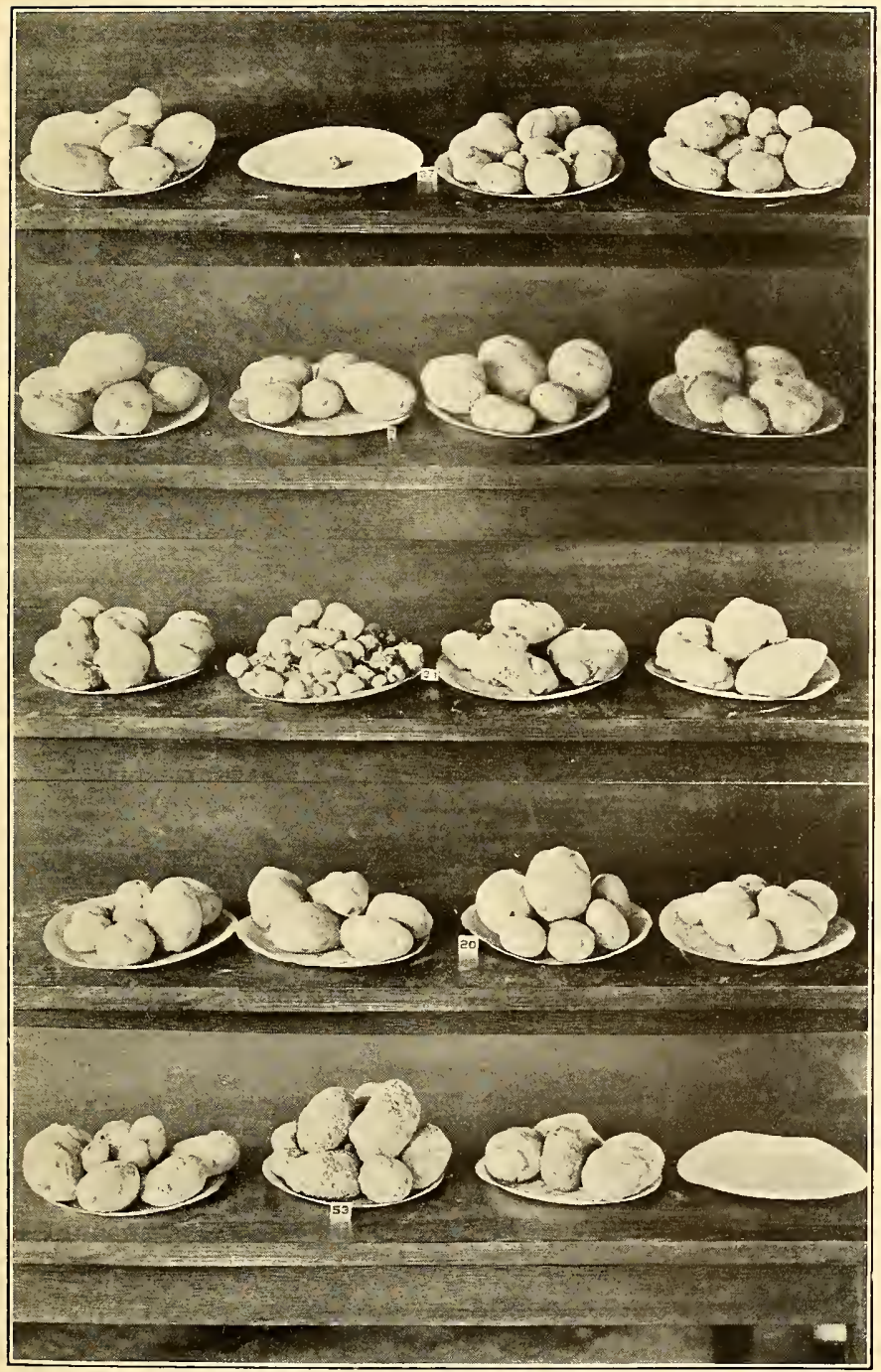

Plate VI. - Breeding - Each group of four plates represents the progeny of a tuber; and each plate is the produce of a single hill. 

require little else of the grower than their multiplication; and third, by crossing plants to combine the best qualities of two or more parents in a new and improved variety.

\section{Improvement of the potato by selection}

The principal method of improving the potato is by bud-selection. Potato hills are very variable, and improvement is made by planting tubers from the best hills. Many of these apparent improvements may be due to some advantage in growth, such as increased fertility, more light or moisture and so forth. Of course, this increase is only transitory, and not being inherited, produces no permanent advancement.

The potato, however, presents variations which are inherited. These are of two kinds, - smaller differences whose inheritance produces a gradual change, and large differences or so-called "bud-sports" or bud-mutants which immediately become the starting point of new varieties.

Potatoes differ from most farm crops in their manner of reproduction. They are propagated vegetatively without the intervention of a sexual process like corn or wheat. Each hill of potatoes comes from one tuber or a part of a tuber which was the product of one bud of the mother plant. Hence the entire hill becomes a unit, and hill selection is, in reality, bud-selection. Single tubers cannot be said to be units from the breeder's standpoint. Therefore, it is of supreme importance to take into account the yield of an entire hill and not the presence in it of two or three large tubers resulting in low total yield for the hill.

So far as man is concerned, the origin of the initial variation is largely chance, but this start or variation 
once given, he has the power, in most cases, to perpetuate it and to modify its characters. There are two very different factors or problems in the origination of potato varieties by selection, - the production of the first departure or variation, and the subsequent breeding of it.

It is apparent that the very first effort on the part of the potato-breeder must be to secure individual differences. If the plants which he grows are very much alike, there will be very little hope of obtaining new varieties. He should, if possible, cause his plants to vary. This initial variation may usually be induced by changing the conditions in which the plant has habitually grown, as a change of seed, change of soil, tillage, varying the food supply, crossing and the like. As a matter of fact, however, nearly all plants which have been long cultivated, like the potato, are already sufficiently variable to afford a starting point for breeding. The grower should have a vivid mental picture of the variety which he desires to obtain; then he should choose those hills which most nearly meet that ideal.

Experimental breeding has demonstrated that the different varieties of farm and garden plants, as we ordinarily know them, are not entirely homogeneous and uniform, but are made up of smaller groups now known as "pure lines." It is ordinarily understood that a pure line is the progeny of a self-fertilized individual, that is, one in which all effects of crossing have been eliminated by constant self-fertilization. In potatoes which are ordinarily propagated asexually, a pure tuber line would be the progeny of a single tuber.

Experiments seem to demonstrate that the group of individuals known as a pure line vary much less than the variety as a whole, and that selection of the best indi- 
viduals within a pure line has little, if any, effect in raising the average of the line. This has not been proved, by any means, but the indications are that only a very slight advance is made by continued selection after a pure line has been reached, unless an exceptionally good individual should arise whose progeny would constitute a new and better line.

It will now be seen that the first work in improving potatoes by selection is to determine the best tuber lines and plant them for seed. This necessitates carrying out a system of breeding whereby individual tubers must be planted separately and properly labeled and their progeny kept separate for a few years to determine whether or not the desirable plants transmit their qualities to future generations (see Plate VI). This is known as "pedigree breeding." Myers gives the following table to show variation in the yielding capacity of different tubers. Each unit is the product of a different parental tuber :

\section{Table $\mathrm{X}$}

UNIT
No.


If the first work of breeding consists of separating out pure lines and if there is very slow progress within these lines, it is obvious that the choice of individuals for planting the first few years is all-important. As large fields as possible should be grown to give opportunity for all of the best plants to appear.

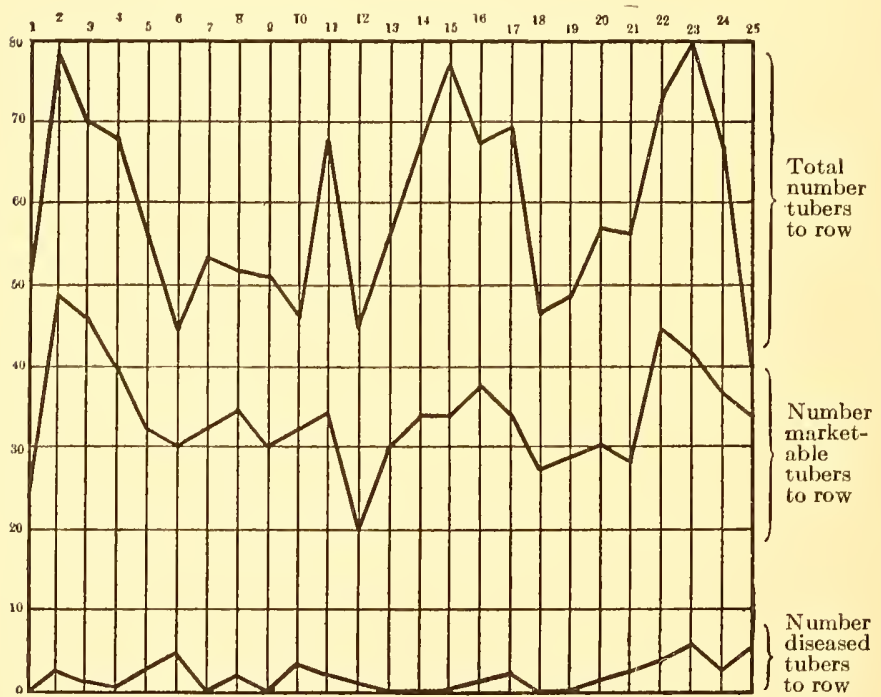

FIG. 8. Potato yields. Diagrams showing variation in yield of individual rows of potatoes grown on special seed plots in 1909. (Carman No. 1, by R. H. Croslyy, Markham, Ont.)

Until recently, the method of selection has been to choose from the potato bins in the spring the requisite amount of seed, using tubers having the desired size and shape but without knowledge of whether they came from high yielding strains or not. This method of choosing seed from year to year, using merely the best tubers 

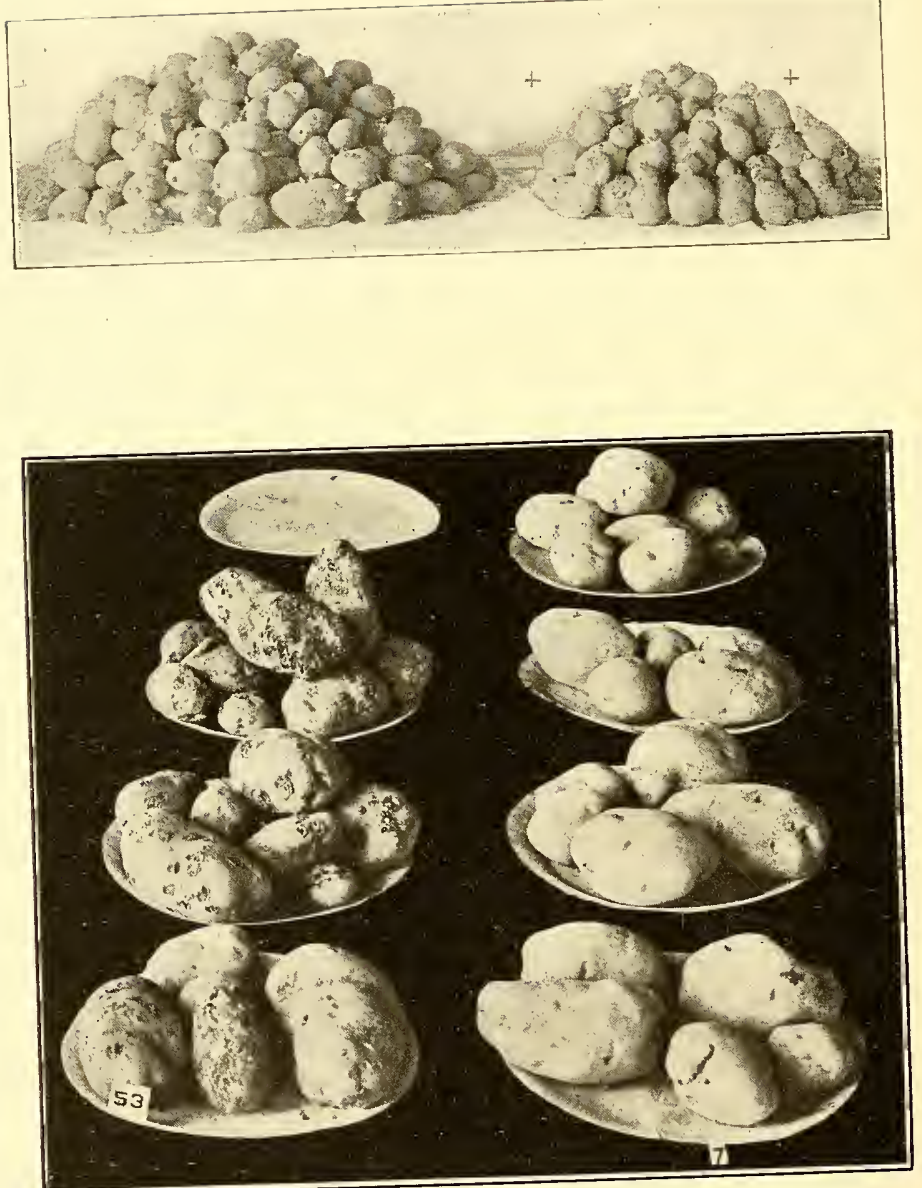

Plate VII. - Tubers with histories. Upper, influence of unfavorable growing season, showing the second-growth tubers on the right compared with normal uniform tubers on the left. Lower, Breeding - the immunity and susceptibility of two tuber progenies. 
without a knowledge of their ancestry or obtaining a test of their producing power, is known as "mass-selection." This method will inevitably lead to improvement

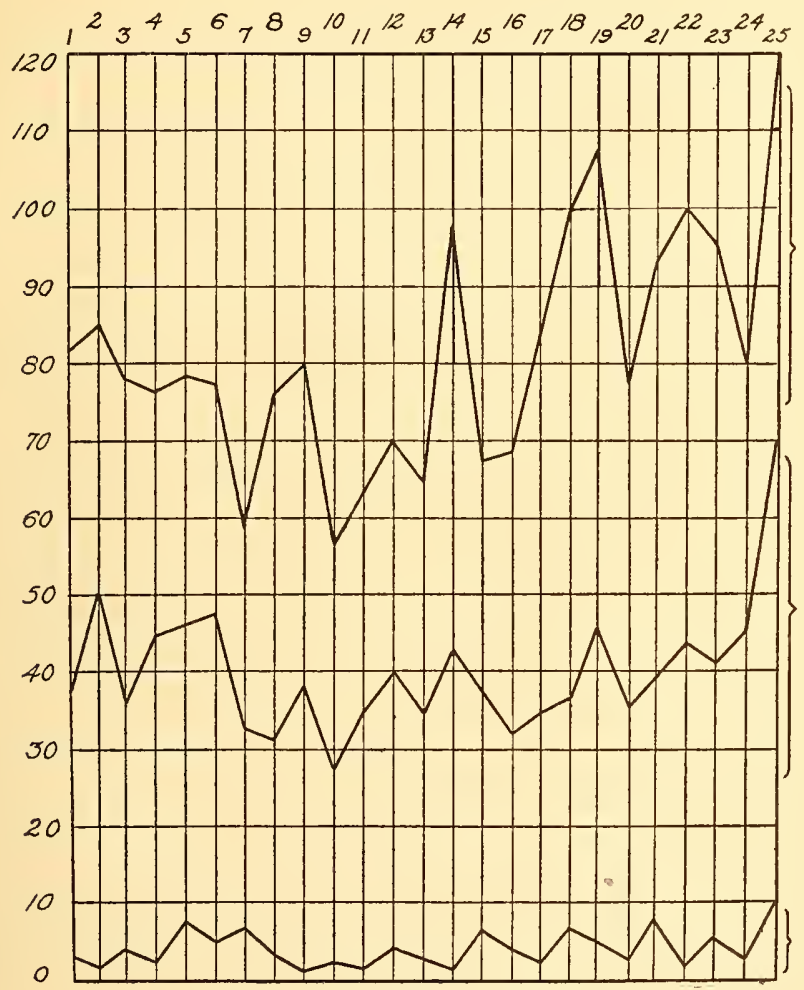

FIG. 9. Continuation of Fig. 8.

because the very poor hills will not produce good tubers, and hence will be eliminated. But the improvement is a very slow one. In employing this method of mass selec- 
tion, growers were working blindly without knowing how or when or even whether they were going to reach a stability of type. On the other hand the method of pedigreed culture or "individual selection" eliminated the fear of failure because of the appearance of the hitherto unsurmountable variations.

Plants which have any desired characteristics in common may differ widely in their ability to transmit these characters. It is generally impossible for the cultivator to determine, from the appearance of any given progeny, the most invariable and the most like its parent; but it may be said those individuals which grow up in the most usual or normal environments are most likely to perpetuate themselves. A very unusual condition, as of soil, moisture or exposure, is not easily imitated when providing for the succeeding generation, and a return to normal conditions of environment may be expected to be followed by a more or less complete return to normal attributes on the part of the plant. If the same variation, therefore, were to occur in plants growing under widely different conditions, the operator who wishes to preserve the new form should take particular care to select his tubers from those individuals which seem to have been least influenced by the immediate conditions in which they were grown.

The method of individual selection or pedigree breeding is now universally accepted by the best breeders. In potato-breeding it is known as the "tuber-unit" method, that is, the progenies of individual tubers are tested for a number of years to determine the best pure lines which are constant from year to year.

One of the first and best methods of breeding potatoes by the tuber-unit or pedigree plan has been devised by H. J. Webber. This method is so satisfactory, when properly carried out, that it is given here in detail: 
Selection of foundation stock of potatoes. - Probably no crop generally grown is more influenced by environment than the potato. The experience of growers indicates that a variety found to be the best suited to local conditions on one farm may not prove to be the variety best suited to the conditions existing on an adjoining farm. It thus becomes desirable for any farmer who is growing potatoes extensively to test varieties sufficiently to determine which is the variety best suited to the local conditions concerned. This ordinarily does not require an extensive test as the experience of growers in a region has usually shown the general superiority of a comparatively few varieties, and a test can thus be linited to these varieties which in general are known to be the best. The writer would not urge this test of varieties, if it were not very important to begin any breeding work with the best variety available. Breeding work requires so much attention that it does not pay to start with an inferior variety. The first effort of any one contemplating breeding with potatoes is thus to determine the best foundation stock to use for the selection work. If the grower has had extensive experience in growing potatoes and has determined that a certain variety gives the best results under his conditions, he is in a position to start the selection without a further test of varieties.

Growing potatoes for selection. - The influence of the number of eyes and size of piece planted as seed has so much to do with the vield of the hill that fields planted in the ordinary way are very poorly adapted to begin the work of selection. It is of primary importance that the first selections be of the very highest type obtainable, as it is a common experience that the first selection is the most important. Too much attention cannot be given therefore to the first selection. The writer would thus urge the following method as one of the most satisfactory to be pursued:

(1) Examine a large number of tubers of the variety selected as the foundation stock and decide on the most desirable shape and type of tuber. In general a moderately large tuber, which is oblong or somewhat cylindrical in shape and oblong in cross section, is considered most desirable. A spherical tuber if sufficiently large to be desirable is so thick that in cooking the outside is likely to become overdone before the interior is properly cooked. A tuber with shallow eyes, netted surface and white color is also usually preferred. Probably the best-sized potato for general use is one weighing seven to eight ounces. A potato of this size does not have 
to be cut when served, as a single tuber is about the right size to an individual. Again this sized tuber is well fitted for cooking and it is small enough so that the interior will cook nearly as quickly as the exterior. Probably the most desirable shape is when the tuber has a major axis or length of three and one-half inches to four inches, with a width of possibly three to three and one-fourth inches, and a thickness of two to two and one-fourth inches. In a tuber of this shape the center of the potato at any point is only about one inch from the exterior.

(2) When the ideal character and size have been determined, examine a large number of tubers and pick out a thousand or more having this size, shape and general character. This is work that can be done in the late fall and winter when there is no rush of other farm work, and time should be taken to secure a considerable number of these tubers of the same character. These are to be used for planting the selection plot, and the number selected should correspond to the size of the plot which it is desired to plant, four hills being planted with each tuber. There should certainly not be less than one thousand, and a much larger number is more desirable. The prospective breeder should remember that success in breeding work depends upon selecting the one individual that gives the very highest yield possible under the conditions, and the larger the number of individuals examined the more likely is he to discover the one producing the maximum yield which will give a valuable new strain. There is no loss in growing this selection plot aside from the greater amount of time required for the digging, so that one should grow a considerable number of plants.

(3) The planting should be arranged in such a way as to secure a test of the productivity of each tuber. To do this the following method may be recommended. Cut each tuber into four uniform sized pieces, making each cut longitudinally so that each piece will contain an equal proportion of the basal end and the apical end of the tuber. Plant four hills with each tuber, one piece in the hill. These should be planted consecutively in each row beginning at one end, so that starting at that end the first four hills will be from one tuber, the second four from another and so on throughout the length of the row. The object in planting this way is that four hills can be dug together and the total product weighed to obtain a measure of the productivity of the seed tuber planted. Probably the best way to plant these is to drop the selected tubers one to each 
four hills and then go over the row and cut each tuber and plant its quota of four hills. The hills in the row should be planted somewhat farther apart than in ordinary planting, probably 20 to 24 inches. If this is not done, a somewhat greater distance than ordinary should be left between each two four-hill tuber-units. The writer would advise that one hill be left unplanted between each two fourhill units. It would doubtless be convenient and desirable to have the plants in rows both ways to facilitate digging. For this selection-plot of potatoes, choose a field of moderately good fertility and as uniform throughout in soil as it is possible to obtain.

(4) Manure and cultivate the plot of potatoes grown for selection just the same as you do your ordinary crop.

How to make the selection of potatoes - field examination. - A careful examination of the selection field should be made as the vines begin to mature and while they are yet green. This examination should include observations on diseases and vigor of the tops. If there are any marked differences apparent between the different four-hill units, those with the best-appearing, most healthy tops should be marked by small stakes which can be stuck in the ground beside the hills. This field examination, while important in careful work, probably could be omitted without very great loss, as after all the yield is the primary character.

Digging the selection field. - The digging of the field grown for selection purposes requires considerable care, and here hard work is necessary. Dig each four-hill unit grown from the same tuber separately, being careful to get all of the product, and avoid cutting or injuring the tubers if possible. Carefully place the product of each four-hill tuber-unit together at one side of the row, and if it is a tuberunit marked with a stake in the field examination, keep the stake with the product of the unit. A good way to dig in order to avoid getting the hills of different tuber-units mixed is to dig across the field, in a direction at right angles to the direction the rows were planted. First dig the four hills of the first tuber planted in the first row, then the four from the first tuber in the second row, then the same in the third row, fourth row, etc., through the field. Next dig the four hills from the second tuber planted in the first row, then the four from the second tuber in the second row, etc. By this method of digging, especially if the hills are rowed both ways, there will be little danger of mixing the product of the four-hill units.

Making the selections. - The problem after digging is to select 
fifty to one hundred of the best tuber-units, - best, that is, in yield, uniformity of product, color, shape, etc. After the potatoes are dug and the product of each tuber-unit is laid out separately, the real work of selection begins. The following are the important steps in this process :

(1) Go over the field and study the tuber-units in a gross way until you have well in mind the variations in yield and the general uniformity of the tubers in the various tuber-units. Remember that the total yield is not the only important character. What one wants is to discover those tuber-units which have the largest yield of good merchantable potatoes of the best shape and appearance. Size up the field as a whole with reference to these characters.

(2) Go over each row carefully and throw out all of those tuberunits which can be clearly seen to be inferior; these may be thrown together and placed with the general crop of potatoes. For the interest of the grower, however, it would be well to weigh the product from some of the light-yielding tuber-units and preserve the figures for the sake of showing the extent of variations occurring. By this first discarding process the number of tuber-units will probably have been reduced to two or three hundred. It is very probable that in some cases one or more of the hills of a four-hill tuberunit will not grow. In such cases the tuber-unit will have to be judged in proportion to the number of hills actually grown.

(3) Now provide yourself with scales of some handy pattern like the ordinary counter scales used by grocers, with which the product of each tuber-unit can be easily and quickly weighed. A satisfactory scale should weigh accurately to at least a half ounce. Weigh the product of the remaining tuber-units, examine the tubers more carefully as to their character and uniformity of size in the tuber-unit and select about fifty of the best units. These fifty units should naturally be from those marked as having good healthy vines in the first examination before digging, unless all of the vines at that time were in fairly good condition. In making these final selections, if some hills in the tuber-unit are missing, the comparative yield can be easily calculated. If one hill is missing, a comparative yield for four hills is obtained by increasing the weight from the three hills by one-third. If two hills are missing, a comparative yield for four hills would be double that obtained from the two hills. If more than two hills are missing, discard the unit entirely. 
The product of the tuber-units selected should then be placed in paper bags, the product of one tuber-lunit only being placed in a bag. A good bag for the purpose is the 12 or 16 pound manila paper bag used by grocers. The 12-pound paper bags of good quality should cost only about 40 cents per hundred. If the 12-pound paper bag is too small, use a 16-pound bag. In your notebook record under the number of each tuber-unit, the number of large, medium-sized, and small tubers and the total weight of the product. The bags containing the seed should then be placed in suitable storage where they will not be torn or the tubers mixed. The tubers from the best discarded tuber-units should be retained to plant the general crop the next year.

If at digging time the grower is crowded with work and wishes to save time, the two or three hundred tuber-units retained after the first gross selection (see paragraph 2 above) could be placed in paper bags and the more careful examination and weighing of the product delayed until some convenient time during the winter when the final selection could be made.

Selecting seed for the second year's planting. - Some time during the winter or at any convenient period before planting time carefully examine the product of each select tuber-unit and pick out the ten best tubers of each as judged by the ideal standard of a good tuber which has been taken as the type of the selection. The ten best of each retain in the numbered sacks for planting and discard the remaining tubers.

Second year's planting. - In the further handling of the selections made the first year the planting the second year must be arranged in order to test the productive power of each of the fifty select tuber-units. Plant each tuber-unit in a row by itself by the same method used in planting the first year's crop (see p. 64). That is, plant four hills with each tuber, cutting the tuber longitudinally into four equal-sized quarters, making each cut from base to apex of the tuber. As ten select tubers were retained from each tuberunit this will make forty hills per row, and if fifty tuber-units were selected, there will be 500 tubers to plant, which will make a total of 2000 hills in the breeding-plot. The land used for this breedingplot should be carefully chosen for uniformity, as variations in the land will modify the comparative vield and are likely to render the results untrustworthy. Number each row of forty hills with the number given the tuber-unit of the preceding year. It is desirable 
for comparison to plant about every tenth row with unselected seed of the same variety, cut and planted in the same way, but without reference to keeping each tuber separate. The production of these check-rows will show whether progress is being made in the selection.

Cultivate the breeding plot and treat it otherwise just as an ordinary crop is treated.

Making the second year's selection. - When the breeding plot nears maturity, the individuals should be examined and either the best and healthiest vines marked or, if easier, the diseased vines showing weakness marked, so that they can be discarded later. Then dig each tuber-unit as in the preceding year, placing the tubers from each four-hills together at the side of the row. Each unit should then be weighed and the number of large, medium and small sized tubers recorded. This will enable the breeder to determine which of the original fifty tuber-units selected in the first year has given the largest average yield in the ten tuber-units or forty-hill test, and this is the primary test of the value of the original selection. Following the same method as used the first year, select from the breedingplot the fifty best tuber-units, and preserve the tubers of each unit separately in a paper bag. The majority of the selection in this year should naturally be made from those rows which have given the highest yield. Number the tuber-units selected in this second generation 1-1, 1-2, 1-3, etc., and 2-1, 2-2, etc. In such hyphenated numbers the first figure refers to the number of the tuber-unit selected the first year, and the second number, that following the hyphen, refers to the number of tuber-units elected from this progeny the second year. Thus in the case of 2-2, the first 2 indicates that it was the second tuber-unit selected in the second year from progeny of unit No. 2 of the first year's crop. In the third year the numbers can be extended by the same principle, the tuber-units selected from progeny $2-2$ in the third year being numbered $2-2-1$, $2-2-2,2-2-3$, etc. These numbers can be placed on the bags and notes on weight of yield, number of tubers per unit, etc., recorded under the same number.

All of the good tubers from the remaining tuber-units of the breeding-plot not selected should be retained for planting a multiplication-plot the third year, which should furnish sufficient seed for planting the general crop for the fourth year.

At some convenient period before planting time, as in the pre- 
ceding year, go over the product of each select tuber-unit and pick out the ten best tubers of each for the next year's planting.

Continuing selections in third year. - In the third year, the fifty selections of heavy yielding tuber-units should be planted by the same method used the second year, at least forty hills of each selection being planted. The row from each unit should be plainly labeled or otherwise marked to avoid mixing the pedigree. Treat this breeding-plot as described for the breeding-plot in the second year, weigh up the product of each four-hill tuber-unit in the same way to determine which unit of the second year's selection has transmitted in greatest degree the tendency to yield heavily. Finally, select again the best fifty tuber-units to continue the breeding, and retain the good tubers of discarded units to plant a multiplication in the fourth year.

In the third year, a multiplication-plot should be planted with the good tubers from the discarded tuber-units of the breeding plot of the second year. In planting this plot the grower can use any method of cutting and planting the tubers which he thinks most desirable. This plot should give enough seed to plant a fairly large plot in the fourth year.

Continuing selections in fourth and succeeding years. - In the fourth and succeeding years the selection should be conducted by the same plan as outlined above. When this system is well under way, it will be seen that each year the breeder is growing a small breeding-plot, a large multiplication-plot for seed and a general crop.

Further considerations. - As the selection progresses many of the strains from the original fifty tuber-units will be entirely discarded. The breeder must be continually watching for the appearance of a heavy yielding strain, and if such a strain is discovered, all of the further selections should be made from this strain.

In advocating the selection of but fifty tuber-units and the planting of ten tubers only from each select unit the writer has had in mind the reduction of the work to a comparatively simple plan which would be better to handle larger numbers if the grower is so situated that he can take the time for it. It is, however, better to use comparatively small numbers carefully than to attempt to handle large numbers and find the work too extensive. 
Another method of selection has been suggested which is simpler than Webber's method, probably not as satisfactory, but which has been found very useful by many growers. It consists of planting, growing and digging the tubers the first year as previously suggested, but instead of weighing the hills and keeping them separate for further tests, they are chosen by means of counting instead of weighing. If the season has been an average one, the hills which have six or more good tubers are saved for future planting. Perhaps it may be necessary to use five as a standard of selection or even seven may be used if the crop is good. There is no attempt at pedigree breeding by keeping the different strains separate. All hills meeting the established standard are thrown together and saved for seed. The next year these are planted and grown like the rest of the field. In the fall they are dug by hand and again the best hills by count are saved for seed. This method will gradually eliminate the poor strains and raise the average yield of the crop very rapidly.

Spillman says: "A potato grower in Michigan some years ago began the practice of digging by hand enough potatoes for seed and saving only those hills that had six or more merchantable tubers and no small tubers. When he first began this practice, only sixteen hills out of each hundred dug came up to his standard, but after he had continued this practice for five years the number of such hills had risen to seventy in a hundred."

Another similar instance is found in some unpublished results secured by Dodge of the office of Farm Management, who for several years has been teaching some New England potato-growers how to select seed potatoes. The method adopted is to save for seed those hills that 
produce six or more merchantable tubers. This experiment has extended over three years. The first year, from 7 per cent to 8 per cent of hills were found that met the requirements; the second year from 17 per cent to 20 per cent. This season the number of hills which have produced six or more merchantable tubers has risen to 24 per cent to 27 per cent.

Whenever pure lines or strains or varieties of potatoes are compared, every effort should be made to eliminate soil differences or other factors of environment, so that a direct test of the heredity only can be made. Potatoes are so easily influenced by environment that real hereditary differences are often covered up. Absolute uniformity in time of planting, methods of culture, spraying and so forth are essential. The seed pieces should be as nearly the same weight as possible. Arthur says, "Whatever increases rate of growth at the beginning, increases yield."

If tuber-units are being compared, they should be planted in duplicate or preferably in triplicate in different parts of the field and their production averaged.

If single high-producing hills are saved for the next year's planting, one should make sure that they did not come from some highly fertilized part of the field. Preferably they should be chosen from the poorer parts of the field when their production may be high in spite of their environment, the real test of heredity.

Zavitz, of the Ontario Experiment Station, selected the best hills of seven varieties of potatoes for a period of sixteen years. During the first four-year period the average yield was 120 bushels. During the three succeeding periods of four years each, as a result of selection, the average yields were increased to 216,218 
and 249 bushels. Within the sixteen-year period, the methods of culture were kept practically the same and the result is, therefore, attributed to the result of selection.

Waid has conducted at the Ohio Experiment Station a series of experiments for the purpose of securing data to throw more light on the question of the value of hill selection in potatoes. In this work, starting with the same original lot of tubers, three strains were grown as follows: (1) seed from high-yielding hills; (2) seed from low-yielding hills; (3) unselected seed. The following table gives the summary of the results that were obtained from high-yielding hills and from low-yielding hills :

Table XI. - Summary of Results from Use of Seed Potatoes From High-Yielding Hills and From Low-yielding Hills. (Variety, Carman No. 3)

\begin{tabular}{|c|c|c|c|c|c|c|c|c|}
\hline \multirow{2}{*}{ Source of Seed } & \multicolumn{4}{|c|}{ Yield of 100 Hills } & \multicolumn{4}{|c|}{$\begin{array}{c}\text { Number of Tubers iN } \\
100 \text { Hills }\end{array}$} \\
\hline & $\begin{array}{l}\text { Total } \\
1904\end{array}$ & $\begin{array}{l}\text { Total } \\
1905\end{array}$ & $\begin{array}{l}\text { Total } \\
1906\end{array}$ & $\begin{array}{l}\text { A verage } \\
1904-5-6\end{array}$ & $\begin{array}{l}\text { Total } \\
1904\end{array}$ & $\begin{array}{l}\text { Total } \\
1905\end{array}$ & $\begin{array}{l}\text { Total } \\
1906\end{array}$ & $\begin{array}{l}\text { Average } \\
1904-5-6\end{array}$ \\
\hline & $L b s$. & Lbs. & $L b s$. & Lbs. & & & & \\
\hline High-yielding hills & 125 & 173 & 116 & 138 & 781 & 865 & 676 & 774 \\
\hline Check rows . . & 115 & 136 & 79 & 110 & 713 & 630 & 479 & 607 \\
\hline Low-yielding hills & 84 & 75 & 61 & 73 & 566 & 546 & 364 & 492 \\
\hline
\end{tabular}

Running out of varieties

Potatoes are grown in many parts of the world where the climate and soil are very different from that of their native home. Also all of our varieties which have been developed as a result of breeding give yields far in excess 
of the wild forms. The stress of uncongenial environment and large production of tubers causes most varieties to lose this abnormal (from the standpoint of the plant) producing power and to decline unless selection is constantly practiced. Disease may be partially responsible for this degeneration.

Running out of varieties is often caused by repeated planting of culls and poorer specimens while the best are sent to market.

Newman ${ }^{1}$ says, that in Sweden there is a potato known as the Dala, which is said to have been introduced about 150 years ago and is still one of their best sorts. The opinion held at Svalof is that there is no period of old age in a variety of potatoes; that where suitable sorts are used, and where suitable tubers of these sorts are used for seed purposes each year, the planting of the variety may be maintained indefinitely under all favorable conditions of soil and climate. The main considerations are maintenance of vigor and control of disease, and this implies careful selection of seed tubers, careful cultivation and spraying and rotation of crops. Special emphasis is laid upon the latter point.

Orton says: "The same system of seed selection and treatment and crop rotation that will free the potato fields of wilt, leaf-roll, and curly-dwarf will at the same time not only bring under control the blackleg and some other diseases but will insure the maintenance of the strains cultivated in their most vigorous and productive condition and be free from objectionable mixtures with other varieties."

The following statement from Fruwirth is representa-

1 "Plant Breeding in Scandinavia." Canadian Seed Growers Association, Ottawa (1912). 
tive of the opinion held by most of the European experimenters. "And the real degeneration, an ageing of a variety, which has been under uniformly favorable conditions and of which good seed is used has not been proved and is improbable."

Varieties seem to differ in their staying qualities. Some have held up for 50 to 60 years, while others have passed out quickly. The old Peachblow variety which was widely grown forty years ago has largely run out now except in certain localities like the Carbondale region, where it has been given careful selection and is better to-day than ever before.

Another reason ascribed is that long-continued bud propagation results in an inner physiological weakening. It is difficult to see, however, how prolonged asexual propagation affects stocks injuriously.

What appears to be the running out of a variety may, in some instances, be due to a change in market demands and the varieties disappearing which do not meet these demands. For example, the old long Burbank has given place to the more round varieties such as the Rural, and the Blue Victor has been replaced by white varieties and has now practically gone out of existence. Fruwirth believes that a lack of adaptation to local conditions results in a degeneration of certain varieties. Poor attention to the selection of seed tubers is also suggested as a cause of deterioration. Fruwirth summarizes the opinions of a number of German experimenters in support of these two views.

East points out that perhaps the potato requires frequent crossing to keep up the vigor, and that possibly continual propagation by asexual methods causes a loss of heterozygosis. 
Certain plant characters are often associated together. In breeding practice a knowledge of these associations is often valuable. If easily observable physical characters, such as color of flower or texture of skin, are associated with chemical composition, which is less easily detected, the appearance of the former is a valuable index to the existence of the latter. It has been often observed that there is a certain shade of green in the leaves which is correlated with vigor and high productivity. If the leaves are too light green, few tubers will be produced, or if too dark, the yield is again small or a large number of small tubers will be found, due to late maturity or possibly to disease. Correlations are especially valuable when they enable one to select out good plants in a young stage, or when they save the trouble of making elaborate chemical analysis. Only a few definite correlations have been discovered in the potato. East reports nearly all of these in Illinois Bulletin 127.

There appears to be a positive correlation between yield and the following: flat shape of tuber, number of stalks to the plant and length of the growing season. With a heavy setting of seed berries, we may usually expect a light production of tubers. No correlation has yet been found between color of the tuber and yield.

Fischer of Germany (reported by East) says that roundflat tubers tend to produce plants which are rather compact in habit. Cylindrical tubers produce large, scraggly plants.

Round-flat tubers are richest in starch. Quality is said to improve directly with an increase in starch content up to a certain point. An excessive amount of starch causes the tuber to be coarse and woody. A netted skin is usually associated with high quality. 


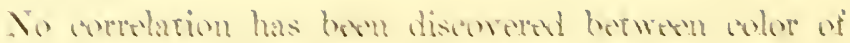
tabers and andor in the scems amb thmos.

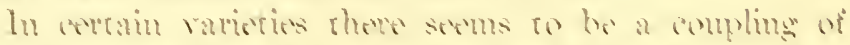

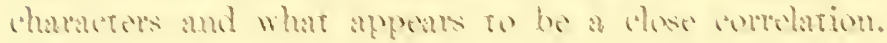

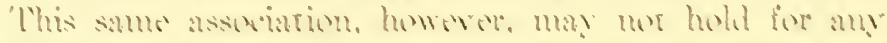

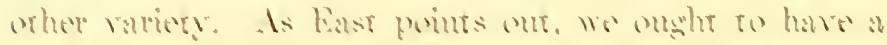

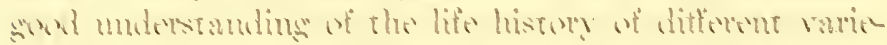

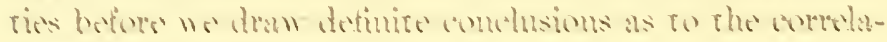
rion of ahmotituts.

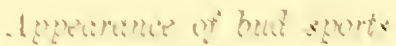

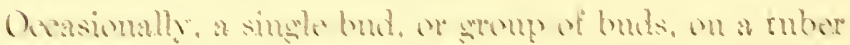

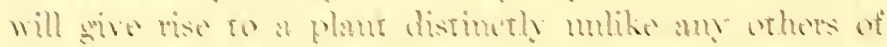

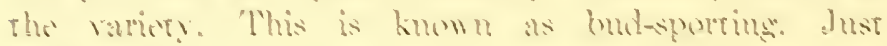

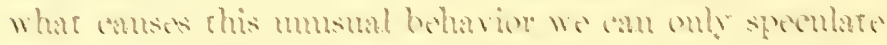

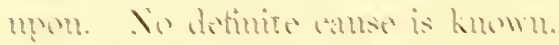

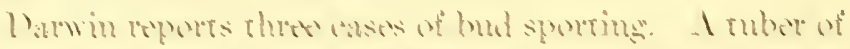

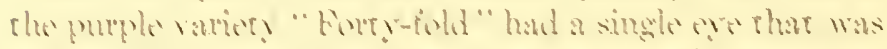

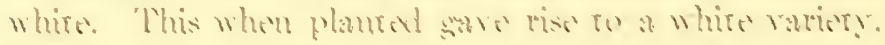

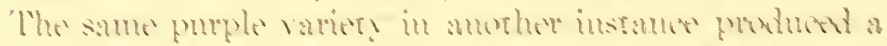

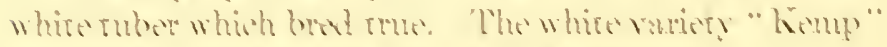

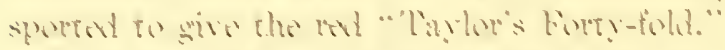

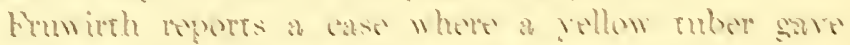
rist on a violor-skimet form. Fimmples of this som ats mathe mumeroms.

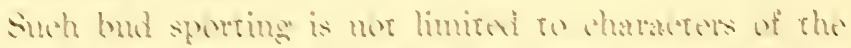

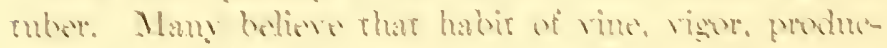

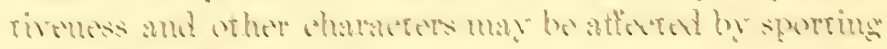
at ethe ruber buts.

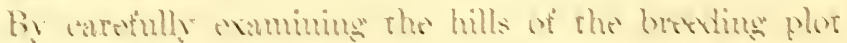

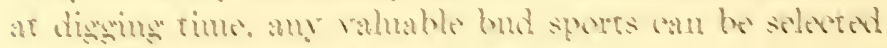

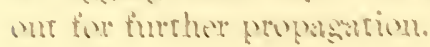




\section{Improtement by hybritisation}

It is hardly adrisable for the protionl potato-grower to attempt an extemsive improverment of his arop by hybridization. While the methest has riedded goosl results in some rases, there are many dillionlties in the way and the results are vere mertain. 'The major portion of a farmer's potato howeding phot shombl be given orer to tuber-mit rests. If the grower foeds that he anu spare the time and is willing to risk a failure in his enterprise, it womld be of interest and possibly of profit to attempt a lew arosises between his bedter strans. Otherwise this methot should be liet to the experiment station worker, who las the time to make the large number of manipulations neesisary, and who and derote large areas to the growiug of the serellings.

Plants are hybrilized prinarily to increase the variabiligy and to lurnish more material on which to pratedere selection. In the light of modern mendelian studies, we have come to look npon hybrids as recombinations of elaraeters present in the parents. Care should be exeresed to choose parents having as many desimble chatanters as possible. Subserpuent selections should preserve those plants which combine the latgest mumber

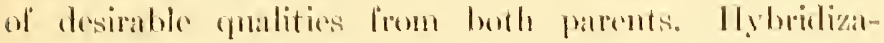
tion usnally increases vigor and is oftem useful in restoring this characteristic in weakened strains.

'There are entain conditions which make dhe smeresshol mybridization of potatoes very dillicult. In the lisst place, there is a strong tendemey in most varieties not to set seed. In such varieties, the flowers drop ofl shortly alfter pollination. This necessitates making a gereat. many pollinations with the hope that a few plants will 
set seed. Salaman ${ }^{1}$ estimates that only 5 per cent of his crosses set seed. East ${ }^{2}$ found it difficult to get a good setting of seed in very dry seasons.

In some cases, persistent attempts have finally resulted in a successful cross where at first it seemed impossible. A second drawback is the scarcity of pollen. Many rarieties produce little or no pollen and have to be crossed if we are to get sexually produced seed from them. Also, some plants produce yellow pollen which is sterile and does not function. Other varieties rarely, if ever, flower.

Nost varieties of potatoes are already hybrid and when seed from them is sown, the type breaks up into many elementary forms, most of which are of no value to the grower. This adds another difficulty to those mentioned above. Each variety which is crossed transmits a number of undesirable, latent characters which come out in the hybrids. Often the seedlings from a cross will show so many of the traits of the wild potato that none of them is worthy of further attention. Securing a valuable new variety from a cross seems in this case to be largely a matter of chance. There is an element of uncertainty in the work, which is not encountered with most crops.

The potato flower consists of a rotate corolla of white, lilac or purple petals, five green sepals, five anthers and a single pistil. The strle projects up through the "cone" formed by the closely adhering anthers. The anthers open at the tips and give out a small amount of pollen. In the day time, the flower is in an erect position, and it is impossible for pollination to take place. At night, however, the flower bends over and some of the pollen can fall

2 Illinois Bul. 127. 
down on to the stigma. The flowers open in the morning and close late in the afternoon. Fruwirth says that potato flowers usually give off pollen the second day after opening and wilt the third or fourth day. The period of flowering for a single plant is between 28 and 33 days. It seems to be a general opinion that the potato flowers are only rarely visited by insects, and that wind, also, plays little part in the pollination of the blossoms.

The first thing to be done in hybridizing plants is to decide on a definite ideal. We then choose our parent plants with reference to this imaginary type, trying to obtain plants which have as many as possible of the qualities sought in the new form.

Generally speaking, it makes no difference which variety we use as male and which as female parent. A great deal will depend on the nature of the varieties themselves. Obviously, we must pick for male parent a variety which bears at least a moderate amount of pollen.

It is well to keep in mind a few general principles of hybridization as we proceed. First, the plant to be used as female parent should be emasculated to prevent its setting seed by its own pollen. This must be done before the anthers have matured. Secondly, it is safest to bag flowers to be used in crosses, to prevent the entrance of foreign pollen. And lastly, the pollen should be applied to the stigma when that part is in a receptive condition.

Mature potato flowers should be examined so that one may become familiar with their structure. One should learn when the anthers are mature and when the stigma is ready for pollination. Just before the bud unfolds the flower to be used as a seed parent is opened with a pair of fine-pointed forceps. All the stamens are carefully removed, being careful not to break any or to leave 
parts of them in the flower. This must be done before the pollen is mature. All near-by flowers should be removed and buds other than those emasculated. As the flowers invariably fall off when bagged, this precaution must be omitted. The potato is not frequently cross pollinated (Salaman) and the danger of contamination is slight. It is necessary to tag the flowers thus treated in order to know later on when to pollinate them. The tag should bear the date of emasculation and other facts of which the hybridizer wishes to keep a record. A day or two after emasculation, the pistils of the emasculated flowers should be examined. When the tips have turned a slightly darker color and look sticky, they are ready to receive the pollen.

As the pollen is usually borne in small quantities, it is well to open the anthers with the point of the forceps and scrape it out on to the thumb nail or on to a watch crystal. A thin film of pollen on a watch crystal will pollinate a number of blossoms. It is customary to make two or three pollinations on the same flower in order to catch it in a perfectly receptive condition. Once the ovary starts to swell, there is little likelihood of the flower falling off. The berry should be picked off when fairly dry and before it falls off and rolls away. A record should be kept of the dates of emasculation and pollination, and of the parents concerned in each cross.

Potato seed should be washed free of pulp and carefully dried, in the fall. If left in the pod, it is likely to decay. Each pod normally bears from one to three hundred seeds. The seed should be planted indoors in March or April. The seedlings are potted up when they need moving, and set out in the field in June. They should be planted about two feet apart. 
Shoots are sent down into the ground from the axils of the first leaves, and it is on these that the tubers are borne. As a rule, the tubers for the first year vary in size from that of a marble to that of a hen's egg. In unusual cases single tubers have been obtained the first year which weighed over a pound. Wilson ${ }^{1}$ reports a total yield of 6 pounds 3 ounces for a single seedling plant.

It is often necessary to plant the tubers for another year or two in order to secure plants which will bear a normal crop of good-sized tubers. The tubers should be harvested separately for each plant, put in paper bags, and carefully stored until spring. Usually one is able to make his final selection the second year, but in some cases it is necessary to plant the tubers again before he can be sure that his choice of strains is a wise one. The tubers should be planted about 40 inches apart the second year to allow a careful study of individual plants.

One ought to remember that it is comparatively easy to produce new varieties of plants, and that the mere fact that we have secured new sorts does not mean that they are worthy of culture. Any new variety of plant should be distinctly superior to others on the market in at least one respect. The markets are already cluttered with mediocre varieties. Set your ideals high and do not be content with anything which falls short of them. Also do not waste time trying to select good qualities in strains where no such possibilities exist. Selection will not build up characters which are not potentially present.

In spite of the many hindrances to hybridization, some careful studies have been made on the inheritance of characters in the potato. We must remember, however, that in some cases at least, the material studied was not

1 Wilson, J. H. High. and Agri. Soc. Scot. Trans. 1907, pp. 74-92. 
pure. Perhaps it would be safest to look upon the results as showing certain tendencies in heredity, rather than as accurate character analysis. Salaman ${ }^{12}$ of England and East ${ }^{3}$ of this country have done most of the mendelian work on the potato. A résumé of their work will be given in the sections that follow:

Stem color. - Some varieties of potatoes have pure green stems, while others have traces of purple varying from light purple to almost black. The purple seems to be partially dominant over the green. The pure greens appear to be recessive and to breed true. Salaman ${ }^{1}$ found that the deep purple stem color of the Congo gave a good mendelian segregation. No ratios were given.

East (loc. cit.) reports the following: One purple-stemmed variety when selfed gave only purples. Four purple-stemmed varieties gave both purple and green when selfed. Four green varieties when selfed gave only green. A pure green $\times$ a heterozygous purple gave 6 purples and 7 greens $-\mathrm{RR} \times \mathrm{DR}$.

Flower color. - Potato flowers may be either white, heliotrope or shades of purple. The color is usually confined to one or the other of the surfaces of the flower. In all the domestic varieties studied by Salaman (loc. cit.) the color was limited to the upper surface. S.tuberosum had color only on the lower surface. In S. verrucosum the color appeared to be present on both sides of the flower.

East (loc, cit.) reports one purple which broke up into 14 purples to 5 whites when selfed. He says that purple is probably dominant to white.

Color in the tubcrs. - The skin of the tuber may be either white (yellow), red or purple. The flesh in like manner may be either white or colored. Purple-skinned varieties often have white flesh, and white-skinned sorts may show traces of color when cut open. Salaman ${ }^{1}$ says that these colors are all due to pigments dissolved in the cell sap.

${ }^{1}$ Salaman, R. N. The Inheritance of Color and Other Characters in the Potato. Journ. Gen., Vol. 1, 1910-11.

2 Salaman, R. N. A Lecture on the Hereditary Characters of the Potato. Roy. Soc. Hort. Journ., 38 : 34-39 (1912-13).

${ }^{3}$ East, E. M. Inheritance in Potatoes. Amer. Nat., 44: 424-430 (1910). 
East found that purples when selfed gave in some cases only purples; in other cases, purples and whites; and in still others, purples, reds and whites. Reds when selfed gave either reds alone, or reds and whites. Whites gave only whites. No mosaics of red and purple were obtained. The conclusion was that red is epistatic to white, and purple, to both red and white.

Salaman ${ }^{1}$ selfed a red-tubered plant of the variety Flourball and got a ratio of 9 reds : 7 whites, suggestive of the action of two pairs of factors. He believes that chromogen, a color base, is present in all tubers. In the red tubers he assumed the action of an $\mathrm{R}$ factor for color and a D factor which develops R. The second generation wonld then give :-

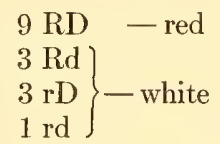

The red-tubered plant which Salaman self-fertilized was assumed to be of the constitution Rr Dd.

The Congo $\times$ Flourball (heterozygous for red) gave in $F_{1} 13$ black : 12 red : 4 white.

Salaman holds that a factor for purple $-\mathrm{P}-$ is necessary in addition to the $\mathrm{R}$ and $\mathrm{D}$ factors to give purple. He has on four different occasions united strains bearing white-skinned tubers to get colored types. This may be a case of factor interaction similar to Bateson's case of complementary colors in the sweet pea.

Solanum etuberosum seems to have an inhibitor to the formation of purple in the tubers.

Flesh color. - Very little work has been done on this character. Salaman notes that the color of flesh is inherited independently of skin color. He says that colored flesh is apparently due to the action of one pair of factors.

Shape of tuber. - Both East and Salaman found roundness recessive to other shapes. Round potatoes bred true in all cases. Salaman found that long tubers bred true for long axis, but often varied in diameter and hence in shape. Many oval-shaped potatoes were found to be heterozygous and to break up when selfed into round,

${ }^{1}$ Salaman, R. N. The Inheritance of Color and other Characters in the Potato. Journ. Gen., Vol. 1, 1910-11. 
oval and elongated. The kidney and cylindrical shaped tubers have about the same length of axis, but seem to have different factors determining diameter.

Depth of eyes. - The deep eye is a recessive character and breeds true. Shallow eyes are dominant over deep eves, but often not completely so.

Sterility. --Salaman ${ }^{1}$ finds that a tendency toward sterility is dominant over a fertile condition of the pollen. In a cross of Record (no pollen) $\times$ Flourball (abundant pollen), the $\mathrm{F}_{1}$ generation gave 12 pollen-bearing plants and 20 with no pollen. One of the sterile (for pollen) $\mathrm{F}_{1}$ plants crossed with the male parent used above gave 19 pollen bearing to 20 non-pollen bearing. This is practically the $1: 1$ ratio which we should expect to get from a cross between a heterozygous and a pure recessive.

Stolon length. - The stolons on which the tubers are borne are unusually long in the species, S. Commersonii and S. verrucosum, often reaching 6 feet or more. In the domestic varieties the stolons average 9-12 inches. Very long and very short stolons breed true. Intermediate stolons break up into various lengths, suggesting the action of multiple factors. Salaman ${ }^{1}$ thinks there may be two or perhaps three pairs of factors involved.

Plant habit. - Salaman ${ }^{1}$ states that upright and prone habit of plant are due to the action of one pair of factors. A duplex condition of the factor for uprightness gives a perfectly upright plant. Heterozygotes, Aa, are upright at first, but droop toward the close of the season. Prone plants have the constitution aa. Both prone and upright plants bred true to type. Intermediates gave a ratio of 1 upright : 2 intermediates : 1 prone, when selfed.

Shape of berry. - The seed berries of domestic varieties of potatoes are round. Those of the wild species tend to be long. Salaman concludes that one pair of factors is involved. He believes the long berries to be due to a duplex dose of a factor for length. When the length factor is simplex, a heart-shaped berry results. The double recessive factor gives round berries which breed true to shape.

${ }^{1}$ Salaman, R. N. A Lecture on the Hereditary Characters of the Potato. Roy. Soc. Hort. Journ., 38 : 34-39 (1912-13). 


\section{REFERENCES}

EAsT, E. M. A Study of the Factors Influencing the Improvement of the Potato. Ill. Bul. 127, 1908.

EAst, E. M. Inheritance in Potatoes. Amer. Nat., 44: 1910, pp. 424-430.

Fraser, S. The Potato. N. Y. (Orange Judd Co.), 1-185, 1901. Breeding and Selection, pp. 171-177.

Fruwirth, C. Die Züchtung der landwirtschaftlichen Kulturpflanzen. Vol. 3, Berlin, 1905.

Newuan, L. Plant Breeding in Scandinavia. Ottawa (Can. Seed Growers Association), 1912, pp. 193. (Potatoes, 168-182.)

Salanan, R. N. The Inheritance of Color and Other Characters in the Potato. Journ. Gen., Vol. 1, 1910-11, 7-46, pls. IXXIX.

Stuart, Wu. Potato Breeding and Selection. U. S. D. A. Bul. 195 (professional paper), 1915, pp. 35, pls. XVI, figs.

WaId, C. W. Results of Hill Selection of Potatoes. Amer. Breeders Association, Ann. Rept., Vol.' 3, 1907, pp. 191-199.

Webier, H. J. Methods of Breeding and Improvement of the Potato Crop. Cornell Farmers' Reading Course Bul. 43, 1909, pp. 753-768. 


\section{CHAPTER V \\ CLIMATE, SOILS AND ROTATION}

\section{By Daniel Dean}

The climate of most parts of the United States is not well suited to the production of the potato. The heat of summer is too great and the water supply in the soil and in rainfall during the growing season is too small. It is not known what are the possibilities of the potato in the mountain regions of South America from which it was brought by white men in the sixteenth century, but it is certain that up to the present time growers of northwestern Europe have often secured higher yields to the acre than those of the United States. One great reason for this fact is the difference in climate. The most famous potato-growing regions of Europe are several degrees north of any part of the United States, except Alaska. The average summer heat of northern Germany is estimated by the United States Department of Agriculture at nearly ten degrees Fahrenheit lower than that of most of the potato-growing sections of the United States. The climate of the principal potato-growing regions of Europe is so cool that Indian corn is not grown in them, while there is heat enough for corn in most of the northern United States and even for cotton in the South. Most of northwestern Europe has very heavy rainfall because of the Gulf Stream. The potato is grown in the United 
States because of its high value for human food, not because of favorable conditions. These facts are emphasized because knowledge of the nature of the potato plant helps the grower to adapt his methods to his local conditions to secure the best results. Except in northern Maine and the adjoining provinces of Canada, there are few parts of America where summer heat and moisture do not limit the yield of the potato to a figure below the best possibilities of the plant. Methods which prevent the effects of these two factors result in largely increased yields. In occasional seasons, as in parts of New York in 1909 and 1914, the climate is favorable and large yields are grown. It might be possible in such years to get yields equal to those of northwestern Europe, but it would be necessary to equal their large expenses for additional labor, seed and fertilization and this would result in heavy loss in the other years when climate limited the yield. Hot and dry years are known in Europe, but are the exception instead of being the rule as in most of the United States.

The United States Department of Agriculture Yearbook for 1914 gives the average yield of potatoes to the acre for the whole United States for ten years as being 96 bushels, while that of the state of Maine, with cool and damp climate, for the same period, was 206 bushels. The figures for the countries of northwestern Europe are 311 for the Netherlands, 388 for Belgium, 210 for Great Britain and Ireland and 200 for Germany. Yields are lower in the warmer or drier countries of Europe, being 130 in France, 115 in Hungary and 106 in Russia. A similar contrast is marked between hot Australia with an average of 101 bushels and cool New Zealand with 216, though both are settled by the same race of people. 
The warmest province of Canada, Ontario, averages 121 against 207 for the cool and moist maritime provinces and 229 for British Columbia.

Land is much higher in price in the potato-growing regions of Europe than in America. An extreme case is on the Island of Jersey, where land is worth $\$ 1000$ to $\$ 2500$ an acre. The annual rental under the tenant system common in Europe is often higher than the sale value of an acre in sections of the United States which raise millions of bushels each year. Labor is much cheaper in Europe than in America, allowing the use of very intensive hand culture at low cost. If European growers are to secure a living profit above their high rentals, they must farm this high-priced land very intensively with large expenditure of cheap labor, seed at the rate of an average of over 37 bushels to the acre and heavy fertilization.

American agriculture has been developed in the direction of heavy production to each worker engaged rather than in that of large yield to the acre. 'The high-priced day's work is the unit, not the high-priced acre of land. From the time when the Massachusetts Bay colonists "went west" to the Connecticut Valley in 1635, it was necessary to go westward, even to northwestern Canada, for there has been a new region of cheap land awaiting settlement. Almost until the present time, the competition of new soil of virgin fertility has kept down the price of farm produce and of land in the older settled communities to figures far below those of Europe. An even worse effect of this competition has been that little attempt has been made to keep up soil fertility. Methods of farming suited to frontier conditions of low prices and highly fertile soil have continued in use too long. Land is now 
rapidly rising in price, and methods of increasing the yield of crops will become more important than before.

The high cost of labor in the United States compared with that of land has resulted in the invention and use of labor-saving machinery for nearly every process of farming by which the power of horses or of engines has displaced that of human muscle. Machinery cannot so much increase the production to an acre as the production to each worker engaged in farming by increasing the number of acres farmed by each. For example, the use of horse-drawn tools compels a wider spacing of potato rows than where most of the work is by hand labor. This reduces the yield to the acre by reducing the number of plants. On the island of Jersey, rows of potatoes are spaced 16 inches apart and 24 to 27 in other parts of Europe, compared with 33 to 42 in America.

\section{FACTORS INFLUENCING POTATO CULTURE}

Study of the factors governing the choice of methods for the culture of the potato shows that eight are of principal importance: (1) heat in air and soil; (2) water; (3) soil texture; (4) available plant-food; (5) drainage and soil air; (6) the "critical period" in the life of the plant; (7) type, variety and strain of the seed; (8) diseases.

The tern "limiting factor" is frequently used in other connections and is peculiarly appropriate in potatogrowing. Any one of the above factors may be inhibiting in some conditions and may be able to place a limit on the size of the crop which cannot be removed by the others being favorable. For example, all farmers are familiar with the loss of yield caused by drouth, although 
not all know that the direct effect of great heat is perhaps even more harmful than the lack of water. The results of unchecked attacks of insects like the Colorado potato-beetle or of the late blight and rot, are other familiar examples. The potato-grower who would raise good yields every year through a series of years must study very earefully every factor which enters into the growing of potatoes under his particular conditions, with the idea of making sure that no one condition will limit the results of his labor in other directions. Such care counts heavily in increasing the income of the farm, because seasons in which a crop is generally poor from any cause are the ones in which prices are high.

\section{Heat}

Numerous experiments have shown that temperatures in the soil above certain limits injure the vitality of the potato plant. The extent of the injury depends on the degree of heat and on other injurious factors, as drouth and insect injury. The effect varies from reduction in yield to practical failure with tubers ruined for use as seed. Potatoes are not grown in the South in midsummer. When grown in the months of late winter and spring, the vitality of the tubers for use as seed is ruined by the heat at the time the tubers mature. The "second-crop" for seed in the South is planted in July or August and forms its tubers in the cool weather of late fall. At this time seed of good vitality is obtained. Near the Canadian line and in the Rocky Mountain region there is little more time in the whole growing season than is needed by the late main-crop varieties. When hot seasons occur there, as at Ottawa, Canada, in 1906-7-8, and at Greeley, Colo- 
rado, in 1911, there is no way of avoiding the heat by early or late planting. In intermediate sections like those from Long Island through to Iowa, growers avoid the effects of summer heat to some extent by planting either very early or very late.

Another method used more or less unconsciously by growers to prevent the effects of summer, is the use of heat-resistant varieties. The McCormick or Late Hoosier is used in Virginia and Maryland in summer because of its peculiar ability to produce crops in weather too hot for any other variety. The Rural or Blue-Sprout type is the one which is grown more than any other in the United States. It owes much of its popularity to the fact that it will yield well in hot and dry seasons. The use of the Green Mountain or White-Sprout type is mainly confined to the cooler sections, like Maine, because of its inability to stand heat as well as the Rural type. The Triumph, Cobbler and Early Ohio types are used to avoid extreme heat by growth in early spring rather than by heat resistance.

Heat is such a decisive factor in the growth of potatoes in most of the United States that growers must ever keep its effects in mind if they are to succeed with the crop. Many of these methods of culture now used have been forced on growers unconsciously by the influence of heat on the plant. Nuch is to be expected in the future from further investigations. Straw mulches have been found very beneficial in the hot regions of the western plains to insure coolness in the soil. It has been proved that thorough spraying with bordeaux mixture greatly reduces the injury from heat. This is shown by some of the gain from spraying in hot seasons when blight and insect injury are absent. A possibility is in the use of over- 
head irrigation in humid sections. One of the greatest needs of potato-growers everywhere is a new variety possessing the table quality, yield and appearance of those now in use together with the heat-resistance of the McCormick.

\section{Water requirements}

Lack of sufficient water is often a limiting factor on the yield of potatoes. Many experiments indicate that about 400 tons of water are used by the potato plant for each ton of dry matter produced, or over three tons for each bushel. This equals 3 inches of rainfall for each 100 bushels to the acre. Study of Weather Bureau records of rainfall shows that the average amount in the entire growing seasons in most potato-growing sections is only 10 to 18 inches. The losses from run-off and from evaporation are so heavy that this factor must be provided for if exceptional yields are to be raised. Methods of conserving the soil water left by winter rains, for the use of the crop, are of great value. The use of ordinary surface irrigation in the West and of overhead irrigation in the East produces much heavier yields than when rainfall is the whole dependence. With these methods, yields of over 500 bushels to the acre are common.

Surface tillage to prevent evaporation and the incorporation of organic matter with the soil are the principal means of conserving moisture. Plants on rich soil or when manures or fertilizers are used, are able to secure their plant-food from the soil by the use of less water than when grown on poor soil. Any means of extending the growth of roots makes more water available. The great need of water for the potato crop comes at the time when the tubers are forming. It is a matter of 
common observation that a small amount of rainfall at this time may be worth much more than larger amounts at other times. As this comes immediately after the critical period in the life of the potato, it will be seen that every effort should be made to keep the plant well supplied with water by tillage, organic matter, and the like.

\section{Soil texture}

The root system of the potato is weak and small compared with that of other standard farm crops, such as corn. It is especially weak in penetrating heavy soils. In any soil, loose texture greatly favors the potato by allowing wider and deeper distribution of the roots. The development of the tubers is checked and rendered irregular unless the soil is loose and open in texture. Most of the early crop for sale in summer is grown on sandy soils. On account of their advantages in structure, potatoes would be raised only on sandy soils did they not have other disadvantages which offset the value of good structure and earliness. Too great soil heat and lack of moisture often limit the yield of potatoes grown on sandy soils as a late main crop in summer. Much of the work of the potatogrower must be directed to give heavier soil types a structure more loose and open. Increasing the proportion of organic matter loosens up the structure of soils. Some of the greatest potato-growing soils naturally possess plenty of organic matter, as the Aroostook soils and the tule lands of California. The increased value of irrigated soils for the potato-growing where organic matter is supplied by rotation with alfalfa, or the use of humus-producing cover crops in the South, shows the importance of organic matter. There are few American soils which are not 


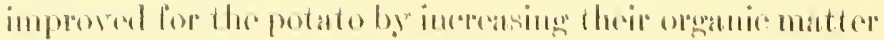

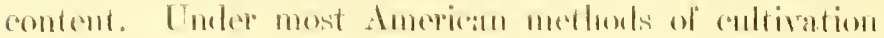

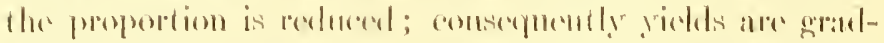

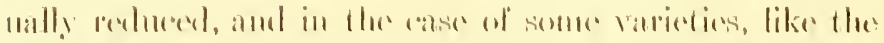

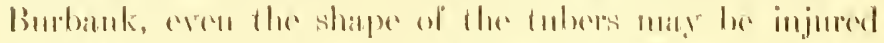

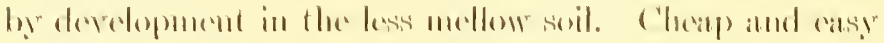

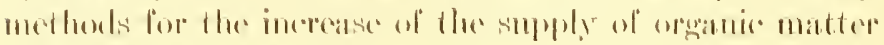

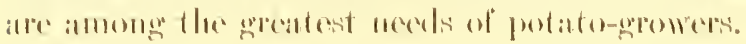

\section{Inailabli plant-finol}

For several reasous the potalo is lass ablete to sereure its

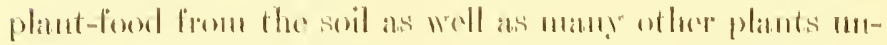

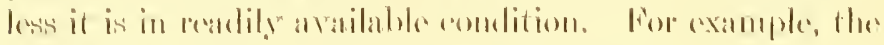

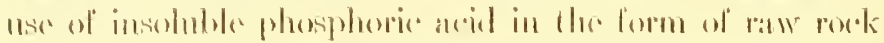

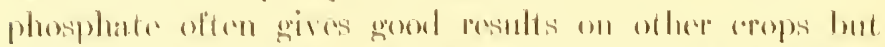

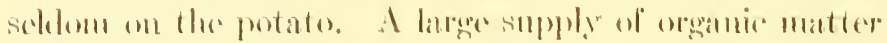

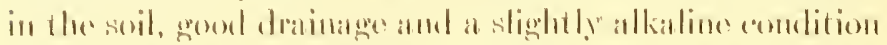
are essential to the liberation of the sterese of plant-fenel

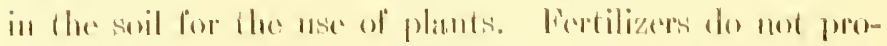

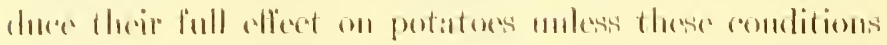

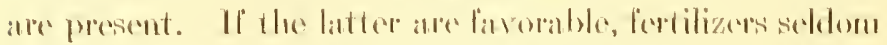

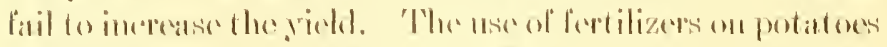

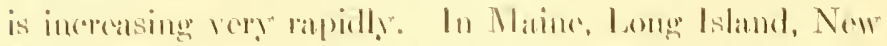

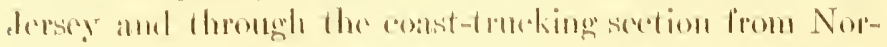

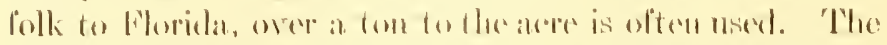

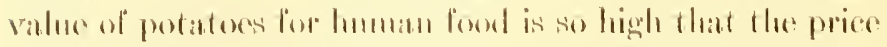

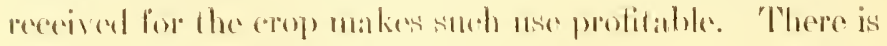

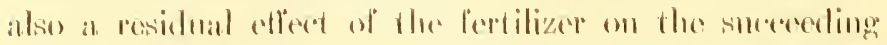

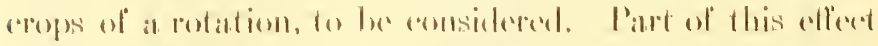

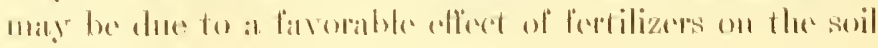
lincleria.' 


\section{Draimage and, sovil air}

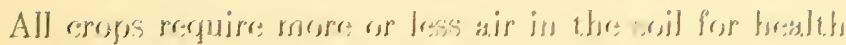

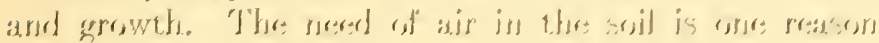

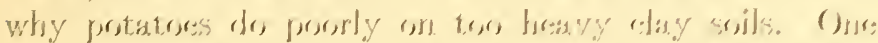

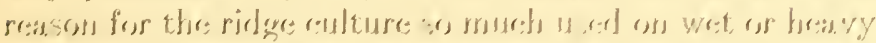

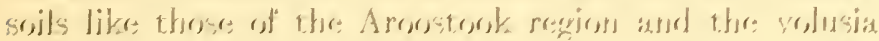

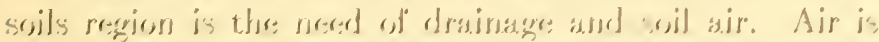

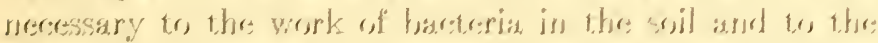

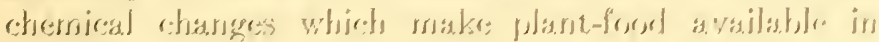

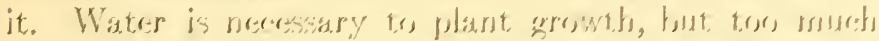

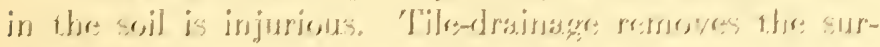

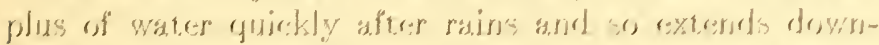

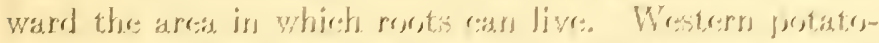

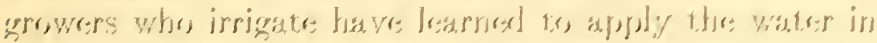

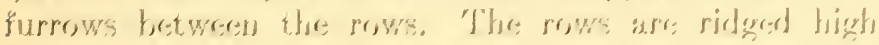

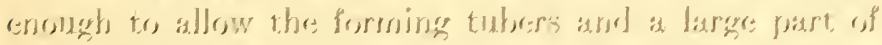

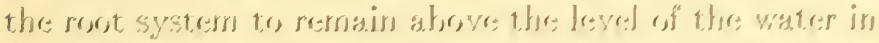

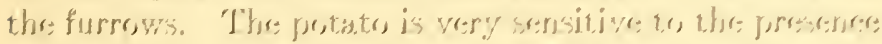

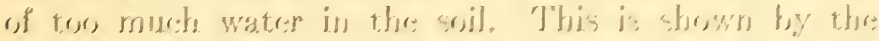

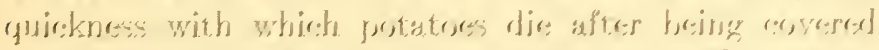

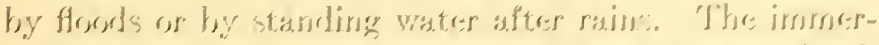

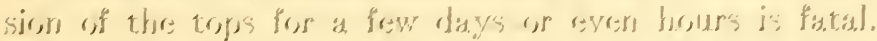

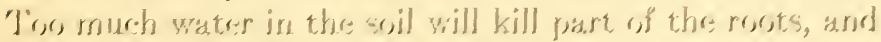

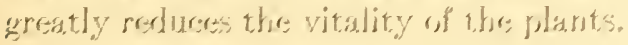

\section{Critiverel perivell}

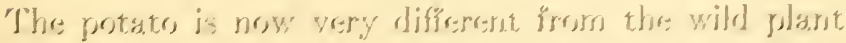

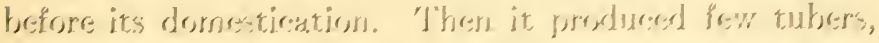

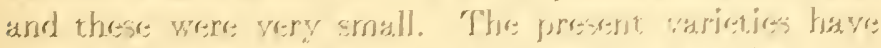

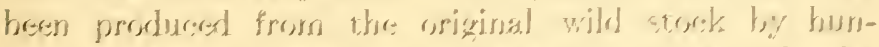

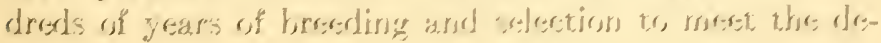


mands now made upon the plant. The yield of tubers has been enormously increased above that of the wild plant. Many shapes and colors have been discarded to keep the few which suit the eyes of civilized men. The length of the life of the potato plant has been shortened from nine months or more in the wild state to only three or four months. Vast numbers of seedling varieties which may have possessed greater natural vigor have been discarded to keep those which possess these qualities. It is not surprising therefore that the potato plant is not a strong one. One period in its life is especially precarious. The cultivated plant now produces much less seed than the wild plant, some kinds seldom or never blossoming; but blossoming is still a demand upon the strength of the potato. In the wild state the tubers were set after the seed formation. Under domestication the life of the plant has been shortened and the two processes overlap. When this time comes in hot weather, as with the late main crop of the northern states, the heat and drought which occur so often make the poorest possible conditions for the potato. Insects, diseases and careless methods of cultivation often further reduce the vitality of the crop. This has been called the "critical period" of the life of the potato. If it is passed in high vigor, the potato has later a more or less indeterminate growth. That is, there is no clearly defined time for its maturity, as with grain crops, but instead it gradually weakens, all the time increasing the yield of tubers. This condition occurs but seldom in the United States on account of the heat of summer, but it is an ideal towards which potato growers should strive. Production of a high degree of vitality in the growing plant in its early life and good soil conditions and care during the hot weather, will carry 
the crop safely through heat and drought which would not only badly reduce the yield but also spoil the crop for use as seed. Practically the whole yield is produced after this time.

\section{Type, variety and strain}

In this chapter, reference to the seed used is made to show that the variation between different types, varieties and strains allows the grower considerable latitude in adjusting the potato crop to different conditions. The use of quickly maturing types in the South and of heatresistant types in all but the most northern sections are examples of these adaptations. Much effort has been expended in the effort to find new varieties possessing the quality of resistance to some of the more serious potato diseases, but with little success as yet.

\section{Diseases}

Several of the most important potato diseases affect cultural methods. Examples of such are the use of long rotation to eliminate common scab, rhizoctoniose, the nematode eelworm and the fusarium wilt, from affected soils. Early spring planting to insure maturity before possible attacks of late-blight is employed in some sections.

GENERAL TYPES OF POTATO-GROWING IN THE UNITED STATES

Conditions of climate, soil, seed and markets vary so much that every grower has his problem to select the methods which will give him the most profitable results. The climate is something the grower cannot change. 
The markets have demands which the individual can do little to change. But in the selection of methods he has wide range of choice. The great variation in the climates and soils of as large a country as the United States makes for a wide range in culture methods. Broadly speaking, most of the potato-growing of the United States may be divided into five general types:

(1) The early truck crop of the southern states, extending to about the latitude of Washington. This belt is characterized by extreme summer heat which prevents growth in summer, excepting that of the heat-resistant McCormick variety. The crop is grown in the cool months of winter and spring for shipment to city markets because too perishable to store in the hot summer. Most of the seed is imported from the north or grown in the cool fall months as a "second crop." Commercial fertilizers are heavily used in this belt. The summer heat does not permit growth of most of the perennial hay crops used in other sections. Annuals are mainly used for hay and for the cover-crops that are often raised to prevent erosion and loss of plant-food in winter. Owing to the higher prices for extreme earliness, only short-season early maturing varieties are used and these are usually dug immature. Less machinery is used than in other sections.

(2) The northern belt of the principal potato-producing states. This extends from Maine to North Dakota and down to the latitude of New York City. This belt supplies the cities and southern states during the fall and winter and competes with the southern truck crop from April to July. The climate here is cool enough for the potato to maintain its vitality in most seasons, if given good care. Early varieties are now grown but little except for shipment South as seed stock. The use of fer- 
tilizers is steadily increasing, being very heavy in the East from Maine to New York. Spraying with bordeaux mixture for the late blight and rot is prevalent in the East. Digging comes so near to freezing weather that the grain crops grown in rotation with potatoes are those sown in spring. Oats are used mostly with spring wheat in the Red River section. Oats and peas and barley are grown to less extent.

(3) An intermediate belt between these two from Nebraska to New Jersey and Long Island. Potatoes from this belt come on city markets in summer and early fall, part being stored for winter shipment. Summer heat is not so dangerous as in the South, but there is usually an effort to avoid its effects to some degree either by planting early enough to get the crop nearly mature before midsummer or else late enough to have much of the growth come in the cool fall months. The effect of summer heat on seed vitality is often severe, but a large share of the seed is grown locally. The use of imported seed from the North is increasing, particularly in the regions of more intensive culture, such as Long Island. Winter wheat and rye often follow the potato in rotation in this belt.

(4) The irrigated sections of the West, destined to great extension in the future. The problems of the potato-grower in other sections are here largely replaced by those peculiar to the growth of the crop under irrigation. New systems of culture have been worked out to meet the new conditions. Control of moisture has enabled some of the heaviest yields ever grown in the United States. Owing to the natural high fertility of arid soils, fertilizers are unknown. Nitrogen and organic matter are secured by rotation with alfalfa. 
(5) Potato-growing by the so-called dry-farming methods, and local conditions such as the delta section of California, are as yet less important types.

\section{SOILS}

The choice of the soil on which to grow the potato is peculiarly difficult because of the fact that those which best meet the needs of the plant in one respect may be unfitted for it in others. Sandy soils permit free development of the root system, are well drained and are capable of early tillage in spring. Although usually poor soils unless fertilizer is applied, the growth of the crop is rapid ; and for these reasons most of the early truck crop of the South is grown on sandy soils, as earliness secures the highest prices. The great problem of potato-growing on sandy soils is that of sufficient water supply at the time the tubers are forming. This tendency to drought and heat injury of the crop has operated to lessen the use of sandy soils in the northern states for the late main crop in favor of soils cooler and more retentive of moisture. A large proportion of organic matter is of great value to sandy soils in increasing available fertility and the ability to hold moisture. The organic matter in sandy soils is easily exhausted by tillage, and constant effort is needed to keep it up to a high standard.

The larger part of the potato crop of the United States is grown on soils ranging in texture from sandy or gravelly loam to clay loam. Such soils are capable of holding enough moisture to supply the growing plant continuously, are cooler than the sands, and are usually of fair fertility if not too deficient in organic matter. While the extension of the roots and the formation of the tubers 

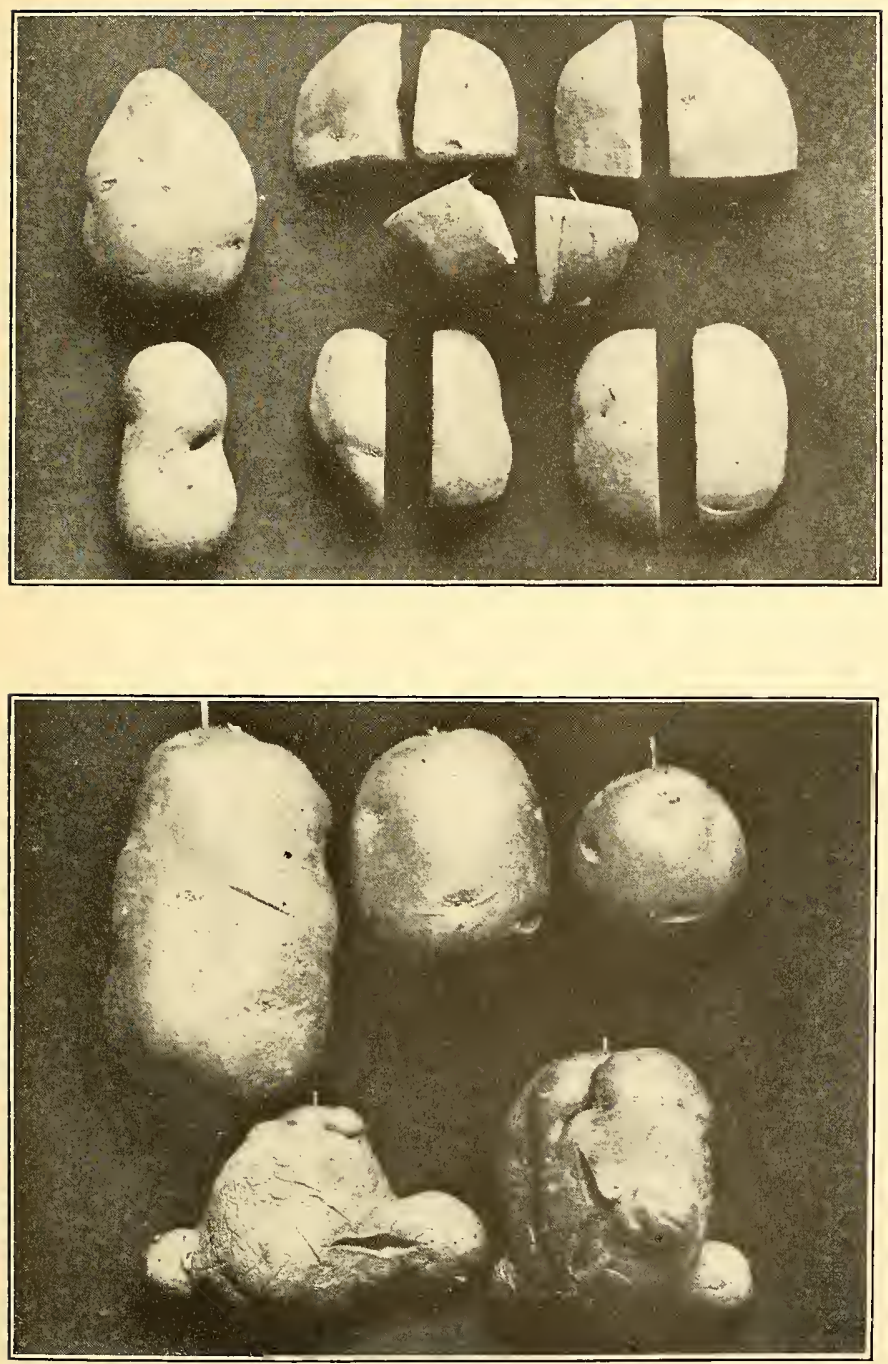

Plate VIII. - Seed potatoes. Top, different ways of cutting. Bottom, good and bad types for seed. 

are not as easy as in sandy soils, these types are not heavy enough to prevent success with the potato. Clay soils are too hard and heavy for the potato. Too much water at times and poor ventilation often affect the health of potatoes on clays. Careful tillage, tile drainage and the incorporation of organic matter lighten clay soils until they will produce good crops of potatoes in most years. Except in special cases, as near-by markets, it usually pays better to grow potatoes on lighter soils and use the clay soils for crops more adapted to them, as grass. Muck soils, as the tule lands of California, often produce large yields of potatoes. The quality is likely to be poor.

The importance of organic matter in the soil is seldom fully appreciated by American farmers. Most American soils outside of the arid regions contained more organic matter when first brought under cultivation than now. The gradual depreciation from year to year is not noticed until heavy loss in fertility has occurred. Another cause which has contributed to the depreciation of American soils is the low price of farm produce. The Department of Agriculture estimates the cash labor income of American farmers to average about $\$ 320$ a year besides the items secured from the farm as house-rent, garden, and the like. Too often this condition leads to robbery of the farmer's capital, the soil. The settlement of the last free land has led to a rise of the prices of farm products, which now makes it profitable to replace and increase the lost organic matter and lime fertility of older soils.

Organic matter has great power to absorb water and hold it for the use of plants. The potato is very susceptible to injury from lack of water, making this property of organic matter of great value. The physical nature of any soil is greatly changed by organic matter. Heavy 
soils are lightened, often to a degree which insures success instead of failure with the potato. Sandy soils are improved by their particles being bound together. The presence of abundant organic matter makes the soil more healthy as a home for plants and for the beneficial soil bacteria. Both need water and air. The plant-food in the organic matter is in condition to feed the crop as fast as it decays and breaks down. Indirectly the decay helps to dissolve the mineral plant-food in the soil.

Many kinds of bacteria and other microscopic forms of plant life are found in the soil. Their action and value are seldom understood by farmers. Too often the word "bacteria" conveys only the idea of disease, or at most that of the particular bacteria associated with legumes to take nitrogen from the air. These latter form but a fraction of the microscopic life of the soil, part of which is beneficial and part detrimental. Organic matter in and on the surface of soils is the food of many kinds of bacteria, and is broken down by them to forms which plants can assimilate. The nitrogen of organic matter is changed first to ammonia and then to the soluble nitrate form. Other bacteria like the azotobacter group take nitrogen directly from the air without being associated with any particular plants. The solution of mineral plant-foods is helped by some kinds of bacteria. The statement is generally true that the fertility of a soil varies according to the number of bacteria present. The number of the beneficial forms is increased by attention to maintaining the best conditions for their growth, as a large supply of organic matter for their food, an alkaline soil, sufficient water but not too much, and sufficient soil air.

Organic matter in the soil is of so great importance to 
the potato crop that methods for maintaining its supply need careful study. In the natural wild state the soils of humid regions receive constant additions of organic matter from the death of plants and the leaves of trees. The richness of newly cleared forest land and of the western prairies when first broken are examples familiar to all. Under cultivation most crops annually produce more organic matter than do wild plants, but in most cases only a fraction is returned to the soil. Part is shipped away from the farm for the use of man or of animals, part is destroyed by the animals fed on the farm in the process of digestion and part is lost in handling the manure. Operations of tillage and exposure of bare soils to the air rapidly use up organic matter. A few American soils are being handled in ways which increase their organic matter, but most of them probably are not.

The principal method of maintaining soil organic matter is that of crop residues. All crops leave part of their organic matter in the soil after being harvested, the proportion varying greatly. When potato tops are burned to prevent disease, very little organic matter is left in the soil from the roots. Other plants have more extensive root systems and also leave other residues in the form of stubble. A larger proportion is left when only the grain or seed of crops is removed and all stalks or straw is left on the land. Feeding off crops in the field, as in "hogging down" corn, leaves all the organic matter except that destroyed in the process of digestion. In practice, hay crops leave more residues than others like grain and potatoes. It is unfortunate that so little attention has been paid to hay crops in the United States compared with that given to the inter-tilled crops and to the grains. Tillage, manure, fertilizer and care are 
too much concentrated on the other crops of a rotation and the hay is left to grow as best it can. The handling of meadows and pastures is far better understood in Europe than in America, some being hundreds of years old. The use of better seed mixtures, of better methods of seeding, of better adaptation of the different hay crops to soils and of better fertilization will not only add directly to the yield and value of hay crops, but will increase greatly the yields of the other crops of any rotation by increasing soil fertility.

The statement is often made that when farm crops are fed to animals, the entire crop is returned to the soil in the manure. This is nearly true in regard to the mineral elements when the manure is well cared for. But the organic matter is very largely lost in the process of digestion. Over sixty per cent of that of hay and straw is used in this way, somewhat less in the case of grain feeds. In addition there is the loss in the handling of the manure. While the remainder is in more quickly available condition than in straw or in stubble, the question of whether to harvest the crop to feed or to return directly to the land will depend on the profit expected from feeding, the need of the soil for organic matter, the cost of labor and the effect which either practice will have on carrying out the rotation in use. The millions of people in cities must be fed. The organic matter and mineral plant-food in the produce shipped is lost to the farm, but other means can be found of replacing both. The price of farm produce within easy shipping distance of cities is often greater than its value as feed for animals on the farm. Under these conditions it pays to sell crops and keep up soil fertility by fertilizers, catch-crops, and by attention to increasing crop residues left in the soil. Prices for farm 
produce are now high enough so that this can be done. The great danger which the history of American farming has shown is that the temptation to sell off cash crops too closely is so great that attention to maintaining fertility is put off too long. Animal husbandry has the advantage in practice that the return of the manure to the soil is a necessary part of farm work and soil robbery is less likely to result.

The third way to return organic matter to the soil is to return the entire product of any crop. Any crop may be used for this purpose, although, in practice, those used are usually of low cash value. Great need of soil organic matter and increase in yield incident to such a valuable cash crop as the potato may make it advisable to plow under crops like clover which would be inadvisable in other crop rotations of less value. The term "greenmanure" refers to crops plowed under before maturity. The term "catch-crop" refers to one grown between crops raised for sale or feed or for other uses. The term "cover-crop" is usually restricted to those grown to occupy the soil during the winter. In addition to supplying organic matter, any of these may cover and protect the soil and so prevent losses by erosion and leaching. A crop plowed under while still green and immature, and which contains such a large proportion of water that it decays quickly, may give only a small net gain over the cost of seed and planting and the amount of organic matter destroyed by tillage. Green-manures must be used with caution wherever their use is likely to reduce the soil moisture for the following crop. Rye plowed under in spring is often injurious in this way. The amount of water needed for large crops of potatoes is so great that early spring plowing or surface tillage is usually 
advisable to save as much moisture as possible for the potatoes. Another danger from the use of any form of organic matter plowed under shortly before planting is that movement of the soil water may be hindered and the plants injured for lack of it. So much of the money value of grain crops is in the seed that it usually pays to harvest the crop, sell or feed the grain and return the stalks or straw only to the soil. Many experiments have shown that the amount of organic matter in any crop increases most rapidly in the latter part of its life; so that in the straw of a grain crop there is likely to be found more than that in the whole crop if plowed under a few weeks before maturity. The value of the grain is several times the cost of harvesting and threshing. The use of the hay crops seeded with the small grains to plow under gives larger net returns of organic matter to the soil, because, unlike rye, buckwheat, or soy beans, there is no destruction of organic matter by tillage in planting.

The need of winter cover-crops for soils is least where the ground is constantly frozen or covered by snow throughout the winter. Mild and open winters, as in the South, make it desirable to have the soil covered by plants which will prevent erosion and save plant-food which would otherwise leach away. Unless left to grow too long in spring, there is little danger in humid sections of loss of enough water to injure later money-crops like potatoes.

The choice of catch-, cover- and green-manure-crops for any particular rotation, soil and climate depends on many factors which differ from those governing the choice of the money-crops of the rotation only because covercrops seldom have a cash value. Those crops of any rotation which have the greatest value, as is generally the 
case with potatoes, naturally govern the choice of others to a great extent. The degree of its adaptability to soil and climate, ability to fit into rotation with other crops, money value, net increase or decrease in soil fertility, and cost of growing are all to be considered.

\section{ROTATION}

It is seldom desirable to grow the potato continuously on the same soil. The reasons for the rotation of the potato with other crops are: (1) Plant diseases often rapidly become worse when crops are grown continuously. This has often been the case with the potato. Modern scientific methods of care of seed, selection, disinfection, spraying and other details of culture somewhat reduce this danger. (2) In the business management of the farm, rotation reduces the danger of excessive losses in seasons of low prices or of poor yields, and arranges the work of the farm through the season to better advantage. (3) Weeds are easier controlled under a system of rotation. Those which flourish under the conditions of growth of one crop may be easily kept down under another. The high value of the potato crop pays for thorough tillage and care which cleans the soil of weeds for the rest of the rotation. (4) Insect pests are kept down easier under rotation. (5) The high cash value of potatoes justifies considerable sums of money spent on fertilizers and enables more of the time of the rotation to be used in producing organic matter to be returned later to the soil. The thorough culture, late digging and winter exposure of soil after potatoes in the northern states rapidly uses up the soil organic matter. The cheapest and easiest way of replacement is by rotation 
with grass, clover and other hay crops which have a money value as food for animals, and also leave large amounts of organic matter in the soil from their roots and stubble, as well as that in the manure from the hay fed. Legumes are able to draw part of their nitrogen from the air to increase the soil supply. Some nitrogen is also obtained from the air in other ways, as by the non-symbiotic bacteria. This is shown by the great fertility of the wild prairie soils which have had few leguminous plants. (6) Different plants draw on the plant-food in the soil in varying proportions. Consequently a rotation of crops enables each to secure its plant-food easier than it would if grown continuously. (7) Though the potato sends its roots deeper than some crops, there are others, like clover and alfalfa, which root much deeper. These bring up fertility from the subsoil, and the roots of potatoes following are able to grow lower, even in hard clay soils. ${ }^{1}$ (8) It is believed that plants throw off in the soil in their growth toxic substances which by accumulation become injurious to succeeding crops of the same plant but not to others. (9) The physical condition of the soil for succeeding crops is improved by the thorough culture given the potato. Instances of this are the use of wheat following potatoes without plowing in fall, and oats without plowing in spring.

The net return of the rotation as a whole must be the deciding factor in the choice of crops. The potato gives such large cash returns to the acre and responds so well to the use of fertilizers that it is usually the most important crop of the rotation in which it is grown. Wherever this is true, the choice of the other crops to go with it is largely governed by their effect on the soil for the production of

${ }^{1}$ Colo. Bul. 216. 
the potato. In the northeastern states the most common rotation is one of a tilled crop like potatoes or corn the first year, a small grain crop usually oats or wheat the second year, in which grass seeds are sown. In regions of the most intensive culture, this hay crop is cut only one year and in that case it is clover. In others the mixture is clover and timothy with occasionally redtop, which is cut several years. Further South, where grasses do not grow well, it is necessary to use annual hay crops like crimson clover or cowpeas. In the North grass seeds are seldom sown alone. The practice of summer tillage before sowing alfalfa has been found so valuable that it is coming into use for the sowing of the grasses as well, particularly on weedy soils, or on those on which it is difficult to get seeds sown with grain to catch.

The relative profit to be expected from the growth of potatoes, grain and hay determines the number of years which each will use in a given rotation for any locality. In New England hay and potatoes are both relatively more valuable than grain, and each may occupy the soil for two years out of a five-year rotation. In New York and Pennsylvania the hay may be cut for several years. Going South, hay is grown less and less until in the trucking section potatoes are rotated mainly with other truck crops as spinach and cabbage. In the middle West the higher cost of transportation of potatoes and hay compared with grain causes the latter to be grown several years in a rotation, as is often the case in the Red River section.

\section{Hay plants}

Alfalfa is the best crop to rotate with potatoes where it can be grown with profit, as in the Rocky Mountain 
region. It is a perennial, is deep-rooted, produces several cuttings to distribute labor and risk of bad weather through a longer period, yields heavily, is of high value for either feed or sale, gets part of its nitrogen from the air and part of its mineral food from the deep subsoil, and leaves the soil in excellent condition to grow potatoes. Its use is gradually extending in the eastern half of the United States as the methods necessary for its growth become better understood. It may never attain to the commanding position here which it holds in the agriculture of the western half of the country, but it is certain to become more generally grown than now. An objection to the use of alfalfa in a potato rotation in the East is that the heavy liming generally necessary induces scab on the potatoes.

The hay crops usually grown in rotation with potatoes in the northern states are the clovers, timothy and redtop. Except for growing only one season, red clover has most of the good qualities of alfalfa. The growth of either is a sign of land in good condition. Both require considerable lime in the soil, though clover needs less than alfalfa. While the potato will make fair crops on land that is sour and low in organic matter, it grows better if the soil is in the well-drained and slightly alkaline condition in which the beneficial soil bacteria live best. The second cutting of common red clover is often turned under in potato rotations on account of benefit to the soil. Mammoth red clover is a larger and coarser variety of the red. Alsike clover is lighter in yield than the red, but is able to grow on many poor, wet or sour soils where red clover will fail. It should be substituted for the red wholly or in part wherever there is danger that the red will fail to grow. Timothy is a hay plant of great value 
when handled correctly. It will grow on many soils, furnishes a fairly heavy root system and stubble to keep up soil organic matter, gives a good yield of hay which is easily cured and finds ready sale at good prices for horse feeding. The ciose sod formed by timothy prevents erosion and helps to keep weeds down. The use of lime, manure and fertilizers on timothy greatly increases the yield and keeps it longer at a high production. A very common fault in the handling of timothy is to let it stand so long that many plants die out and when the remainder are turned under there is but little organic matter to supply succeeding crops. It should be plowed while there is yet material to enrich the soil. Redtop is a hay plant seldom appreciated outside of New England. A prejudice against redtop in mixture in market hay reduces the price on account of a common practice of letting it stand until woody before cutting. Properly handled, its value for feeding is practically that of timothy. By the well-known principle that a mixture of grasses yields better than either alone, redtop increases the yield of mixtures in which it is included and is particularly valuable for humus production on account of its very heavy sod. It grows in soils too poor, wet or dry for timothy.

The selection of the hay plants to be grown in any rotation with potatoes should be carefully considered with the idea of building up soil fertility as well as producing hay for feeding or sale. Alfalfa, red clover, alsike clover, timothy and redtop require for their growth soils varying in fertility, drainage and lime content in about the order named. Potatoes should be rotated with alfalfa where it succeeds. In all others, and this includes nearly all the northern and eastern states from the Red River to Maine, the capacity of the soil determines whether red clover 
should be sown alone, or another mixture. This might be red and alsike clover, the clovers with timothy or both timothy and redtop, or perhaps on some of the poorer volusia soils and others of that low grade of fertility, red clover is best left out unless limed and only alsike, timothy and redtop sown.

In southern sections there is difficulty in growing the northern hay plants mentioned. Reliance must be placed on annuals for most of the hay and for cover-crops. Crimson clover, wheat, rye, winter oats, hairy vetch, soybeans, cowpeas, peanuts and velvet beans are used in the southern states for these purposes.

In the West where irrigation is practiced, alfalfa is used more than any other crop to rotate with potatoes to supply organic matter. Field peas are also used.

\section{REFERENCES}

AgEe. Crops and Methods for Soil Improvement.

Brooks. Agriculture, Vol. I, Soils.

Fraser. The Potato.

Grubb and Guilford. The Potato.

Terry. The A. B. C. of Potato Culture.

Bul. 87, Bur. Pl. Ind., U. S. Dept. Agr. Authority for "Critical Period," p. 96.

Bul. 49, Can. Central Exp. Farms, Effect of Heat on Seed Vitality. Buls. 347, 352, 397 N. Y. (Geneva) Exp. Sta., and Bul. 159, Vt. Exp. Sta., On Effect of Spraying in Dry Season. 


\section{CHAPTER VI}

\section{MANURES AND FERTILIZERS}

\section{By Daniel Dean}

The supply of plant-food elements present in soils will produce potato crops of varying size according to the climate, the original natural fertility of the soil-type and the degree to which it has been reduced or improved in condition since bringing under cultivation. Manures and fertilizers are used to add plant-food in forms so easily and quickly available that the crop will be able to take up and use more than it could without them. On account of its tender nature, compared with other farm crops, the potato responds well to the use of fertilizers. Manures and fertilizers are used wherever the increased yield brings enough in the market returns to meet the additional cost and leave a profit. For these reasons, the use of fertilizers is more or less localized in the particular sections where their use is most profitable. For example, the cool and moist climate of the Aroostook region of Maine is very favorable to the production of large yields of potatoes to the acre. In spite of the great natural fertility of the soils, these fertilizers are used to the extent of over 1900 pounds to the acre on the average at a cost of over $\$ 30$, because the practice pays. The great trucking region which supplies city markets from April till autumn and extends along the Atlantic coast from Florida to Long Island is nearly all made up of sandy soils of low natural fertility. 
The comparatively high prices received for this early crop makes heavy fertilizing, often over 2000 pounds to the acre, profitable. By contrast, the irrigated sections of the Rocky Mountain region often have soils very rich in the mineral plant-food elements. Though often low in the supply of nitrogen, this is obtained by rotating the potato crop with alfalfa. This would render fertilizers of little value for these conditions even if the high freight costs from our present sources of supply did not put fertilizers out of the question.

Scientists are not fully agreed as to the functions of the different elements in the soil used by plants. Experiments have proved that several must be present or plants will not grow. The common term "plant-food" is applied from these experiments. Fertilizers have other actions of value to plants, some well understood, and some which have only been discovered and are as yet not very well known. One is their favorable action on the beneficial bacteria present in the soil. ${ }^{1}$ Certain fertilizers, by rendering soil conditions more favorable for them, increase indirectly the fertility of the soil as well as by their direct action. Our knowledge of these bacteria is limited at present in some directions, but it is certain that their importance to agriculture is very great, much greater than is generally known. One limit to the yield of farm crops is the amount of water which is available for their use. This is shown by the great gains from the practice of irrigation. Fertilizers practically increase the water supply by increasing the concentration of the solution of plantfoods in the soil water and so enable the plants to secure more from the same amount of water in the soil. ${ }^{2}$

1 Office of Expt. Sta., Bul. 194.

2 U. S. D. A., Bureau of Soils, Bul. 22. 
It is thought that to some extent fertilizers act as disinfectants to reduce damage by unfavorable agents in the soil.

\section{FERTILIZER PRACTICES}

Elements often present in the soil in too small quantities for the best growth are nitrogen, phosphorus, potassium and calcium. When these are added in the form of fertilizers or manure, the yield of most crops is increased. The extent to which farmers may use fertilizers depends on the cost of the fertilizer compared with the net value of the increase in the crop. Another factor which must be considered is the residual effect of fertilizers on the soil. In the early days of the use of fertilizers, small applications were often made without much attempt to maintain the soil supply of organic matter. When the amount supplied was sufficient only to give the young plant a better start, it is probable that the increase in yield removed more of the plant-food elements than was added in the fertilizers. Being usually applied to grain or to tilled crops, there was but little increase in the amount of organic matter returned to the soil in the plant residues, not enough to replace that destroyed by the processes of tillage. This has led to a strong belief among older farmers that "fertilizers will run out the soil." The present tendency among potato-growers is to use much larger applications, which supply an excess of soluble plant-food elements over those removed in the crop.

Practice in the use of fertilizers was for many years based on the theories of the famous German chemist Von Liebig. He taught that plant-food must be returned to any soil to equal exactly that removed in the crop. The practical error in the assumption that the composition 
of a fertilizer for any crop is determined by the chemical analysis of the crop itself is that it does not sufficiently take into account the great natural stores of plant-food in the soil, nor the biological conditions. The plant-food needs of the growing plant at any time are not necessarily based on its final composition. The presence of a particular number of pounds of an element in soluble form somewhere among the millions of pounds of soil on an acre is no guarantee that the plant roots will be able to find and use it at the time when it is most needed.

Growers in specialized potato-growing regions like Aroostook County and the early truck potato section apply more plant-food than the potato can be expected to remove in the crop, in order to make certain that it will not have to suffer for a lack at any time. The effect of this practice is seen in the subsequent crops. In southern trucking regions, the choice of the crop to follow heavily fertilized potatoes is largely governed by its ability to make good use of the fertilizer left by the potatoes. The longer experience of European farmers with fertilizers has resulted in England in laws by which the value of the fertilizers left in a soil by crops is computed. Under the tenant system, by which most of the farms of England are worked, an outgoing tenant must be paid by his successor for the unused fertilizer left. This proportion of the value of the fertilizers applied varies with different materials, being lowest with the soluble nitrate of soda and highest with such slowly acting materials as ground bone and lime.

\section{MARKET FORMS OF FERTILIZERS}

Commercial fertilizers are found on the market in the form of many different materials which are also manu- 
factured into many brands of mixed fertilizers, usually being prepared for some special crop or soil. Both the materials and mixed fertilizers are sold under statement of definite percentages of the plant-foods they contain. Annual state inspection and analysis show that these statements are usually reliable. Each has advantages for farmers' use. The mixed factory goods are usually in good mechanical condition for sowing and are generally kept or can be soon obtained from dealers. These dealers usually extend credit to buyers. The manufacturers contend that by the wet or acid process they are liable to utilize materials too insoluble for use directly by crops. The many trade brands for the same crop may differ greatly in composition; and often a number of brands having the same analysis are sold as "special fertilizers" for widely varying crops.

The variation between soils is so great that the same crop raised on different lands may require widely varying fertilizers for the best results. Only experience and careful study will show what these requirements are. Such study and observation are rather rare in America. In Europe, farmers are more accustomed carefully to mix their fertilizers according to the special needs of each combination of soil and crop. In Germany this goes so far that the materials are often applied separately at the most favorable time for the action of each, although this would not be advisable here on account of greater cost of labor. The materials used by farmers in home mixtures are usually of high grade. Sometimes, as with nitrate of soda, acid phosphate and muriate of potash, a mixture that is of the right analysis for a particular crop may be composed of materials that are sticky in combination and do not drill well. Care must often be taken to include materials like dried blood, tank- 
age, ground bone and sulphate of ammonia that drill well. The cost of home mixing may be one dollar a ton, more or less, sometimes under fifty cents. A tight wagon box or barn floor, screen, measure and shovel are the only belongings needed if enough is mixed so that batches are made up of one or more bags of each material. If less, scales are needed. Dealers do not like to sell materials in small quantities, but by clubbing together farmers can buy carload lots.

Most of the phosphoric acid in factory-mixed fertilizers comes from acid phosphate. The value is the same from any source if acid treated. If not so treated, as in tankage or ground bone, it is slower to become available. Most of the potash comes from muriate and kainit, which differ but little in their action; some comes from sulphate. Fertilizers vary mostly in the value of the nitrogen. The highergrade factory-mixed fertilizers are more certain to have high-grade nitrogen than the low-grade cheaper mixtures.

Before the great European war, the prices of fertilizers had remained fairly constant for a number of years. The experiment stations in the northeastern states usually value the best grades of nitrogen at 15 to 18 cents a pound, soluble phosphoric acid in acid phosphate and potash in muriate at about 5 cents. These prices are ton lots of the best materials bought for cash in large markets. Buyers of car-lots usually purchase enough cheaper to cover the cost of freight to country points at these prices.

Lack of knowledge of fertilizers among farmers has led to a failure to appreciate the fact that it is the cost a pound of the plant-food which the fertilizer contains and its quality that determines the actual value of any fertilizer, not the price a ton. Many farmers look too often at the cheapest, regardless of the analysis. For example, 
muriate of potash contains four times as much potash in a ton as kainit and often costs less for the one ton than for four tons of the less concentrated material, making the potash cost less a pound, in addition to the saving in labor of hauling and applying. The cost a pound of nitrogen in high-grade dried blood, nitrate of soda and sulphate of ammonia at $\$ 50$ to $\$ 70$ a ton, may be less than in the cheaper grades of tankage and the like, besides being of far better quality.

There is less variation in the price a ton of acid phosphates because the best sold in America seldom exceeds 16 per cent. The relative cheapness of plant-food in mixed fertilizers depends largely on the analysis.

Mixtures of acid phosphate and potash are comparatively low priced and at the same time are of high grade and cheap for the amount of plant-food which they contain. Nitrogen is so expensive that a small percentage runs the price up rapidly. Usually the higher grades of so-called "complete fertilizers," costing $\$ 30$ a ton or more, are relatively cheaper than lower grades selling around $\$ 20$ a ton. It is usual for the makers of the higher-priced complete fertilizers to claim that the nitrogen in them is in a variety of forms of varying quickness of solubility, thereby becoming gradually available to the crop through the growing season. This is something which should be considered by farmers in making up their orders for material for home mixing.

\section{NITROGEN}

Nitrogen helps rapidly to increase vegetative growth. When nitrogenous fertilizers are extensively used, the foliage grows large and rank and has a dark green 
color. In extreme cases the foliage may become too loose and open and porous in texture, and so render the potato plant more liable to the attacks of disease and sun-scald. Lack of available nitrogen for the plant is shown by small size and light yellow color of the foliage. Commercially, nitrogen used in fertilizers comes from a variety of sources which vary greatly in value and in the quickness with which they become available. Nitrate nitrogen, the form to which other forms must be changed in the soil before the plants can take it up in the soil solution, is the quickest available. Nitrate of soda is the principal commercial form. It comes from deposits in Chile, hence the old name of "Chile saltpeter." It is so rapidly soluble in water that it may sometimes be dissolved and lost to the plant if heavy rains fall before the feeding roots have had time to form. For this reason, it is either applied after planting as a top-dressing or is used for only a part of the nitrogen of a mixture, the remainder being in slower acting forms. Because of this rapidity of action, nitrate of soda is particularly valuable for use in early spring, on early potatoes before the soil warms up enough for the processes by which the other forms of nitrogen change to nitrate. It contains about 15 per cent of nitrogen. Sulphate of ammonia, a by-product of coke and gas manufacture from coal, is next in order of availability. It contains the largest pereentage of nitrogen of any material -20 per cent. It has good mechanical condition for mixing or sowing. One drawback is that its use tends to make land sour and that it is not very efficient on sour soils. Nitrate of lime and cyanamid are comparatively new commodities, being made from the gaseous nitrogen of the air by the use of electricity. While not extensively used, it is probable that in time they will become very 
important sources of nitrogen. Cyanamid is difficult to mix well in fertilizers and has other drawbacks.

Much of the nitrogen of factory-mixed fertilizers comes from organic sources. These are slower in their action, as the organic forms of nitrogen must be changed first to ammonia and then to nitrate before the plants can take them up. Warm weather and warm soil are needed for this. Dried blood is the best of the organic forms, with tankage, fish scrap and cottonseed meal also used in different sections. Other more slowly available forms like leather, animal bone and horn meal are nearly useless to the potato crop unless treated with acid by the wet process to make them more soluble. In comparing the prices of any of these materials, the degree of availability must be considered as well as the price a pound of the nitrogen. It is unfortunate that state laws do not compel the statement of the percentage of each of the principal forms in which nitrogen is found in fertilizers as well as the total. At present the nitrogen in as poor a material as dried peat, often used as a drier in mixed fertilizers, counts as high in the total percentage of nitrogen as from nitrate of soda or dried blood.

Nitrogen is so much more expensive than the other elements of plant-food and so easily lost from the soil that every effort should be made to conserve and increase the soil supply by the use of rotations which provide plenty of organic matter, including legumes, and by making soil conditions as favorable as possible for the different soil bacteria which take or change nitrogen. The other plantfoods are in the soil in stable forms which are not easily lost. Nitrogen exists largely in very unstable forms which are easily lost in drainage water or by changing into the gaseous form of nitrogen. 


\section{PHOSPHORUS}

Phosphorus, usually referred to under the name of its form as phosphoric acid, or $\mathrm{P}_{2} \mathrm{O}_{5}$, is often in very small quantities in American soils, even in those abundantly supplied with other elements of plant-food. ${ }^{1}$ Its actions on growth are not fully understood, but are very important and are becoming more and more appreciated. A deficiency in soluble phosphoric acid quickly reduces a crop yield. Unless a sufficient amount is present, plants do not mature properly. Its use tends to produce early maturity and is marked by dark green foliage.

The principal supply for use in fertilizers comes from deposits in the South which are supposed to be derived from fossil bones. When ground finely, this material is sold under the name of "floats" or "raw rock phosphate." It is much used in the corn belt states and gives good results there on general farm crops. It is too slowacting for the more delicate potato crop, and has not given very good results in most experiments in the colder northeastern states. Acid phosphate is made by treating this raw rock phosphate with sulphuric acid. This unites with part of the lime in natural combinations with phosphoric acid. Instead of the insoluble phosphate in which three parts of lime are united to each part of phosphoric acid, there is formed the water-soluble form in which only one part of phosphoric acid is united to each part of lime, together with a small proportion of the reverted form soluble in weak soil acids in which two parts of lime are united to each part of phosphoric acid. The sum of these makes up the available $\mathrm{P}_{2} \mathrm{O}_{5}$. Acid phosphate is also made from animal bones, but the supply is only enough for a small

^ See Bulletins by Hopkins, Ill. Agri. Expt. Sta. 
fraction of all that is used. Acid phosphate is the principal source of phosphoric acid in this country, either for factory-mixed fertilizers or for home mixing. The word "acid" has created a foolish prejudice against its use which is not warranted by facts. A very small application of lime will prevent any chance of the soil becoming sour from its use. Ground animal bone and basic slag are valuable sources of phosphoric acid for some other crops, but are too slow acting for the tender potato. Different grades of American acid phosphates vary in the percentage of phosphoric acid from 12 per cent to 16 per cent or more. Only the highest grades should usually be bought. The price a pound of the phosphoric acid applied to the land is the real cost.

In the northern states the price a pound at the railroad station is usually less in the higher than in the lower grades and in addition there is the cost of hauling to the farm and applying to the land. Three tons of 16 per cent acid phosphate usually cost less than four tons of the 12 per cent and the cost of hauling and sowing the extra ton is saved.

\section{POTASSIUM}

Potassium, usually referred to as "potash" or $\mathrm{K}_{2} \mathrm{O}$, is present in large quantities in most American soils. Some of the very sandy soils near the seacoast and the swamp mucks are likely to be deficient in it. Potash helps in the translocation of starch within the potato plant and tends to lengthen the life of the crop. Practically all the commercial supply of potash comes from deposits in Germany, controlled by a syndicate there. The principal form used in America is that of muriate of potash containing 47 to 50 per cent of actual potash. This is usually the cheapest 
form in which to buy potash. The chlorine in the combination with the potash has some tendency to make soils sour, and in some experiments ${ }^{1}$ has produced smaller yields and poorer quality than when sulphate of potash was used. The latter, 47 to 49 per cent potash, is more expensive and is but little used except for tobacco fertilizers. Kainit is a raw material of low grade (12 per cent potash), and is relatively higher in price a pound of potash contained in most places on account of the freight on material of less value. Potash fertilizers are mixed in the soil after applications and are not likely to be lost by leaching. The solutions in soil water are rather caustic, and heavy applications are likely to burn the roots of plants if applied close to the seed. The old idea of mixing fertilizers according to the chemical composition of the crop has led to the use of fertilizers containing much more potash than practical experience of farmers and scientific experiments warrants. Mixed fertilizers often contain 7 to 12 per cent of potash. A number of experiments by the Geneva and other agricultural experiment stations have shown that this is too high for profit. Five per cent is usually all that will pay. Potash is so abundant in most American soils that nitrogen and phosphorus are likely to be much more needed.

\section{CALCIUM}

Calcium, in the form of lime, is seldom so deficient in American soils as to render its use directly necessary as a fertilizer for potatoes. In fact, very heavy yields of potatoes are often grown on soils too acid to grow clover. The potato seems to be very tolerant of acid conditions. Heavy applications of lime produce conditions under which the

1 Brooks, Mass. Expt. Sta. 
common scab is likely to injure the tubers. ${ }^{1}$ The powdery scab prefers acid soils and is reduced by liming.

There are other reasons which make the use of lime of great value. The other crops of a potato rotation are more likely to be benefited than the potato, and the net profit of the rotation as a whole must be considered. The clover and grass crops are the ones most benefited by liming, and these are the ones that do most to maintain the soil supply of organic matter. Heavy sods and other residues from hay crops bring up soil fertility rapidly at small cost. In this way subsequent crops of potatoes are benefited. Lime is also essential for the action of the beneficial soil bacteria. Many American soils are now becoming deficient in lime. Lime should be added to soils in rotation in which potatoes are grown to as large an amount as the soil can use without producing scab on the tubers. What this amount will be can be found only by careful trial on every soil and sometimes on every field. Some soils can use several tons of limestone to the acre without danger, while 500 pounds might be too much on limestone soils or those in high condition of fertility. Burned lime has been almost the only source of lime for many years. Ground limestone is now coming into use very rapidly, and it is probable that before many years will entirely displace burned lime in most places. It is much easier to apply and its use is safer. Burned lime is thought by some to have a tendency to use up the organic matter in the soil, even when thoroughly slaked before application. Hydrated lime is too expensive to compare with the others. Any form of lime should be applied to the crop in the rotation which follows potatoes, and should be thoroughly harrowed into the soil.

1 Vt. Bul. 184. 


\section{SULPHUR}

Sulphur is present in all soils and is not likely to be deficient in any way. There is some ground for the belief that part of the value of acid phosphate is due to the sulphur contained in it.

\section{APPLYING FERTILIZERS}

The method by which fertilizers are applied to a soil often determines the profit to be obtained from their use. Nitrate of soda is so quickly and easily soluble in the soilwater that it can be sown on the surface of the land at any time with the certainty that the first rain will dissolve it, or that it will quickly dissolve if mixed with the soil. Other fertilizers require weeks, months or even years to become available to plants.

A gradual evolution is taking place in the ideas as to the proper use of fertilizers. In the earlier days of their use, when the quantity applied was limited to perhaps 100 to 200 pounds to the acre, it was rightly considered as only a starter for the young plants. It was applied to the soil close to the seed, being often dropped by hand. The roots starting from the young plants were certain to find a supply of readily available plant-food as soon as they could use it. This would give a quick start to the young plant, which would enable it to grow more quickly to a size when it would be able to forage for itself. As the profits from the use of fertilizers became known, the amounts gradually increased. About the same time machine-planters came into use. These applied the fertilizer in the form of a strip several inches wide in the bottom of the furrow-mark. This wide-strip application 
is essential to prevent root injury. Application with the planter works well whenever moisture is abundant in the soil throughout the growing season in Maine. As the amount applied to the acre increased to 1000 pounds or more, growers began to use a wider distribution through the soil. With such large amounts, there is no need of specially placing some of it near the plants, as a fraction is enough to act as a starter.

At the present time heavy applications of fertilizer are used in the specialized potato-growing districts in this country, with the idea of supplying so much that the growing plant will never suffer for lack of plant-food at any time. For such amounts as 1000 to 3000 pounds to the acre, broadcasting is coming into use in whole or in part. Ordinary grain-drills or special broadeast fertilizer sowers are used. All fertilizers broadcasted should be thoroughly worked into the soil. While there is some tendency for soluble fertilizer salts to work downward into the soil, there is likely to come any summer, after potatoes are planted, a hot and dry time when several inches of the top soil is very dry. The fertilizer in such a dry soil is practically useless to the crop for lack of sufficient water to dissolve it. This is especially true when a surface mulch of dry soil is maintained for the purpose of conserving the moisture in the earth below. This accounts for some of the contradictory results obtained by experimenters on comparisons of the application of fertilizers by the drill and broadcast methods. Under the conditions of northern Maine, in which the water in the soil is usually abundant, part of the heavy fertilizer used is often put on after the plants are up, being applied to the ridge and covered with soil. It is doubtful whether this method would be a success in other regions, even in some other parts of 
Maine, ${ }^{1}$ unless soil moisture conditions are fairly certain to be favorable at the time of the second application. Nitrate of soda may be applied at any time, as it is so easily dissolved. Success with any method of applying fertilizer depends on soil moisture conditions. The correct method in one case may be entirely wrong in another.

The writer has developed, for his own farm conditions, a method which has been very successful for applying large amounts of fertilizer. The soil is a silt loam of good water-holding capacity, further increased by the incorporation of large quantities of organic matter. The total rainfall for the whole year averages under 30 inches. Periods of dry weather after planting, sometimes extending to several weeks, keep the surface soil very dry. In some fertilizer experiments, acid phosphate applied as a topdressing after planting did not become dissolved to produce much increase in yield. At the same time, when it was applied deeper in the soil before planting, a good increase resulted. The soil is deep, and potato roots easily penetrate to the depth of several feet. The fertilizer is usually 1500 to 2000 pounds of a mixture of acid phosphate and muriate of potash.

Part of the fertilizer is sown broadcast in early spring on the surface of fall-plowed land, thoroughly disked in to the depth of 7 to 8 inches and the field replowed to the depth of 10 inches. The remainder of the fertilizer is then applied and disked in as before. The essential idea of this method is to have a large amount of fertilizer so evenly and thoroughly distributed through the soil to the depth of 10 inches that the potato roots are drawn out and down completely to fill this whole space, rather than to have a tendency to remain in the more limited space occupied

1 Maine Agri. Expt. Sta. Bul. 246. 
by the fertilizer when either the drill or the broadcast method of sowing is used. Scientific experiments show that roots multiply mostly in the soil where the supply of plant-food is most abundant. ${ }^{1}$ The surface mulch of dry soil keeps the lower parts both moist and cool. Later the heavy tops shade the ground with the same result. This cool lower soil, although itself too dry for roots to grow in, is a marked advantage in hot seasons in preventing degeneration of the potato as well as in increasing yield. ${ }^{2}$

This method of applying fertilizers has produced very striking results in dry seasons. In periods of extreme drought the tops showed but little injury from tip-burn and grew continuously. The writer thinks that this success is due to the greater moisture supply made available to the plants by the wide and deep distribution of the root system. This enables the plants to find and utilize the water in a larger volume of soil at the time when the plants need it most. When the roots are encouraged to develop near the surface by broadcasting the fertilizer and working it in shallowly, the drying of the upper soil layer deprives the plants of the use of much of their root system, and may leave them in poorer shape to withstand hard conditions than if the roots had been forced to spread out and down earlier to find plant-food. ${ }^{3}$ In the corn-belt, dry weather in June is recognized as a favorable factor for the future success of the corn crop because it forces the plants to root deeply, while a wet June would result in shallow rooting which would be certain to suffer later in the summer.

1 Storer, "Agriculture." Vol. 1, pp. 297-300.

2 Neb. Agr. Expt. Sta. Bul. 146; and Colo. Agr. Expt. Sta. Bul. 216.

3 Bureau of Soils, Bul. 22, p. 52 . 


\section{FARM MANURES}

Farm manures increase the productiveness of the soil in four ways: first, by the actual plant-food added to the soil; second, by the physical effect of loosening and aërating the soil and adding to its moisture-holding capacity; third, by the action of the organic matter of the manure in making available to the plants by its decay the insoluble plant-food of the soil ; and fourth, by improving the soil conditions for the work of the beneficial bacteria. Any computation based on the trade value of the plantfood may be falsified by the other values being even more important. A better way is to consider the results obtained in farm practice by particular crops through a series of years long enough for the residual effect of the manure on the soil to be measured. The potato usually responds well to the use of manure throughout the humid sections, and the increase in yield of a cash crop like the potato gives quick returns for the use of the manure.

There is some danger that common scab will be worse on potatoes grown on land heavily manured. This danger is reduced by using smaller amounts, by having the manure rotted, and by spreading some time before planting. Horse manure is thought by some to favor scab more than other manures, but this is doubtful.

Manures are poorly balanced fertilizers. They contain relatively much more of nitrogen than of the other plant-food elements and are likely to produce plants with large growth of tops without corresponding tubers. This can be prevented by using with the manure 50 pounds of acid phosphate to each ton, and in rare cases potash may be added also. Coarse and strawy manure may make some soils too open and porous, 
causing them to dry out, particularly in dry years and dry climates.

A practice in handling manure that is gaining ground is to apply it to the hay crop preceding potatoes in the rotation. By increasing the yield of the hay, the organic matter left in the soil by the roots, stubble and aftermath is increased for the use of the potatoes later. When manure is applied directly to the potato crop, it is better spread in the previous fall or winter than just before plowing. The manurespreader does better work than hand-spreading because of the practical impossibility of getting as even distribution with a fork as with the machine. Unless the potatogrower has only a small area, it is more profitable to give the whole a thin coat of manure than to have parts heavily covered and the remainder without any. Experiments extending over many years show that the profit to a ton decreases as the size of the application increases. The manure-spreader has an advantage over hand-spreading in this respect because smaller amounts to the acre can be spread evenly.

The value of farm manure is greatly reduced by poor methods of handling. The best net returns from its use come from spreading as soon as possible after it is made. When necessary to keep it for some time, as when fields are occupied by growing crops in summer, precautions should be taken to prevent loss. Exposure to rains may leach away half the value in a short time. By heating in piles, much of the nitrogen escapes. Keeping under cover prevents leaching. Keeping in shallow piles, tramping by animals and occasional wetting prevents heating. Land plaster and other substances are mixed with the manure to prevent the loss of nitrogen. Raw rock phosphate or "floats" is valuable for this purpose in addition to 
its phosphoric acid, the element needed to balance the manure as a potato fertilizer. Acid phosphate is valuable for this purpose, but it must not be used under the feet of animals. Manure spread in the winter suffers no loss from heating and but little from leaching unless the field is so sloping that water runs off rapidly. It is so difficult to prevent loss in manure kept in other ways that spreading as rapidly as made is the best method in most cases.

\section{REFERENCE}

VoelCKer and HaLl. The Valuation of Unexhausted Manures. 


\section{CHAPTER VII}

\section{PLANTING}

\section{By Daniel Dean}

SoIL preparation for planting potatoes should be such as will meet the peculiar demands of the potato plants. A loose and mellow soil is needed for extension of the weak and tender roots and for the development of the tubers. Preparation should be designed to correct the faults of the local soil and climate as far as that can be accomplished. Preparation before planting should be such as will reduce the tillage after planting as much as possible. Weeds are more cheaply killed by wide-spreading tools, like harrows and disks, than by small, single-row tools or by hand hoeing later.

Fall plowing is of great value in all but the lighter soils. It rots the soil organic matter, puts the land into better physical condition by exposing the bare soil to winter freezing, stores up more water for the use of the crop and sprouts and kills part of the weed seeds in the ground. The control of insects, like the white grub and wire-worm, is easier with fall plowing because the larvæ are more exposed to freezing and to attacks of their natural enemies, such as birds. As a rule, the heavier a soil, the more it is benefited by fall plowing. There is some saving in labor by fall plowing in the northern states because potatoes are usually followed 
by spring-sown grain, which requires considerable work early in the spring. The harrowing needed to place fall-plowed land in condition for planting takes less time than spring plowing and the harrowing necessary to cut up the sod well. Harrowing must be deep and thorough or the benefit of fall-plowing may be largely lost. While there is some additional loss of moisture from plowing a second time in spring, this later plowing greatly reduces the amount of harrowing necessary and makes certain that the soil is well pulverized to the depth of the furrow. It is well to fall-plow land as roughly as possible with the furrow-slice standing nearly on edge. A rough surface catches the rains better, exposes the soil better to the action of frosts and reduces the damage by winds through the winter. Water is saved in fall-plowed soil because the layer of sod or trash at the bottom of the furrow prevents the water in the subsoil from escaping as readily. Straw or manure spread on the surface before fall plowing will usually become rotted enough by spring to give little trouble if replowed. The mellow soil with rotting organic matter holds more water than unplowed land would, especially in places like dry knolls. Clover sods rot quickly, but sods of the grasses take longer. With spring plowing only, it is beneficial to cut up the grass sods with a disk harrow before plowing. The sod rots more quickly and the soil settles together better so that the movement of the water in the soil is not hindered.

Earliness is a great advantage in spring plowing in the northern states. An experiment by King at Wisconsin showed that water equal to $1 \frac{3}{4}$ inches of rainfall was evaporated in one week in spring. Water evaporates from the soil very fast in the first days of spring after 
the frost goes out. This water can seldom be fully replaced by later rains. Its conservation may often turn the scale between success and failure in droughts late in the season. Fall plowing has here an advantage over spring plowing because it is possible to cover many acres with harrow or disk in a few days as soon as the ground can be worked without injury in the spring. By going over fall-plowed potato ground once before sowing spring grain, the saving in moisture for the potato crop will more than pay for any loss of grain by slightly delayed sowing.

\section{TILLAGE TOOLS}

The plow is the standard implement of tillage. Except in special cases, nothing has been found to equal its work. The common plows used in the East and South are drawn by one, two or three horses or mules. The two-bottom reversible sulky plow is coming much into use in the East. It is heavier and more expensive than the common plow, but will work better in soils of varying hardness, and in plowing alfalfa sod. This reversible sulky plow, like the ordinary two-bottom gang sulky used in the central West, does poorer work in plowing under straw, stalks and the like than the ordinary walking plow. The plow can turn under sods, and so forth, more perfectly than any other tool, and its use distributes surface organic matter. The jointer enables sod and trash to be buried more completely.

The type of harrow to be used depends upon the work to be done. Harrows may be used merely to fine and smooth a rough surface, like the spike-tooth harrow, or may be designed to tear up and fine the soil to considerable depth, like the disk and spring-tooth types. The 
disk and its variation, the cutaway, are used most in soils nearly or quite free from stone. With these the soil can be thoroughly fined nearly to the depth of the plowed furrow. The disk will cut up sods or straw and will work in soils so full of weed-roots that other types of harrows will be clogged. The spring-tooth harrow is used more than the disk in sections with stony soils. It pays to keep the cutting edges of the disk or the points of the teeth sharp. The spike-tooth smoothing harrow should follow the disk to level the surface before planting. It is also valuable to keep a surface mulch before planting and to kill weed seeds that have sprouted.

The roller is a tool of great value, but is often used with poor judgment in potato-growing, because it has considerable weight for the small surface. Its action, resting on the soil, is to firm the earth to a considerable depth, something seldom necessary with potatoes unless on very light soil, and is often harmful. Used to follow the plow after plowing in the spring, it may help to prevent sods on edge from making open spaces in the soil. Too often it is used with the idea that it is necessary, as with the grains and grass seeds, to firm soil around the seeds to furnish moisture for germination. The roller is used to assist the germination of grain and grass by packing the soil around them, causing it to become damp by the capillary rise of water. Such seeds are dry and need water to start, and their small size demands closely packed soil for the benefit of the roots. Unlike the dry grain seeds, the large potato seed-pieces have all the water they need, 80 per cent, and can grow for weeks without any from the soil. This fact is familiar to those who have seen potatoes in cellars send shoots to the length of several feet. Soils are seldom too loose for the 
potato and are very often too hard. The plank float, or elod crusher, is a better tool to crush lumps, and does not settle the soil below the surface as does the roller. Such lumps crush easiest a few hours after a rain.

The depth of plowing for the potato should be as great as the fertility of the soil will permit. The weak potato roots need all the space they can get. Outside of the arid regions of the United States, care must be taken not to expose much of the cold and infertile subsoil at any one plowing. Where it is necessary to plow land deeper than formerly, not over one inch of subsoil should be turned up at a time. Organic matter must be added to lighten the subsoil turned up, as it is very deficient in this. Sandy soils, in which potato roots penetrate easily, need deep plowing less than heary soils. Only three to five inches is used in some sandy sections. Heavier soils, if well provided with humus, are frequently plowed to the depth of ten inches or more, usually about 6 or 7 inches.

\section{RESULTS OF TILLAGE}

The results of soil tillage are:

(1) The organic matter in stubble, manure, and the like is buried in the soil, to decay there.

(2) The mineral particles are made finer, and fresh surface exposed to the action of solvents, such as soil water and carbonic acid.

(3) The soil organic matter is broken up and easily changed into more useful forms. The rapidity with which soil organic matter is destroyed by tillage is little appreciated. The common saying, that "tillage is manure," is practically true. Tillage is expensive in 
labor and also expenstwe in the changes it pocduces in ite soil. A sol thoroughly tilled for a potato crop bas thereby lost a considerable amount ct organic marter. The expense of replecing this must be constdered in the final profit-acd-los aceoun ot ine crop. In mene parts of the Lnited Sates. potatc-goming has gaimed a bect reputation from the rapility with which it retuces the ferrilit of the sili. In others. where organic matter is beot uo by goot rutation and where fertilitess are used hearily. potato-rowing is regentei as a sure mag to entich the lant. A single tilled cop. Hike potatoes or corn. Jlaces the soil in better phosil contition to grow sucteting crogs of gain ati hat. The altermation of tillage cops. whet excite and increas bactial activity. With the hav eno will protide organie matter as a food to the barteria and thereby keep un tertility at low expense.

1 The inmera of the rolume of the ait-spaces of the soil by thomugh tllage meatlo increases the chemical and hacterial actirtie of the sol. Tae orger of the

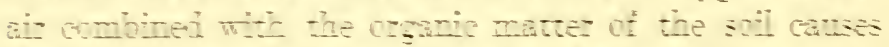
the formation of caroon doride. In: in cum. act with the scil weter as a slrent of mineral compoumes.

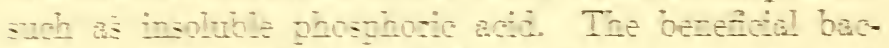
terita of the soil are farcedi by plenty of air in the soil and increased preatly in number and wetirity. Treir action increase the arailatility of the soil piantSore sotres $c^{2}$ soll bacteria are injurious. As these mainl. thrite there little or no dir is present. tillage teCuces their effect.

5) Tillage expose thesh soll surtaces to the air and at

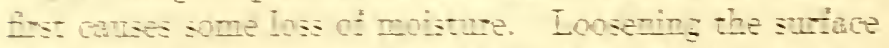
soil b\% tillage prevents eraporation from the lowe: parts ct the soil bo breating uo cavillar. conmection between 
the soil under the tilled ares and the surface. Intil capillary action is again established by the settling together of the tilled soil, but litele water ean be lest by eraporation. A thin lasere only of loose soil is suttienent to prevent eraporation. I thin linger setrles togerhere somer than a thick one and needs breaking more often. Xore cmphasis hats nsublly berm phaced on tillage of potatoes after planting tham before planting. "The gereat soil supply of water in latte winter mel carly spring presents opportmitis for cons.tration that evered those during the gerowing period of the erop. In resent years a change has ame about in the attitude of imestigators towards the value of smmmer tillage. Batemed experiments have shown that one fater which wats largely neglected by early experimenters is of importance - this is the ability of the plant root to serize upon the use of soil moisture. When the soil is not ocenpied by a growing erop, there is no clonbt that a surface muleh of loose soil does comserve moisture by preventing eraporation, but when the soil is well filled with plant roots, there is little more water evaporation from untilled soil than from tilled. The gans in vichs observed from tillage come from another souree - weed killing - rather than from prevention of the eraporation. This means that the farmer will till practiolly as much as under the former practiec, but will have in mind weed killing as his primeipal object, instend of preventing loss of water. In practice this will mean that the tillage of the potate crop during the growth of the (rop) will be done earlier tham has been the enstom. Water will be conserved by fall plowing where possible; by the addition of organie matter to the soil; and by carly spring tillage to save the water supply. The soil will not be 
allowed to dry out for the late main crop of the northern states before planting. All this early tillage also kills many weeds which have formerly been left to be killed by inter-tillage later on.

After planting there is a period of several weeks when large and wide tools can be used to advantage in tillage. The harrow, leveler and weeder cover several planted rows at once and kill weeds very cheaply, besides saving moisture.

The necessity of weed killing for the production of large crops is even greater than the saving of moisture by tillage. Weeds not only rob the potatoes of moisture, but are able by their stronger root systems and greater foraging ability to seize upon and use the soluble plant-food in the soil. Tery small weeds in this way injure the potato crop more than would be supposed. The weeds which sprout from seeds in the soil are more easily killed before coming up than afterward. The tender shoots from the seeds are killed by a light stirring of the soil which would not affect them at all a few dars later. The sprouts starting from the seed have but little vitality until they can reach the surface, and produce green leares. Then roots start to secure plant-food which is worked by the leaves into material for further growth. Every day now adds to the ability of the young weed to stand punishment and live. Several successive crops of weed seeds can be sprouted and killed by tillage between planting and the time when the potato tops are six inches high. Tillage at this time can be done carefully enough to prevent injury to the growing sprout of the potato before it comes up and until it is established for itself in the soil. Perennial wreeds with root stalks, like quack or witch-grass, are much easier controlled by previous 
cultivation in the fall or early spring than by tillage during the life of the potato. The reserve of nourishment in the root stalks enables them to stand punishment for several weeks and recover from it to injure the potato after tillage is no longer possible.

The preceding results of tillage have all been favorable to the potato plant. Tillage has another action which has not been sufficiently studied and which has led to many conflicting results in experiments and in farmers' practice. It is a fact that tillage can injure the potato plant even easier than it can the tough and hardy weeds. It is very difficult to work with soil near the potatoes without injuring them. As the season advances, this becomes more dangerous to the potato. While the young plant is still attached to the seed piece and drawing on it for nourishment, it can lose part of its small roots without great loss, particularly as the weather is yet cool and favorable to the vitality of the crop. Each day the potato grows older increases the danger of loss of yield from injurious root injury. In the later part of the plant's life, the whole upper soil becomes filled with roots. These come so close to the surface that it is most difficult to work any tillage tool without some injury. Few tools except the hand hoe can be worked as shallow as one inch, and many of the larger roots are that close to the surface. Under some conditions, late tillage may do less injury to the potatoes than under others. In periods of abundant rainfall, the plants may tend to root too close to the surface and some root-pruning may force the potato to root deeper. If drought comes later, this will be a benefit to the crop. In very cool seasons in which the potato does not suffer from extreme heat, root-pruning by tillage tools does less damage than in 
hot and dry seasons. The loss in yield from tillage at the wrong time, too deep, or too close to the plants, often amounts to a large percentage of the crop. The greatest danger from excessive tillage is likely to come in the northern states in which late cultivation of the main crop comes at the hottest time of summer. When the "critical period" of the plant's life comes at the time when climatic conditions are most unfavorable to the potato, any injury to the roots is likely greatly to reduce the yield.

\section{PLANTING}

The time of planting depends on the market for which the crop is grown and the local soil and climate. The higher prices received for extreme earliness in the southern truck crop compel the use of short-season varieties, like the Triumph and Cobbler, and planting very early to get the crop on the market before prices fall. All cultural methods are arranged with this end in view, so there is little choice in the time of planting. Along the Canadian border and in much of the Rocky Mountain section the whole growing season is but little longer than the life of main-crop varieties. But in most of the principal growing states, from New England to Iowa and Nebraska, it is possible to vary the time of planting by sereral weeks. Here, as a rule, most potatoes are now planted in late Nay and in June. The later plantings yield better because the crop matures in cooler weather than with early planting. Moisture is more likely to be abundant in fall than in late summer. The dangers of late planting are late-blight and rot, - unless spraying with bordeaux is practiced,-injury from early frost and early fall freezing of the soil, and conflict of 
the later tillage of the crop with the rush period of haying and harvesting. But increasing competition of the southern crop is forcing many growers to abandon the previously profitable early crop for local trade. Bordeaux spraying has been found to lengthen the life of the potato, and potatoes to be sprayed may be planted slightly earlier than those unsprayed, for that reason.

The methods of ridging and level culture with deep and shallow planting are best illustrated by their use in two of the best-known potato-growing regions of the United States. Ridge culture with comparative shallow planting is used in Maine. The northern latitude of Maine makes the growing season short compared with the southern states. The mean temperature of the month of July is only $62^{\circ}$ to $65^{\circ} \mathrm{F}$. Frosts are frequent in June and September and may occur in August. Not much field work can be done before the month of May, and October 10th is regarded as the danger line beyond which potatoes are likely to be frozen in the ground. Only a short distance away in the Atlantic Ocean, the cold ocean current from the Arctic reaches the warm Gulf Stream. The fogs of the fishing banks here are well known. The rainfall is heavy and is seldom deficient throughout the growing season. The rainfall of winter is largely available to the potato crop. The ground is covered with snow all winter and the loss by run-off and evaporation before time of planting is much less than that of the other great producing states. The soil conditions of Aroostook County, the great potato-producing section of Maine, are favorable for the retention of soil water. Most of that section has been cleared from the forests only a few years, compared with the longer settled communities, and the soil is well supplied with organic 
matter. The region is so damp that the higher and dryer parts are usually considered safer and better for potatoes than those lying lower. The more or less gravelly limestone loam soil crumbles easily and seldom gives trouble by baking. With such conditions under which surplus of water is more to be feared than a deficiency, Naine growers use an extreme ridge culture. Instead of leveling down the ridges left by the planter and depending mainly on the use of leveling tools and the weeder to kill the weeds sprouting among the plants in the row, Maine growers kill the weeds in the row by ridging several times. There is little danger that the growing plants in the ridges will suffer from lack of moisture. Ridge culture is also the favorite in the adjoining provinces of Canada, in which conditions are similar. This culture is suited to wet climates and wet seasons. Digging is rendered easier by ridging where the soil is likely to be wet. The first ridging after the plants come through the ground covers the small plants and prevents injury from late frosts. In many other sections, such covering would result in baking the soil. Ridging is necessary under the methods of irrigation in order to prevent injury to the potato plants from the irrigating water.

Long Island potato-growing stands as an example of prosperous farming, where a different method than the ordinary is used. The soil of Long Island is a rather light sand which is easily tilled and dries out quickly after rain. Level culture is used because much better yields are secured than by ridging. Less soil surface is exposed to evaporate water by level culture.

Partly owing to the high prices in late summer, Long Island potatoes are planted as early in the spring as the 
ground can be worked - last of March and April and mature in the dry weather in July and August. Deep planting and level culture exposes less of the easily heated sandy soil to the sun and reduces danger of heat injury as well as that from drouth. The light soil usually is dry at digging time, gives little trouble in digging, though sometimes fields left late before digging are ridged to kill weeds which have started. Level culture is a relative term as some earth is thrown toward the plants by the teeth of the cultivators. This prevents the growing tubers from being sunburned. Deep planting allows the soil over the rows to be thoroughly worked in the week subsequent to planting. Weeds are easily killed at this time and soil water conserved for the later use of the crop. As a rule, early planted potatoes should be put in shallower than late potatoes, as the sprouts start more slowly in the cooler soil. Very shallow planting is seldom advisable unless the soil is so wet and cold that heavy ridging is necessary for drainage. Growers in other sections of the country use methods between the two extremes, according to their conditions. The truck crop of the South is raised under soil conditions similar to those of Long Island. The need of securing warmth in the soil to hasten growth leads to some ridging. Shallow soils with hard-pan close to the surface as in the volusia soils of New York, Pennsylvania and Ohio, present a hard problem. Ridging is the usual method used in this section on account of trouble in digging in wet seasons, and with the usually stony soil, it is difficult to control weeds near the plants by the use of other tools than those which ridge the rows. Light and dry soils particularly, if likely to be fairly dry at digging time, do better with nearly level culture. 
The advantages of having sufficient soil over the seed to permit wide tillage after planting are so great that it pays growers to plant deep enough for this purpose. The bottom of the furrow made by the planter or marking tool should be at least two inches below the level of the surface of the soil and better three or four; for sandy soil likely to be dry, even more. Growers are often deceived at the depth they plant by looking at the depth of the mark below the level of the earth thrown out by the marking tool instead of taking the measure from the true level of the surface soil to the bottom of the furrow.

\section{Hill and drill planting}

Two principal methods of planting are used in the United States. Potatoes are said to be in hills, checks or squares when the ground is marked both ways and the seed dropped at the intersection of the mark. This method is much used for hand planting. It has the advantages of permitting cultivation both ways and so weeds are easier kept under control. With poor soils the large area allowed to each hill is an advantage, as each hill has enough space to produce a good yield. Rows in the United States are from 30 to 42 inches apart according to the value of the land, the amount of stone in the soil and according to the fertility. Unless the ground is very poor, it is advisable to have the hills closer together in the short way of the field to give a large yield. When planted in drills, the seed is planted from less than 12 inches apart in the row in the best soils, to sometimes nearly 2 feet in poor soils. Planting in drills is rapidly gaining ground in the United States, as the yield from the larger number of hills is larger to the acre than when 
planted in hills. Growers in all the important potatogrowing sections find it practicable, by modern tillage methods, to keep weeds subdued in drills as well as in hills. The prices received for potatoes from sections in which drill culture is general are higher than from those where hill culture is mainly used. City markets demand medium-sized tubers, and pay better prices than for the coarse and overgrown tubers raised in hills. When machine diggers are used, digging costs the same when either method of planting is employed. With hand digging, the larger number of hills to the acre under drill culture takes more time to dig than with hills and may reduce the acreage by limiting the amount which can be dug before freezing weather. The constant improvement in the manufacture of diggers is producing machines that will dig in very stony soils.

The general rule for spacing hills is to vary the number of hills to the acre according to the yield which may be expected. As the distance apart decreases, the weight of the individual hills and the size of the tubers is reduced and the total yield to the acre is increased. The cost of planting and digging may be increased. Digging closeplanted hills is rather expensive. The smaller size from close planting brings higher prices in city markets. An extreme case of close planting is that in the island of Jersey where potatoes are planted 12 by 16 inches, or over 32,000 hills to the acre. With very rich soil and hand tillage, a yield averaging over 400 bushels to the acre is secured, even when dug for the early market, while still growing. The type of the potato variety affects the spacing. The common Rural or Blue Sprout type sets fewer tubers to the hill than the Green Mountain or White Sprout type and should be planted closer on that 
account to prevent coarseness, a common fault complained of by city buyers in Rurals. Early types like the Bliss Triumph and Irish Cobbler are usually planted closer together than late varieties. In Europe it is a common practice to use small tubers uncut for seed. These are often secured by planting very close, sometimes as little as six inches apart in the row. As before noted, wide spacing allows faster digging on stony soils. Regions of intensive potato-culture, such as Maine, Long Island and the coast-trucking region, usually plant rows 30 to 36 inches apart and the seed dropped 12 to 16 inches apart in the rows or 12,000 to 16,000 hills to the acre. Regions with stony soils, as the Steuben County and Chateaugay sections of New York, plant to some extent in checked hills about 3 feet each way or less than 5000 hills to the acre. The regions where the expense for rent of land, fertilizer and care are high use close planting, while low-priced land with other small expenses allows more space to each hill, which may be of value in bad seasons.

\section{Planting tools}

Machine planters of several types are in use and a larger proportion of the total crop is planted by machinery each year. Hand planting is used mainly in stony and rough sections, in the South where the labor is cheap and not well adapted to using machinery and to sections and farms where potato-growing is of small extent and regarded as secondary to other farm crops. Machine planters are nearly universal in such regions of intensive potato culture as northern Maine and Long Island.

Machine planters are of two types. In one the seed is picked up from a hopper and dropped by revolving 
pickers; in the other the seed potatoes are fed on a platform containing a revolving wheel. An assistant to the driver sits behind this and corrects the mistakes of the planter by removing the extra pieces where two or more are fed between pairs of spokes and by filling the spaces which are empty. The first requires only a driver, an advantage where labor is scarce. The picker type does fair work where the seed planted is small and round, and on smooth land. Its efficiency falls off with the use of cut seed and on rough or stony land. The picker may injure the seed and spread disease. Picker planters are most used where land is cheap and labor high, where cheap cull seed is used with mellow soil and in general where it is the object to raise large areas at low expense. The platform type planter is adapted to higher priced land where every missed hill is expensive. It will feed cut seed perfectly with much less trouble to the feeder if care is taken to cut the pieces somewhat blocky in shape. With expensive seed and when spraying, manure and fertilizer add to the acre cost, it does not pay to have any missed hills to cut down the income from each acre. The cost of each acre is the same whether every hill is planted or not and the cost of the wages of the second man on the planter is small compared with the increased income.

The use of machine planters has called attention to several advantages in their use which may be copied with profit by growers planting by hand. The saving in cost of labor over hand planting may or may not be great when the cost of the machine is considered. The gain from the use of machine planters is largely in other ways. The machine opens the soil with a small plow or disk and the seed is dropped into soil which is cool and damp. 
There is no tendency, as is often the case with hand planting, for the seed to become dried out before covering. In some sections as on Long Island there is trouble with seed slightly infected with late-blight germs rotting in the ground after planting. Trouble of this kind is much worse where furrows are left open and the soil warmed to a temperature at which the blight germs develop and rot the seed. Seed which becomes dried out before or after planting seldom produces as good a yield as where it is allowed to keep all its moisture. The seed planted with the machine planter is put in to a more uniform depth than seed in rows dropped by hand which falls on each side of the center of the row and forces the cultivator teeth to be kept away on account of injury to the plants which are set out of line by hand planting. The seed dropped by a machine falls in a straight row which is less liable to injury from cultivating tools than that dropped by hand. The weeds growing next to the plants are the ones hardest to kill, and a perfectly straight row easily kept clean reduces the damage from weeds. It is noticed that in sections where machine planters are in common use the rows are usually planted close. The soil in the space between the rows is so tramped by horses and wheels of tools that it is of less value to the crop than that in the row. The yield is increased by a larger number of rows to the acre. Planters are often furnished with a fertilizer attachment which applies the fertilizer along with the seed. The fertilizer should be dropped in a strip several inches wide and covered with soil before the seed is dropped or the sprouts may be injured by the action of the dissolved fertilizer salts. 


\section{Hand planting}

More potatoes are planted by hand than by machines. If well done, hand planting can be made nearly as good as machine planting in some respects and far better in others. It is scarcely possible to make a row as straight and in as perfect a line as with a machine, and in practice the seed and soil must be exposed to drying for a short time at least. The objection is often made that machines cannot be made to plant deep enough. Much hand planting is too shallow because the tools used in marking the rows do not make the marks deep enough. The three or four point markers used in many sections cover ground fast, but the marks are very small. In light soils these markers ean be shod with iron points large enough to make a fair mark. In heavier or stony soils a small landside plow, or better a wing shovel plow such as is often used for ridging should follow the marker to deepen the furrows. All marking tools should be run with great care to keep the rows straight. Crooked rows result in damage to the potato plants by the cultivator teeth later in the season. Opening the furrows just ahead of dropping, and covering right after, reduces the danger of drying out seed and of warming the soil too much. Covering the seed may be done with the hoe or with a small plow, with a shovel plow or "middle buster" in the South or with a hiller with wings on each side of the row. With shallow soils the hand hoe does the poorest work, as there is not enough earth placed over the seed to allow tillage with harrow, weeder and the like. Seed covered with the hoe in deep soils allows such tillage to gradually fill up the mark, at the same time killing many weeds. It has a great advantage for 
early potatoes in heavy soil, as the amount of earth covered over the seed is so small that the plants come up much quicker in cold springs than where several inches of dirt are ridged over the seed.

\section{SEED POTATOES}

The problem of conserving the full vitality of the seed potato until planted is a hard one unless cold storage is available. The white sprouts formed in ordinary storage cellars rapidly reduce the vitality of the seed, are easily broken off and cannot be planted. The potato requires a resting stage for some time after maturity, after which it starts the sprouts rapidly at temperatures as low as $50^{\circ} \mathrm{F}$. If the temperature of the storage space can be kept down to from $34^{\circ}$ to $36^{\circ}$, the sprouts will not start and the whole strength of the seed will be saved to grow the crop. Every attention should be given in early fall, winter and spring to keep the temperature down. Keeping the doors and windows open on cool nights and closed daytimes in fall and spring and using ice to keep down the heat reduces the sprouting. Potatoes intended for seed in cellars sprout less in shallow piles on the floor than when piled up too near the ceiling, owing to difference in temperature. A special cold-storage plant would be ideal but is too expensive for farmers unless for very large growers. A very good method of storing seed which is falling into disuse is that of storing in pits covered with alternate layers of straw and earth to prevent freezing.

A European practice which may in time be adopted in America is that of greening seed. The high cost of land in Europe, low cost of labor, large proportion of small tubers in the varieties grown, vigor of small tubers which 
makes them safe for use as seed, use of immature seed, and trouble with seed germinating, have led to the use of a method of care of seed by which it is kept in winter and spring in shallow trays racked up in buildings so constructed that each tuber is in the light. The sprouts at the seed ends start and grow short, green and stubby. When planted, these potatoes start quickly and grow rapidly. The cost of the equipment and of the labor required to place the seed in the racks and again to place the seed in the ground with every seed end up, would be very heavy in America. Unless seed which has been sprouted in this way for some time is planted with the sprouts up, there is trouble in loss of stand. A modification of this plan may be used, however, for American conditions of cost of labor. Such short green sprouts grown in the light for a short time, perhaps two weeks or less, will not be broken off in a potato planter and will give no trouble about coming up. It is, therefore, practical to keep the seed on a barn floor in the sun for that time and save the strength of the sprouts which would be lost by growth in a cellar. For a few days the seed may be left in crates in the sun without making too long sprouts in the crates.

When seed potatoes are disinfected with formaldehyde solution for common scab or with corrosive sublimate solution for both rhizoctonia and scab, the crates may be disinfected at the same time by having a vat of solution in which the crates of seed are immersed. Soaking too long or in too strong solution injures the vitality of the eye. The seed must not be cut before soaking and must be dried at once or rot may result.

The above-mentioned plan is much used in Europe to plant tubers from $1 \frac{1}{4}$ to $2 \frac{1}{4}$ inches in diameter without 
cutting. Trouble with soil diseases affecting the stand is causing the use of similar small seed in some of the western potato-growing sections. The use of small culls as seed is usually condemned in the United States. Very often the vitality of the cull seed is low on account of disease or degeneration in the parent hill. Many experiments have generally resulted in higher yields from use of large seed cut than from small uncut seed. Even if the small seed is used on part of the field on account of the lower cost, it will pay growers in the northern states to have seed plots in which large cut seed is planted. While the results of the many experiments of the cutting and size of seed are often conflicting some general rules may be stated:-

(1) The yield to the acre increases with the size of the seed piece up to 50 or more bushels of seed to the acre when the distance of planting is the same.

(2) The yield to the acre increases with the size of the fraction of the seed tuber from one eye up to the whole large tuber.

(3) The net yield to the acre above the amount of seed planted and the increased value of seed potatoes kept till spring compared with an equal number of bushels on increased yield which must yet bear the expense of digging, storage and marketing, reduce the size of the most profitable seed to plant to much smaller size.

(4) Increasing the number of hills to the acre together with the amount of seed used, while keeping the size of the seed constant, increases the total yield and reduces the yield of the individual hill and the size of the tubers.

(5) Cutting the same weight of seed to an acre into smaller pieces may or may not increase the yield because 
the seed will, at some size, be cut too small to insure a good start to the plants.

(6) As noted above, salable tubers used as seed usually outyield cull seed, because of the fact that a larger portion of the culls come from weak, diseased or degenerate hills. The cull is not poor seed because small, but because there is a greater chance that its inherited vigor is low. In cool and wet climates, like those of Scotland, Ireland, and Maine, there is less risk of small seed being injured in vigor than in climates too hot and dry for the best growth of the potato. The use of the systems of field seed selection to find the strain having the greatest inherited vigor with seed plots to multiply the selected seed produced a stock of which the small culls may be saved for use as seed.

Experiment stations have found conflicting results in studying the relative value of eye in different parts of the tuber, which need further investigation. The eyes at the seed end of the tuber start first to grow and are practically the only ones which grow under greening in the sunlight. When these seed-end eyes start sprouts, which are broken off in handling before the others start the vigor is likely to be more equal. Observations indicate that the eyes nearest the stem end, particularly with varieties having few eyes as the Rural type, are the ones most likely to fail to grow and are the ones from which degenerate strains originate. Under the present state of knowledge of the subject, it is safest for growers to eut seed in such ways as to have the seed end eye on as many of the cut pieces as possible, and to allow a slightly larger amount of flesh to the pieces with stem end eye, to make up for their slower starting growth in spring.

Smaller seed pieces can be used with fertile soil than 
with poor soil. The young plant can become established and get its nourishment from the soil quicker.

Whole seed matures the crop a few days earlier, an advantage for early high prices, and is less likely to rot in cold weather, and to attacks from soil diseases, as in Colorado.

\section{Cutting seed}

Many tools have been invented for cutting seed potatoes, but none is able to do as good work as the knife, either in the hand or fastened in some way. The Colorado cutting rack is a box on legs with slanted or sloping bottom, having an opening at the side. To the rim of a ledge at the front of the operator, a knife is fastened with the point vertical. The seed rolls through the adjustable opening at the side to the ledge. The operator picks up the seed without motion except that of his hand and wrist and cuts the seed by pulling against the knife. Some operators prefer to push against the knife, but the pulling motion is better because the eyes are then always in view, and better judgment can be used in allotting the eyes to the different pieces from each potato. The cut pieces drop into a crate or sack. Trouble with potato diseases of the seed makes it always advisable to have some means of disinfecting the cutting knives, even if the seed is soaked, as no treatment reaches into the interior of the tuber. All seed suspected of being dangerously diseased should, of course, be thrown away. A dish of formaldehyde solution in which to disinfect the knife is advisable. Corrosive sublimate solution is a better disinfectant, but is a very dangerous poison to have around.

With the Colorado cutting rack, the operator can do 
even better work than with the knife held in the hand and can cut nearly or twice as fast with less fatigue, due to the fact that there is no lost motion in reaching some distance for every potato cut. All roll down to within a few inches of the hand. The cost is small, being only that of a little rough lumber, as the knives can be used for other purposes. A knife may be held by fastening to a board and potatoes picked from a crate. Any knife used in cutting seed should be ground thin and kept very sharp.

Under most conditions a larger yield is secured by planting as fast as the seed is cut. The reduction of yield of seed allowed to dry may be heavy. Lack of labor in planting time often leads farmers to cut seed in periods of bad weather and to save the time of cutting later. To prevent the loss of seed by heating, it should be kept in separated containers, as sacks or crates, with a small amount in each in a cool place. The moisture on cut surfaces must be dry to prevent heating and rot, but no more drying should be allowed. Such carefully dried cut seed may do better than freshly cut in cold and wet soil. Land plaster (gypsum) may be used to dry cut seed. Sulphur has been advocated for disease-prevention, but its use does not completely prevent any disease and it is very disagreeable to handle.

The principles of seed cutting are as follows:-

(1) Seed pieces should be cut blocky in shape to make surfaces as small as possible. Blocky pieces feed better through machine planters and the smaller exposed cut surface reduces loss of moisture and danger of infection by rot germ (see Plate VIII).

(2) The probability in most cases that the seed and eyes are more vigorous makes it better to cut each tuber 
in such shaped pieces that will give the largest number having eyes from the seed end. Seed of size to make two pieces should be halved through center of seed end group of eyes. Tubers short and round enough to make four pieces without their being too long and slender should be quartered through the seed end group. Those which will make too slender quarters cut in this way should be cut once lengthwise and then transversely, making four blocky pieces. Many tubers will be the right size and weight to furnish three seed pieces. These should be cut with one piece taken off the stem end about one-third of the length from the stem and the remainder of the tuber halved through the seed end group of eyes. This gives two out of three pieces with a more vigorous seed end eye and the third being cut with a little more flesh to make up for the slower start given by its eyes compared with those of the seed end.

Fairly blocky seed large enough for six pieces is cut in a similar way, splitting the stem end into two pieces and the seed end into four. Seed cutting into more than six pieces often has so few eyes, compared with the amount of flesh, that it is difficult to cut well, especially towards the stem end. The seed end of such large seed should usually be cut into four pieces.

(3) To make sure of one good eye on every seed piece, it is well to have two wherever possible.

(4) The average weight of the seed must be adjusted to the needs of the crop for the soil planted. Garden soils will need little more than the eye itself to produce plants, while soils in very poor condition need large seed to furnish nourishment to the young growing plant for some time before it can grow roots far enough to support itself. The commonest size of seed used runs from one 
to two ounces. The average amount of seed used to the acre in America is estimated at 11 to 12 bushels, the range in most cases being from 9 to 16 bushels. Under European conditions, growers find it profitable to plant larger amounts. In England a long ton, or about 37 bushels to the acre, is the usual amount and is often exceeded. 


\section{CIIAPTTER VIII \\ CARE OF TIIE GROINTNG CROP}

Bro Danial Dan

The tillage of the potato crop is lest considered as a eomected whole from the time of plowing mill the last cultivation. 'The results of tillige before planting and after, in rendering soil fertility arailable, in conserviug moisture and in killing weeds are the same. There is no danger of injury to the growing plant before planting. 'Therefore, as large a part of the tillige ol the potato as prateticable should be done before planting. If soil moisture has been well eonserved, plant-food made available and a large part of the weeds in the soil killed, the amount of the tillige alfere planting ean be largely redued. The dimger of injury to the plants ean thus be largely prevented. 'The cost of tillage with wide tools like the harrows is less than that of work between rows. Only eareful men ean be trusted to work tools between rows withont dangere, while much poorer labore can work in the open tield. When plowing is dedayed mutil just before planting, as dey period following will badly injure the erop.

'Tillage is most profitable when given at one partieular time. After every rain the soil is at first too wet and stiff to work without injuy. It should be carefully watched until in the driest part of the field it becomes mellow enongh to rook. At this stage, the soil crumbles easily 160 
and has passed the time at which stirring will cause baking. Stirring the soil at this time saves the maximum amount of moisture for the use of the growing crop. Evaporation is so rapid that a few hours' delay results in a great loss of water. 'The air is usually cool and the soil stirs easily. With fresh horses, a large area can be covered in a few hours. Weed seeds which have been sprouted by the recent rains are stirred about and the weeds killed. Growing weeds which have escaped previous cultivation are torn out and left on top of the soil to be dried and killed by the heat of the sum. The potato plants have just received the stimulation of needed rain and the dissolved plant-food which has been forming in the soil during dry weather but not available on accomnt of lack of moisture. Under these conditions, the potatoes can stand root injury which woukl be more dangerous at drier times.

Wide tools ean be used in tillage nearly up to the time the spronts break through the surface of the soil. The common practice in the principal potato-growing states, outside of Maine, of harrowing down the ridges, left by the planter or by ridging tools alter planting, is very beneficial. Plank-floats or clod-crushers are often used, but they are dangerous to the growing sprouts. The ideal tool for this purpose would be a level which woild smooth down the ridges without crushing the soil around the sprouts. A tool male of plank $2 \times 10$ inch standing on edge and long enough to cover two rows, has been found very useful. The driver stands on a horizontal plank fastened to the rear of the plank which does the work. Aceording to the hardness of the soil, the vertical plank is slanted slightly or dropperl below the level of the horizontal plank. Frequent adjustment is needed as the soil changes texture rapidly after rains. The horse should be 
hitched close to the level to keep it from digging into the soil. On any but perfectly level fields, the use of level or harrow on more than two rows at a time is likety to result either in injury from working one row too deeply or in poor work from going too shallow on one and hurting the others. Leveling the rows ean be delayed longer when the seed is covered deeply. Many stones in the soil make it advisable to level earlier if it ean be done at all on account of stones moving the seed.

A practice used much in Maine and suited to wet and cold climates is to ridge the potato rows just after the plants come up. If frost follows, the plants are safe from it for several days longer than if left uncovered. Such ridging kills many weeds, but is suited only to sections in which the soil is sure not to bake over the little plants, and to conditions of damp soil which make ridging the best practice.

Without heavy ridging late in the season, the weeds hardest to control are those closest to the potato plants. Thorough stirring before the plants come up and a frequent use of the weeder afterwards enables one to control the weeds near the plants as easily as those between the rows.

Many forms of cultivators are made for tilling the soil between the rows of potatoes. Very heavy soils, such as those of the Greeley region of Colorado, need four-horse cultivators which use two teeth four inches wide and fourteen inches long on each side of the row and stir the heavy clay to the depth of eight or ten inches. Other cultivators for light sandy soils may merely stir the surface with twelve or fourteen peg teeth. Between these types, every gradation of size and number of teeth may be found according to the soil conditions. 
As a general rule the first cultivation after planting is made as deep and as close to the seed as possible, because the potato roots have not started far yet and are safe from injury. The soil settles together so quickly that it should be kept mellow in this way as long as possible. Sometimes a second deep cultivation may be given. Later cultivations after the roots start are made with the teeth working as shallow as they can be marle to work, so as to form a mellow soil mulch. This depth will vary in different soils from one to three inches. Measurement will show that cultivator teeth often work much deeper than the grower is aware. As the tops begin to grow and form a mass, the cultivator teeth can be narrowed. Weeds start less in the shade of the tops and evaporation becomes less, partly on account of the shade and partly because surface roots lorm to use the moisture. Wide, deep teeth are manufactured to cut the roots of perennial weeds like the Canada thistle. Such teeth may often be substituted in part for the common teeth. Cultivators are made for one, two, three or four horses, with wheels and without, and for the driver to walk or ride. One-horse walking cultivators, common in the East and South, have great disadvantages. Even when fitted with wheels in front to regulate the depth, the teeth cut much deeper in some soils than in others. The machine is too light to hold in the soil in stony ground. Masses of weed roots, like those of quack- or witch-grass, clog the teeth and canse the teeth to rise ont of the soil at the very places where the best work is needed. Wheel cultivators enable one to regulate the depth of working to better advantage. 'The weight of the wheel cultivators, with that of the driver, holds the teeth into the ground among stones and weeds. 'The wheels prevent the teeth from cutting too deeply in mellow places free from weeds. 
Deep cultivation is most dangerous in dry times. The gain from weed killing may be offset by the loss of the potato roots.

A tool which is used less than it should be is the weeder. Weeds like ragweed, foxtail or barn grass, pigweed and the whole class which grow from small seeds in the potato field are very easily killed by the frequent use of the weeder until the potatoes are nearly a foot high. Weeders are made with either two or three rows of teeth, with wheels and without and with different styles of teeth. The principle is the same in all, that the light and somewhat flexible teeth tear out and destroy the tiny weeds starting in the surface soil with littlc or no injury to the larger sized potato vines. The weeder is a tool which demands certain soil conditions to be effective. It will not work at all on hard soil. Many growers have discarded weeders after trying them where the soil was not suited to their use. Most soils have a short period after every rain when the flexible weeder teeth are able to penetrate and stir the soil. If that time is taken for their use, many sprouting wecds can be killed in a very short time and the surface mulch established close to the potato plant. The weight of the weeder selected and the stiffness of the teeth should be carefully chosen according to the character of the soil. If necessary, weight can be added. A needed precaution in the use of the weeder is to keep the teeth free from trash. Weeders are often used to follow a cultivator with large teeth to better level the soil between the rows. Weeders and leveling tools, like the harrow, are sometimes driven crossways of the potato row. It may be possible to do the work a little better in this way, but the danger of injury to the growing sprouts and roots of the potatoes from crushing under the feet of the horses is so great that it is a 
practice of doubtful advantage. In most cases, practically all of the weeds can be killed by driving along the row. The weeder is a tool for prevention of weeds rather than their cure. It will not kill those which have got much of a start above the soil or those with underground rootstocks like quack-grass.

A comparison of potato-growing of 1916 with that of 50 to 75 years ago shows how great has been the substitution of tools operated by the power of animals for those worked by man. Where formerly the plow and harrow were nearly the only tools not worked by hand labor, the farmer may now use the horse-drawn planter, fertilizer-sower, manurespreader, numerous types of cultivators, weeders, ridgers and other tillage tools, the sprayer and the different types of diggers.

Within the last twenty years the gasoline engine has been developed to a wonderful degree. Millions have been built for automobiles and probably millions more have been sold for farm use, for threshing, feed grinding, pumping water and other uses. Gasoline tractors are being rapidly developed to draw farm tools in the field. As yet they have been little used in potato-growing exeept for plowing and harrowing. A great obstacle to the use of present tractors between potato rows is the width of a track, usually four or five feet. Potato rows are usually about three feet apart and tools for work between the rows must have a tread of about three feet, or else have a six-foot tread, like most potato sprayers. Four-wheeled tractors used to draw tools need two operators, one for the tractor and another to handle the tools. On any but perfectly level land the side movements of front or rear wheels in skidding quickly injure the potato plant. New types of tractors are being developed by which the same two wheels 
are used for driving and steering, the tool itself taking the place of the other wheels of the tractor. One operator handles both engine and tools. Similar small enginepropelled tools are being made for garden use.

Engines are being used on potato sprayers to give better results by higher pressures than horses can furnish. The elevating and separating machinery of potato diggers is sometimes driven by engines, horses being used to draw the tool only.

Harrows or leveling tools are usually used once; occasionally twice. Weeders may be used up to a dozen times in extreme cases and half a dozen pay well. Cultivators are used from three to eight times with four or six as the most common number. Outside of Maine, the ridging tools are used once or twice. Thorough tillage and a good condition of the soil before planting necessitate less work later. It is a good rule to cultivate after every heavy rain, and to cultivate more frequently in hard soils than in light. Tillage is less needed in soils which are mellow and full of organic matter, because such soils supply plant-food and water more readily.

The danger of the growing tubers protruding out of the soil and being sumburned is prevented by ridging lightly after the tubers are formed. Ridging earlier does not prevent sunburn because the depth at which the tubers form is controlled by the depth of planting. Very shallow planting results in the tubers forming below the seed and very deep planting in forming at a depth where little sunburning results. Usual depths of planting are not deep enough to entirely prevent sunburn. While late ridging is somewhat feasible, the difficulty is that any injury to the roots of the growing potato plant at that stage is dangerous.

Tillage is so necessary in potato-growing for the libera- 
tion of plant-food, maintenance of healthful soil conditions, saving moisture and weed killing that it must be practiced after planting the potato crop. As the potato plants are more tender than most weeds, great injury may result from careless tillage. The tender white sprouts starting from the seed tubers are usually injured by a touch. The soil about the seed may be thoroughly stirred with a harrow and level during the first few days after planting without danger. The weeder can be used with good results in killing weeds and keeping a soil mulch above the plants if great care is used to prevent the teeth from injuring the sprouts. If the number of injured sprouts is small, the gain from the tillage may outweigh the setback which the injured plants receive.

The next period, from the time the plants form green leaves above the ground till the tops are eight to twelve inches high, is one when the benefits of tillage are usually greater than possible injury. During a large part of the time the plant-food in the seed tubers is still available, and the leaf surface is not yet large enough to transpire enough water to seriously injure the plant. Sun-scald and tipburn are not common until the plants are larger. Roots are being developed close around the seed and stalks. Until the roots are numerous enough for tillage to destroy more than a small proportion of the whole root system, tillage is beneficial. Later the horizontal roots extend until they cross between the rows. These roots are now of the size to make their injury a serious matter to the growing plant. The greatest development of the roots is in the plowed area, or five to ten inches below the surface. Many roots also extend down to the depth of three to four feet. A large part of these vertical roots drop downward from the large horizontal roots close to the surface. It is 


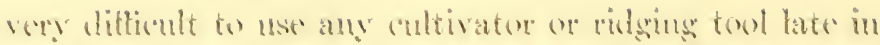
the seasom withut arting these lateral reots. The loss

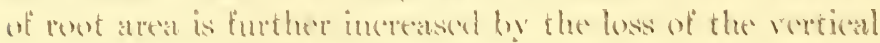

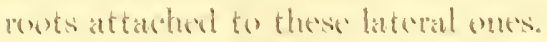

The relation of the value of these lents to the yold of

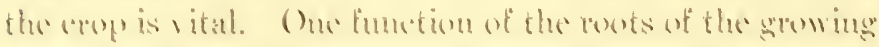

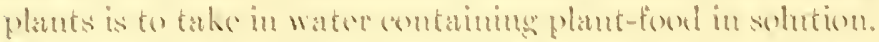

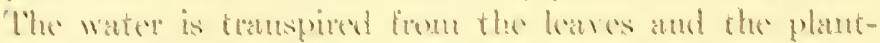

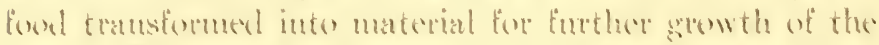

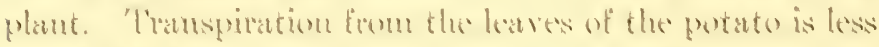

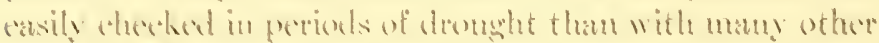
plants. 'Tha potato has less abolity to mogulate its use of

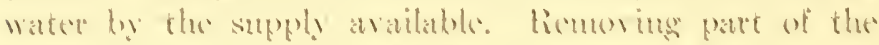

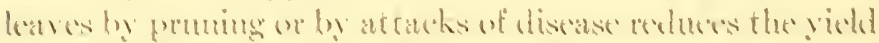
ber taking andat from the plant the fintory in which tho matrovial for the cubers is chabotated. Is the smpply of

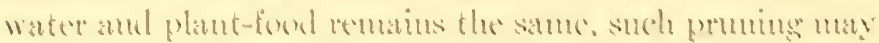

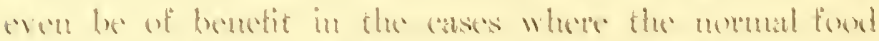

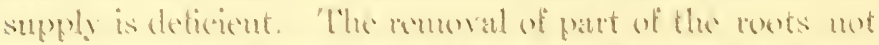

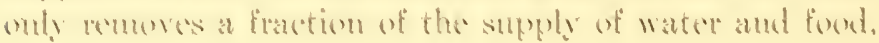

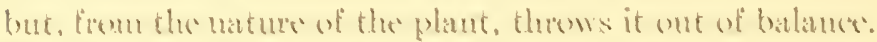

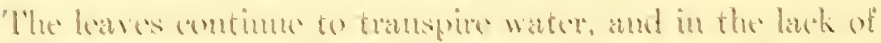
full supply trom the reot. Uste up patte of the watere in the

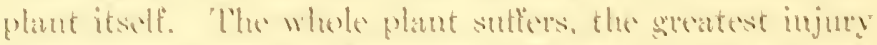

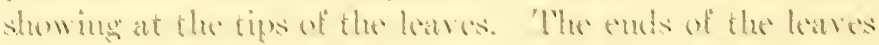

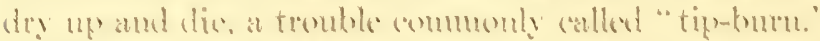

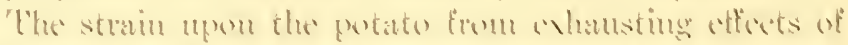
blossoming mul forming tubers at momly the same tixnt is

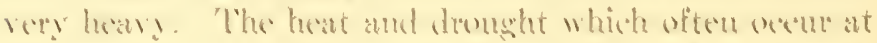

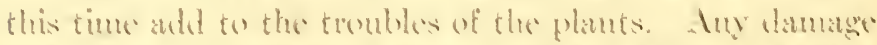

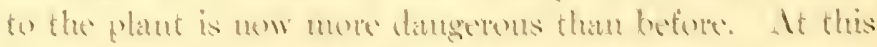

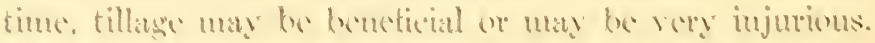
It che weather is cool and the soil water ample, tillage may 
greatly increase the crop. Hot and dry weather, at or following the time of tillage, may nearly ruin the crop, weakened by root injury.

Tillage so loosens the upper inches of the soil that the roots cannot develop there until after tillage stops. The plant-food contained therein may be of great value to the growing crop. Exhaustive experiments show that with corn practically the same amount of water is found in the soil late in the season whether tilled or not. The plant roots are able to use the water before it can escape from the surface. ${ }^{1}$ If weeds have been killed, there is little need of stirring the soil late in the season. The frequent grinding of the upper soil layer by early tillage has changed much of its contained plant-food into a condition in which it is available to the plants. If the previous care has been such that the crop has passed the critical period in good condition, the roots soon fill the surface soil and use the plantfood supply for the production of tubers. A few weeds which may have escaped the tillage tools should be pulled by hand in July and August before they go to seed.

Spraying is commonly thought of only in its relation to insects and diseases. Thorough spraying with bordeaux has been found to give an increase in yield in the absence of disease and insects. This action is noted most in hot and dry seasons. It should always be considered among the methods to insure goorl yields in sections where heat and drought are likely to limit the yield.

${ }^{1}$ Ill. Bul. 181. Bul. 257, Bur. Pl. Ind., U. S. Dept. Agr. 


\section{CHAPTER IX}

\section{POTATO INSECTS AND THEIR CONTROL}

The amount of damage to the potato crop by insects is very large, much larger than is ordinarily supposed. Spraying with poisonous substances has to be resorted to in order to obtain a crop which has been uninjured by insects. They do four kinds of damage and may be classified in this manner: (1) insects chewing the leaves; (2) insects sucking the leaves and tips; (3) stalk borers; and (4) insects affecting the tubers. Most of the damage is done by the Colorado potato-beetle and the flea-beetle.

\section{The Colorado potato-beetle (Leptinotarsa decemlineata)}

(Fig. 10).

This is a leaf-eating insect, and its ravages are very general. It seems to be always present where potatoes are grown, and the damage it causes is very great. Indeed, in most sections, it is impossible to obtain a crop at all unless its ravages are held in check by the application of some poisonous substance to the leaves.

This insect is a native of a strip of country which lies just east of the Rocky Mountain range and includes eastern Colorado. In its native state the beetle lives upon the wild weeds of the potato family, the chief of which is the sandbur (S. rostratum). It is a general feeder, living on 
not only potatoes, but tomatoes, eggplants, tobacco and peppers.

"It was first brought to notice," says Greo. C. Butz, "about the year 1856. In 1861 it was found in the potato fields of the settlers of Kansas. In 1862 it was in Iowa, and in 1862 it appeared in southwestern Wisconsin. It crossed the Mississippi River into Illinois in 1864. It was in Michigan and Indiana in 1867, Ohio in 1868 and Pennsylvania in 1870. It moved eastward at the rate of about fifty miles a year for a number of years, but later it traveled more rapidly. It is reported to have reached the Atlantic Coast about 1874, and Nova Scotia about 18S2. When it reached the Atlantic Coast, it had traveled 1500 miles in sixteen years, and nearly 1000 miles more the next eight years in its march to Nova Scotia."

The mature beetle hibernates in winter in the ground usually at a depth of eight to ten inches and begins to fly early in the spring. As soon as the first leaves of the potato appear above the ground, the beetles fly to them and soon lay their reddish yellow or orange-colored eggs in clusters on the under side of the leaves. In about a week the young beetles or larvæ appear and begin to devour the foliage with great rapidity. The larvæ pass through four stages or instars and are mature in sixteen to twenty-one days, according to the weather. Then they go into the ground and transform into the pupa or resting stage, in which they remain at least a week usually longer - before coming out as the adult beetles. The egg-laying period lasts about thirty-five or forty days. The minimum time for the life cycle is about four weeks. The last brood of larvæ which disappear into the soil before severe frost pupate there, remaining in the ground in the form of perfect insects until the following spring. 
The adult beetle is oval in shape, about three-eighths of an inch in length and a trifle narrower than long. The ground is yellow and the wings are marked by ten black lines running lengthwise. There are also black markings on the thorax (see Fig. 10). These insects have great power of endurance. They will walk for great distances in search of food, and it is said by direct experiment they are known to have lived thirty days without food. Their eggs are a bright yellow when fresh and the young are dark red or brown grubs with black heads and markings

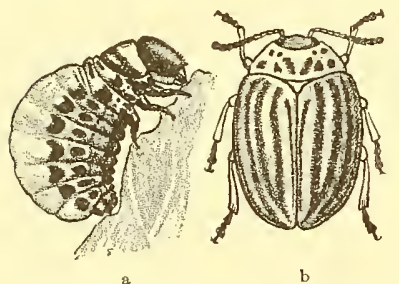

Fig. 10. Potato bug, larva and mature beetle enlarged. of black spots in double rows on each side. The color becomes lighter as the grubs mature.

Control. - The Colorado potato-beetle is controlled by the use of poisonous substances which either in solution or suspension are sprayed upon the vines. The most common of these arsenical poisons are paris green, arsenate of lead or arsenate of soda. Any one of them may be sprayed upon the vines alone or mixed with bordeaux mixture and applied. Poison is usually necessary only for the first two regular sprayings, but should be added at any time the larvæ become numerous. The eggs should be watched carefully, and after they are well hatched and the young have begun to feed, the first application of the poison should be made. A second spraying will doubtless be necessary in ten days to two weeks. The necessity for subsequent applications of poison will be determined by any later appearance of the pests. The first sprayings should not be delayed too long, as the larvæ develop very 
rapidly after hatching and much harm is often done before one is aware of it. With fifty gallons of water, if the poison is to be used alone, or of bordeaux mixture, use three to five pounds of arsenate of lead or one pound of paris green, and add two pounds of quicklime to prevent burning. One pound of paris green to the acre in either water or bordeaux mixture is ordinarily recommended. Growers should be warned against the use of excessive quantities of paris green because it burns and injures the vines if put on too strong. Arsenate of lead has the advantage of adhering to the vines and is only slightly washed off by rains. After long-continued rains, the vines may often be seen to be grayish in color because of the arsenate still clinging to them. When these poisons are applied with water, whether with or without bordeaux mixture, some provision must be made to keep them constantly agitated so that they will not settle to the bottom of the spray tank.

\section{Flea-beetle (Epitrix cucumeris) (Fig. 11)}

This is a leaf-eating insect. There are several kinds of flea-beetles which are troublesome to potatoes, the one named above being the most common. In the South the tobacco flea-beetle (Epitrix parvula) and the eggplant flea-beetle (Epitrix fuscula) do considerable damage. Another larger, more elongated form, known as Systena hudsonias, has been found to cause considerable damage in the North.

These flea-beetles all belong to the leaf-chewing class. The adult beetles frequently do much damage to the potato crop, but being so small, less than onc-twentieth of an inch, they are often not seen. They are black and jump when alarmed, which also makes it difficult to see 
them. The result of their depredations will be found in the many small holes which may be noticed in the leaves of the young potato plants, and in the lessening of the crop on this account. These many small holes make excellent starting places.for many diseases to get a foothold to injure the plant. The beetles stay mostly on the under side of the leaves and are not seen, their presence being detected only by their work. The larvæ occasion-

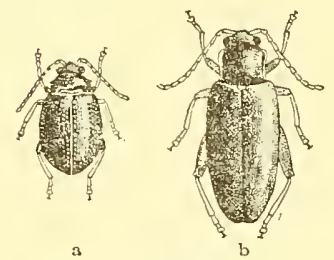

Fig. 11. Flea-beetle, enlarged. ally do injury by mining into the tubers and cause pimply potatoes. During the hot, dry summers, especially, they often become the worst enemies of the potato. The insects very often congregate in such numbers that the leaves of the plants appear almost black with them. Young potatoes and newly set tomato plants frequently have their leaves so badly eaten that they shrivel, and the tomatoes may die.

The life histories of the different flea-beetles are practically the same. The adult insects live over winter under leaves and rubbish and appear during the latter part of May and first of June. As soon as they come out, they lay eggs near the roots of the potatoes or of weeds related to them. The larvæ mine into the roots; and when full grown, they pupate and later emerge as adult flea-beetles.

In some sections, particularly in Colorado, the greatest damage is done by the larvæ, which are tiny white grubs about a quarter of an inch in length. They frequently cut into and destroy the young tuber stems of the potato and prevent a regular setting of the crop.

One brood of potato flea-beetle appears yearly in the North and two broods in the South, the second ordinarily 
appearing in August and September. This brood, coming at a time when the tubers are partially or wholly grown, bores into the flesh and underneath the skin of the potato, causing a pimply or scabby appearance which detracts from their market value.

Control. - Flea-beetles are very largely controlled by bordeaux mixture, which acts as an effective repellant. They ordinarily feed, however, on the under side of the leaves, and thorough spraying both on the upper and lower sides of the leaf is necessary to be satisfactorily effective. Spraying may have to be begun somewhat earlier for the flea-beetle than for other insects or diseases. The insects are so small and their damage begins on the under side of the leaves, so that often a great amount of damage may have been done before it is detected. It is a good practice to eliminate from the farm such plants of the solanacex family as nightshade, bitter-sweet, horse-nettles, ground cherry and jimson weed. The flea-beetles breed on these as well as the potato itself.

\section{Blister-beetle (Epicauta and Macrobasis)}

These are leaf-eating insects. The so-called "blisterbeetle" or "old-fashioned potato-bug" consists of four or five species of insects which do a tremendous amount of damage to the potato in some years. They sometimes appear in great numbers and are not easily vanquished. They are all medium-sized elongated beetles of different colors: spotted, striped, black, light or dark gray. The adults damage the potato plant, but the larvæ are especially beneficial in destroying the egg masses of the grasshoppers.

A large number of eggs are deposited by the female in a small cavity in the ground. The larvæ are provided with 
legs by which they crawl about until they find a grasshopper's egg mass, upon which they feed. They then molt, their legs becoming rudimentary. As helpless grubs they complete the remainder of their larval stage surrounded by an abundance of food. 'There is one brood a year.

Control. - If potatocs are carefully sprayed for the Colorado potato-beetle and flea-beetle, there will be little danger from the attack of these insects. Sometimes, however, they appear in large numbers and should be immediately killed by additional applications of arsenieal poisons.

\section{The three-lined leaf-beetle (Lema trilineata)}

These leaf-beetles are leaf-eating insects. Both the adults and larre of this insect feed on potato leaves. This beetle is smaller and more elongated than the Colorido potato beetle and hats only three black lines on a yellow ground eolor. The larva are distinguished by haring their backs covered with their own excrement.

'The adults hibernate over winter and come out in the spring, laying their eggs on the mderside of the potato leaves along the veins. There are two broods a year; the larvae of the first brood appear in June and those of the second brood in August. The ardults of the second brood go into the ground to hibernate over winter.

Control. - 'This insect is controlled in exactly the same way as the blister beetles.

\section{Tortoise-beetles (Cassida and Coptocycla)}

Tortoise-beetles are leaf-eating inseets. The insects of these genera are of minor importance, but may do some damage in unsprayed fields. Their oval shape and flaring 
edge of the thorax give them some resemblance to a tortoise shell. They are of small size and green, gold or black in color.

The adults make their appearance in May, having lived through the winter in crevices under bark and in similar dry places wherever shelter could be found. The female begins to lay eggs soon after her appearance. The eggs are laid singly on the leaf-stems or on the under side along the larger veins, and each is covered with a little daub of black excrement, so that all that is visible to the eye is a little mass of black, pasty material that soon hardens. This mass incloses the whitish oval egg and protects it. During the first part of June, many of the eggs have hatched and larvæ, eggs and adults may be found on the plants all at once. "The larvæ are decidedly flattened, more or less oval, with lateral spines or processes from the margins, and at the end of the body is a fork which, in some species, holds all the excrement voided during life and sometimes the cast skins as well, often making a mass nearly as large as the larvæ itself." These feed, preferably, on the under surface of the leaves and do much damage. The larva pupates about the middle of July. The beetles appear during early August and feed very little, all trace being gone before the beginning of September. There is one brood a year.

\section{The potato plant-louse (Macrosiphum solanifolii)}

This plant-louse is relatively large in size, and either pink or green in color. Its mouth-parts, like those of all plantlice, are adapted for sucking the juices from the tender, growing tips of the vines. The infested vines grow brown at the ends and often die back for four or five inches. In 
certain seasons, these insects become very numerous and their depredations check the growth of the vines considerably. The wounds made by the beaks of the aphids often admit fungi and indirectly result in greater injury than the work of the insect alone.

The potato aphid passes the winter in the egg stage, the eggs being attached to weeds. In the early spring, the adult insects are to be found feeding on the succulent tips of rose bushes. In July, the aphids migrate to potato fields and start feeding there. The potato seems to be an ideal food for this insect, for it increases in numbers very rapidly, a single female often producing over fifty young in two weeks. Late in August or early in September, the lice leave the potato vines and go to rose bushes or other food plants. Here they produce several more generations of young. The last generation of the year consists of wingless females and winged males. The females lay the over-wintering eggs on the shepherd's purse, potato, and other food plants.

Control. - There are certain natural agencies of control over these insects which frequently make them of little consequence. Among these are cold weather, frequent rains, parasitic fungi and insects, and various predacious insects. These factors cannot be relied upon, however, to keep the pest in check every year. Fall plowing will turn under many weeds and old leaves on which the eggs have been laid. It has also been suggested that the farmer burn the dead vines in the fall in order to destroy the eggs. The adult insects can be killed by using any good contact insecticide like one of the tobacco extracts, kerosene emulsion and the like. Spraying is usually only resorted to when the insects become very troublesome. 


\section{Leaf-hoppers (Empoasca mali)}

These leaf-sucking insects do some damage to potato tops by sucking the juices and making holes in the leaves. The most common of the leaf-hoppers is Empoasca mali, which is a small, elongated, pale-green insect, very active, jumping and flying readily.

This insect spends the winter either in the adult or in the egg stage. It appears in the spring and starts to feed upon the apple or other food plants, and soon lays its eggs. The nymphs from the over-wintering eggs are found about the middle of May. Usually about four broods develop during the season. The leaf-hoppers are generally all gone by the first of October.

Control. - They do not require special treatment, never appearing in sufficient numbers to do any great damage. Treatment for other insects readily keeps them in check.

\section{The potato-stalk weevil (Trichobaris trinotata)}

This is a stalk-boring insect which does considerable damage in the south central states. The adults are small ash-gray beetles with a long snout, and the larvæ are small white grubs.

The adults appear in the spring after hibernation and eat holes in the base of the stalk with their long snouts and deposit an egg in each hole. These soon hatch, and the larvæ make their way into the main stalk and branches. These grubs become full grown near the middle of August, and then they pupate in cocoons which they have spun near the base of the stalks. Adults appear a week later and remain in the stalks until the following year.

Control. - Since the adults hibernate in the old stalks, 
the best method to keep them in check is to rake the fields over after digging the potatoes and burn all the refuse. Destroy also all other solanaceous plants which may be growing in the neighborhood.

\section{The stalk-borer (Papaipema nitella)}

The potato is probably not the normal food plant of this insect, but when other food material, such as certain weeds, tomatoes, corn, cotton and some grasses, are lacking, the potato is sometimes infested. The adult is a gray moth, and the larvæ do damage by boring into the stems of the plants on which they feed.

The insect lives over winter by means of eggs which are laid in the fall in masses of fifty or sixty on grasses and weeds. The eggs hatch in the spring, and the larvæ puncture the leaves and then work down into the stalk. Frequently they travel from one plant to another. The larvæ, when mature, eat holes in the sides of the stalks and pupate. Late in August, the adults emerge and lay eggs for next year's flock. There is one generation in a year.

Control. - The stalk-borer should have the same treatment as the stalk-weevil.

\section{White grubs (Lachnosterna species) (Fig. 12)}

These are the larvæ of the May-beetles or June-bugs. They are large, white, soft-bodied grubs which are commonly found in sod ground. They feed on the roots of many plants and sometimes eat into the tubers of potatoes, especially those planted on new ground.

This insect lives in the ground over winter either as an 
adult beetle or as white grubs. It takes two or three years to complete its life cycle. The adults lay eggs in sod ground in June which hatch in about two weeks. The larvæ or grubs feed on roots and require one or two summers to become fully grown. They pass the first winter as grubs living deep down in the ground and the second summer are much larger and more destructive than the first, so that those fields left in sod one year are likely to be badly infested the next year. The larva, ordinarily, pupates in June or July of its second year

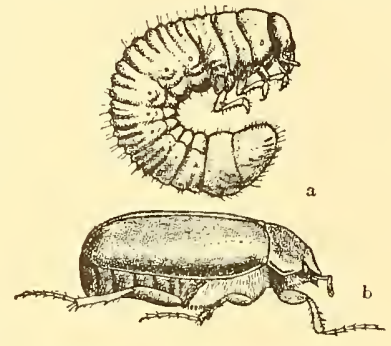

FIG. 12. White grub and May-beetle. and after remaining a pupa for about three weeks, changes into an adult beetle and remains in the ground until the next spring.

Control. - If the ground is badly infested with white grubs or wire-worms, it should be given a thorough fall plowing and either plowed again or thoroughly harrowed in the spring. Land which has been in sod for many years would ordinarily need this treatment. Potatoes should not be planted immediately upon such ground, but it should be planted for a year or two to such crops as buckwheat or some of the other small grains which are damaged but little by white grubs or wire-worms.

\section{Wire-worms (several species) (Fig. 13)}

These insects do much damage to the roots of many crops, including the potato. Like the white grubs, they normally live in sod ground and feed on roots, and are not usually 
injurious to potatoes unless the ground has been in sod a year or two. Wire-worms are the

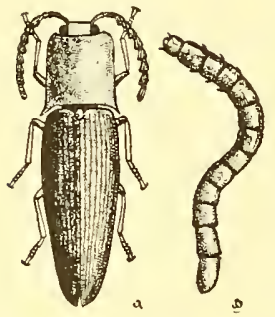

FIG. 13. Wire-worm and the beetle. long, hard, cylindrical larvæ of the click beetles. They include several species.

Like the June-bugs, the eggs are laid on sod ground and the larvæ require from three to five years to mature. They transform to adults under ground in midsummer, but usually remain in the soil until the following spring.

Control. - See methods of control of white grubs. 


\section{CHAPTER $\mathrm{X}$ \\ DISEASES OF THE POTATO}

By M. F. Barrus

When healthy potatoes are planted in a warm, moist soil, vigorous sprouts will grow up from the tubers. These develop into vines with green expanded leaves. On underground stems there will be formed young tubers which enlarge greatly in the latter period of the growth of the plant. When the healthy tuber is planted, the food stored within is used for the production of tissue for roots, stems and leaves. As soon as the leaves have expanded they perform the important task of making food during daylight from the carbon dioxide of the air and from water and soil solutions absorbed by the roots. This food is used for the maintenance and further growth of the plants, and whatever is made in excess of this is stored in the tuber largely in the form of starch. After the vines have obtained their greatest growth, the leaves make a large excess of food above that needed for maintenance, and consequently the storage of food in the tuber takes place rapidly. It is plainly to be seen, therefore, that in order to have a large amount of food stored in the tubers, that is, to have a large yield, it is necessary first to have a good growth of vines and to have them remain healthy until the tubers become of maximum size. A destruction of the leaves by any means reduces the yield of tubers. 
When the leaves of the plant become crinkled and curled, mottled, rolled, spotted, blighted or dead at the edge, when the vines show a yellowing and wilting, or become stunted, or the stem shows discolorations on the outside or within, or when the tubers have rough scabs or pustules or show rotted areas, or the tissue within is streaked with brown or is decayed, we say the plant is diseased. Any one of these appearances, called symptoms, may indicate the presence of disease, and its appearance means that the plant is unable to produce its maximum yield. It is to the interest of the farmer to know what these diseases are and especially to know how to prevent them.

A plant, like a person, may be small and also be healthy. Poor soil often produces small plants, and late planted tubers may produce vines which may be killed by frost before they have attained their maximum growth. Such small plants are not diseased. Other things being equal, however, small vines will not produce as large yields as large vines. But plants may be small because they are affected by some disease, so that it is often difficult to tell whether small plants growing in a field are affected by disease or are small for other reasons. Some plants grow "all to vines," that is, the vines continue to grow vigorously all the season and by so doing use up a large amount of the food made by the leaves so that there is but little left for storage in the tubers. Such plants usually have small or unmarketable tubers. This condition may be brought about by too much shade or by a soil too rich in nitrogen. On the other hand, such a condition may be the result of a disease known, for the want of a better name, as "large vines and many small tubers." A disease of a plant is an abnormal condition which 
prevents it from completely carrying on its life processes and producing its fruit naturally. There are many agencies capable of bringing about disease of the potato, some of which are not well understood at present. Disease may be brought about by conditions of soil and climate unfavorable to the plant, by physiological disturbances within the plant, the direct cause of which is not clear, and by the attacks of parasitic organisms. Troubles resulting from the firstnamed condition may sometimes be remedied by selecting varieties or types of plants better adapted to the climate in which they grow, or by adopting

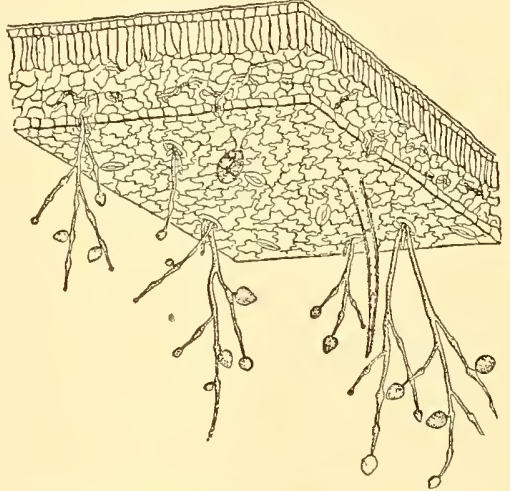

Fig. 14. Section through a part of a diseased potato leaf, showing the spore stalks, with spores attached, extending down through the breathing pores of the leaf.

a system of culture that will overcome or obviate the unfavorable condition. The second group of troubles are often heritable, and the only means of avoiding them are through the elimination of tubers from affected vines for planting purposes. The third type of disease, and often the most destructive, is caused by parasitic organisms and may be communicated to healthy plants by the transfer of the parasite or some special portion of its body adapted for the purpose.

For convenience in discussing them, we may classify parasites of the potato into plant and insect parasites. The plant parasites include fungi, bacteria and slime- 
molds. I fungus is itself a plant. but without leaves or green eolor. It is not able to prepare its own food as higher plants do, but must live mpon the product of other plants. Mamy fumgi and bacteria and most slime-molds are saprophytes, that is, they obtain food from the produets of plants or amimals that are dead. Others are parasites - obtaining their food from the products of living plants by attalking the living tissnes, injuring or killing them and thus eamsing a diseased condition in the plant or the death of the cutire plant.

A fungus dithers from a higher plant in that it does not. have roots, stems or leaves in the semse in whichwe gencrally regard these oruans, but in its regetative stage
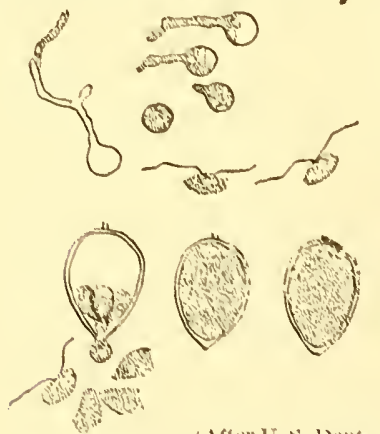

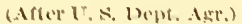

Fre. 15. below from right to left she shown four stages in the formation of sw: sm spores. Tha w:1, in which f'u swarm spores serminate is shown :howe.

as spores (Fig. 15), of which chormoms mumbers are usnally produced. 'These are disseminated hy water, air or animals, depending on the kind of fungus producing them. When spores of parasitic fumgi fall upon their host plant, that is, the plant from which they are able 
to extranet their food, they will germinate under basorable conditions of temperature and moisture. Indead most spores will germinate under livorabole conditions without the presenes of the host plant. 'These conditions viry with diflerent lumgi, but, in general, al linily warm, moist. eondition is forsorable for the germimation of most spores. 'Tlie sprent, or serm-tube (Fig. 16), produced by the germinating spore suters the tissue of the host direetly through the: wall which it is able to dissolve, through wounds or through the breathing peres. 'The reot-hacirs of

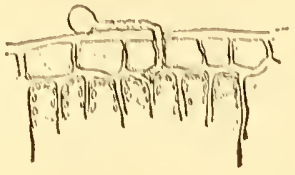

F木, 16. 1 germinat ing swarm sporo, showing gorm-tuix ontering leaf.

higher plants have very tender walls, and these maly serve als a point of infertion by parasitic fongi of the sovil. Alter at fungus ganins entrame to a plant, it lives mpon the erell products and usually brings about the death and disceloration of the tissues at the peint, so that the infested area may be seen as a spot, rot, blight or emoker. The: fungus, sooner or later, puts forth liniting hodies on the ontside of its hest, and on these bodies the spores are borme.

Bacteria are plants of a lower order than fompi, many kinds consisting of but a single mimute all. In the presence of oxygen, water, food and suitable temperature they reproduce very ripidly. 'They' do not produce spores like fungi, alud arre mubble to penetrate maided the outer tissues of plimts, but mily enter the plant through inseet and other wommls or throngh other openings. Thus, parasitic bateterial may be carried frem plant to plant by inserts and be introdued into their tissues during dry weather when fimgi would be mable to do so. Bateteria also live entirely within the host plant and 
do not produce fruiting bodies on the exterior, though the living bacteria may ooze out with the sap through wounds or breathing pores.

Iost slime-molds are entirely saprophytic, though a few attack living plants. The one producing powdery scab is the only example of a slime-mold disease of the potato. The slime-mold differs from a fungus or a bacterium in that it consists of a naked mass of protoplasm, often of many cells, in its regetative stage. The spores of the one producing powdery scab germinate as a tiny mass of naked protoplasm which gains entrance to its host through the lenticles or breathing pores on the tuber. It passes from cell to cell within its host, infesting the contents and itself greatly increasing in mass. Finally, its body is transformed into spores which become exposed with the rupture of the skin above them.

\section{CLASSIFICATION OF CAUSES OF DISEASE}

According to their causes, we may classify the diseases of potatoes as follows:

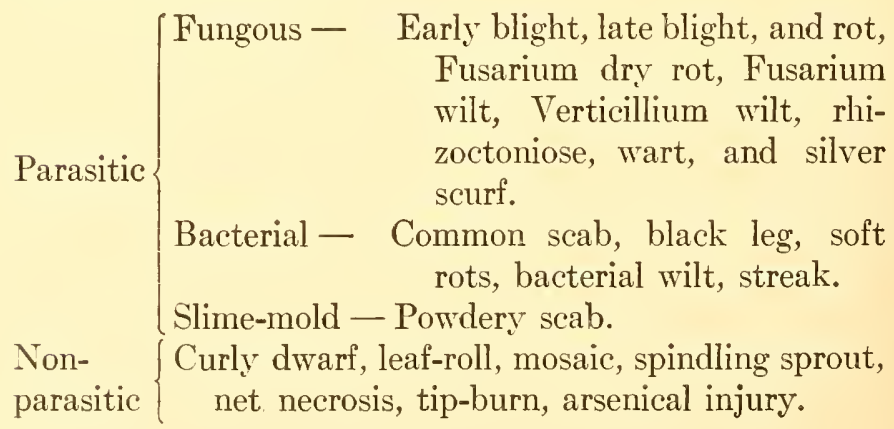




\section{Early blight (Plate X)}

Early blight, caused by the fungus Alternaria solani, appears as angular, dark brown dead spots on the leaves, which may become so numerous as to kill the entire leaf. The spots are marked with concentric rings of elevation, giving the dead area a target-board appearance. The vines usually do not become affected until after blossoming has occurred, but may then become so severe as to cause the vines to die. The spots often occur around a flea-beetle puncture or other injury, but may also be found on an otherwise uninjured surface. The fungus commonly attacks the older and weaker leaves first, but may spread from them to the younger ones.

The disease may be confused with tip-burn or with arsenical or other injury to the foliage. The fungus may attack such injured or dead area first and later spread to healthy tissue. The spores are large, thickwalled, many-celled bodies produced on both surfaces of the older dead areas. The fungus is able to live over winter as a mycelium in the dead leaf tissue, and the spores themselves will remain alive for more than a year. They germinate in water, each cell being capable of sending out a germ-tube. These are able to enter the leaf through stomates or penetrate the epidermis directly. The fungus attacks the foliage only, but as a result of the attack the tubers may be small and thus the loss will be considerable. This will depend upon the virulence of the attack and may amount to one-half or more of the crop.

The disease can be held in check by thorough applications of bordeaux mixture. 


\section{Late blight (Plate IX)}

Late blight, also known as downy mildew, is caused by the fungus Phytophthora infestans. It occurs in northeastern United States and adjacent parts of Canada and sporadically farther south and on the Pacific Coast. It has also been known for years in many countries of Europe, and has been reported as occurring in Australia and in the high plateaus of South America where potatoes are grown. It prevails in those regions where the weather is relatively cool and moist, conditions most favorable for the growth of the potato itself, and, even there, is destructive only during especially favorable seasons. For this reason the disease appears in epidemic form in many sections in occasional periods of years, the intervening periods being comparatively free from it.

The disease shows on the leaves as water-soaked or brown areas that may occur on any part of the leaf. In moist weather these spots rapidly enlarge so that the entire leaf may become affected, and over the recently affected area, usually on the lower surface, a fine white mildewy growth may be noticed. The stem may become affected in a similar manner. In moist weather the affected areas soften instead of drying and give off a disagreeable odor characteristic of decaying vines.

The fungus causing the late blight may attack the tubers (Plate IX), the upper surface of those lying nearest the surface of the soil being first infected, producing on them a discolored, water-soaked area which may be small or, if the soil is moist, may extend over much of the tuber. The affected area becomes somewhat sunken at digging time or later in storage and the flesh has a rusty-brown color. This condition is known as dry rot. The flesh 

is not affected to a greater depth than one-fourth to onehalf an inch, although such affected tubers in a heavy wet soil or even in storage may be invaded by saprophytic fungi or bacteria that produce a soft, malodorous condition known as wet rot.

The fungus causing late blight lives as a mycelium in or near the margin of the diseased area in affected tubers. When such tubers are planted under conditions favorable to the fungus, namely, a warm moist soil, the mycelium will grow into shoots often weakening them and sometimes destroying them.

When these affected sprouts succeed in growing, they appear above the ground as a slender, weak stalk often hidden by healthy neighboring ones from the same tuber. On these weak stalks the fungus, during moist weather, forms its fruiting bodies on which are produced a large number of spores. These are blown by air currents to neighboring healthy vines, where, if the vines are wet, they germinate in two to four hours in an interesting manner. An opening appears at the tip of the spore, and six or more zoöspores are pushed out as naked masses of protoplasm that are able to move about in the water on the leaf surface by means of whip-like strands of protoplasm extending from their bodies. After moving about for an hour or so, they settle down on to the surface of the leaf and after a time send out a little tube, the germ-tube. The germ-tube is able, after a few hours, to penetrate the surface of the leaf. Once inside, the germtube grows rapidly into a mycelium extending between the cells and even penetrating them. These cells become disorganized and turn brown and from them the mycelium obtains its nourishment. Cell after cell is killed in this manner, and the discoloration resulting upon 
their death is noticed as a blighting of the leaf. After four or more days, the mycelium has produced fruiting bodies bearing more spores. These are carried by air currents or by other means to healthy leaves, which in turn become infected if the weather is wet, or they fall to the ground, where during rains they are washed into the soil. Thus under favorable weather conditions the fungus may spread from an infected vine to neighboring ones, causing them to blight, and thence to all the vines in the field until all are blighted. The spores, washed into the soil, come into contact with the new tubers and infect them in much the same manner as the leaves were infected, so that they rot in the manner described earlier. If the soil remains wet and soggy, as heavy soils often do during rainy periods of the fall, the fungus grows luxuriantly in the tuber and produces fruiting bodies on its surface. Spores produced there infect other tubers in the hill and possibly spread to other hills. It has been shown that the fungus may fruit on the surface of the tuber in storage and infect mature tubers there, though this does not often happen. All that is necessary for infection of the tubers is the presence of spores on their surface under moist and fairly mild or cool weather. Infection readily occurs when the blighting vines come into contact with freshly dug tubers. These points are of importance, as it teaches us to leave blighting vines until they are dead and dry before digging unless we can dispose of the crop at once or unless there is danger of the tubers rotting badly in wet soil. Tubers infected shortly before digging time may show no evidence of it then, but the dry rot will appear later in storage.

It has also been shown that throwing the soil over the tubers with a shovel plow to the depth of four or five 
inches before or at the time the vines begin to blight will prevent a large amount of tuber infection. This method of control is a makeshift at best, and the practice in some localities is known to have reduced the yield. Spraying the soil with bordeaux mixture will aid in preventing infection of tubers, but usually is not practical.

As the fungus grows best in the tubers under mild or moderately cool moist conditions, it naturally follows that infected tubers will rot but little or not at all when stored in a dry place and held at a low temperature $\left(40^{\circ} \mathrm{F}\right.$. or below). The application of lime or formaldehyde to the tubers in storage is of no value in preventing rot.

The disease, then, is caused by a fungus carried to the field with infected tubers. The fungus spores produced on infected vines spread readily during moist weather to the other vines in the field and to neighboring fields, producing blight whenever infection occurs. Many spores fall from the vines to the soil below and are washed to the tubers, which upon infection sooner or later show the dry rot. When the soil remains wet, such tubers become invaded by other soil fungi and bacteria which bring about a soft malodorous rot.

As a result of many experiments it has been found that spraying the vines with bordeaux mixture is the best practical way to control the disease. Thorough applications made frequently during the summer to keep the new growth covered, especially before rainy periods, and in the late summer and the early fall, will prevent infection of the vines. If the vines do not blight, the tubers will not rot. More complete directions regarding spraying practices will be found under the chapter on Control Measures. 


\section{Rhizoctoniose (Plates X and XII)}

This is a name given to the several symptoms of a disease caused by the fungus Rhizoctonia, which when producing its perfect spores is known as Corticum vagum var. solani. The fungus forms small black irregular masses often the size of a half-pea or smaller on the surface of the tuber. These resemble little chunks of muck, but can be readily detected by washing the tuber, for they do not wash off as soil does although they can be easily scraped off. These bodies, called sclerotia, enable the fungus to pass the winter without injury. In the spring, when planted with the tuber or even when kept in a moist place, a fine mycelium grows out from them. This attacks the sprouts and produces cankers on them, so that the portion above is commonly destroyed. Younger sprouts may then appear from below the cankered area, but these in turn may be infected, so that the plants are late in making their appearance above the ground or do not appear at all. Affected plants that succeed in appearing may continue to grow and produce well. The fungus, however, commonly attacks and destroys the stolons and in this way reduces the yield. Older plants are sometimes weakened by cankers on the stems, and brown strands of mycelium may be observed over such affected areas. The cankers may be so severe that the vines become yellow in color and the leaves roll upward the same as when the vine is affected with blackleg. Indeed, in such cases the stem is sometimes found to be decayed by a black-rot similar to black-leg. Affected vines often have small aërial tubers formed in the axils of the leaves and the stems themselves are thickened. Such vines usually have a large number of small 

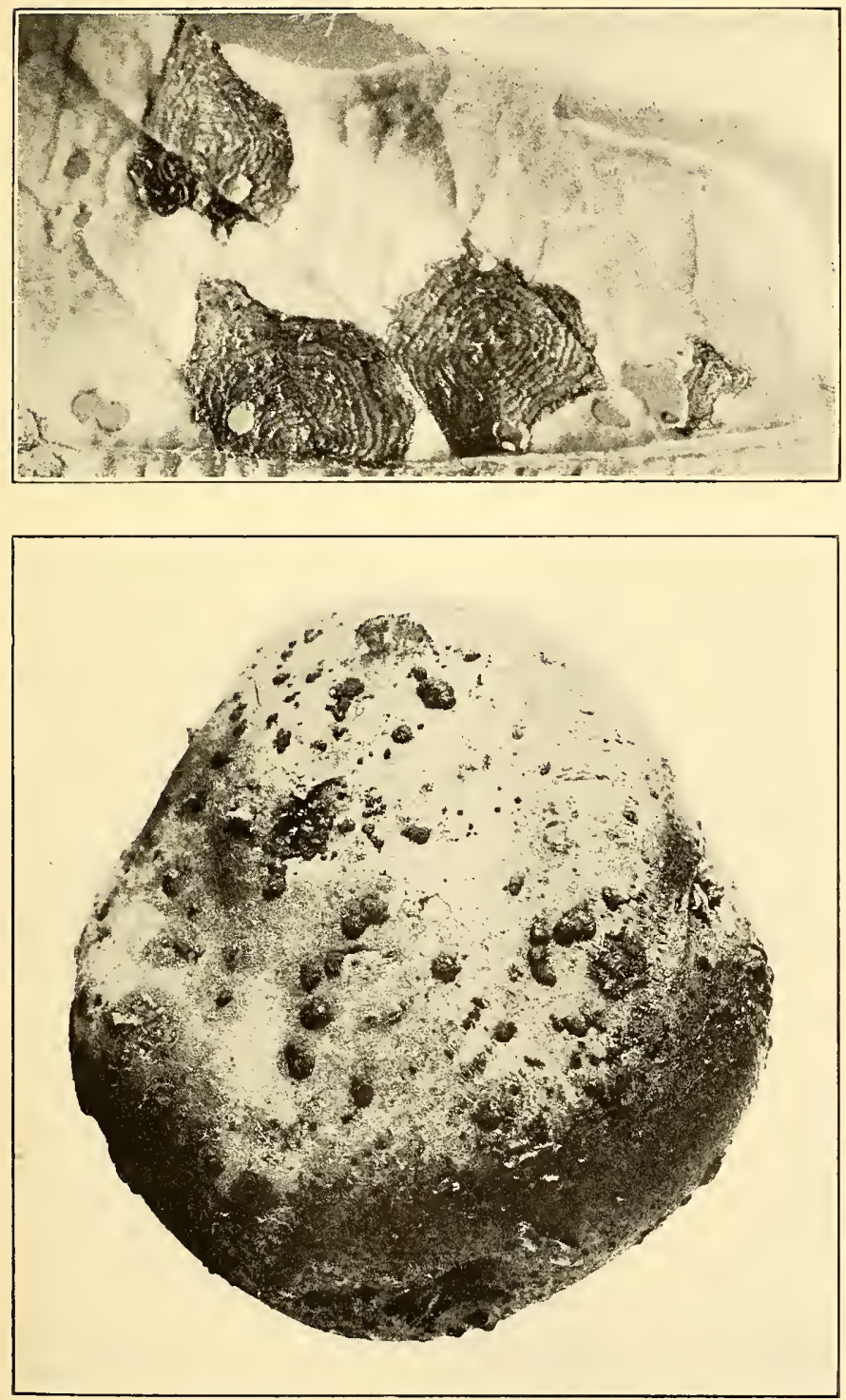

Plate X. - Potato diseases. Top, part of a potato leaf showing spots of early blight ; magnified. Bottom, rhizoctoniose.

(Courtesy Dept. of Plant Pathology, College of Agrieulture, Cornell University.) 

tubers clustered close to the base. The fungus produces its spores, during moist weather on a thin, white, frost-like growth extending over the base of the stalks.

This fungus is able to attack many kinds of plants and to live as a saprophyte in the soil from year to year. For this reason it is difficult, if not impossible, to eradicate it.

The sclerotia on the tubers can be killed by soaking the tubers in corrosive sublimate solution, and if this treatment is coupled with a judicious rotation of crops on the land, the injury from the disease will be greatly reduced.

\section{Fusarium wilt}

This disease is caused by the fungus Fusarium oxysporum, which gains entrance through the roots from infected tubers or from the soil and works upward in sap vessels, interfering in that way with the normal circulation of the sap. The fungus mycelium destroys the roots and, later, fruits on them, producing abundant spores. The diseased condition of its roots and of the sap vessel causes a yellowing, dwarfing and finally a wilting and dying of the vines. The stem pulls up easily and its tissues beneath the outer layer have a light brownish color. This color in the vascular tissues extends to the roots, stolon, and tubers. A section across an affected tuber near the stem end shows a brown ring of sap vessels. This browning of the vascular ring is associated with some other diseases and is always found in tubers in which this Fusarium has developed to any extent, although in the earlier stages of infection no discoloration may be noticed.

- Such diseased tubers should never be used for seed purposes, as vines coming from them nearly always become infected. The only successful way to control the 
disease is the selection of tubers from healthy plants and a wide rotation of crops as outlined under the chapter on Control Measures.

\section{Verticillium wilt}

This wilt is caused by the fungus Verticillium albo-atrum and shows symptoms much like the Fusarium wilt, and the two are very easily confused in the field. The fungus Verticillium gains entrance to the plant in much the same way and also inhabits the sap vessels of the plant. Affected plants show yellowing, wilting and dying of the leaves, beginning with the lower ones and progressing rapidly upward. The plants have a straggling appearance, usually die earlier than is normal and yield poorly. As with Fusarium wilt the tissues underlying the outer layers of cells show a brown discoloration, which in this case extends upwards into the branches as well as downward into the roots, stolons and tubers. The tubers show a blackened ring in a section of the stem end. The fungus passes the winter in such infected areas of the tuber and is also capable of living in the soil. The same methods of control should be practiced as for Fusarium wilt.

\section{Fusarium dry rot (Plate XI)}

This rot, caused by one or more species of Fusaria, is a dry rot extending deep into the tuber. The surface of the rotted area is much wrinkled and often shows numerous clusters of a white, moldy growth. The fungus gains entrance to the tuber through the skin wounds or through lesions caused by other fungi, so that the rot may occur at any point on the tuber. The powdery dry rot caused by Fusarium trichothecioides, common in 
(2)

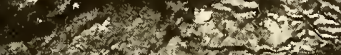

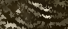

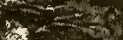

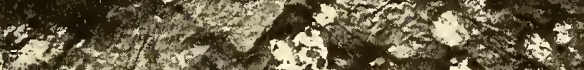

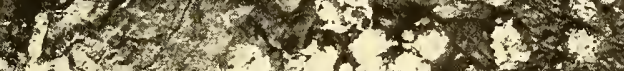

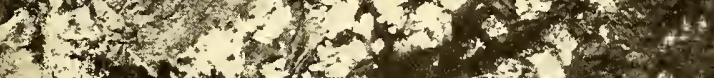

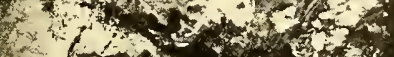

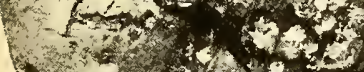

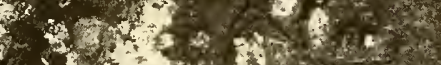

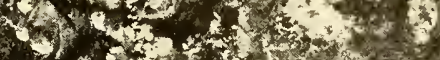

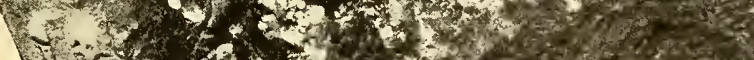
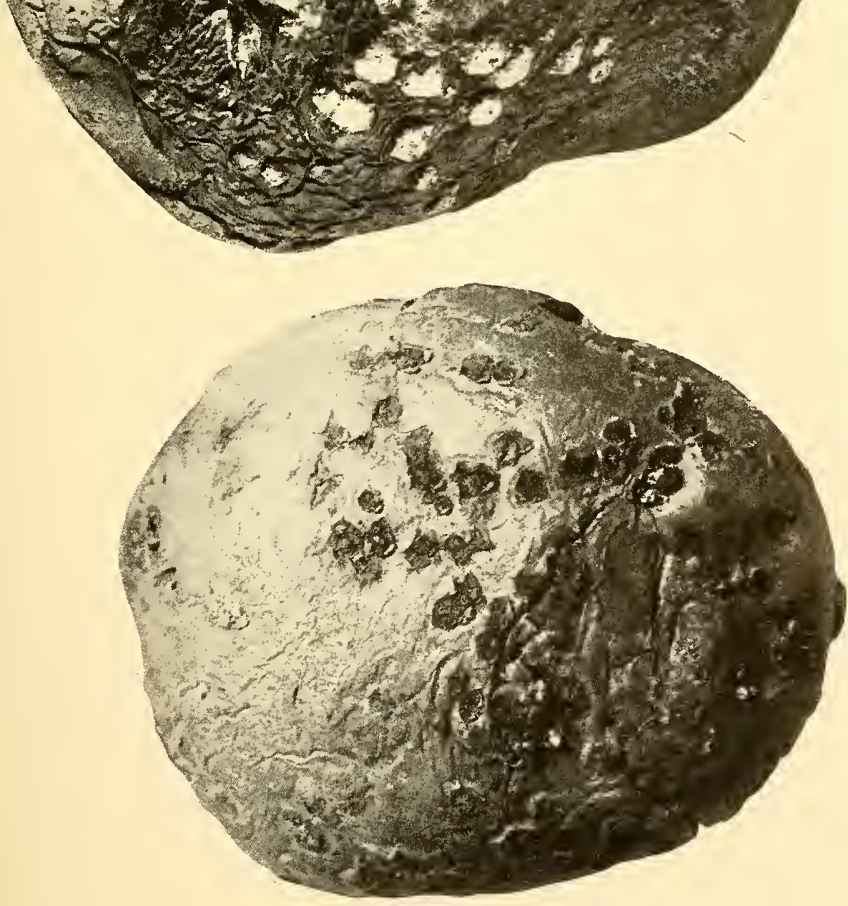

$\underset{\substack{\infty \\ \infty}}{\infty}$

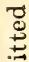

范

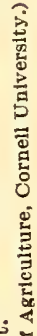

范范

要

过

范

을

范

要

龸

ค1

范

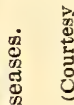



the western United States, "spreads rapidly in potatoes in transit to market or stored under unfavorable conditions." None of these dry rots is known to affect the vine to any extent. The fungi causing them will live in the soil and infect the new crop when an opportunity comes, so that in control all rotted tubers should be discarded for planting.

\section{Silver scurf}

This is caused by the fungus Spondylocladium atrovirens, recently introduced from Europe, and has been commonly observed in the United States. It shows as dark spots or areas on the surface of the tuber. In these areas fine black points are found which make up the sporebearing area. The fungus destroys the skin so that the moisture escapes and the affected tuber shrinks badly. The affected areas at this time and even before have a silvery luster, a character which gives the disease its name. The market value of such tubers is lessened, and they should not be used for planting, as seed treatment is apparently ineffective in destroying the fungus.

\section{Potato wart}

This disease, caused by one of the lower forms of fungi called Synchitrium endobioticum, does not appear in the United States and should continue to be kept out by strict quarantine measures. The disease has been known in Hungary since 1896. It has been found in many European countries and also in Newfoundland. It is reported to be very destructive and is very difficult to control, a long rotation of crops being the only measure recommended. 
The fungus causing the disease gains entrance into the eyes, which become black and swollen. "In more advanced stages one or more nodules, varying in size from that of a wrinkled pea to a lump as large or larger than the tuber itself, may be found. 'These are green where they project from the ground and white below, turning as they grow old to dark brown or almost black. They have a wrinkled coral-like appearance like the head of a cauliflower. 'A still more advanced stage occurs when the fungus has utilized every particle of food stored in the tuber and has reduced it to a brownish black soft mass, giving off a very unpleasant putrefactive odor.' Such potatoes cannot be harvested whole. The black pulpy mass breaks up, liberating millions of sporangia (spore-sacs) which live for years in the soil. These sporangia have been known to infect potato crops after an eight-year interval." 1

\section{Common scab}

Common scab, caused by a soil bacterium, Actinomyces chromogenus, is too well known to require detailed descriptions. The organism affects only the outer layers of cells, though there are deep scabs supposed by some to be caused by the same organism. It has been shown that gnats and possibly other insects may be responsible for the original deeper injury, though the scab may also be present.

The scab organism winters over on the scabby tuber, but may also live from year to year in the soil. Badly scabbed tubers should not be planted. Clean tubers, as well as those not badly scabbed, after being treated may be

${ }^{1}$ U. S. D. A., Farmers' Bul. 489. 


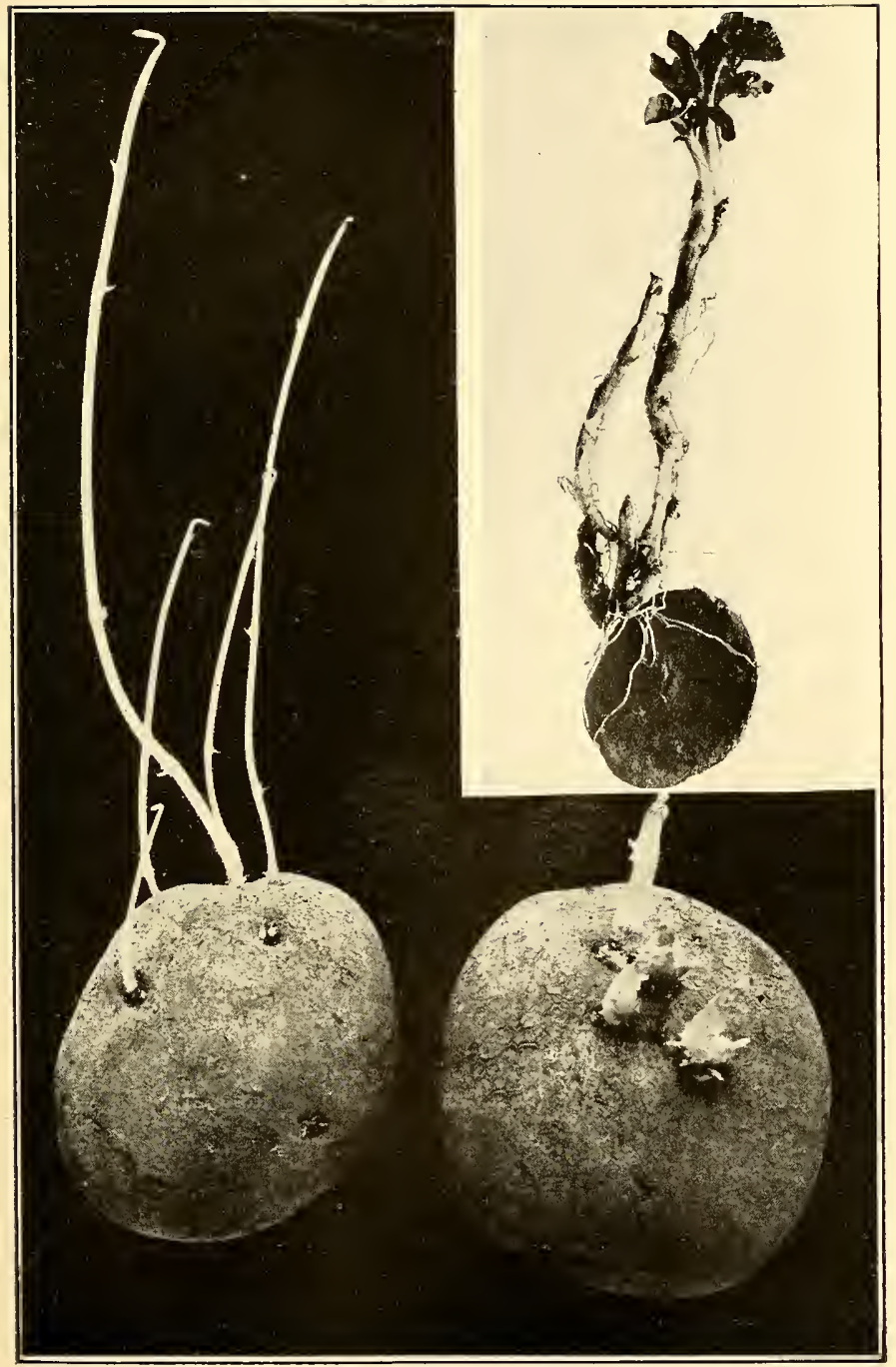

Plate XII. - Spindling potato sprouts; upper picture, the disease rhizoctiniose.

(Courtesy Dept. of Plant Pathology, College of Agriculture, Cornell University.) 

planted on land where crops have been rotated. Lime, wood ashes, manure and other materials giving alkaline reaction should not ordinarily be used on potato soil in connection with the growing of that crop. If it is necessary to apply any of these substances in order to grow other crops the application should be made in the fall after digging the potatoes. Manure may be applied best as a top dressing to the meadow.

\section{Black-leg}

This disease, which is caused by the bacterium Bacillus phytophorus, affects the vines and tubers. Infected vines have a lighter green color than is usual and have a stiff upright growth instead of the normal spread of foliage. The leaflets have a tendency to roll about the midrib. The plant also may be smaller than it would naturally be, though this is not always so. The base of the stem is quite black and somewhat shriveled. The diseased area commonly extends two or three inches above the ground, sometimes much farther. It also extends downward to the old seed tuber and may extend into the stolons and young tubers.

The affected tubers may show a stem-end black-rot, and when cut lengthwise sometimes show a black, foulsmelling center decay and even a hollowed condition. This center decay may be present with little evidence of it at the surface.

The disease is distributed mainly by affected seed tubers, or by bruised, cracked or decayed tubers harboring the organism. Control consists in the selection of seed tubers from healthy plants, in discarding bruised, cracked and rotted tubers, and in seed treatment. 


\section{Bacterial wilt}

Bacterial wilt, caused by the bacterium Bacillus solanacearum, is a disease that affects potatoes, tomatoes, eggplants and a few other solanaceous plants. It occurs mostly in the southern United States. The vines wilt suddenly, often on a single stalk, but later affecting the entire plant. The stems lose their bright green color and become shriveled and blackened. The vascular tissues, at an early stage, have a brown color somewhat similar to that described for Fusarium wilt. This color can be seen through the outer cells and extends upward as narrow black streaks, even out upon the leaf petioles and vines. When such stems are cut across, tiny drops of liquid ooze out of the vessels at the cut surface. These are of a dirty or yellowish white color, but not sticky or foul smelling. Examination with a microscope shows them to be swarming with bacteria.

This discoloration of the stem extends downward into the stolons and tubers. A section across an infected tuber at the stem end usually shows a blackening of vessels, making a dark ring around the cut surface of the tuber near the periphery. Bacteria similar to those found in the stem are present in these vessels of the tuber and later invade the other tissues, finally rotting the entire inside of the tuber.

The bacillus is carried from infected to healthy plants by insects that infest the potato vines. Probably this is the common means of dissemination. Control, therefore, would consist in destroying the insects as far as possible and in the early removal of infected plants from the field. 


\section{Powdery scab (Plate XI)}

Powdery scab is a disease of the tuber which is caused by a slime-mold, Spongospora subterranea. It may be easily observed at an early stage in young tubers as brownish colored blisters. These, later, show as pits filled with a brown powder, the spores of the parasite. These pits are bordered by the torn skin of the tuber. In storage the slime-mold may continue to be active, causing a dry sunken rot about the pit. A cankerous stage of the disease has been described as occurring in low, wet lands, in which case the deeper tissues of the tuber are invaded by the slime-mold and by other organisms, so that it becomes badly rotted. The disease has not been serious in the United States, and its development seems to be arrested in the warmer potato sections.

The parasite is disseminated by the distribution of affected tubers and by any agent upon which the spores may become lodged. The disease is difficult to control, but it is said to be materially reduced by seed treatment and rotation of crops. Affected tubers should be destroyed by burning or by boiling, and no tubers, even though healthy, coming from fields known to be infested should be used for planting.

\section{Tip-burn}

This is a disease characterized by a browning and shriveling of the tips and margins of the leaves. The trouble may become quite severe and greatly reduce the yield of tubers. It is often confused with blight, but it is not due to parasites, but to hot, dry weather following a period when the conditions of temperature and 
moisture favored a rapid growth of the vines. Cultural practices that aid in the conservation of moisture combined with frequent applications of bordeaux mixture will reduce the amount of leaf-area injured.

\section{Arsenical injury}

This is a burning caused by a heavy application of paris green or other insecticides containing free arsenious acid. The injury often resembles early blight, but is lighter colored and usually occurs about flea-beetle punctures or other injuries to the leaf, while early blight spots may occur on the otherwise uninjured leaf. The necessary amount of the more caustic poisons used with bordeaux mixture or with equal parts of lime should cause no burning.

\section{Spindling sprout (Plate XII)}

Spindling sprout is a disease characterized by very small, weak, needle-like sprouts coming from the eyes instead of large vigorous ones. Vines from such sprouts remain small and weak and only small unmarketable tubers are produced from such hills. It is believed that tubers becoming unduly heated by the hot soil during their growth produce sprouts of this character. If this is true, northern-grown seed is less likely to be affected.

\section{Net necrosis}

This name is applied to a diseased condition of tubers in which brown streaks occur within the tuber. These streaks are confined largely to the vascular system, though they do not appear as a dark ring on the surface of a cut across the tuber as is usually the case with other vascular 
diseases, but they may also be found within the central area of the cut surface. They may be found throughout the length of the tuber or be confined to the stem end. The exterior appearance of the tuber gives but little indication of conditions within. The vines also become affected, but the symptoms have not been studied carefully enough to differentiate them from those of wilt disease. No organism has been found associated with the streals in the tubers, but an organism has been found associated with affected stems and roots. Affected tubers should be discarded for planting as they may produce weak plants, but they are not unfit for food. The same or a similar disease is known in England as "Sprain" and in Germany as "Eisenfleckigkeit."

\section{Curly dwarf}

Curly dwarf is a non-parasitic disease characterized by a wrinkling and curling of the leaf-blade about the veins and midribs. Affected plants are usually dwarfed and die earlier than healthy ones, though all stages of the disease may exist in a field, and in some plants it may be so slight as to be hardly noticed. The yield in advanced cases is very much reduced. Tubers from affected plants, while they show no evidence of disease when planted, will produce vines that show a more advanced stage of the disease. Since the presence of the disease is partly responsible for reduced yields, no tubers from affected vines should be planted. The elimination of these can best be accomplished by inspection of the vines in the field about blossoming time of the plant, at which time affected hills should be removed or marked for removal. 


\section{Mosaic}

This disease is characterized br a crinkling of the foliage and br a mottled condition due to numerous small areas of the leaf-blade haring a lighter green color than is usual. In some plants this is not especially noticeable, for there are all gradations from healthy plants to badly diseased ones. The disease is more commonly found on white sprout rarieties and is said to reduce the rield materially. Since, like curly dwarf, it is transmitted br" means of the tuber, the same selection should be practiced.

\section{Leaf-roll}

Leaf-roll is the name given to a non-parasitic disease of the plant and is characterized by a dwarfing and a yellowing of the rines and by an upward rolling of the leaflets about their midrib. The leares hare a tendencr to point upward and are rather stiff to the touch. There are, perhaps, sereral types of the disease. In one trpe the lower leares at first show a tendencr to roll and be stiff though the plant is otherwise normal in appearance. In another type the foliage has a rellowish cast. The leaflets of the upper and rounger leaves point upward and roll and often show a rose or light purple color at the lower margins. There are all gradations of the disease, and the well-marked types show great reduction of growth and rield. The disease is transmitted br means of the tubers, so that rigid selection in the field is necessary to aroid it.

The cause of curly-dwarf, mosaic and leaf-roll is unknown. Many theories have been advanced to explain them, but it is unnecessary to discuss them here. All 
three diseases are evidently widespread and may be important factors in causing reduced yields and "running out" of potatoes. Tubers from such vines are usually small. For this reason the selection of small tubers from the bin is likely to increase the percentage of such affected plants. It is possible to avoid them by the selection outlined in the chapter on Control Measures.

Constitutional degeneracy and other weakened conditions of plants

Constitutional degeneracy is a name given to a condition of weakness of growth showing as small, of ten spindling stems producing but a few small tubers to a hill. Such a condition is inherent in the plant and is inherited by the progeny. This trouble may be confused with similar conditions associated with the non-parasitic diseases already enumerated. Very small, spindling plants producing no commercial tubers are often found to be associated with an early rotting of the seed tuber after being planted, and similar plants sometimes appear when the only eye on the piece of tuber is near the cut surface. Rotting of tubers may be due to such practices as keeping cut tubers undusted a week or more before planting and as planting cut tubers in hot soil or leaving them exposed to the sun after hand-planting. Avoiding such practices may be of assistance in reducing the number of weak plants in the field, but tubers from degenerate hills should never be used for seed. The elimination of these can be accomplished to some extent by grading, but selection from the field is the surest way. 


\title{
CHAP'TER XI
}

\section{CONTROL MEASURES AGAINST DISEASES}

\author{
By M. F. Barrus
}

IT will be noticed from reading the preceding pages that for some diseases the selection of seed tubers is advised and for others seed treatment, crop rotation or spraying is recommended. It may be necessary to practice more than one control measure in order to control some diseases. For the seed potato grower, it is desirable and is becoming more and more necessary that all measures be employed that will tend to produce sound tubers free from all diseases. Detailed directions for carrying out these measures are given in these pages.

\section{Control of curly-dwarf, mosaic and leaf-roll}

As has already been pointed out, such diseases as curlydwarf, mosaic and leaf-roll, transmitted by the tubers, cannot be detected by the appearance of the tuber outside or within. There is very little or no outward evidence on tubers affected with Fusarium and Verticillium wilt, bacterial wilt and net necrosis, and occasionally on some tubers affected with black-leg. Even a section of the stem end will sometimes fail to reveal the presence of these last-named diseases. In such cases, it is very 
necessary, if these diseases are to be avoided, to inspect the field one or more times during the growing season in order to detect the affected hills from the appearance of the vines. If only one inspection can be given, this should be made at about the blossoming time, because the nonparasitic and other troubles can be best detected at this time. A second inspection before the vines die will often reveal diseased vines that could not be seen earlier. At the time of inspection all diseased hills should be marked for removal before digging the others in order that they may not be mixed with them. If there is a considerably large percentage of them, more than 10 or 15 per cent, the crop should not be used for commercial seed purposes. The grower, however, may select from such a field plants that are healthy for his own seed, and these should be dug before the others and stored by themselves.

\section{Field inspection}

The grower may feel that he is unqualified to do such inspection himself, but certainly he can detect poor hills, and with a little instruction from an expert can learn to distinguish the various diseases. If, however, individual farmers growing seed potatoes for sale make their own inspections, there will be a great diversity of standards, hence it is more practical for one man to inspect all the fields in a certain locality. Such a man should be trained for the work. He may be employed by an association of potato-growers or by some other organization, or he may be an official inspector of the state or country employed to inspect fields, and tubers after digging, for the purpose of certifying them. Some such method will greatly improve the seed stock, and the grower of such stock will 
not only be able to secure better prices, but will increase his own yields because of the use of better seed. The time will not be long before the southern potato-grower will demand seed tubers certified by some responsible organization, and poor seed will find a market for table stock or some other purpose.

Not all the vines thought to be healthy in the field will produce satisfactory seed tubers. There may be hills among them that produce a small number of marketable tubers, and these should be eliminated from seed stock, if possible. However, this can be done only by digging each hill separately and selecting tubers from desirable hills, as explained in an earlier chapter. Growers should do this whenerer possible to improve their own seed, but, to improve further the seed stock for sale, much can be done by grading because of the small tubers, many of which come from weak or diseased hills. Growers at planting time should discard all rotted, bruised or badly scabbed tubers, for these are not as satisfactory as healthy, smooth ones, eren when treated.

\section{Seed treatment to prevent disease}

Seed treatment as directed will destroy organisms living on or anchored on the surface of the tuber. For this reason, it is to be advised when such diseases as common scab, powdery scab, rhizoctoniose and black-leg are troublesome. Treated tubers often give a better stand because rot organisms, ordinarily saprophrtic, found on the surface of the tuber are destroyed. Treating the seed also eliminates the danger of introducing disease organisms into new soil or soil that has been freed from them to a greater or less extent. Few growers have 
believed that these organisms introduced with the seed affect not only the crop of that year but remain in the soil to attack subsequent crops of the same or other kinds.

Treating seed tubers is not as troublesome as some farmers think. The treatment, if desired, can be made several weeks in advance of planting, but less handling is necessary if it is made immediately before cutting. Where one has only one hundred bushels or less to be treated, it is convenient to place two or more barrels on a platform, which should be high enough to draw the solution off through a hole near the bottom of the barrel. The potatoes are dumped into the barrels and are covered with the solution, which may have been prepared in another barrel. One barrel of solution will cover two barrels of potatoes. After they have soaked the required length of time, the solution may be drawn off at the bottom and emptied into the barrel in which it was prepared. The treated tubers can now be emptied on to the ground to be dried, but care should be taken that they are not overheated by the sun. The barrels can be filled again witl potatoes and the same solution used once more. While waiting for this lot to soak the tubers already treated may be cut for planting. This saves time. By using two barrels, it is possible for one man to treat about 50 bushels of potatoes in a day and have time to cut tubers for planting between treatments. Two men can treat about 250 bushels in one day by the use of 10 barrels in making the treatment.

Either formaldehyde or corrosive sublimate may be used. The former is much cheaper, less poisonous and can be used in metal vessels if desired, but it is not as effective in destroying the sclerotia of Rhizoctonia as corrosive sublimate. A pint or pound of 40 per cent form- 
aldehyde, costing about 30 cents, should be diluted with 30 gallons of water. This can be used over and over again for at least ten times without losing strength, but the quantity will, of course, be diminished with each treatment. The tubers should be soaked in it for two hours. A longer time may injure the sprouting power of the tuber. When corrosive sublimate is used, four ounces of the dry powder, costing about 50 cents, should be used to 30 gallons of water. The powder should first be dissolved in a quart or two of warm water and then added to the other. It dissolves more slowly in cold water. The solution should not come in contact with metal, as it reacts with it and loses strength. Neither should it be used more than three times in treating potatoes unless renewed with fresh solution, for it loses its strength rapidly with use. Tubers should be soaked in it for at least one and one-half hours, but never longer than five hours. Great care should be taken in its use, for it is exceedingly poisonous. Treated tubers should never be used as food.

Where one has large quantities of tubers to be disinfected at one time, the formaldehyde gas treatment may be used. For this purpose the tubers should be placed in crates or in shallow slatted bins so as to permit the free movement of gas about them. The disinfecting room should be made as air-tight as possible. Spread potassium permanganate evenly over the bottom of a large deep pan or bucket. Twenty-three ounces should be used for each 1000 cubic feet of space within the room. Pour over the permanganate three pints of 40 per cent formaldehyde for each 1000 feet of space. Give the pan a tilt, leave the room as quickly as possible, and close the door tightly, leaving it closed for 24 hours or, at least, over night. The door can then be opened and the room aired 
out, after which the potatoes may be handled as any other treated tubers. The following recommendations should be observed by those using this method. Make the treatment before the potatoes sprout. Place the generating pan so that no potatoes are within three feet of it and none directly above it. Use at least 167 bushels of potatoes for each 1000 cubic feet of space or injury will result to the tubers. This injury shows as a pitting about the lenticels. Do not attempt treatment when the temperature of the room is below $50^{\circ} \mathrm{F}$. It is most affective at $80^{\circ} \mathrm{F}$. Thoroughly wet the floor of the disinfecting room with boiling water just before adding the formaldehyde to the permanganate, as moisture in the air of the room is very essential for effective work. Do not attempt to treat potatoes in sacks or piled high in bins.

The question often arises as to whether the crates or bags in which the tubers are to be carried to the field should be sterilized or whether cutting-knives should be often disinfected. It is possible for spores of the organisms causing potato diseases to be carried on containers or implements and later come in contact with the tuber under such conditions that infection may take place. The writer is of the opinion that infection in this manner does not frequently take place, but if one desires to avoid every possible contamination, this disinfection will be necessary. It may even be desirable when such diseases have been very troublesome, but ordinarily it is not necessary, although one should use judgment in the matter.

If potatoes are cut more than a few dlays in advance of planting, they should be dusted to prevent decay from the action of saprophytic bacteria under favorable conditions of heat and moisture. While other kinds of dust will prevent the decay, flowers of sulphur is preferable as 
it has fungicidal properties. Indeed, it has been shown that when sulphur is used in sufficient quantities, it aids in the reduction of powdery and common scab. Gypsum makes a satisfactory material for dusting, but lime in any form should not be used for this purpose as it may induce scab.

\section{Disease from organisms already in soil}

It must be remembered that seed treatment, while it destroys certain pathogenic organisms on the surface of the tuber, does not insure immunity of the crop from these diseases. Many of these organisms also live in the soil from year to year, and these are as able to attack plants coming from treated as from the untreated seed. The treated seed must be planted in soil that is free from these organisms or where they are much reduced or in an inactive condition. It is impractical to sterilize soil for growing potatoes, although for greenhouse and other valuable crops it is considered to be a good practice. The application of chemicals to the soil that will destroy or retard the growth of these organisms has not given very satisfactory results. Sulphur applied at the rate of 450 to 900 pounds to the acre has reduced the amount of scabby tubers to a considerable extent, but it may also reduce the yield. It has been observed that clover will not grow in soil treated in this way. Fertilizers such as lime, which increase the alkalinity of the soil, greatly favor the development of scab, while acid phosphate, sulphate of ammonia and the like, at least, do not increase scab injuries.

When potatoes are grown year after year upon the same land, the parasites, especially those that live in the soil, are likely to increase unless one constantly guards 
against them. On the other hand, if the potato crop is alternated with other crops or can be grown in a threeto five-year rotation, these parasites depending upon the potato for food will be starved out during the intervening years. Unless such parasites are introduced again by planting affected seed, or with manure containing these organisms, or with infected soil washed or carried on to the land, the potato crop planted in a rotation should be comparatively free from them.

This would be the case were it not the habits of some organisms like Rhizoctonia to live on hosts other than the potato, or of others like the scab organism to live from year to year on dead organic matter in the soil. However, a rotation aids in reducing these organisms when they are troublesome, and for this reason, if for no other, should be practiced when possible.

Often there are a large number of missing hills in a field caused by the decay of the seed tuber from attacks of Rhizoctonia, or for other reasons, causing the total yield to be materially reduced. This is especially true when the tubers are planted in hills or at distances greater than 18 inches in the row. When the tubers are planted close together, a missing hill does not mean a complete loss, because the neighboring hills, having more room for growth, will produce a larger yield. Some farmers have found it profitable to replant missing hills with tubers that have been greened, i.e. left in the light so that they have stubby green sprouts. Such tubers when planted grow rapidly and are not much later than the ones planted first and not greened. Greening potatoes is a good practice, for such tubers will give a better stand than those not greened.

There are diseases, such as early and late blight, that occur under favorable weather conditions and do much 
damage even though the seed has been carefully selected and treated and other precautions taken.

\section{Treatment for potato blight}

The blight-rot fungus is not destroyed by seed treatment, and slightly affected tubers may be overlooked in sorting. Blight spores, being easily carried by air currents, are readily disseminated from one field to another and bring about an infection if wet weather prevails. It must be remembered that the tubers are infected by spores produced on blighting vines. Hence, to prevent this rot from occurring, it is necessary only to prevent the rines from blighting. The rines will not blight, even under very favorable weather conditions, if the spores do not gain entrance into their tissues. The spores cannot enter the leaves if the vines are thoroughly sprayed with bordeaux mixture before the spores have germinated. As they germinate only in the presence of moisture, the applications need be made only before moist conditions prevail, that is, before rainy periods. "The grower should not hesitate to spray at such times for fear that the mixture will be washed off. It dries rapidly, and once dried on the rines, enough remains even after heary rains to protect them from the fungus."

Every susceptible part of the vines should be protected by the mixture. To do this effectively, it is necessary that the mixture should come from the nozzle as a fine mist and settle over every leaf and stem like a fog. Such a mist can be produced with a satisfactory nozzle and with good pressure.

One application thoroughly done will protect the parts receiving it for a long time, but new leaves appear, and 
these must be protected by subsequent applications. These applications should be continued as long as growth of the vine takes place. Even when the vines cover the space between the rows and driving through will injure them, the spraying must be done. Less loss will result from injured vines than from rotted tubers. On loamy ground, the injury to the vines is not so great as one would think. Some ingenious farmers have devised a means of pushing the vines away from the wheels by attaching rake teeth on each side of each wheel. Manufacturers of spraying machinery should be able to devise some means of overcoming this objection to spraying.

From five to eight applications, depending upon weather conditions, should be made during the season. The first should be given when the plants are six to eight inches high or when a poison is applied to kill the bugs. For the early applications 50 to 75 gallons of mixture to the acre will be sufficient, but later in the season it will require 100 gallons or more. Enough should be applied to do a good piece of work even though it takes 150 gallons. The operator should determine this. Nozzles capable of delivering this amount of liquid as a mist must be the only kind employed, although pressure has much to do with fineness of the mist. From 70 to 80 pounds of pressure will make a fine mist with vermorel nozzles if there are not too many used at a time, while it will take 100 to 150 pounds of pressure to get a good mist with an equal number of disk nozzles. But the vermorels do not have the capacity that disk nozzles do and more are required to do the same work. One disk nozzle will do good work at first, but two should be employed later on and then should be so adjusted that the spray is directed at an angle rather than straight down upon them. The 
pump of the machine should be capable of maintaining a uniformly high pressure. These are factors that must be considered in buying or constructing a machine. Other points are of secondary importance. For small fields of an acre or less, a small compressed air spray may be used.

The operator should see that the mixture gets on to the vines. It is of little value applied to the soil. It occasionally happens that a nozzle becomes clogged, and the vines below are not being properly sprayed. One cannot hope to spray a field adequately by merely driving through it. Much depends on the interest taken by the driver. One can best determine whether the application is thorough by examining the vines after spraying them.

Various strengths of bordeaux mixture have been recommended. The $5: 5: 50$ formula is commonly used on potatoes. Experiments have shown that the spores of the blight fungus ean be prevented from germinating at a much weaker strength, so that there is little doubt that the blight can be controlled with bordeaux mixture at $2: 2: 50$ or $3: 3: 50$. When copper sulphate is very expensive, as at present, larger profit can doubtless be secured with a weaker mixture than with a stronger one, which may give slightly increased vields from greater stimulation.

For many years potato spraying experiments have been conducted in several states. The bordeaux mixture has been prepared in various wavs, and used at different strengths. The experiments have been conducted on experiment station grounds and on farms in various parts of the country. These applications have been made by scientific men and by farmers with hand machines and with traction sprayers. The conclusion in nearly every case has been that it pays to spray with 


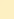




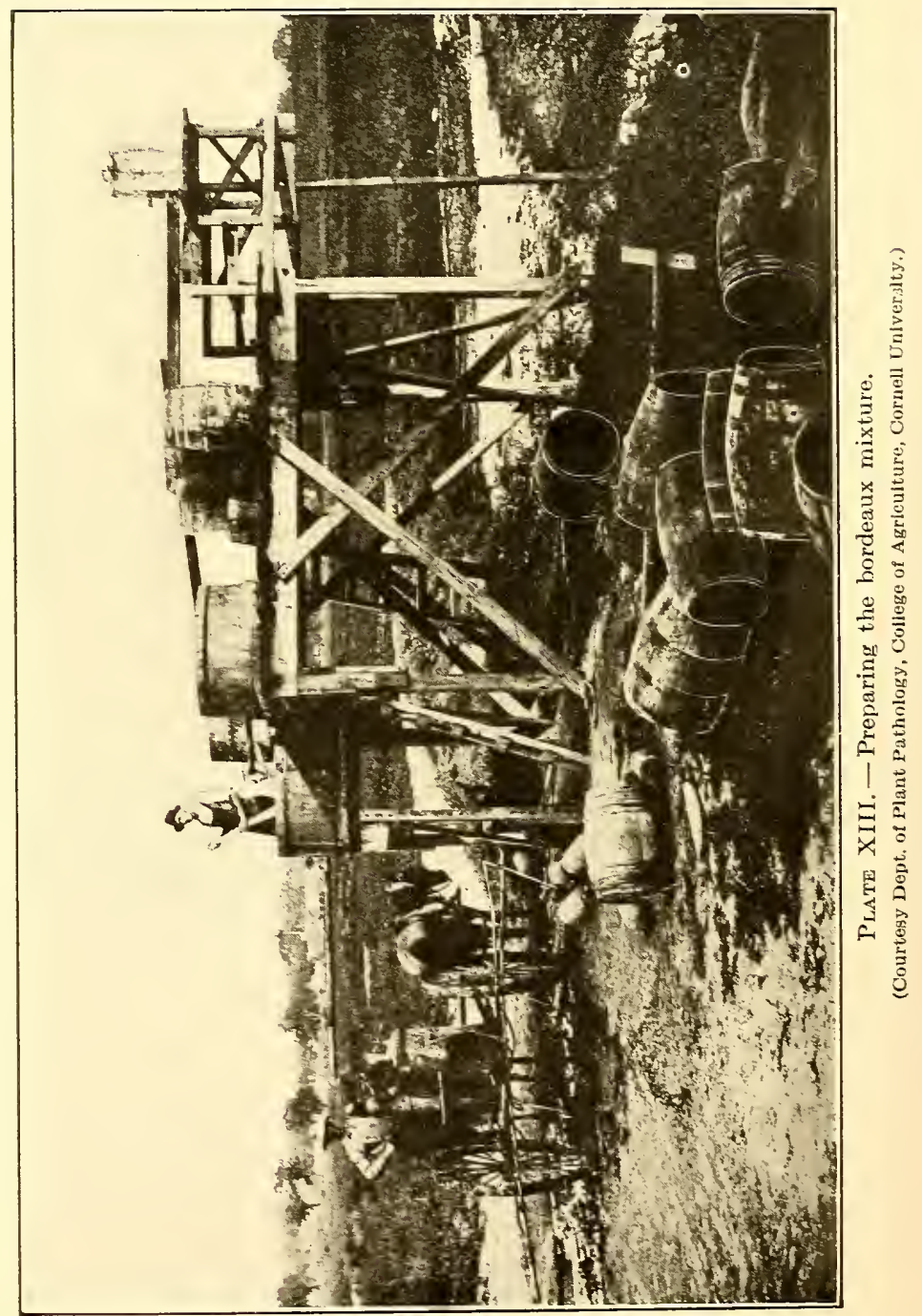


bordeaux. There have been years when certain fields have shown no increase from spraying, but usually a sufficient increase has been obtained, if the spraying has been well done, to pay for the cost of the applications. Even in years when the blight is absent, the application of bordeaux appears to stimulate the vines, for they are greener and remain alive longer than unsprayed vines. Bordeaux also acts as a repellant to the flea-beetle and reduces the amount of tip-burn and so protects the leaves from various injuries. In years when blight is present, the evidence is greatly in favor of spraying. One cannot tell with any certainty when blight will come, so one should practice spraying as a protection. Growers should accept the evidence and make spraying of potatoes with bordeaux a general farm practice every year whether wet or dry on both early and late varieties.

\section{Preparation of bordeaux mixture (See Plate XIII)}

Bordeaux mixture can be purchased on the market as a paste or powder. Usually most of the proprietary mixtures contain in addition an arsenical poison for killing biting insects. They are prepared for spraying by the simple addition of water to a given quantity of material. For this reason they are convenient to use and also safer when one needs to depend on irresponsible help to do the work. Howerer, these do not stay in suspension as well as bordeaux properly made at home, and they are more expensive. Home-made bordeaux, according to most comparative experiments, is the most satisfactory. Its preparation is easy and inexpensive and one requires but a short time, when the apparatus for making it is once constructed. The following directions with a few addi- 
tions are taken from the New York Cornell Agricultural Experiment Station, Circ. 19, 1913.

The best bordeaux mixture is made by mixing a dilute solution of copper sulphate (blue vitrol) with a dilute milkof-lime. The mixture may be made of various strengths by using different amounts of copper sulphate and lime to a given amount of water. A combination of 3 pounds of copper sulphate and 3 pounds of lime to 50 gallons of water is probably strong enough to control the blight, but because of the stimulating action of bordeaux mixture on the potato plant, a strength of 5 pounds each of copper sulphate and lime to 50 gallons of water is usually recommended. This is indicated by the formula $5: 5: 50$. In order to make the bordeaux mixture of any strength, the procedure should be as follows :-

A stock solution of copper sulphate should be made in a barrel from 45 pounds of copper sulphate dissolved in 45 gallons of water. A gallon of the solution will then contain about one pound of copper sulphate. If the crystals, placed in a gunny sack, are suspended so as to be slightly beneath the surface of the water, they will dissolve in three or four hours.

A stock mixture of lime should be made from a bushel of good stone lime placed in a barrel and slaked by the gradual addition of water. Care must be taken not to "drown" the lime. When it has become pulverized by the slaking, water is added to make a paste, and then enough more water may be added to make 45 gallons. This should not be allowed to dry out. Hydrated lime (which is already slaked) may be used in place of stone lime, but air-slaked lime should never be used.

Another barrel or larger container or even the sprayer tank itself may be used for mixing the bordeaux. What- 
ever container is used should be filled three-fourths full of water. If a $5: 5: 50$ solution is desired, 5 gallons of copper sulphate stock solution should be added to this water for every 50 gallons of mixture to be made. The solution requires stirring until it is well diluted, after which 5 gallons of the stock mixture of milk-of-lime should be added to each 50 gallons of mixture. The lime-water should be run through a strainer in order to prevent the larger particles of lime from getting into the sprayer tank. While the milk-of-lime is being added to the dilute copper sulphate solution in the sprayer tank, the material in the container should be stirred constantly. The sky-blue bordeaux mixture will result. Enough water to make the required amount of mixture must be added to it.

It is often more convenient, although not necessary, to make the bordeaux on an elevated platform so as to allow the mixture to run by gravity into the sprayer tank (see Plate XIII). When such a platform is provided, it is easily possible to dilute both the stock copper sulphate solution and the stock lime solution in separate containers before mixing them by allowing them to run together. This method makes a bordeaux that stays in suspension a little better than that made by diluting but one stock before mixing. In case the latter method is used the required amount of stock in each case should be diluted with onehalf the amount of water necessary to make the mixture.

The mixture should now be tested with a few drops of a solution of potassium ferrocyanide. This is made from crystals of potassium ferrocyanide dissolved in soft water. Five cents' worth of crystals dissolved in a pint of water will provide enough of the solution to last throughout the season. Should a brown precipitate result when a few drops of this solution are added to the bordeaux 
mixture, it would indicate that more lime-milk is needed to neutralize the copper sulphate solution. When sufficient lime is added, no brown precipitate will be formed by the potassium ferrocyanide solution. Bordeaux mixture will burn the foliage of plants if it is not properly neutralized. It is unnecessary to measure the milk-oflime in making bordeaux mixture if the mixture is tested from time to time with the ferrocyanide solution while adding the lime. The test will indicate when sufficient lime is present.

When it is necessary to spray with a poison in order to kill potato beetles and other biting insects, the required amount of poison may be added to the bordeaux mixture.

\section{Other remedies}

Soda bordeaux, in which an equal amount of sal-soda is used in place of lime, has been employed by some potatogrowers, but carefully conducted experiments indicate that other preparations with copper compounds are inferior to lime. Dry bordeaux applied as a dust has not proved to be a satisfactory fungicide. Lime sulphur solution is also unsatisfactory and unsafe. Where it has been used in experimental work, potato plants sprayed with it have given smaller yields than the unsprayed ones. Powdered sulphur and arsenate of lead or arsenate of zinc have been tried in New Jersey on early potatoes, but have been found to be less satisfactory and more expensive than bordeaux mixture.

Fusarium dry rot and other rots are caused by organisms that gain entrance to the tuber through wounds. Potatoes with tender skin loaded into cars in hot weather soon after digging often rot badly. Care in handling the 
tubers is necessary if one wishes to avoid these troubles. Provisions for ventilation should be made when the tubers are placed in storage. A potato tuber contains living protoplasm which gives off carbon dioxide, water and a certain amount of heat, and when provision is not made for ventilation, black-heart or center decay may occur.

\section{Disease-resistant varieties}

These various control measures have been discussed because it is necessary to adopt some or all of them if one is to grow healthy tubers. However, each practice adds to the cost of producing the crop. If such measures do not increase the yield or add to the value of the tubers, they are not worth putting into practice. If it were possible to obtain potatoes that would not become diseased even when subjected to the parasite under favorable conditions for infection, much labor and expense would be saved. It is well known that certain individual plants as well as animals have shown marked resistance to diseases that ordinarily occur on their kind. By selection and breeding, it has been possible to obtain highly resistant plants producing crops of good quality. Notable examples are wilt-resistant melons, cotton and flax, rustresistant wheat and anthracnose-resistant beans. For several years scientists have been endeavoring to secure a satisfactory strain or variety of potatoes that is blight resistant. Some varieties have been secured that have shown a fair degree of resistance to blight or rot. Unfortunately, a variety that seems to show a slight degree of resistance to blight may show considerable susceptibility to rot, and varieties showing resistance to early blight may be subject to late blight. William Stuart of the 
Department of Agriculture, Washington, D. C., has reported certain varieties that have shown considerable resistance to both early and late blight. These are Apollo, Sophia, Professor Wohltman and Max Eyth. They are all foreign varieties and under conditions of climate and soil in the United States they succeed very poorly, being light yielders and rather poor in quality. Stuart remarks that it would seem as if high diseaseresistance of the vine was correlated with low yield and undesirable tubers. He found no varieties tested to have strongly marked scab-resistant qualities when grown in soil well infested with the scab organisms. He believes that the value of disease-resistant varieties is problematical, but that the plant-breeder, by mating them with the most desirable commercial American types, may develop commercial types of resistant varieties.

\section{Summary}

It may be well to summarize control measures in the following way:-

What selection does. - It aids in eliminating curlydwarf, leaf-roll, mosaic, the various wilts, black-leg and other diseases showing on the vines and also transmitted by the tuber. It eliminates low-yielding hills. It eliminates impurities in a variety.

What seed treatment and rotation do. - They reduce injury from rhizoctoniose, scabs and black-leg. They increase the stand of potatoes in the field.' They give clean tubers.

What spraying does. - It prevents early and late blight. It prevents the blight rot. It reduces injury from tip-burn. It repels flea-beetles. It kills the bugs. 
It stimulates the vines to longer periods of growth. It gives increased yields.

\section{REFERENCES}

Duggar, B. M.

1909. Fungous Diseases of Plants. (Ginn \& Co.), 1-508, Figs. $1-240$.

Gloyer, W. O.

1913. The Efficiency of Formaldehyde in the Treatment of Seed Potatoes for Rhizoctonia. New York (Geneva) Agri. Expt. Sta. Bul. $370: 417-431$, pl. 1. .

Jones, L. R.

1899. Certain Potato Diseases and Their Remedies. Vt. Agri. Expt. Sta. Bul. 72: 3-32, Figs. 1-17.

Jones, L. R., Grddings, N. J., and Lutman, B. F.

1912. Investigations of the Potato Fungus. Phytophthora Infestans. U. S. D. A., Bur. Pl. Ind., Bul. 245 : 5-100, Figs. 1-10.

LUTHAN, B. F.

1911. Twenty Years Potato Spraying for Potato Disease. Potato Diseases and the Weather. Vt. Agri. Expt. Sta. Bul. 159: 215-296.

Lutman, B. F., and Cunningham, G. C.

1914. Potato Scab. Vt. Agri. Expt. Sta. Bul. 184: 3-64, Figs. 1-6, pls. 1-12.

Mann, Tros. F.

1911. The Fusarium Blight Wilt and Dry Rot of the Potato. McAlpine, D. Ohio Agri. Expt. Sta. Bul. 229 : 229-336, pls. 1-15.

1911. Handbook of Fungous Diseases of the Potato in Australia and Their Treatment, with 158 figures. Dept. of Agriculture, Victoria.

Melhus, I. E.

1913. Silver Scurf-A Disease of the Potato. U. S. D. A., Bur.

Melhus, I. E.

Pl. Indus., Circ. 127: 15-24, Figs. 1-4.

1914. Powdery Scab (Spongospora sulterranea) of Potatoes. U. S. D. A., Bul. 82 : 1-16, pls. 1-2. 
Meturs, T. E.

1915. Hibernation of Phytophthora Infestans of the Irish Potato. I. S. 1. A., Jour. of Igri., Research l3ul. 5: 71-102. Figs.

MELIIT, 1. E. $1-3$, pls. $1-8$.

1916. Germuntion and Infestion with the kungus of the Late Blight of Potato. Wiscomsin Agri. Expt. Sta., Rescarch Bul. : ic: 1-6t, Figs. 1-S.

Molist, W. J.

1909. Bhack-leg- L Bacterial Disense of the Irish Potato. Maine Igri. Expt. Sta. Bul. 17-t: 309-3̈:s.

Mokse, W. d.. and Sulpoveroy, M.

1914. The lihizoetonia Disease of the Potato. Maine Agri. Expt. Sta. Bul, 2iv0: 193-216, Figs. 61-73.

Morise, II. J.

19lt. Powdery Seab of Potatoes. Maine Agri. Expt. Sta. Bul.

Mux, M. 'T. 2.7: $: 59-104$, Figs, $4-50$.

1912. Lime Sulfur re. Bordeaux Mixture as a Spray for Potatoes. lart 11. Now Lork (Genera) Agri. Expt. Sta. Bul. $35: 2: 319-326$.

Onток, W. A.

1913. Potato 'Tuber Disease. U. S. 1). A., Firmers' Bul. 54t:

Ortox. II. A. $3-16$. lips. $1-16$.

191-t. Potato Wilt, Leaf holl and Related Disense. U. S. 1. A., Bul. 6t: 1-ts, pls. 1-1t.

Surru, b. F., and swixtile, 1). 13.

19(-). 'The Dry liot of Potatoes due to Fusarium Oxysporum. L. S. 1). A., Bur. Pl. Indus., But. 55:3-tit, pls. 1-s.

SМтн, Е. F.

1596. A Bacterial 1)iseise of the 'Tomato, Eggelant and Irish Potato. I. S. D. A., Div. Veg. Phys. and Path., Bul. $12: 3-205$.

STEYEX, F, L., and Hal. J. G.

1913. Disenses of Economic Plants. (The Macmillan Co.). New lork, 1-513, Figs. 1-21t.

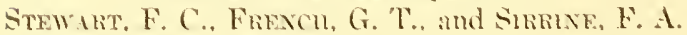

1912. lotato Spraving Experiments - 1902-1011. New Jork (Geneva) Igri. Expt. Sta. Bul. 349: 99-139. 
Stewart, F. C., and Gloyer, W. O.

1913. The Injurious Effect of Formaldehyde Gas on Potato Tubers. New York (Geneva) Agri. Expt. Sta. Bul. 360 : $385-416$, pls. 1-2.

Strwak, F. C., and Sirime, F. A.

1915. The Spindling Sprout Disease of Potatoes. New York (Geneva) Agri. Expt. Sta. Bul. 399 : 133-143, pls. 1-3.

STEWART, F. C.

1916. Observations on Some Degenerate Strains of Potatoes. New York (Geneva) Agri. Exp. Sta. Bul. 422:319Stuart, Wn. 357, Pls, 1-12.

1914. Disease Resistance of Potatoes. Vt. Agri. Expt. Sta. Bul. 17!) : 147-173, Figs. 1-8. 


\section{CHAPTER XII}

\section{HARVESTING THE POTATO}

There are several important considerations bearing upon the harvesting of the potato crop. These must be kept in mind when one is planning the time and method of harvesting, if the best returns are to be realized. Improper attention to any of these points may result in a very material decrease in the crop.

In the first place, the harvesting should be done at such a time and in such a manner as to give the maximum yield of tubers possible for that season. This means that we are to let the processes of starch formation and storage go on as long as they will. Secondly, we should aim to employ such methods as will give us potatoes of the best cooking and keeping qualities. And thirdly, we must eliminate, as far as possible, all traces of disease from the crop. Each operation in the process of harvesting should be carried on with careful consideration of its effect on total yield, quality and disease.

\section{Time to harvest}

The time of harvesting is influenced by the weather conditions and by the kind of potatoes grown. In general, one does not need to be as particular with early potatoes as with the late varieties. Early potatoes may be dug as soon as they are large enough to eat. Late potatoes, 
generally speaking, should be left in the ground as long as is possible without freezing. It should be remembered that starch is being formed and stored as long as the tops of the plants are green. To harvest the crop before the tops die, therefore, means a loss in quantity of potatoes. Early varieties may be dug a week or two before maturity, providing the higher price a bushel more than compensates for the decrease in yield. Late potatoes, which are usually stored for part or all of the winter, should preferably be fully mature and in good condition when harvested.

Kohler, ${ }^{1}$ of the Minnesota Experiment Station, presents some interesting data on the results of digging potatoes during the period of development. The variety on which the studies were made was the Early Ohio. The tubers were planted by hand on June 3, and the diggings were begun about two months later and continued at intervals of about a week, until the tops of the plants had died:

Table XII.-Results from Digging Early OHio Potatoes at Intervals during the Period of Development

(In Bushels to the Acre)

\begin{tabular}{|c|c|c|c|c|c|c|c|c|c|}
\hline $\begin{array}{l}\text { Date of } \\
\text { Digging }\end{array}$ & 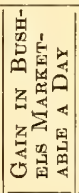 & 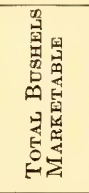 & 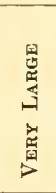 & 慈 & $\begin{array}{l}\text { 总 } \\
\text { 兽 }\end{array}$ & 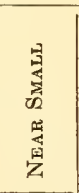 & 㟟 & 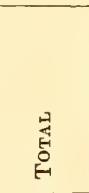 & 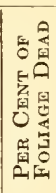 \\
\hline July 31 & - & 10.9 & - & - & 1.2 & 9.7 & 27.8 & 38.7 & 0 \\
\hline Aug. 7 & 7.5 & 62.3 & - & 3.3 & 30.5 & 28.5 & 25.4 & 87.7 & 1 \\
\hline Aug. 14 & 7.6 & 115.4 & - & 29.3 & 59.5 & 26.1 & 26.1 & 141.5 & 8 \\
\hline Aug. 23 & 7.2 & 182.1 & 6.7 & 42.9 & 97.3 & 35.2 & 21.1 & 203.2 & 22 \\
\hline Aug. 30 & 6.4 & 226.8 & 6.7 & 93.5 & 92.8 & 33.8 & 27.0 & 253.8 & 99 \\
\hline
\end{tabular}

1 Minn. Bul. 118. 
The plants took practically three months to mature. Three weeks of this time were taken up in coming through the soil. About five more weeks were consumed by the crop in getting ready to produce tubers. Most of the potatoes are produced during the last month of growth. During this last month, there was a daily gain of about 7 bushels of marketable tubers to the acre - up to the time the vines died.

The potatoes were classified as to size on the following basis :

Small $-1 \frac{1}{2}$ ounces or less.

Near small -2 ounces to $1 \frac{1}{2}$ ounces.

Medium -5 ounces to $2 \frac{1}{2}$ ounces.

Large -9 ounces to 5 ounces.

Very large - over 9 ounces.

This table warrants the conclusion that potatoes should be harvested after the tops die, if we are to secure the highest yield. It also shows that there is a loss of yield if we harvest the crop before it is mature, and that this loss increases with the increase of time between the date of harvesting and the time of maturity.

In the case of early potatoes, it is often possible to obtain prices high enough to overbalance the loss in yield and to make it profitable to dig them before they are mature.

Table XIII has been arranged from figures given by Kohler, to show relative prices at which potatoes should sell if dug one and two weeks before maturity.

Potatoes which are harvested before the tops die and before the tubers can be easily separated from the stems are usually immature. Such potatoes are not up to the American standard of quality for cooking, and are almost 
sure to disappoint the buyer. The immature tubers are also poorer in keeping qualities than those which have matured on the vines.

\section{Table XiII. - Early Digging for Market}

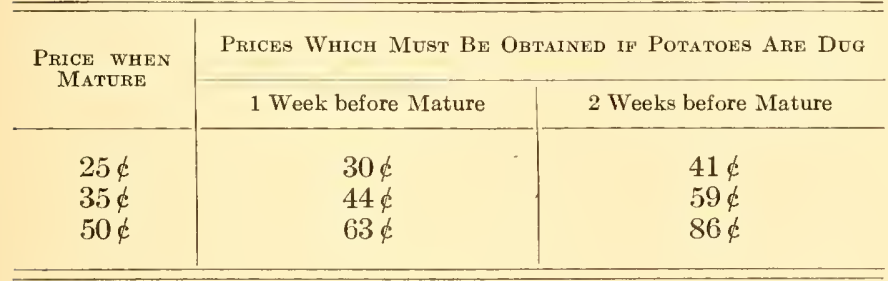

For several reasons it is best to harvest potatoes in dry, cool weather. The tubers should be dug when the soil is fairly dry, in order that they may go into storage in a dry condition and as free from dirt as possible. The cool weather prevents their wilting unduly and makes it possible to get them into storage in good condition. If the soil is not too moist, potatoes are best left in the ground for a time after the tops have died, at least until there is danger of a freeze. Most authorities agree that no harm results from such a practice as long as the soil condition is as described. In some sections this may be almost necessary, especially where several weeks of warm weather are likely to follow the dying of the vines. It is difficult to store potatoes successfully if there are two or three weeks of warm weather immediately after they have been put into storage. In the North, cold weather usually follows the dying of the vines so closely that it is best to dig and store as soon as the tops die, and occasionally the digging must be done while the plants are still green in order to save the tubers from freezing. Where 
there is any disease in the crop, the practice of leaving the tubers in the ground for a time after they have matured has a distinct advantage. The infected tubers start to rot in the ground, and when they are dug they can easily be discarded. Otherwise they are stored with the sound potatoes and frequently cause a great deal of rotting.

The progressive grower of potatoes will have on his farm a breeding plot on which he is attempting to isolate one or two superior strains of the variety which he is growing. He ought to be constantly on the watch for plants which show promise, and bring in the tubers produced by these for a tuber-unit test. Some time during the growing season the farmer should go through his commercial field and stake any plants which show qualities of unusual vigor, disease-resistance, desirable habit and so on. The product of such plants should be dug by hand, bagged separately and records taken as to uniformity, size, weight and so on. A consideration of the data taken on each plant will show the grower whether or not he should keep the tubers for further growing and selection.

\section{Methods of digging}

The method employed in getting potatoes out of the soil will depend a great deal on the area planted, the type of soil and the cheapness of labor. Formerly, all potatoes were dug by hand with spades or forks. Later on, many growers used an ordinary plow to lift them. Then a special type of plow, the shovel plow, was employed. Later came the various types of mechanical diggers.

Small plantings of potatoes must always be dug by hand, because of the high cost of the digging machines. 
It is often necessary, also, to dig early potatoes by hand. In the early varieties the skin is tender and easily injured by the digging machinery. The tubers also cling to the underground stems and frequently have to be pulled off. A man will dig from $\frac{1}{8}$ to $\frac{1}{2}$ acres a day, depending on the yield and type of soil.

Digging by plows is not to be recommended unless it is a case of getting part of the crop or none. The plows cut and otherwise injure many of the tubers, and they cover nearly as many potatoes as they turn up. Growers usually agree that hand-digging secures enough more potatoes than plowing to make the extra labor well worth while.

When the planting is relatively large, it pays the grower to buy a good digging machine. Such machines work quickly and are usually very satisfactory. In heavy soils and stony soils, and in cases in which the plantings are deep, there is a question as to their efficiency.

The type of machine commonly used in this country has a steel nose which runs under the row and lifts potatoes and soil onto a grating of iron rods. The soil falls through the grating and the potatoes travel along the rods and are dropped at the back of the machine on top of the ground. From two to four horses are used on such a machine. A good machine will dig from 3 to 6 acres of potatoes a day, and will keep from 10 to 15 men busy picking them up. A second type of digger, less commonly used, has a revolving frame with forks which dig into the ground at right angles to the row. Potatoes and soil are thrown against a screen and the soil passes through, leaving the potatoes in a row upon the ground.

When a digging machine is used, it is sometimes necessary to remove the dead vines from the rows before 
digging. 'This can be done by rumning' a spike-toothed harrow across the field lengthwise of the rows. It has the added adrantage of leveling off the ground where the soil has been hilled up about the plants.

\section{Picking and sorting}

It is usually considered best to let the tubers dry on the ground for trro to six hours before picking them up. 'This results in a drying and falling off of the excess dirt and also toughens the skin and lessens its liability to injury in handling. If the potatoes are left for too long a time in the strong sunlight, they turn green and their eating quality is injured.

Potatoes are usually picked by hand into bushel baskets or crates (see Plate $X I V^{\gamma}$ ). Formerly it was the practice to empty these containers into a wagon box and to cart the potatoes to the storage, where they were shoveled into boxes. This method of handling usually resulted in considerable injury to the potatoes and greatly impaired their keeping qualities. At present, potatoes are usually hauled from the field in two-bushel bags or in one-bushel crates.

Alva Agee ${ }^{1}$ recommends the use of one-bushel boxes for carting potatoes from the ficld. Such boxes, he says, should be made of basswood or some other light wood and should be of 2685 cubic inches eapacity. These boxes

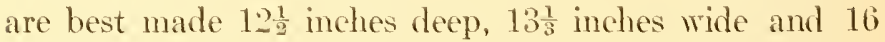
inches long. The sides and bottom should be $\frac{3}{8}$ inch thick and the ends $\frac{1}{2}$ inch thick. The length of tro such boxes is about equal to the ridth of an ordinary wagon bed. With high side-boards on the wagon, these can be

1 Penn. Dept. of Agr. Bul. 105. 


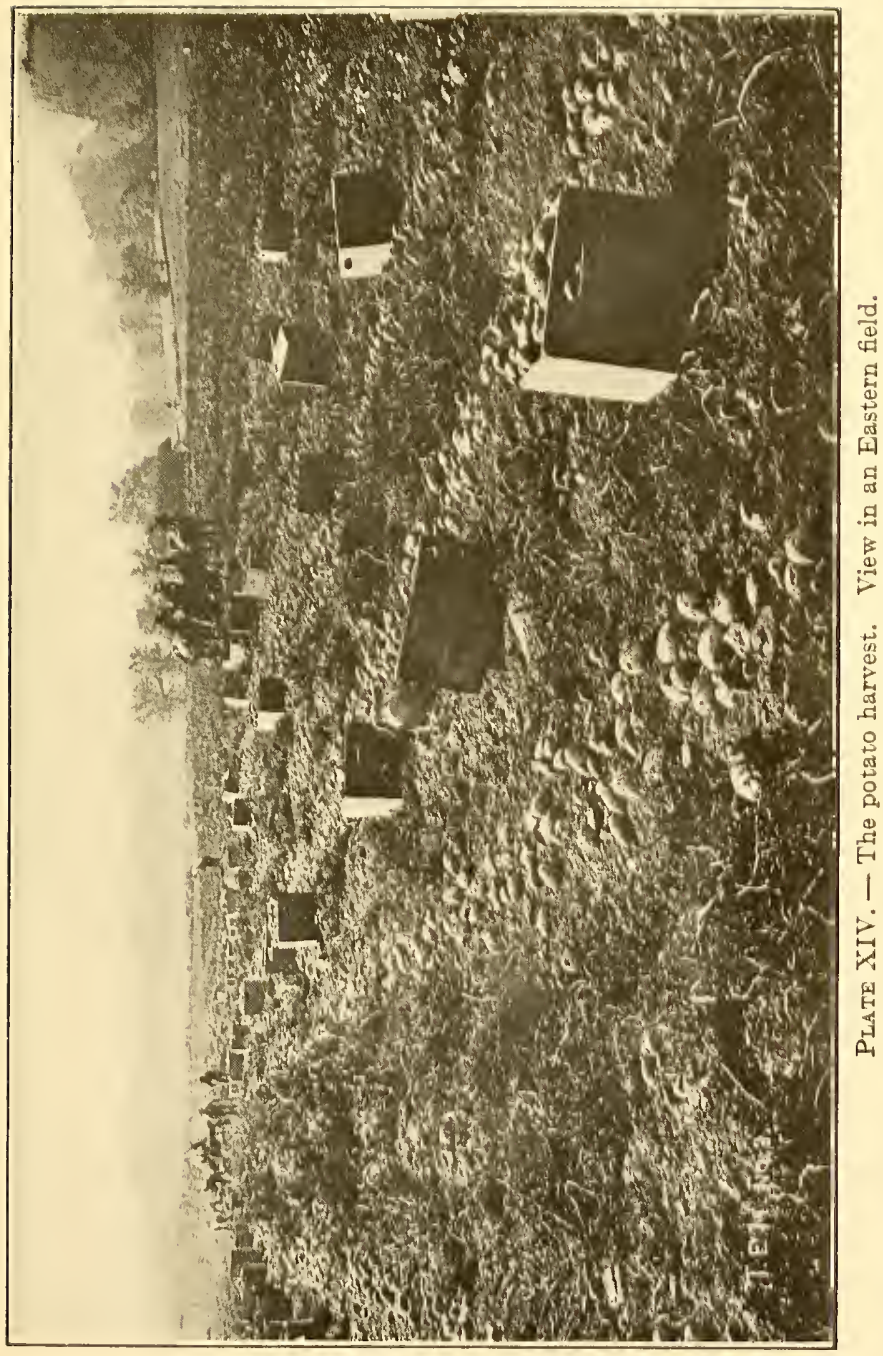






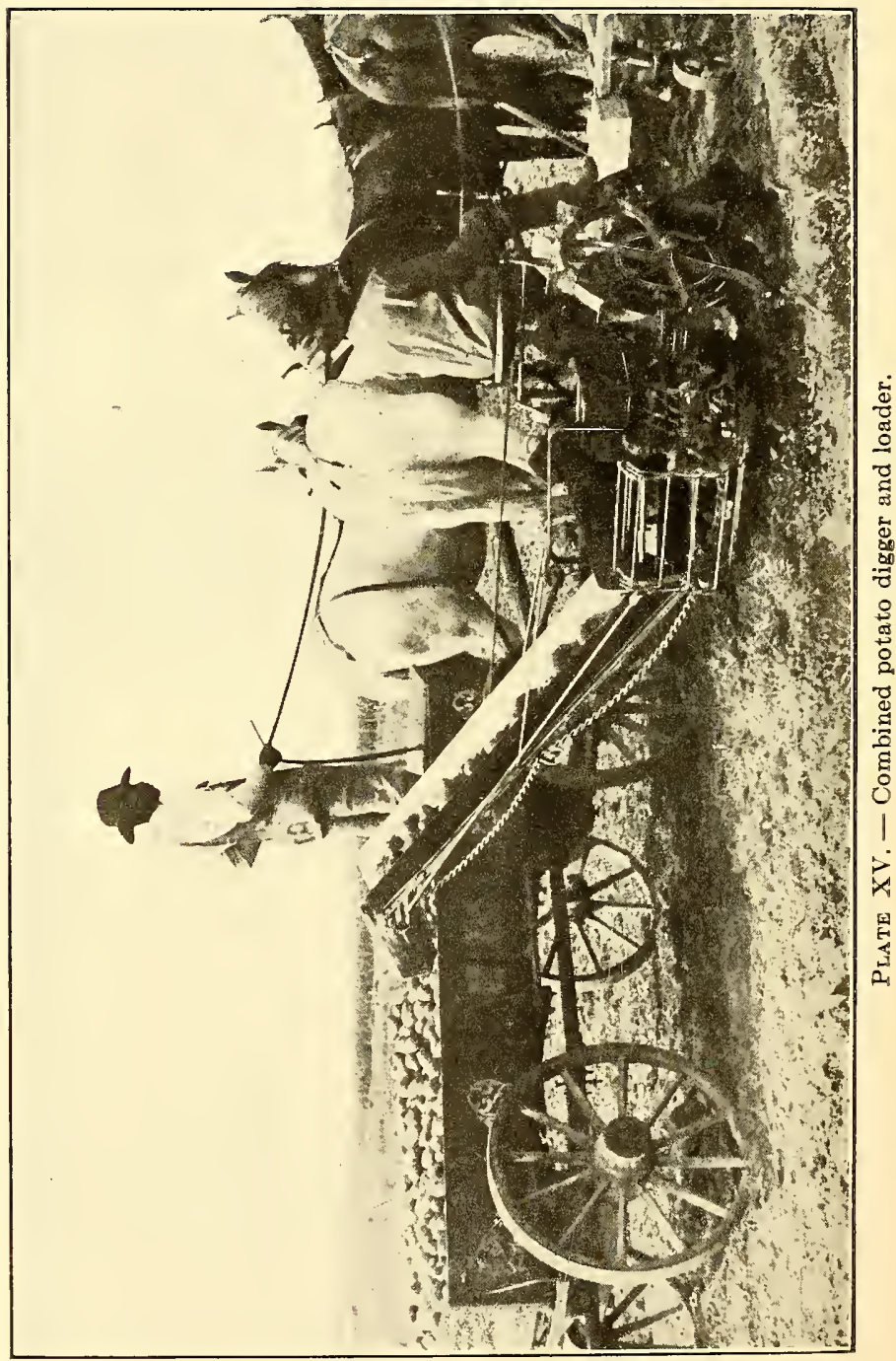


piled up in tiers and about 60 boxes put on a load. Boxes of this description can be purchased for about 18 cents each. Slat crates of cheaper construction can be had for about 12 to 18 cents each. These boxes are quite durable and with proper care should last 10 or 12 years.

There are now on the market machines which dig and bag potatoes in one operation. Machines of this sort undoubtedly save a great amount of labor, and in some

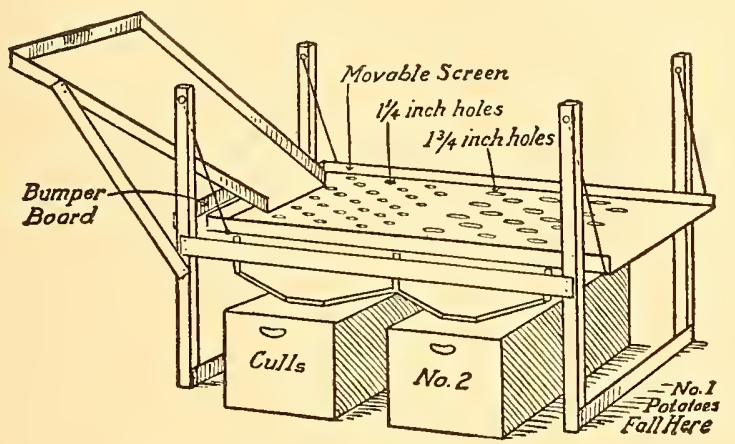

Fig. 17. One type of potato sorter.

cases will prove to be good investments. We should remember, however, that potatoes harvested in this manner have no chance to dry off and are therefore more likely to rot in storage than those which have stood for a few hours on the surface of the ground.

Where the weather will permit, it is usually advisable to sort potatoes in the field. Various types of sorting machines are used for this purpose (see Fig. 17 and Plate $\mathrm{XV}$ ). One is simply a wooden frame on runners, having two inclined sieves of heavy wire. The largest potatoes roll down the top sieve into a sack at the end. The smaller potatoes fall through the upper sieve on to a finer 
one, and the larger of these potatoes roll down into a bag at the end of that sieve. The very small potatoes and pieces of dirt fall through the sorter on to the ground. A horse can be attached to this sorter, and it can be drawn around the field as the men pick.

Other sorters of a more complicated type are often used in grading potatoes, but most of these are too cumbersome to be hauled about for field sorting.

Some potato-growers are heartily in favor of washing potatoes after bringing them from the field. This is done by the use of sprayers, and the potatoes are poured on to racks to dry. Those who advocate washing claim that it not only makes the tubers more marketable, but that it also reduces the loss by rotting in storage. Other growers insist that the labor of washing is not worth while, and still others say that it is injurious to the potatoes to wash them. Experimental evidence on these questions is lacking.

\section{Labor and cost of harvesting}

It is difficult to make an exact estimate of the cost of harvesting an acre of potatoes, because of the differences in the methods, the skill of the laborers, the type of soil and the size of the crop. Only approximate figures, therefore, can be given.

If the digging is done by hand, $\frac{1}{8}$ to $\frac{1}{2}$ an acre can be dug by a man in a day. Fraser ${ }^{1}$ estimates the cost of such digging at from two to six, or even eight, cents a bushel.

A machine will dig from 3 to 6 acres a day. If we allow three dollars a day for the use of the team and two dollars a day for the driver, the cost of digging an

I S. Fraser. "The Potato." 
acre by machinery will vary from 87 cents to $\$ 1.67$. As this machine, digging between 3 and 6 acres a day, keeps from 10 to 15 men busy picking, it would appear that about 3 men are needed to pick up the potatoes on an acre.

If the potatoes are sorted in the field, this item must be added in figuring the cost of harvesting. The quantity which can be sorted in one day will depend a great deal upon the type of sorter used. From 500 to 1000 bushels can be sorted by a machine in one day.

It is almost impossible to make an accurate estimate of the cost of hauling from the field to the storage cellar. The size of the wagon used and the distance of hauling will vary greatly, and even an approximation of the cost of this operation would probably be valueless.

The grower should always remember that the care which he exercises in harvesting his crop will mean an appreciable difference in its marketability. Cut and bruised tubers bring a lower price when sold directly from the field, and they are a complete loss when put into storage. Poor judgment as to time and method of harvesting will have a detrimental effect upon yield and upon quality. The farmer who spends time and money to raise a good crop of potatoes should be equally careful in getting his crop to the market or into storage in the best possible condition.

\section{REFERENCES}

Agee, Alva.

1904. Potato Production. Kansas Agr. Report.

Agee, Alva. Penn. Dept. Agri. Bul. 105.

Bennett, E. R. The Colorado Potato Industry. Colorado Bul.

Fraser, Samuel.

1905. The Potato. N. Y. (Orange Judd Co.), pp. 143-146. 
GrubB, E. H., and Gullford, W. S.

1912. The Potato. N. Y. (Doubleday, Page \& Co.), pp. 111-118. KoHler, A. P.

1909. Potato Experiments and Studies at University Farm. Minn. Bul. 118.

Macoun, W. T.

The Potato and its Culture. Central Expt. Farms, Bul. 49. 


\section{CHAPTER XIII}

\section{MARKETS, MARKETING AND STORAGE}

IT is of interest to know the quantity of potatoes which are marketed every year in the United States, in order to appreciate the importance of the marketing problems. Such a figure, of course, can never be very accurately obtained, because of the lack of statistics of various sorts necessary in computing it. It is possible, however, to make a calculation which is approximately correct. This figure should be considered only as an approximation.

The following table of averages may help to give an idea of the number of bushels of potatoes which are marketed every year in this country :

\section{Table XIV. - Averages For 1904-1913}

Annual production . . . . . . . 326,199,200 bu. Quantity marketed in the fall - 50 per cent . 163,099,600 bu. Quantity stored -50 per cent . . . . 163,099,600 bu. 8 per cent less on stored potatoes . . . . 13,047,968 bu. Quantity used for starch . . . . . . . 5,000,000 bu. Seed needed for next year . . . . . . . 48,286,000 bu. Number of farms raising potatoes . . . . . 3,008,474 Potatoes consumed on farms . . . . . . 75,211,850 bu. Bushels to be marketed (home grown) . . . 183,653,382 bu. Annual imports of potatoes . . . . . . . 2,688,148 bu. Annual exports of potatoes . . . . . . $1,410,831 \mathrm{bu}$. Excess of imports over exports . . . . 1,277,317 bu.

In figuring the seed needed, 14 bushels of potatoes were allowed to the acre. The number of farms raising pota- 
toes is an average of figures for 1899 and 1909. An average of five persons to a farm is considered fairly reliable, and each person is assumed to eat about 5 bushels of potatoes a year. ${ }^{1}$ From these figures we can estimate the number of bushels eaten on farms. We have then figures from which we can compute, rather roughly, the number of bushels to be handled annually on the potato markets of the United States.

From the above table, we see that nearly one-seventh of the potato crop has to be saved for next year. About onetwenty-fourth of the whole crop, or one-twelfth of the quantity stored, is lost through shrinkage and rotting. Starch manufacture and home consumption of potatoes on the farm also take some of the crop. The quantity left, after subtracting all of these from the crop, represents, in a rough way, the number of bushels of Americangrown potatoes to be handled on the market. If we then balance the imports and exports, and add the excess of imports to this figure, we have the total number of bushels of potatoes handled in the American markets. This is approximately $184,930,000$ bushels, or 30,822 cars. ${ }^{2}$

According to statistics published by the United States Department of Agriculture, about 50 per cent of the potato crop has been sold by January first. A relatively large proportion of this quantity is sold by farmers at the time of digging, or shortly afterward. The following table $^{3}$ gives figures for the total of 19 Northern states:-

1 The average annual consumption per capita in the United States is 3.5 bushels. The consumption is higher than this in the North and lower in the South, where sweet potatoes are eaten in place of Irish potatoes. Funk, in Farmers' Bul. 635, finds an average farm consumption (483 farms) of 5.7 bushels.

2 Car of 600 bushels.

${ }^{3}$ Monthly Crop Report, January 31, 1916, p. 8. 


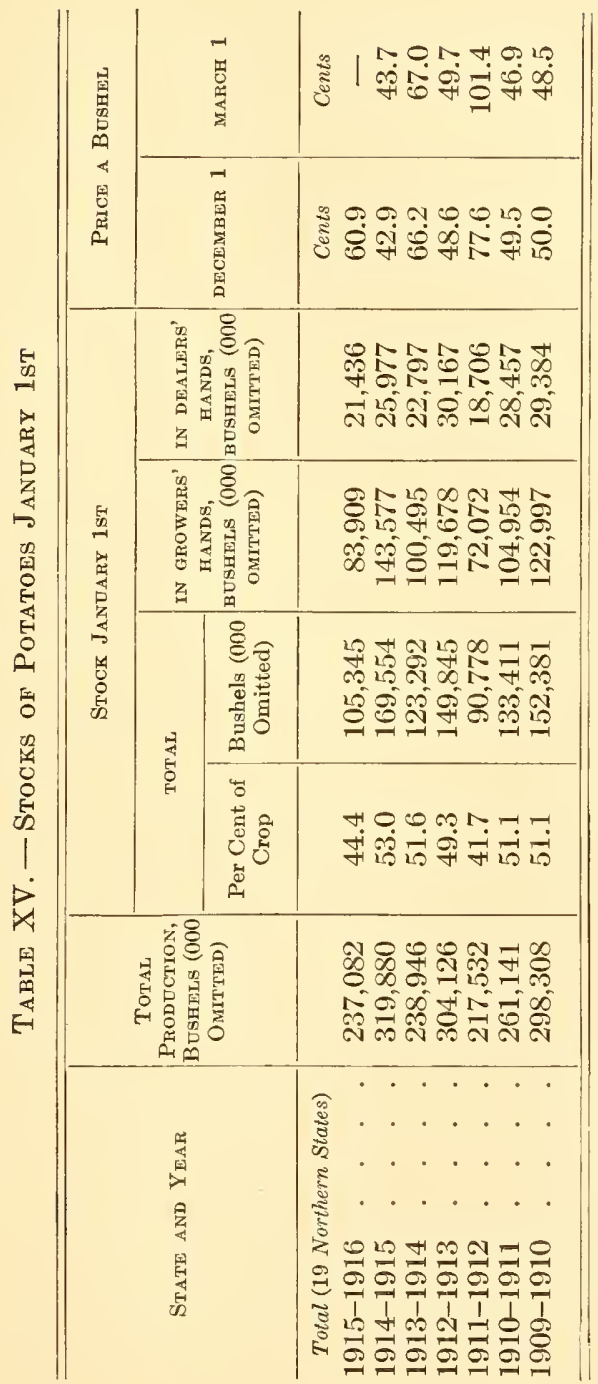


If we average the figures for these 7 years, 1909 through 1915-1916, we have the following:-

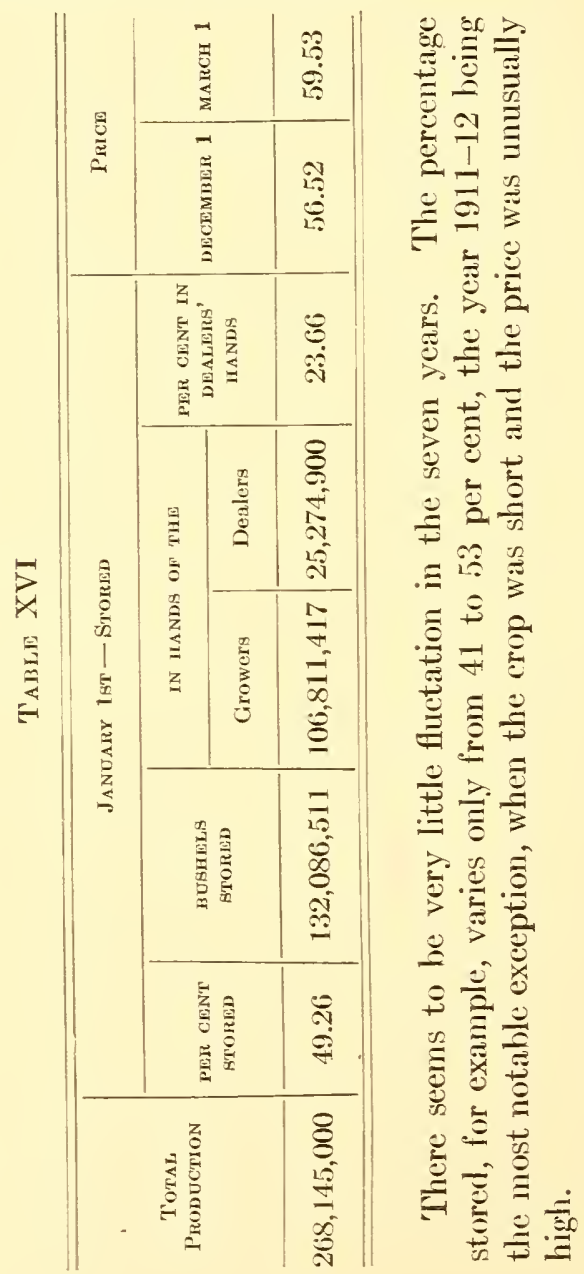


It will be seen that there is an average difference in price for a bushel on December 1st and March 1st of only 3 cents. The question which then suggests itself is "Does it pay the farmer to store potatoes over winter?"

When we compare the prices obtained for a bushel on December 1st and March 1st, it would seem that the farmer loses money by storing his potatoes. Surely the difference of 3 cents a bushel does not begin to cover the extra cost of storage nor the extra shrinkage and loss through rotting. Why not sell all the potatoes at digging time, or at least before January 1st? There are several very good reasons for this.

In the first place, it would be very difficult for the dealers to handle the whole crop of potatoes in the fall. They lack the warehouse room and the help to take care of all the crop at one time. Dealers would be swamped with potatoes for a short time, and then have no more to handle for a long time. Secondly, there is a shortage of railroad cars in the fall, and it would be impossible to ship the whole crop at one time. Then, too, the farmer is pressed for time in the fall and can use his teams to better advantage than in hauling potatoes. He can better afford to cart potatoes in the winter, when there is less to be done.

Probably the principal reason for not selling the whole crop in the fall is the automatic lowering of prices which follows an attempt to market too many potatoes at that time. The dealers in potatoes will take only so many bushels in the fall, and any sold above this quantity are sold at a constantly decreasing figure. By storing part of his crop, the farmer equalizes the distributing of it on the market and gets a better net return than he would by selling all shortly after digging.

If prices hold up in the fall, it will probably be better 
for the farmer to market the larger part of his crop at once than for him to store it. Occasionally, however, the storage of potatoes becomes very profitable.

In 1914 , with a crop of over $400,000,000$ bushels, the price of potatoes dropped during the winter. In 1915, when weather conditions were unfavorable, and the crop suffered badly in storage, prices went up rapidly during the winter. The winter of 1915-1916 was one in which stored potatoes of good quality brought a high price. The following table of estimated values a bushel, taken from the United States Government Monthly Crop Reports, shows the range in price a bushel during the seasons mentioned:

\section{${ }_{4}$ TABLE XVII}

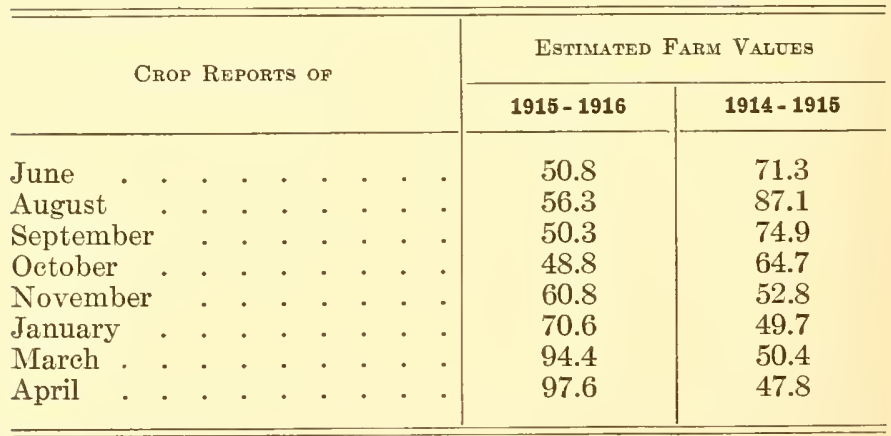

\section{Marketing the crop}

The methods of marketing the potato crop may be simple, or they may become complicated, requiring several handlings and the services of a number of persons.

Probably the simplest method of marketing the crop is for the farmer to sell directly to the consumer, either haul- 
ing the potatoes by wagon or shipping them. This can only be done when the farmer lives fairly close to market and where he has good storage facilities, so that he can sell small quantities at a time. Such a method of marketing is usually highly satisfactory, for it gives the producer the highest possible share of the profits and the consumer the lowest retail price. The farmer may also sell locally to retail grocers, thus eliminating the services of one to three or four middlemen. Obviously, only a very small proportion of the total crop can be marketed in these ways. Such methods of marketing necessitate much labor, and require good storage accommodations and an intimate knowledge of markets.

\section{Marketing through local dealers}

It is usually necessary for the farmer to sell his potatoes to a local dealer, who in turn stores some of them and sends the remainder to the commission men in the larger cities. These dealers are familiar with the requirements of the different markets and are usually able to sell the potatoes to a better advantage than can the farmer.

The local dealers or buyers are to be found in nearly all towns where large quantities of potatoes are being brought in by the farmers. They usually sort and bag the potatoes and load them in cars for shipping. Occasionally a farmer or a small group of farmers will load and ship a car, but the bulk of the crop is handled by local buyers. These buyers, according to Taylor, may be of several sorts. They may be agents of large potato companies in the cities, or they many be independent buyers who combine other lines of business with that of potato-buying, or they may be agents of farmers' warehouses or coöperative associa- 
tions. The large potato companies usually have from one to several buyers in the more important potato-growing sections, to purchase from the farmers and ship the potatoes, at their direction, to the best markets. These buyers handle potatoes at 4 to 8 cents a bushel. The agents of the farmers' warehouses, who are dealing in other produce as well and have lower running expenses, are able to handle a bushel for about 3 cents.

In many of the large cities there are companies which handle only potatoes. These companies get potatoes from the farmers through the local buyers, and then by means of telegraph and telephone ascertain the best markets and direct the shipment of the cars to them. They are handling great quantities of potatoes and can afford to spend large sums in order to get their goods to the best market. Companies of this sort often pay telephone charges of over one thousand dollars a month.

Where farmers can be persuaded to coöperate and to place faith in the organization and in its agents, the cooperative method of selling potatoes has proved very satisfactory. Such organizations have agents in the small towns near which the members live. These agents receive potatoes from the farmers, and ship them at the direction of the manager of the company. These managers have to compete with the large potato companies, and are often at a disadvantage in getting information as to markets. Farmers' companies should either be in touch with large distributors or arrange with some company for "buying information."

Local dealers usually find it necessary to sort and clean the potatoes brought to them, since growers seldom make a practice of sorting carefully. Potatoes are sorted, 
bagged or put in barrels for shipment. Occasionally a farmer will insist that his potatoes be sold without being sorted before shipment. These are sorted in the city and the culls are thrown out. The grower gets nothing for the culls and he must pay the expense of freight on them.

\section{Grading}

Potatoes are poorly graded, and for this reason the cost of marketing is higher than in the case of goods which are classified by grades. Potatoes of several varieties are usually raised in the same section, and it is often hard to fill a car with only one variety. Experienced potato-shippers sort and grade carefully and get a higher price a bushel than is ordinarily paid. One produce exchange in Virginia has so standardized its potatoes that wholesalers order by wire, without seeing the goods. Sorting and grading on the farm, or at least before loading on the cars, not only makes it possible to secure a higher price for the potatoes, but reduces the cost of marketing as well. The farmer ultimately pays the cost of grading, and often after he has paid the freight on as much as a ton of dirt and culls.

\section{Packages}

Early potatoes are usually shipped in three-bushel barrels, covered with canvas, or in bushel boxes. The barrels, with covers, cost about 20 cents apiece. Bushel boxes $-13 \times 16 \times 13$ inches deep - cost about $\$ 30$ a hundred. Seed potatoes are frequently shipped in double-headed barrels of 165 pounds capacity. These cost about 30 cents each. 
Late potatoes are usually shipped in burlap sacks, holding two bushels. Sometimes flour barrels are used, and occasionally the potatoes are shipped in bulk in carload lots.

\section{Shipping}

When potatoes are shipped in bulk, it is necessary to line the whole car with lumber. If the potatoes are bagged, it is not necessary to line the car, but a false floor must be put in. It costs the local dealer ordinarily a little over $\$ 30$ to line a car.

In the winter, it is necessary to heat the cars, and a man has to be sent along with the car to regulate the heat. Here again the larger dealer has the advantage, since he can ship several cars at once and reduce the cost of heating.

Water transportation plays an important part in the shipment of early potatoes from the southern states to the larger cities of the North.

Most of our potatoes are raised near the larger towns and cities, and the distances of shipment are relatively small. Chicago receives potatoes from Michigan, Illinois, and Wisconsin, a large part of her supply coming from the last state mentioned. New York and Philadelphia get potatoes from New York state, New England, Long Island, New Jersey and the southern Atlantic states. Only a few states raise potatoes for interstate shipment. Taylor says that three-fourths of the potatoes grown are consumed in the states which raised them. Maine raises 25 per cent of the potatoes for interstate shipment, Michigan 24 per cent, Wisconsin 20 per cent, Minnesota 16 per cent and Colorado 8 per cent.

After reaching the city in which they are to be marketed, the potatoes may take any one of several courses to the 
consumer. Very often they pass through the hands of a commission man, and frequently they go directly to the wholesaler. In the larger cities, a considerable part of the crop goes to the commission man, who, in turn, distributes it among the jobbers or wholesalers. The commission man may employ a number of salesmen, or he may depend upon an expert potato broker to bring in orders from the wholesalers. Often goods are shipped around the commission men to the brokers, and thence to the wholesalers.

The diagram (Fig. 18) may help to make clear the methods of marketing potatoes. Perhaps it will seem that there are too many middlemen concerned in the marketing of this crop. In many cases there are. We must not lose sight of certain conditions of potato marketing, however. The retailer sells in small quantities, and he has no room to store more than a small supply of potatoes. He must needs depend upon the wholesaler for his supply. The wholesaler in turn has to cater to a fairly definite demand from the retailer. He cannot take everything which is sent to him by the farmer, but must have access to the supplies of the commission man in order to get the desired variety and grade. So we have the potatoes coming to the large dealer or commission man, who sells in small lots to the wholesalers, and the wholesalers divide the product into still smaller parcels and sell to the retailer. The lack of proper grading, the bulkiness of the goods, and the demand for small quantities at a time, tend to make necessary the services of several classes of dealers in the process of marketing potatoes.

There is no chance to gamble on potatoes, as on wheat and certain other crops, since there are no exchanges where the traders can come together. The potato market is 


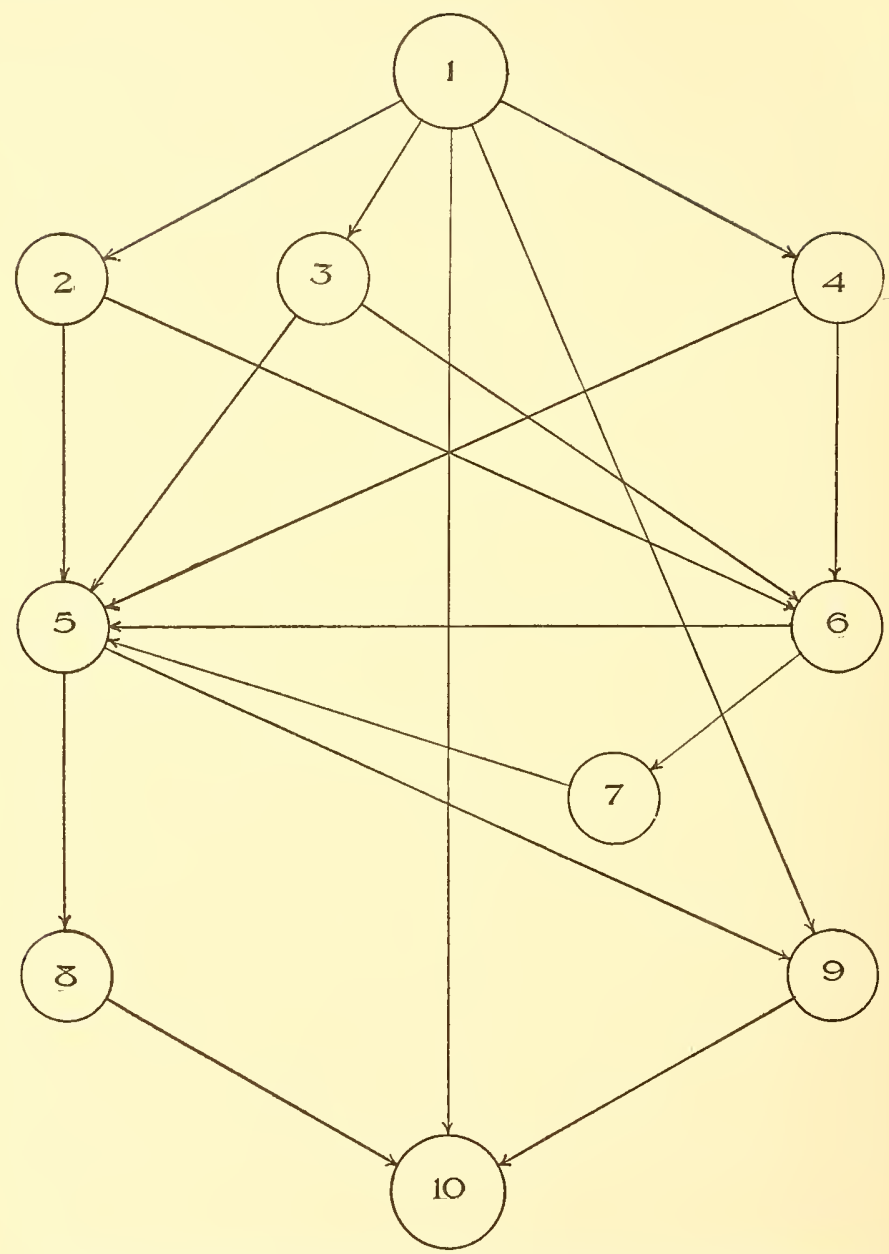

FIG. 18. Diagram illustrating interrelationships of producer, middlemen and consumer of potatoes. 1. Farmer. 2. Agent of farmers' warehouse or of coöperative company. 3. Independent local buyer. 4. Local buyer for large potato company. 5. Wholesaler. 6. Commission man. 7. Broker. 8 and 9. Retailer. 10. Consumer. 
not very highly organized, and exact market information is very difficult to obtain.

\section{Early and late potatoes}

The earliest potatoes to reach the northern markets come from the Bermudas and Texas in January and February. Florida and other southern states add to the supply a little later, and about the first of June a large quantity begins to come in from Virginia and other south central states.

Early potatoes from southern New Jersey enter the market about July twentieth and those from the northern part of the state and from Long Island about ten days to two weeks later. Early potatoes from New York and Maine are usually marketed between the first and fifteenth of September. The southern potatoes have little effect upon the price paid for northern-grown potatoes, providing they are out of the market by August. If southern potatoes are late in reaching the northern markets, potatoes from New Jersey, Long Island and Pennsylvania are sold in competition with them and consequently bring a lower price.

The main crop of late potatoes begins to come into the market early in October. From then on, the extent of the sales and the price for a bushel depend upon many factors. Chief among these is the supply of potatoes then upon the market.

\section{Markets}

The larger potato markets of the United States are New York, Chicago, Minneapolis, St. Louis, Cincinnati, Denver, San Francisco and Boston. Chicago handles annually about 24,000 cars, or over 60 cars a day. Each of these 
cities draws upon several states for its supply of potatoes. The eastern cities often get European potatoes in years of a poor crop, and occasionally these potatoes get as far west as Chicago.

\section{Range and prices}

There are few crops which fluctuate as much in value as the potato. In a single season the prices may show a range of as much as 70 or 80 cents a bushel. The highest prices are usually obtained in the late winter and early spring just as the early potatoes come on to the market. This value is not likely to fluctuate a great deal while early potatoes are abundant, but it drops off rather suddenly as soon as the late crop comes in. Usually the price for a bushel remains fairly constant through the winter, though it may fluctuate a little either way. Later in the winter it is likely to rise somewhat or to drop off slightly. These fluctuations in price are due largely to a change in the relation of supply to demand.

In 1899 , the farm price was as low as 22 cents in Iowa and as high as $\$ 1.10$ in Arizona, with an average price the country over of 36 cents. In 1915, the prices ranged from 35 cents in South Dakota to $\$ 1.15$ in Florida, with an average of 61.6 cents. These wide fluctuations in price illustrate the effect of supply and demand upon the value a bushel. The average farm price a bushel for the years 1906-1910 was 60.4 cents. The highest average farm price on December first, since 1866, was 79.9 cents in 1911, and the lowest in the same period was 26.6 cents in 1895 . In recent years, Arizona has had the highest value to the acre, averaging $\$ 127.68$ for the 5 years from 1910-1914. The lowest value to the acre during the same period was $\$ 42.43$ in Missouri. 
The following table ${ }^{1}$ gives the prices received for a bushel by the Burlington County Farmers' Exchange of New Jersey, for four years :

Table XVIII. - Seasonal Variation in Farm Price for a Bushel

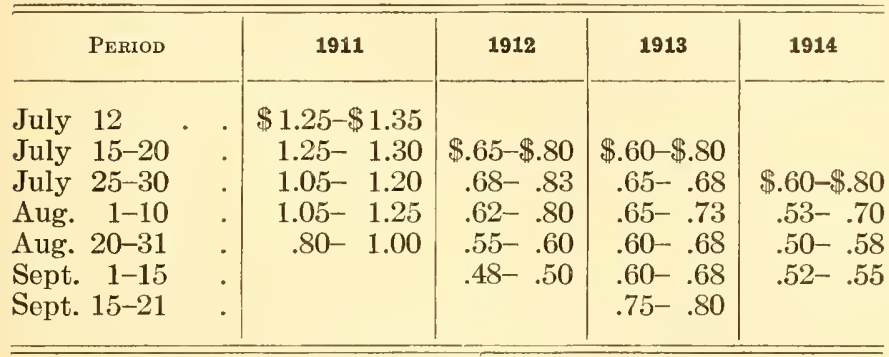

A survey of the figures published by the United States Department of Agriculture shows that the price paid for a bushel on December 1st tends to vary immensely with the size of the crop :

TABLE XIX

\begin{tabular}{c|c|c}
\hline Year & $\begin{array}{c}\text { Production } \\
\text { (000 OMtTted) }\end{array}$ & $\begin{array}{c}\text { Farm Price - IN Cents } \\
\text { December 1st }\end{array}$ \\
\cline { 2 - 3 } 1904 & 332,830 & 45.3 \\
1905 & 260,740 & 61.7 \\
1906 & 308,040 & 51.1 \\
1907 & 298,260 & 61.8 \\
1908 & 278,990 & 70.6 \\
1909 & 289,190 & 54.1 \\
1910 & 349,030 & 55.7 \\
1911 & 292,740 & 79.9 \\
1912 & 420,650 & 50.5 \\
1913 & 331,530 & 68.7 \\
1914 & 405,920 & 48.9 \\
\hline
\end{tabular}

${ }^{1}$ N. J. Extension Bul., Vol. 5, 1915. 


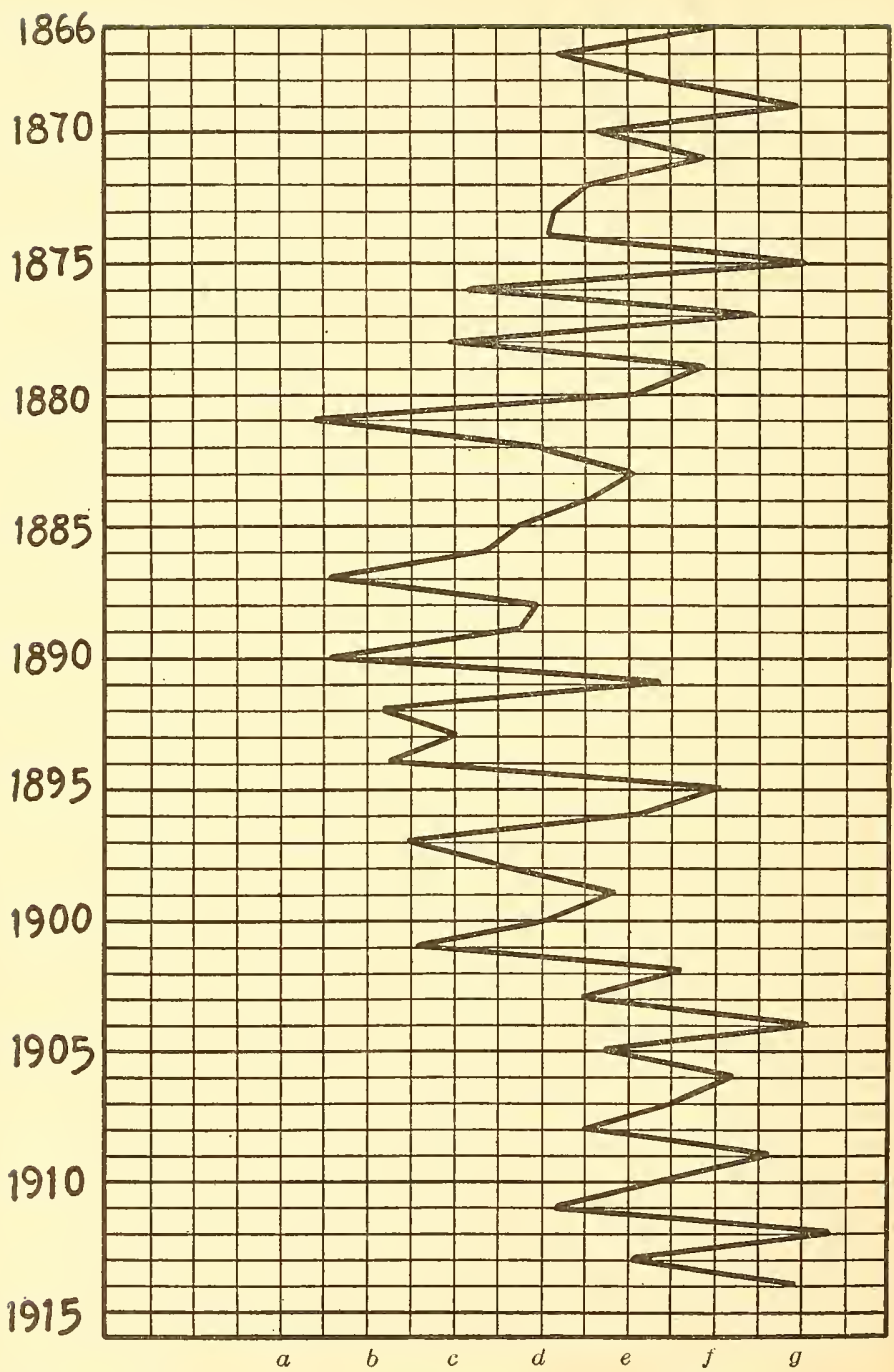

FIG. 19. Average yields of potatoes to the acre. $a, 50$ bushels; $b$, 60 bushels; $c, 70$ bushels; $d, 80$ bushels; $e, 90$ bushels; $f, 100$ bushels; $g, 110$ bushels. 
The graph in Figs. 19 and 20 illustrates this same relation between production to the acre and value a bushel.

If the consumer of potatoes examines a list of farm prices, as published by the United States Department of Agriculture, he is usually surprised to find that he is paying at least double what is paid the farmer for a bushel of potatoes.

Under present conditions the cost of marketing potatoes is relatively high. It could be cut down appreciably if farmers would coöperate in marketing and would grade their stock carefully. Taylor publishes statements from a potato merchant to show the distribution of the cost of marketing a bushel.

The local buyer pays, on the average, three cents a bushel for the labor of handling the potatoes. Bags cost about 5 cents, and the dealer asks a profit of about 2 cents a bushel.

The freight charges vary a great deal with the distance of shipment. Taylor says that it costs about 8 to $8 \frac{1}{2}$ cents a bushel to ship from Wisconsin to Chicago. To the freight must be added the cost of lining and firing the car, when the potatoes are shipped in the winter. This will cost about 2 cents a bushel. It costs the small shipper from $\$ 7$ to $\$ 10$ a car for heating, while the large dealer will send through a string of 5 to 20 cars for about $\$ 1.50$ each. We must count on a certain loss in transit through frosting and rotting. Then, too, under present methods of grading and marketing there is almost always a loss of 20 to 40 bushels of culls to a car, and occasionally as high as 100 to 150 bushels. These potatoes are a total loss to the buyer, and the freight paid on them is also lost. As a result of this loss on culls, the price for a bushel rises somewhat.

The larger distributor or commission man usually nets 


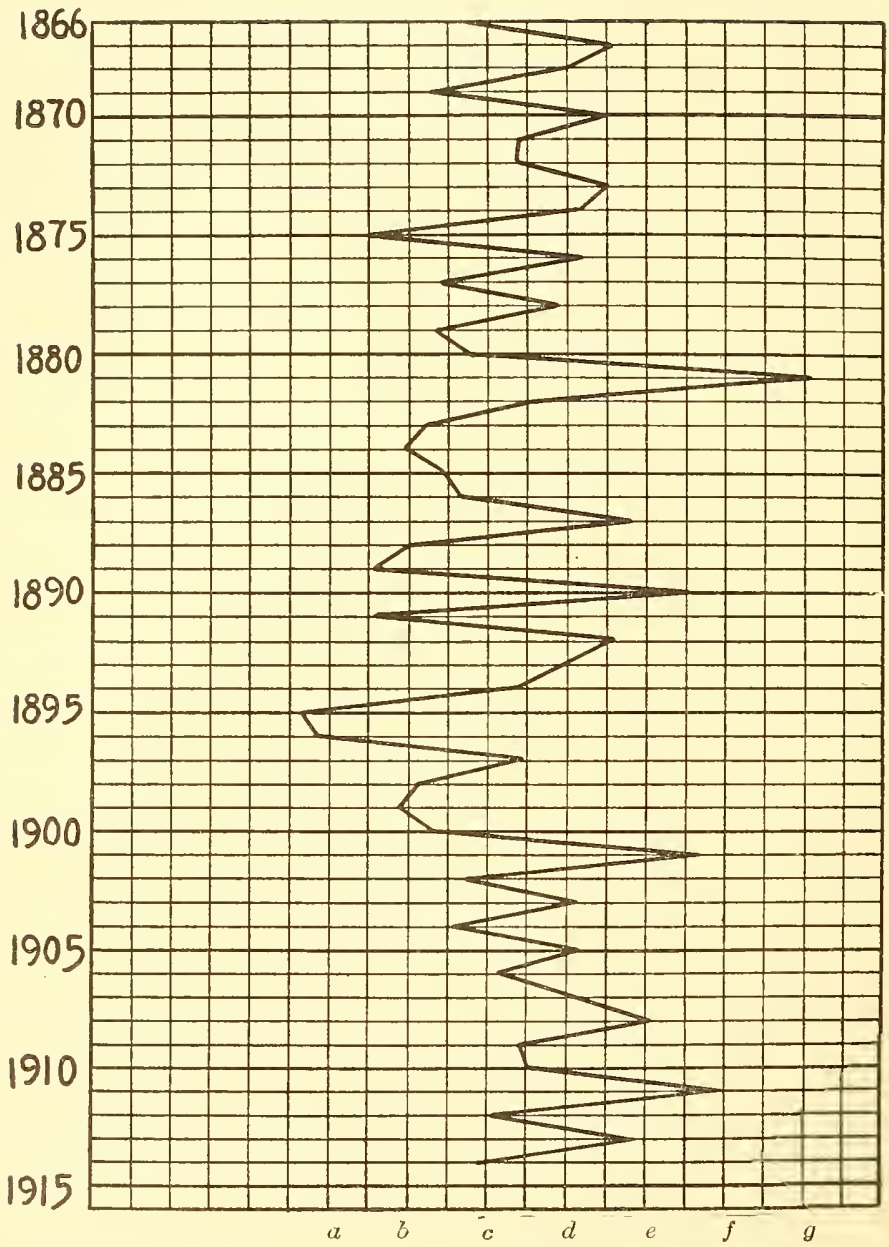

FIG. 20. Average prices of potatoes by the bushel. $a, 30$ cents; $b$, 40 cents ; $c, 50$ cents ; $d, 60$ cents ; $e, 70$ cents ; $f, 80$ cents ; $g, 90$ cents. 
about 2 cents a bushel profit in addition to his expenses of $1 \frac{1}{2}$ to 2 cents a bushel.

The wholesale dealer incurs an expense of 5 to 7 cents a bushel in draying to his warehouse and later distributing to the retailer. He must also make a profit on each bushel handled.

There is also the retailer, whose profit must necessarily be high. This last profit varies from 15 to 30 cents.

A summary of all expenses incidental to marketing the crop shows a cost of 39 to 70 cents a bushel :

\section{TABLE XX}

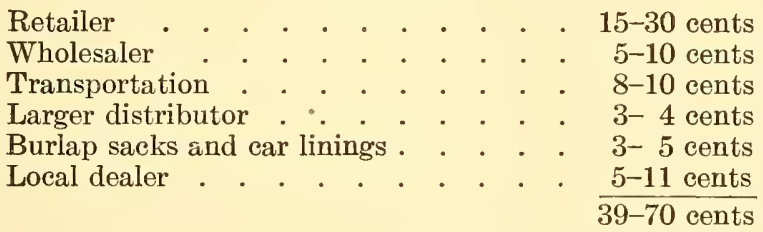

The cost of marketing varies greatly, depending on a number of factors. The distance to market affects freight charges very directly. The time of year when the potatoes are shipped has a bearing on loss in transit and cost of heating the cars. Costs are markedly influenced also by the number of middlemen helping in the sale of the potatoes. Each one must make a profit. There is a lack of definite standards of quality in potatoes, and consequently at each exchange of goods there is keen bargaining to buy low and sell high. The retailers' cost of marketing depends largely upon the quantities purchased at one time by the consumer, and the cost of delivering and of maintenance.

It is obvious that a lowering of the cost of marketing will be profitable both to the producer and the consumer. The 
latter mill be able to buy potatoes for less a bushel, and the former will receive a larger share of the retail price than before. The farmer slubuld aim to ent down the expense of growing and hauling to the local buyer. He can lower freight charges by sorting carefully and thereby not paying freight on culs. Bỵ grading his stock and marketing the best, he can raise the price which he receives a bushel. P'rraps the most effectire moans of lowering the eost of marketing is for the firmers to organize coopperative selling empanies. Such organizations have most of the adrantages of the larger potato eompanies. in the way of dereased eost of hauling and better marketing information. In some cases the number of middlemen can be eut down. We must remember, howerer, that the potato is a bulky" erop of a perishable nature and therefore must be cardully hold in storage while awating shipment. This necessitates, for part of the erop at least. the services of the large distributor who can hold the goods safely" mutil ealled for by the wholosalers. There must be re tailers who ean sell potatoes in small lots to the consumer. Perhaps one or eren two of these steps might be dropped out oecasionally. and the expense of handling sereral times be eliminated.

There are many factors which determine the price of potatoes. A careful study of these and skill in forecasting as acourately as possible the probable price which potatoes will bring from the time they are stored until the last of them are sold late in the spring will determine whether it will pay" to store them or not.

The farm price of potatoes at digging time is msully very lom. MLst growers do not have storage facilities and must put their produet on the market in the fall. This inereases the supply" and lomers the price. 
The prineipal factor which will determine the advisability of storage is the probable winter and spring price: others are the soundness of the tubers at digging time; relative ense of getting them on the market in the winter ; their use for table stock or seed purposes and so forth.

Ordinarily al low-price season, resulting from orerproduetion, will be followed by a season of high priess. The srower should be earefully" informed coneerning the acreage of the whole comnty during the growing season and the reported condition of the erop from different sections. An extensive acreage and a favorable season results in low prices.

The arerage consumption per capita in the United States is from $3 \frac{1}{2}$ to $t$ bushels. If the acreage and weather conditions over the whole country" are likely" to produec a crop of over 400 million bushels, low prices may be looked for. The population of the United States is approximately 100 millions. At the rate of consumption of $3 \frac{1}{2}$ bushels for ench person, the total consumption will be 350 miltion bushels.

The United States Department of Agriculture issues a crop reporter each montl which gives the condition of the potato and other crops from all over the country. It is issued free to all and arrives abont the 20th of each month.

The amount of importation of potatoes into the U'nited States is regulated by the price here and elsewhere, which is in turn largely determined by the quantity of production. The protective tariff on potatoes is 10 eents a bushel.

The basis for storage must take into account American production and the probable price and the foreign production and price. When home prices reach a high level, foreign potatoes are sure to become a price-determining factor. 
It is obvious that all seed stock must be stored either by the grower, who may save his own seed, or by some large concern, who may store it for sale to growers in the spring (see Fig. 21). Seed stock should, perhaps, be stored more carefully than potatoes for eating purposes. Complete dormancy is necessary if the seed is to produce a good crop. If storage is not carried out properly, the tubers

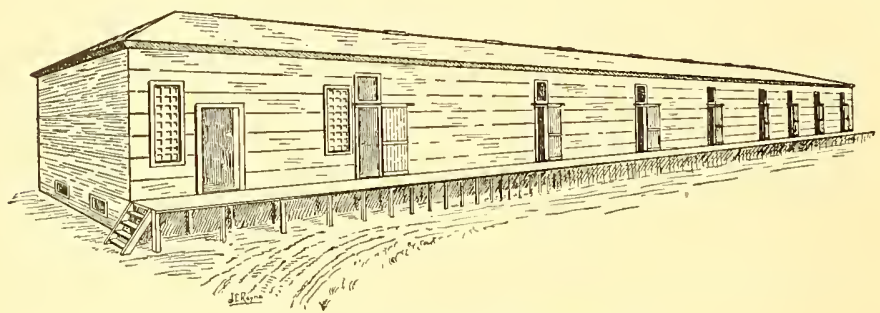

FIG. 21. Potato storage house.

become shriveled and are likely to produce long, weak sprouts, which greatly weakens them. Many growers follow the practice of storing stock in bags and turning the bags every week in the spring to break off the sprouts and prevent rapid deterioration. This practice when feasible seems to be very successful. 



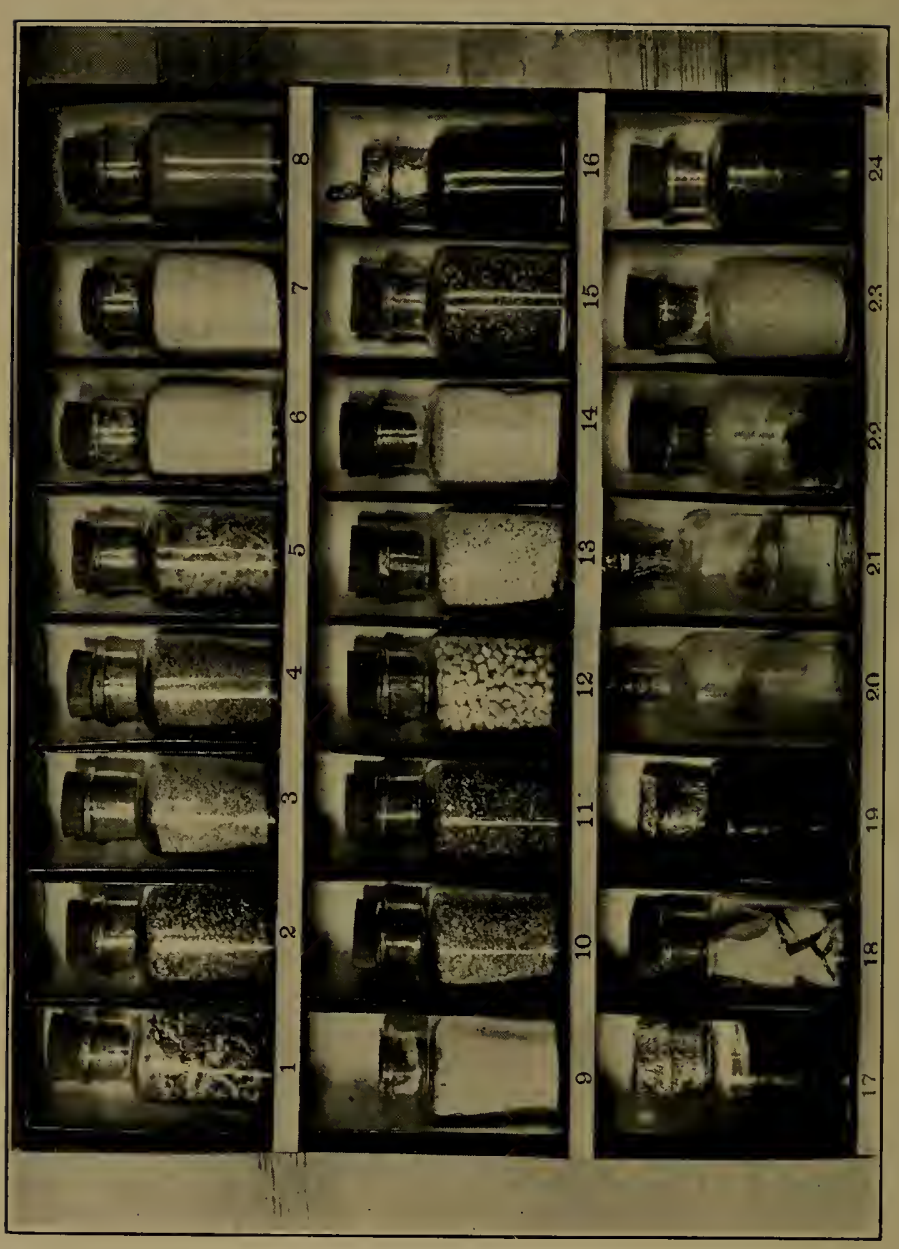

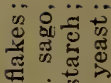
स $\overrightarrow{\text { का }}>$ வ

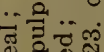
\& व कै कै के गु 리 हैं स돌 iิ 늑 Nㅜ วิ을 का ம …

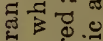
อ 0 ง. $x$ क is $\frac{0}{0}$ is 氙 $0^{\circ}$ $\ddot{q}$ - व ब्त is $\lambda$

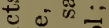

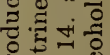
连... ․ㅡㅁ 胥 +... i. .

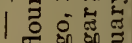

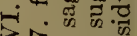
$>$ N 4 ... 동 무웡 을 蛹 A थे क्ष 


\section{CHAPTER XIV \\ USES OF THE POTATO}

The potato is one of the most important vegetable foods. Its rise in popularity since its introduction into Europe has been very rapid. At first the tubers were regarded as poisonous, and only a few of the more venturesome dared to eat them. When these men found the potato to be edible, the people of France and Germany began to plant it as a reserve food in case other crops failed. By 1770 it had become a common field crop in Europe. These potatoes, however, were usually small in size and of poor quality, and for this reason they were used principally as a food for animals. The possibilities of improving the crop were soon learned, and by 1840 it was being widely used as a substitute for the cereals and other starchy foods. In 1900 it was estimated that the potato furnishes about $\frac{1}{8}$ of the total food consumed in the United States.

Although it is primarily a food crop, the potato has a great variety of uses (see Plate XVI). For a long time it was the chief source of commercial starch, and although cornstarch is now preferred, the starch of the potato is still used in large quantities to make sizing for paper and textiles. Another important use for potatoes is in the manufacture of industrial alcohol. This industry is almost unknown in this country, but in Europe it has 
attained large proportions. Potato flour, glucose, sirup, mucilage and a number of tinctures are also made from potatoes. In Europe the small potatoes and culls are used to feed stock, and the slops from the manufacture of alcohol are carted away daily for this purpose.

\section{USE FOR HUMAN FOOD}

So accustomed have we become to the potato that it is difficult to imagine our tables without it. It furnishes us daily with an abundant supply of nutrients at a relatively low price. Primarily it is a starchy food, but it also contains some protein and a little mineral matter,

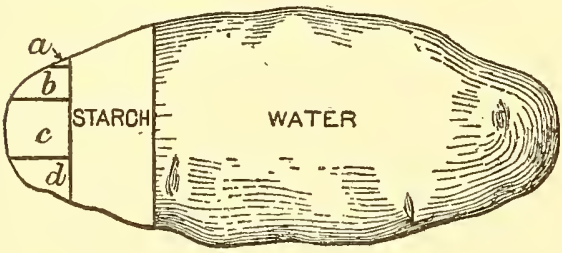

FIG. 22. Composition of the potato. $a$, fat; $b$, crude fiber and other carbohydrates exclusive of starch; $c$, protein; $d$, ash. and it adds bulk to the food eaten. It is said that the potato represents 3.9 per cent of the total cost of food, and furnishes 5.3 per cent of the heat calories needed by the body. As the potato is somewhat deficient in protein and fats, it cannot be used exclusively in the diet, but must be combined with lean meat, legumes, eggs or other protein-supplying foods, and with cream, butter or other fatty substances.

Not only does the potato furnish considerable nutriment, but it supplies it in an easily digestible form. The starch in potatoes is much more readily digested than the starch of cereals or other starch-producing foods. In Germany a gruel made from the pulp of baked potatoes is used to feed infants and invalids. 
It is said that about 20 per cent of the tuber is waste. As this percentage is mostly skin and that part of the cortical layer removed with it, the percentage will vary with the size of the potato, the shape and the care used in feeding it. About 62 per cent of the whole tuber is water, and about 78 per cent of the edible portion is water. Carbohydrates form about 18 per cent of the peeled tuber. About 2 per cent is protein and 1 per cent ash. The fat content is rather low, being only 0.1 per cent (see Fig. 22). A large proportion of the protein and minerals is contained in the outer layers of the potato, and frequently much of this is lost in careless peeling.

\section{Quality when cooked}

The requirements for quality in a cooked potato vary, depending on the personal taste of the user and on the particular way in which the tubers are to be cooked. In America a mealy, white-centered potato is usually preferred for boiling, steaming and baking. Europeans frequently prefer a less starchy potato, which means one with a higher percentage of protein. Such potatoes are richer in flavor and of better substance than the mealy ones. In some sections of Europe a mealy potato is in demand for boiling, and a waxy potato for frying and for salads. If Americans were to discriminate in favor of certain textures of flesh for special purposes, varieties meeting the requirements would undoubtedly be developed.

There are many factors influencing the quality of a potato when cooked and its value as a food. Undoubtedly the nature of the soil in which the tubers are formed has some effect upon these characters, but, so far, no definite relation has been worked out. It is also true that disease 


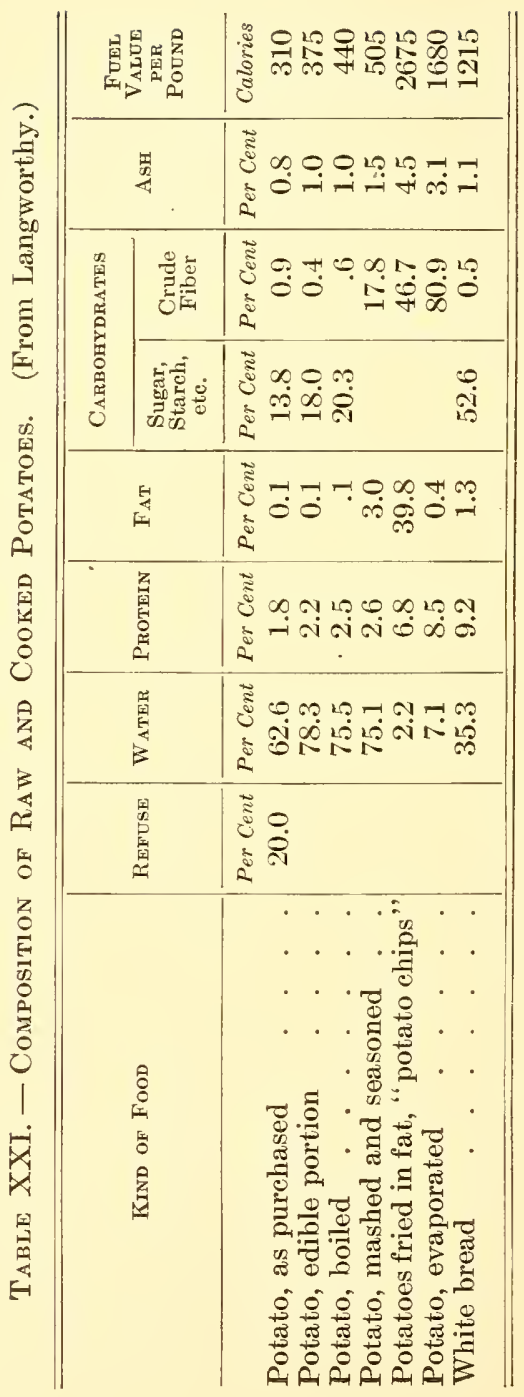


and seasonal conditions affect quality. In addition to these factors, there are chemical composition, degree of maturity, conditions of storage and methods of preparation for the table, all having an important bearing on quality and food value.

There are three textures of flesh in the cooked potato as determined by the chemical composition: soggy, waxy and mealy. The soggy potato is usually rather low in starch and relatively high in protein. In potatoes of this type, when the starch grains are heated they swell up, but there are not enough of them to burst the cellwalls in the tuber and give the starchy and mealy condition so often desired. The tuber more easily absorbs water and becomes wet and soggy at the center. The protein also tends to coagulate and make the flesh heavier than it is in the mealy potato.

In potatoes of a waxy texture, there is a greater proportion of starch to protein. The protein serves as a framework which prevents the starch from forming flaky masses and holds the potato together better. Such potatoes are desired for salads and for garnishing meat dishes.

In the mealy potato, the cells are packed with starch grains. These expand with the heat of cooking and tear apart the cell-walls, making the center of the tuber a mass of flaky starch. If the starch content is too high, the tubers will fall to pieces in cooking. The optimum starch content is about 20 per cent of the peeled tuber.

Potatoes are of the best quality when they have matured fully and have been freshly dug from the soil. At this time the starch has been fully developed. Immature potatoes are usually high in protein, and they frequently contain acids and sugars which affect their flavor. The albuminoids which are frequently found in immature 
tubers gelatinize on cooking and make the flesh moist and soggy. Potatoes with a netted skin and crisp flesh are most likely to be mealy when cooked.

No matter how carefully potatoes are stored, there are changes in composition taking place all the time, which affect the quality. The tuber, like an apple, is a living thing, and life processes are going on in it, though to be sure they are slow. As the winter proceeds, enzymes begin to work upon the starch and sugars and to break them down. Water and carbon dioxide are given off as a result. This causes a loss of starch and a shrinkage of the tuber. The sugars developed usually give the potato a sweeter taste than is found in the freshly dug tubers. Towards spring the potatoes begin to sprout, and of course at this time the chemical changes are rapid. There is a rapid loss of mealiness accompanying the sprouting.

The method of cooking has some effect upon quality and food value, but it is usually because of a modification of the texture or the combination of fats and other substances with the potato in the process of cooking. Boiled potatoes are most likely to lose in food value during cooking. This loss can be minimized, however, by cooking with the skins on. Baked potatoes lose very little, either in nutrients or in quality, when cooked. They are usually more mealy than potatoes which have been boiled or steamed. Mashed potatoes are usually seasoned with milk or cream and butter. This makes them higher in fat than when they are boiled or baked. Potatoes fried in fat are richest in food nutrients. The water is largely extracted and much fat is absorbed. Where possible, it is best to cook potatoes with their skins on. Experimental studies have shown that when potatoes are boiled in the skins, practically no starch is lost and only a 
small amount of the protein and ash or mineral matter. Potatoes which are peeled and soaked in water before cooking often lose as high as 7 per cent of their nutrients.

\section{USE FOR STARCH}

The principal article of manufacture from potatoes is starch. Until cornstarch supplanted it, potato starch was largely used in cooking. Now it is mainly employed for making sizing for paper and textiles, and for other technical purposes. Potato starch has also sometimes been used as an adulterant of fine flours and starches.

The total annual production of starch from potatoes in the United States is about 15,500 tons, of which 6000 tons are produced in the county of Aroostook, Maine. The soil of this county is unusually well adapted to potato growing.

Unless the price of marketable potatoes is very low, only the small injured or refuse potatoes are sold to the starch factory. Whenever the price of good merchantable potatoes is above 50 cents a barrel, the farmers find it more profitable to sell directly to the market.

\section{Process of starch manufacture}

The potatoes which are kept in a storehouse are carried, after weighing, to a revolving washer about 12 feet long and 18 to 24 inches in diameter. They are pushed to the comminutor through the washer by means of a perforated spiral or by arms attached to a revolving axle. A stream of water flowing in the opposite direction to that of the motion of the potatoes secures the final washing with clean water. By the time the potatoes have 
reached the comminutor they are practically free from dirt. A diagram of this machine is shown in Fig. 23.

The rasping machine consists of a cylinder about 30 inches in diameter and 36 inches long. It is made of

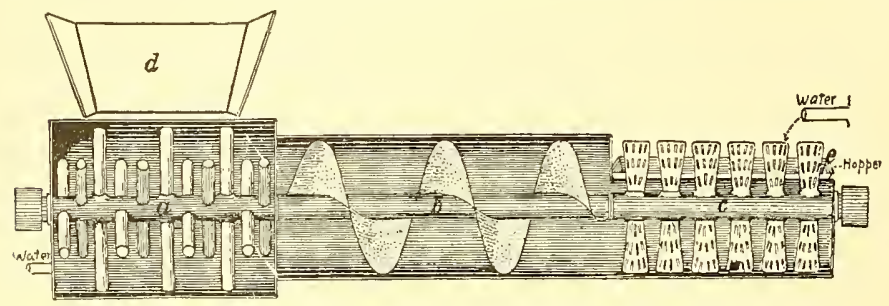

FIG. 23. Machine for washing potatoes.

wood and is covered with pieces of sheet iron punched full of holes about $\frac{1}{8}$ of an inch in diameter. These holes have the rough edges outward. This rasping machine or comminutor is shown in Figs. 24, 25.

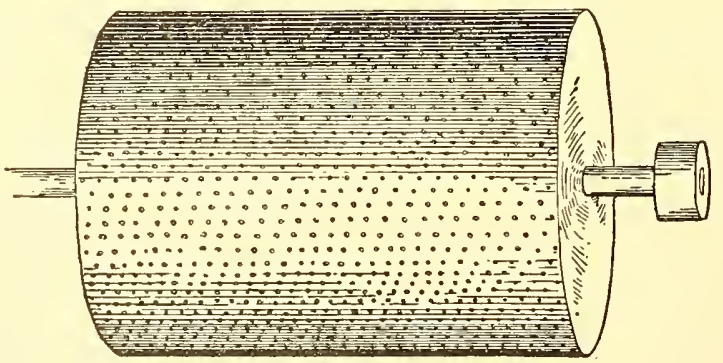

FIG. 24. Rasping cylinder or comminutor.

The rate of revolution of the cylinder is about 600 a minute. It revolves as near a brace of hardwood as possible, and the potato, being stopped from passing by the brace, is reduced to a fine pulp by the rapidly revolving drum. 
From the rasper the pulp falls on to a starch separator, the bottom of which is of fine wire gauze having 30 meshes to the inch, the openings being $\frac{1}{60}$ of an inch in diameter. The separator is slightly inclined, so that the shaking

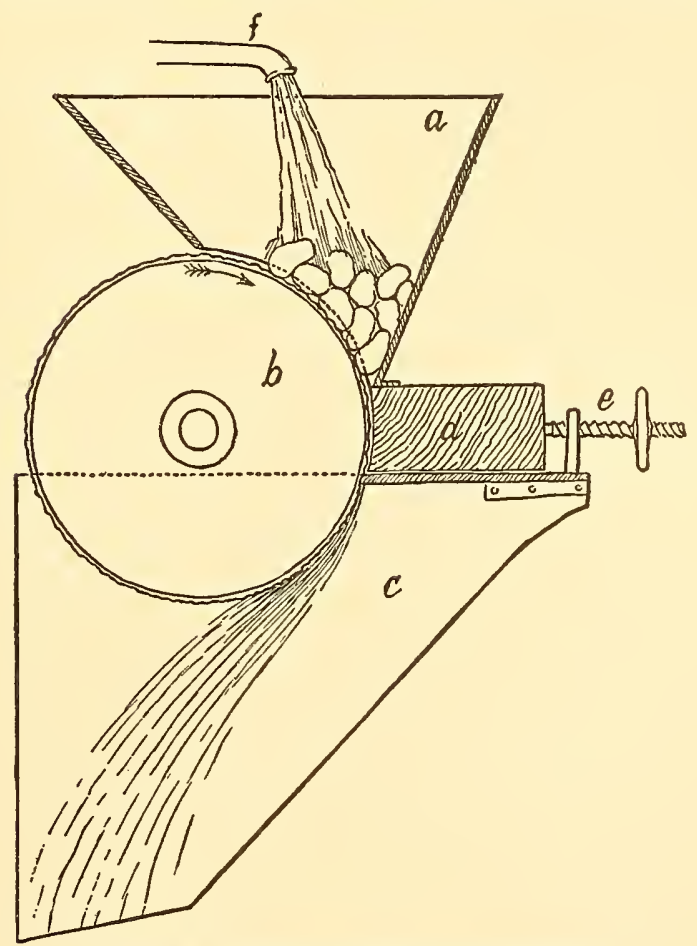

FIG. 25. Rasping machine (cross section).

process gradually moves the pulp toward the lower end. This separator is of the same width as the rasps, namely, about 36 inches, and is about 12 feet long.

During the progress of the pulp along the separator, 
jets of water are thrown upon it from pipes arranged above. This water detaches the starch granules from the pulp, and the granules, being small, are carried through the meshes of the gauze, while the pulp is left on the screen and ejected finally at the lower end.

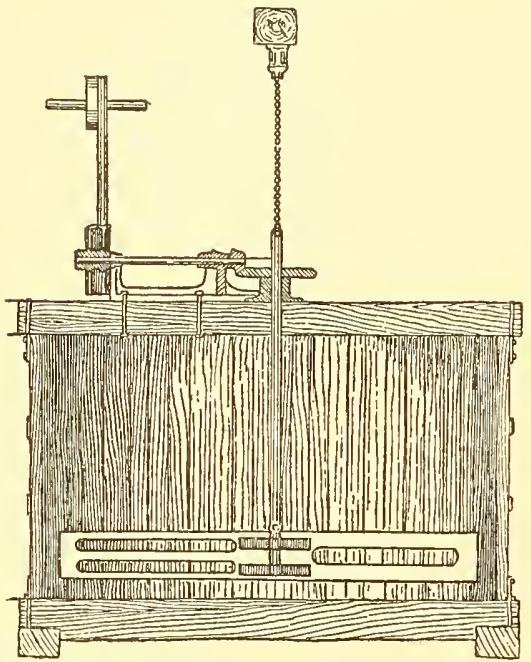

F1G. 26. Starch washer (interior view).

The starch which is carried through by the water falls in large tanks, varying in size from 20 to 40 feet in length and width and from 6 to 8 feet in depth. The starch settles to the bottom very quickly and the reddish-colored supernatant water can be drawn off. In a few hours the starch has all settled in a hard, compact mass at the bottom of the tank. The proportion of starch and water is such that 4 inches of starch is overlaid with about 6 feet of water.

The crude starch obtained in this tank is then thrown into another tank of a similar size which is fitted with a revolving stirrer; water is added in large quantities at the same time and the starch is beaten into a cream and again allowed to settle. The interior view of such a tank can be seen in Fig. 26. This process washes the starch and removes the larger portion of impurities. 
In the second settling the pure starch is first to go to the bottom, and when the water is drawn off it is found to be covered with a thin layer of starch mixed with various forms of impurities. This layer is removed separately, and the pure starch underneath is ready for the drying tables.

The layer of dirty starch removed as above indicated is given a second washing and if necessary a third, until the starch is thoroughly cleaned.

The most modern way of drying is to have the starch stream out on shelves made up of slats through which the dried starch can fall to the shelf below. The drying kiln is heated by steam pipes running along the bottom underneath the shelves. The entrance for air is so arranged that it will come in over the pipes and thus become dried.

The starch is first placed upon the upper floors on these wooden slats which have openings of about $\frac{1}{2}$ inch. This is the coolest part of the kiln, so that the starch which is most moist is subjected to the least amount of heat. It is not safe to submit very wet starch to a high temperature, for there would be danger of converting it into a paste and rendering it unfit for market. When the starch is partially dried, it is raked over the grated floor and the particles which are dry enough to be easily detached fall through and strike similar grates below. This raking process continues until the starch in a fine powder form reaches the lower floor in a state of dehydration suitable for barreling. The dried starch is finally raked into a trough running alongside of the lower floor of the kiln, and from there it is placed in the barrels.

It requires about 12 hours to complete the drying when the most efficient kilns are used, so that the kilns 
are charged twice a day. The size of the kilns is, of course, proportionate to the capacity of the house. For a house using 1200 barrels of potatoes a day the kilns are about 40 feet long and 30 feet wide, and the drying shelves are about 15 feet in height.

After the starch is thoroughly dried, it is placed in heaps in order that the moisture may be evenly distributed throughout the mass. It is evident from the method of drying that some parts of the starch come from the kilns drier than others, as this banking or heaping of the starch is very essential in order to get uniformity of moisture. After the mass of starch has become uniform in its content of moisture, it is placed in barrels and is then ready for transportation.

\section{Uses of potato starch}

Starch and its by-products have many uses in the technical and industrial world. It possesses peculiar properties rendering it especially valuable for use in print works. The makers of prints are even willing to pay a considerable increase in price for potato starch over that which they would have to pay for starch from Indian corn.

In the textile industries, it has come to be used extensively and in many ways.

It is used in the manufacture of cotton, woolen, linen and silk goods for three distinct purposes: as a sizing for the warp yarn before it is woven; for finishing goods after they have been woven; in the form of dextrin or roasted starch, as a thickener, or vehicle for applying colors to the fabric.

In Europe, especially in England, large quantities of 
potato starch are used for the manufacture of dextrin or British gum, as it is called; in which form it is used for various kinds of mucilage, as, for instance, that applied to postage and other stamps. The manufacture of dextrin of this kind is an important branch of the industries connected with starch.

The pomace or residue which is left in the manufacture of starch from potatoes has been used to some extent as a food starch, and its use as a food will be discussed later under food for stock.

\section{USE FOR INDUSTRIAL ALCOHOL}

Next to starch, industrial alcohol is the most important product of potatoes. The potato is one source of such alcohol, and in Europe, especially in Germany, is the chief source. As yet this sort of production in connection with potato-growing has not gained a foothold in the United States. But a brief survey of the wide extent of the practice in Germany may throw some light upon its possibilities.

In Germany, with the extension of the cultivation of the potato, which gives a larger starch yield to the acre than the cereals, the distillation of alcohol has become largely an agricultural industry. The use in Germany of potatoes for making alcohol has steadily increased from $1,915,800$ pounds in 1855 to $4,706,820,000$ pounds in 1905. The consumption of potatoes has increased, therefore, nearly 2500-fold during 50 years. In this connection it must be remembered that the starch content of potatoes has also been increased. The best indication of the growth of the potato alcohol industry is from the output of the finished product. 
1855 . . . . 32,757,700 gallons absolute alcohol 1860 . . . . 42,003,825 gallons absolute alcohol 1865 . . . . 52,570,825 gallons absolute alcohol 1906 . exceeded 115,444,445 gallons absolute alcohol

Distillation is, therefore, a very important and extensive agricultural industry in Germany. There the potato is the principal source of alcohol, and the production of spirits from other substances is insignificant in comparison with that from potatoes.

The agricultural significance of the development of the potato industry as worked out in Germany is manifold.

1. All the ingredients taken from the soil by the potato are returned to the soil.

2. The mash, which is the product obtained after the starch has been converted into alcohol and the latter has been removed by distillation, is a valuable feed for cattle. This enables the farmer to maintain a large number of cattle, and they in turn provide the manure so necessary for the light soil.

3. The introduction of a cultivated crop into the rotation has been of the greatest benefit, because it has made possible larger yields of grain.

4. It has enabled the farmer to convert the unstable crop, especially of those varieties of poor keeping qualities, into a stable product, alcohol, which may be held as surplus stock for several years.

As was shown above, potatoes have been used in other countries as a source of cheap alcohol, and the possibilities of its becoming a profitable enterprise in America are very promising; for conditions in this country indicate that large quantities of potato culls with the necessary starch content are available for this purpose at a price 
which would permit of the profitable manufacture of alcohol therefrom. Experimental work at the United States distillery has shown that the potato can be economically handled in manufacturing alcohol, and the farmer can convert frosted or inferior grades of potatoes into a source of revenue. It also furnishes in the residue, or slop, a feed for stock. In recent years, many persons have become so much interested in this industry that it seems advisable to give a somewhat thorough discussion of the methods of manufacturing alcohol from potatoes.

The alcohol from potatoes is a result of the action of malt or acids on the starch, which is turned into sugar and then fermented to give this final product. The socalled "denatured alcohol" is prepared by the addition of such ingredients as will make the alcohol unfit for drinking purposes. This alcohol is used extensively in the manufacture of varnish, explosives, chemicals and many other commercial substances. It may also be used in various household appliances, both for lighting and heating purposes, and with much more safety than either kerosene or gasoline.

This discussion is limited to the methods which can be used upon a farm, or by a farm community, in a small distillery handled by the farmer himself. The potatoes should of course have enough starch to be worth using for this purpose. From experiments it has been determined that there should not be less than 6 per cent of sugar or starch before the materials can be considered suitable for the profitable manufacture of alcohol. 


\section{The manufacture of alcohol from potatoes}

The first essential in manufacturing alcohol from potatoes is that the distillery should be centrally located in a potato-raising country; and secondly, the railroad facilities should be such that delivery of raw materials and feed, and the marketing of the finished product, can be done at a minimum expense. An abundant supply of cold soft water is of almost equal importance. It is desirable that the plant be near a creek or stream from which water may be obtained and into which it may be drained after serving its purpose in the distillery.

As the distillery cannot be run throughout the entire year, the machinery should be simple, practical and economical. Advantage should be taken of the laws of gravity to save pumping whenever possible. This can be done by arranging the apparatus so that each operation will be on a lower level than the preceding one; thus by elevating the raw material to a height suitable for the first operation, it will flow from one apparatus to another by its own weight. All machinery requiring steam should be placed close to the boiler so as to avoid condensation caused by long pipe connections. Exhaust steam from the engines and pumps should be used in the distillery apparatus and the hot water from the condenser should be utilized as feed water for the boiler. Each piece of apparatus should have a capacity equal to the exact amount of work it is expected to do, the only exception to this being the boiler, upon the efficiency of which depends the proper working of each piece of apparatus. The boiler should be of a slightly larger capacity than is actually required.

This following data on the cost of a distillery are of a supposed plant which has a capacity for handling 8000 pounds of potatoes in one working day of 10 hours. The building is one story high, with a ground space of 1000 square feet. The walls are constructed of any available material. In many cases farm buildings, such as barns and the like, could be used. Such a building will not cost more than $\$ 1500$. Total cost of machinery and equipment not inclusive of motor power is about $\$ 9000$. One 75-horsepower boiler and a 25-horsepower engine will be required and will cost about $\$ 1500$. This would make a total investment of about $\$ 12,000$.

A day's expenses will include the cost of potatoes, barley, fuel and labor. Cull potatoes can be delivered at a distillery in some potato-growing districts at 25 cents for 100 pounds. At this rate the raw material for a day's run of 8000 pounds will cost $\$ 20$. To 
convert the starch of the potatoes into sugar, there will be needed the green malt vielded by 120 pounds of barley, which at 70 cents a busbel will cost $\$ 1.75$.

The cost of fuel varies with the fireman, but with proper care and efficient use one ton at $\$ 4$ should be enough for a day's operation. Three men will be required, consisting of a fireman and two laborers. This will total up to about $\$ 33$ for daily operating expenses.

Operating a distillery. - The first process is to wash and then cool the potatoes so that the starch present can be thoroughly converted into sugar by the action of the malt. The potatoes are placed in a vacuum cooker and steamed until they are thoroughly cooked. The steam pressure in the cooker is allowed to rise to 50 or 60 pounds. The entire time required for warming the potatoes and reaching the maximum pressure should be about one hour. The potatoes are stirred and the pressure held for about ten more minutes to insure a good cooking of the starch. Then the temperature of the cooked potatoes is allowed to fall to $212^{\circ} \mathrm{F}$. The temperature of the cooked potatoes is further reduced by means of the vacuum pump to $140-145 \mathrm{~F} .^{\circ}$ at which point the malt necessary to change the starch to sugar is added. About 2 pounds of malt is added for each 100 pounds of potatoes mashed. The green malt is crushed between rolls, while dried malt is ground in a mill before using. About fifteen minutes before the mash in the cooker is ready for malting, the malt already ground is mixed with water at the rate of 1 gallon of water to 2.5 pounds of dried malt, or $\frac{3}{4}$ gallon of water to same amount of green malt. This is prepared in a tub above the cooker and is dropped into the cooker when the temperature is down to $140^{\circ}$ to $145^{\circ} \mathrm{F}$. The diastase in the malt will dissolve the cooked starch and convert it into a fermentable sugar in about fifteen or twenty minutes, during which time the mash should be constantly stirred. This is kept up until the test for complete conversion shows no starch. This test consists in filtering a little of the mash into a white porcelain dish and adding a few drops of iodine solution (2.5 drams potassium iodide and 75 grains iodine to 1 quart water and shake). If the mixture is blue, it shows the presence of starch, and it is then necessary to add more malt, or allow more time for conversion. The cleaned mash is pumped through the mash cooler, where it is reduced to the "pitching" (this means temperature in which yeast can ferment) temperature, by circulating a constant stream of cold water around the pipes through which the mash goes. This tempera- 
ture most favorable to fermentation is between $60^{\circ}$ and $70^{\circ} \mathrm{F}$., depending on the weather conditions and volume of the mash. At the same time the mash is run through the fermenter the yeast mash (about 3 per cent by volume of the main mash) is also added. It is prepared in a tube above the fermenter and can be dropped into it.

Fermenting the mash. - After the yeast and mash are in the fermenter, the process of fermentation will begin and the sugar in solution will be broken down into alcohol and carbon dioxide gas. The gas goes out into the air, and the alcohol remains. At this point, it is important to know the gravity and aridity of the "set mash" as it is now called. The specific gravity indicates the amount of sugar and is ascertained as follows: Stir mash and filter small portion through cheesecloth into a cylinder. A Balling saccharimeter is placed in the filtered liquid. The reading at the level of the liquid should be $16^{\circ}$ to $18^{\circ}$, showing that the mash contains 16 to 18 per cent of solids, most of which is sugar. The acidity of the set mash is determined by neutralizing a small portion of the mash in a normal solution of sodium hydroxide, and the amount of the latter required will represent the acidity of the mash. It is done in the following way : 20 cubic centimeters of the filtered liquid is placed in a beaker and the sodium hydroxide is slowly dropped in from a burette until the filtered liquid has been neutralized and will not turn blue litmus red or red litmus blue. The number of cubic centimeters of sodiun hydroxide used will represent the acidity of the mash. After the mash has been set for ten or tivelve hours, the fermentation will become vigorous and the temperature will rise. It should not be allowed to go above $80^{\circ} \mathrm{F}$. or much of the alcohol will evaporate. To keep the mash cool, a coil with cold water passing through it is slowly raised and lowered through the mash. The fermentation is allowed to continue at a temperature of $60^{\circ}$ to $80^{\circ} \mathrm{F}$. for 72 hours. The gravity should fall and the acidity remain about the same during the process. The tests should be made every 24 hours. If the acidity rises too much, the fermenters are scrubbed clean with a 5 per cent solution of formalin or other disinfectant. This will clean out the butyric acid which often is the cause for raised acidity.

Distillina the alcohol. - In Fig. 27 is shown a distilling apparatus adapted for the economic separation of alcohol from the mash. It is not complicated, as one would think at a first glance, but is very simple. The fermented mash is slowly pumped into a distilling apparatus, where it is brought into contact with live steam, which boils 


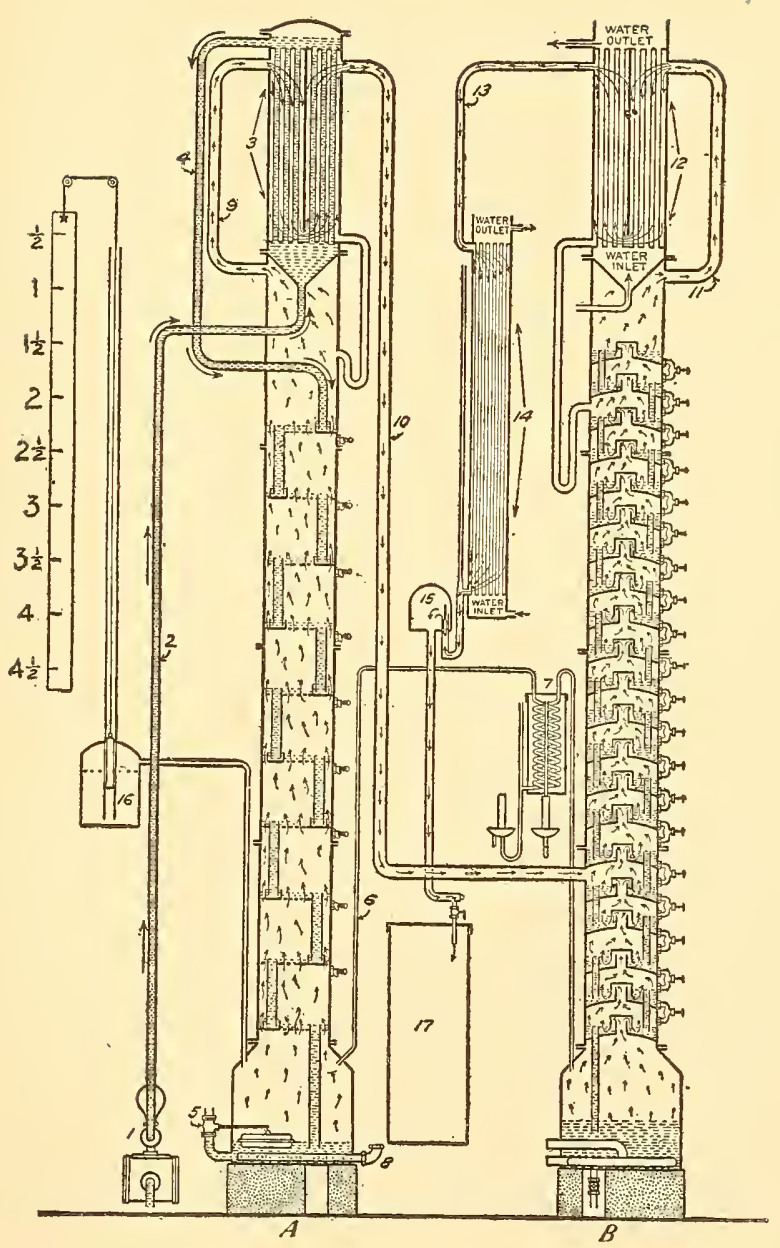

FIG. 27. - Distilling apparatus for making alcohol from potatoes. 
it and carries away the alcohol in vapor form, which in turn is passed through a condenser, where it is reduced to a liquid. The distilling apparatus consists of two copper columns, $A$ and $B, A$ being to distil the alcohol from the mash and $B$ where it is redistilled and raised to desired strength. The fermented mash is continually discharged from pump 1 and pipe 2 into mash heater 3 . This heater is made up of a series of tubes through which the mash gas goes and around which the vapors from the boiling mash are passed when going from $A$ to $B$. The heated mash leaves 3 through pipe 4 and comes in contact with steam. The mash goes through a series of chambers, where it is boiled and the alcohol relieved from it. This mash takes a downward course from one chamber to another, and its course may be followed by the shaded portions in $A$. By the time it reaches the bottom, the mash will lose all its alcohol, and this mash will be automatically discharged through 5. A small portion of the vapors will be sent through pipe 6 to the condenser 7 , and be tested to see whether any alcohol is being lost in the "slop," as the discharged mash is called. The steam necessary to boil the mash comes into the bottom chamber through 8 , and it boils the mash in this chamber and passes upward, boiling the descending mash in the various chambers and carrying with it the vapors. The plates within column $A$ are so perforated as to allow the ascent of the vapors through it, but do not allow the mash to fall through it, because of the steam pressure. The vapors rise up through $A$ and go through pipe 9 to the heater 3 , where they are circulated around the tubes and then carried through pipe 10 over to $B$. The vapors coming from $A$ contain a considerable amount of moisture and other impurities which are freed in $B$, which contains a series of chambers upon each of which is carried about 3 inches of liquid. The plates are not perforated in this column, but the vapors ascend through a central pipe and are deflected downward by a hood over the pipe in each chamber and are forced to boil their way through the liquid in each plate. The arrows show their courses. These vapors become purer as they ascend until they reach the top chamber, from which they are delivered to pipe 11 and thus into a cooler 12 , where they are partially cooled. From the cooler they pass into pipe 13 and through it to the condenser 14, where they are reduced to a liquid. This cooling and reducing is done by circulating cold water around the tubes containing the vapors. The condensed vapor or alcoliol is drawn off at the bottom of the condenser and allowed to flow through the test box 
15, where it can be examined for its purity and strength. The steam pressure in the apparatus is registered by the pressure gauge 16. The alcohol afterwards passes through the test box into the storage tank 17 to be denatured.

Wood alcohol and benzin are generally used as denaturing agents, though other ingredients may be used. The ingredients used must be authorized by the Bureau of Internal Revenue.

Preparation of green barley malt. - There are two operations the first being to steep or soak the grain, and the second, sprouting or growing it. The steeping consists of soaking the grain in water until it has absorbed sufficient moisture to enable it to sprout when spread upon the malting floor. Good barley malt can be obtained from a good grade of barley properly steeped (for two or three days) and grown for a long interval of time (12 to 20 days) with a fair amount of moisture at a temperature not to exceed $60^{\circ}-63^{\circ} \mathrm{F}$. The malt should be thoroughly crushed before using.

Control of operation. - It is advisable to operate a distillery only during the colder months, for instance from early autumn until late spring. During this time the temperature of the cooling water will be considerably lower, and the amount of water required correspondingly less, and the time required for cooling decidedly shortened. This means a shorter working day and consequently less wear on the machinery and a considerable saving of fuel. It is essential that a distillery be operated daily and not intermittently, as each day's work depends in a greater or less degree both upon that of the preceding and the following day. Another very important point is cleanliness, and upon this depends the final yield of alcohol in a great measure. Many injurious organisms will breed and work into the mash and hinder the process of fermentation. This may be remedied by running water through the apparatus at the end of the day's work, and the walls of the building should be kept from mold by whitewashing.

Preparation of a potato-yeast mash. - The yeast mash is prepared in a wooden tub equipped with a ralse for stirring and with proper piping for heating and cooling. The volume of the yeast should be from 2 to 3 per cent of the main mash to be fermented and increased to ten times that of the yeast mash used to start it. Rye is best used to start with, and later the potatoes may be substituted. The rye and malt are mashed together. The malt should be left to work for about three hours, by which time the formation of the sugar will be complete. The gravity should be $20^{\circ}-24^{\circ}$ Balling. Then the mash 
is soured by the addition of some acids (lactic acid is best) which will suppress organisms which infect starchy materials. It will take between 24 and 48 hours to reach the right acidity, which is 2.5 or 3 cubic centimeters. Then heat and then cool. When temperature is about $90^{\circ} \mathrm{F}$., add the yeast (about 10 per cent of volume of mash). Then reduce the temperature to $60^{\circ}-70^{\circ} \mathrm{F}$. Allow to ferment for 24 hours, during which time the temperature will rise, but never allow it to get above $90^{\circ} \mathrm{F}$. Then this can be used in needed quantities to be added to the main mash.

\section{USE AS STOCK FOOD}

The value of the potato as a food is great, for it is a very concentrated starchy food. When fed alone, it is incapable of supplying all of the wants of the body. Experiments by Girarde showed that the feeding of too many potatoes to stock would decrease the digestibility of the protein, the fat and the crude fiber:

TABLe XXII

\begin{tabular}{|c|c|c|c|c|c|c|c|}
\hline ○ి & 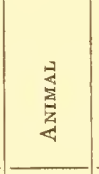 & 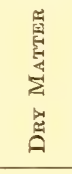 & 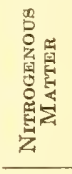 & 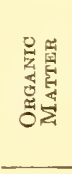 & 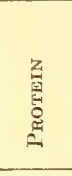 & 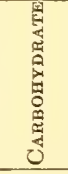 & $\stackrel{\text { 圈 }}{<}$ \\
\hline & $\begin{array}{l}\text { Per } \\
\text { Cent }\end{array}$ & $\begin{array}{l}\text { Per } \\
\text { Cent }\end{array}$ & $\begin{array}{l}\text { Per } \\
\text { Cent }\end{array}$ & $\begin{array}{l}\text { Per } \\
\text { Cent }\end{array}$ & $\begin{array}{l}\text { Per } \\
\text { Cent }\end{array}$ & $\begin{array}{l}\text { Per } \\
\text { Cent }\end{array}$ & $\begin{array}{l}\text { Per } \\
\text { Cent }\end{array}$ \\
\hline Potatoes . . . & Pigs & 97.0 & 84.5 & & $\$ 2$ & 91.8 & 44.6 \\
\hline Potatoes cooked . & Pigs & 95.0 & $\$ 2.0$ & & 80 & 97.6 & 40.0 \\
\hline ground . . . & Sheep & SO.1 & & 81.5 & 19.5 & 42.0 & \\
\hline
\end{tabular}

(From S. Fraser. "The Potato.”)

It was also found to have increased the time of churning butter from 36 to $\$ 6$ minutes. There was no effect on the milk composition, but it did affect its behavior towards rennet, injuring the milk for cheese-making.

Potatoes when fed to pigs have been shown to be almost entirely digestible. 
Snyder found that potatoes, when fed with grains or some milled products like oil meal, beans or good wheat screenings, were very suitable for fattening purposes. In experiments with sheep and cattle a ration composed chiefly of potatoes afforded rapid gains in live weight, a large percentage in dressed weight of the slaughtered animals and flesh of excellent quality.

Experiments in Minnesota have shown that potatoes are very digestible; when 100 pounds are fed to pigs, 23.8 pounds dry matter are digested, while only 75 pounds are indigestible. At the Hohenheim and Proskern stations, the results on this question showed that they may, for practical purposes, be assumed to be completely digestible. Snyder, at the Minnesota Station, found that though cooked potatoes were eaten in greater quantities, the digestibility was not increased.

Thus, it can easily be seen that potatoes, especially when abundant and low in price, may be fed to all kinds of stock. In France, Girarde fed 55 to 66 pounds of cooked potatoes a day to fattening steers and $4 \frac{1}{2}$ to $6 \frac{1}{2}$ pounds to sheep. Von Fanche found uncooked potatoes good for all stock except pigs. He fed 60 pounds raw potatoes, 6 pounds oil meal and 9 pounds clover hay with salt to a 1000 -pounds live weight a day to fattening steers. For milch cows, 25 pounds daily to a 1000 -pounds live weight is the limit. For yearling ewes and wether sheep 25 pounds to a 1000-pounds live weight a day is advised, and for fattening sheep 40 pounds. For horses about 12 pounds to a 1000 -pounds live weight may be given with other food.

Stock should not be watered soon after feeding potatoes, but preferably about $\frac{1}{2}$ hour before feeding. Potatoes are not valuable as a food for young animals as they are 
deficient in protein and ash, hence should not be fed to growing cattle under two years old, lambs and young pigs, unless in small amounts.

\section{Alcohol slops or residue}

The residue remaining from the production of alcohol contains all the constituents of the materials employed, except that portion of the sugars and starch which was converted into alcohol during the fermenting period. This "slop" has been found, both in this country and abroad, to be a feeding stuff of high value, and should be fed to the stock which furnishes the fertilizer for the potatoes to be used in the distillery.

\section{TABLE XXIII}

Composition of the Slop

\begin{tabular}{l|r|r|r|r|r|r|r}
\hline & Ash & $\begin{array}{r}\text { Protein } \\
\text { N.X6.25 }\end{array}$ & Fat & Sugar & Starch & $\begin{array}{c}\text { Crude } \\
\text { Fiber }\end{array}$ & N. F. E. \\
\hline & & & \\
\hline Per Cent & Per Cent & Per Cent & Per Cent & Per Cent & Per Cent & Per Cent \\
Potato. . . & 4.39 & 10.06 & 0.29 & 1.59 & 70.35 & 2.26 & 10.55 \\
Potato skins . & 6.51 & 21.87 & 2.55 & 1.44 & 8.65 & 20.69 & 28.40 \\
Slops . . . & 11.26 & 30.00 & 0.69 & 2.29 & 2.98 & 6.54 & 46.24 \\
\hline
\end{tabular}

(From the U. S. D. A., Farmers' Bul. 410.)

This table shows that the dry substance of the slops is a higher nitrogenous food than the potato. It is due to the fermentation of the starch and sugar resulting in a concentration of the nitrogenous material. 


\section{Potato pomace}

Potato pomace is the residue which is left in the manufacture of starch from potatoes. It contains nearly all of the fiber, protein, fat and a large part of the starch found in the fresh potato. As it comes from the factory it has incorporated in it a large amount of water.

In this country this pulp mass goes to waste, but in Europe the potato and beet residue are rather extensively used as feeds in the wet condition, 80 pounds to 125 pounds being fed to cattle daily a head. There, however, the factories are running throughout the year, and the residue can be fed in the wet state. But here this is not possible, and as the wet residue cannot keep, some method must be devised to dry it out, for in the dry state it will keep well.

\section{Poultry food}

T. W. Saunders, in his book on the potato, very highly recommends the use of potatoes as a poultry food. When given in correct proportion, it will do good in a food. The starchy part of the potato is mainly used in maintaining the heat of the body. It is cheap and easy to prepare and generally liked by all classes of poultry. To get the right proportions, of course, one must take into consideration the condition of the birds, weather, temperature, method of housing, extent of liberty allowed and whether the birds are expected to produce eggs or to lay on fat and flesh.

A cheap good diet used for layers that are at liberty is equal parts by weight of potato and bran. The potato should be boiled, and the latter mashed into the potato while hot and the mixture given warm. If the weather 
is cold, add some linseed oil or fat. For confined layers, the proportion of potato should be reduced. Malt culms or sprouts are very good in combination with potatoes.

Indian meal, barley meal and rice meal should not be fed in combination with potatoes, for they lack nitrogen matter.

For fattening poultry, large amounts of potato can be used. Ducks, geese and turkeys fatten well on a mixture of potato and midds.

\section{Dried dessicated potatoes}

In Germany the manufacture of potato cakes is established, and these can be used as a food. The cakes, of course, are much smaller in bulk than the fresh potatoes, but after the soaking in water before using, their original character is regained. While the flavor and appearance cannot equal those of good fresh potatoes, they are considered appetizing and acceptable where fresh ones are unobtainable. In this form they can be easily preserved in the tropies and in the arctic region and thus furnish an excellent article of diet in a convenient form for transportation.

\section{Potato flour}

In Germany the manufacture of potato flour is very much advanced. Rye flour is improved for baking by its addition. During the winter of 1914-1915, when there was a shortage of flour, owing to the European war, potato flour was used to make cakes and bread. Cakemakers and confectioners used it mixed with wheat flour. 


\section{REFERENCES}

Canon, Helen.

1915. Potatoes in the Dietary. Cornell Reading Course Bul., Gilmian, J. W. Food Series No. 15.

1905. Quality in Potatoes. Cornell Bul. 230, pp. 503-525. Girarde, A.

Potatoes as a Food for Cattle and Sheep. Journ. Agr.

GrubB, E. H. Proc. 59 (1895), No. 20, pp. 709-712.

1912. The Potato. N. Y. (Doubleday), p. 545.

Henslow, G.

1910. Origin and Best of Our Garden Vegetables and Their

1911. Dietetic Values. Roy. Hort. Soc. Journ., 36, pp. 345346.

LANGWORTHY, C. F.

Potato as a Food. U. S. D. A., Farmers' Bul. 295.

Niviere and Humbert.

1895. Manufacture of Potato Cake. Abs. in Journ. Bd. Agr., 2 (1895), No. 2, pp. 190.

Parow, E. Potato Drying in Germany. Mitt. Deut. Landw. Gesell., 21 (1906), No. 25, pp. 264-266.

Searl, O., Springer, J., and KJus, M. J. Manufacture of Potato Starch. Tidsske-Norske Taudbr., 4 (1897), No. 5, pp. 203-208.

Skinner, A. P.

1910. Manufacture of Potato Spirit in Germany. Daily Cons. and Trade Repts. (U. S.) 13, No. 148, 11671169.

Sмiтн, C. D.

1896. Feeding Value of Potatoes. Mich. Sta. Rpt. 107.

SNyder, H. The Composition and Digestibility and Food Value of Potatoes. Minn. Sta. Rpt. 8 (1895), 83-96.

Wente, A. O. Potato Culls as a Source of Industrial Alcohol. U. S. D. A., Farmers' Bul.

Wiley, H. W. The Manufacture of Starch from Potatoes and Cassard. U. S. D. A., Div. of Chem., Bul. 58, pp. 48. 
Wiley, H. W. Potato as a Food. Compt. Rend. Acad. Sci., Paris (1897), No. 1, pp. 43, 46.

Wiley, H. W. Potato as a Food for Milch Cows. Journ. Agr. Pract., 58 (1894), No. 28, pp. 46-47.

Wiley, H. W. Potatoes as a Food for Beef Cattle and Sheep. Journ. Agr. Pract., 58 (1894), No. 28, pp. 43, 46. 


\section{CHAPTER XV}

\section{COST OF GROWING POTATOES}

THE cost of growing potatoes is very variable, depending upon many factors. The cost not only varies among different sections of the country, but among farmers in the same section. The price of land, use of machinery, amount of spraying and extensiveness of operations are only a few of the factors which determine the cost. When figures are compared from many areas, however, a considerable uniformity is found to exist.

Costs are given in the following pages from widely separated areas. They will give the reader a fairly accurate idea of the average expense involved in growing an acre of potatoes in different regions.

Place - Twin Falls County, Idaho.

Authority - Grubb and Guilford, "The Potato."

Detailed cost of producing a 150-bushel crop as follows :- -

Plowing . . . . . . . . . . . . . $\$ 3.00$

Harrowing . . . . . . . . . . $\quad .75$

Floating . . . . . . . . . . . . 1.00

Seed, average planting 700 pounds at 2 cents 14.00

Planting . . . . . . . . . 2.50

Irrigating first year . . . . . . . . 5.00

Cultivating three times at 50 cents . . . 1.50

Digging . . . . . . . 1.50

Picking -150 bushels at 4 cents . . . 6.00

Sacks -75 at 7 cents . . . . . . . . 5.25

Hauling to pit . . . . . . . . . . 2.00

Total 
"If potatoes are worth 50 cents a bushel, this crop would sell for $\$ 75$, leaving a profit of $\$ 30.50$ per acre, not deducting rent or interest or taxes.

"If, however, the grower produces a 600-bushel crop, the cost of producing (figuring twice as much seed and increased cost of the operations) would be about $\$ 95.75$. The crop would sell (at 50 cents a bushel) for $\$ 300$, leaving a profit of $\$ 204.25$."

Place - Colorado.

Authority - Greeley Commercial Club.

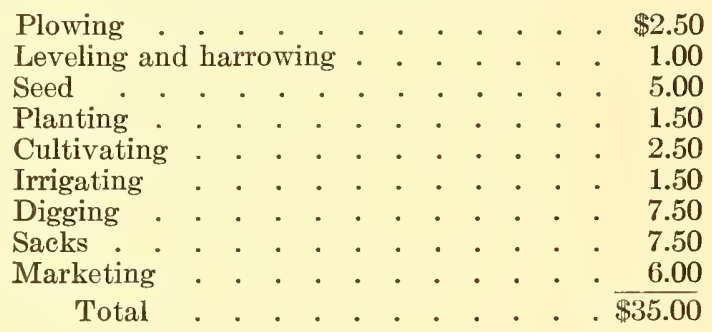

"This estimate is based on what is considered a good yield of from 200 to 300 bushels per acre. The first six items are practically uniform whatever the yield may be, while the last three depend upon the yield per acre, so that a poor yield or a failure reduces the cost per acre by about one-half and an extremely large yield increases it accordingly.

"The price of Colorado potatoes has a wide range from year to year, but the average price for the past ten years has been 65 cents per hundred pounds."

Place - Kansas. Forty representative growers from thirty-two different counties.

Authority - Report of Kansas State Board of Agriculture, 1904. 
Average cost of plowing . . . . . . . $\$ 1.20$

Harrowing . . . . . . . . . . . $\quad .54$

Seed . . . . . . . . . . . . . 7.25

Planting . . . . . . . . . . . . 1.35

Cultivating . . . . . . . . . . . . 1.66

Digging and marketing . . . . . . . 8.85

Wear and tear of tools and rental of land or interest on its value . . . . . . . . . 4.42

Total cost per acre, or 122 bushels.$\overline{\$ 25.27}$

Averages of other items, gathered from those furnishing the forty foregoing reports, are as follows:

Average number of years each of the forty reporters has

raised potatoes in Kansas . . . . . . . . . . . 18

Average number of acres raised by each annually . . . 26

Average quantity of seed planted per acre (bushels) . . 9

Average yield per acre (bushels) . . . . . . . . . 122

Average value of potato land per acre . . . . . . . $\$ 60$

Statements of ten of the growers reporting who are most extensively producing potatoes for commercial purposes, in the Kaw Valley, average as here shown:

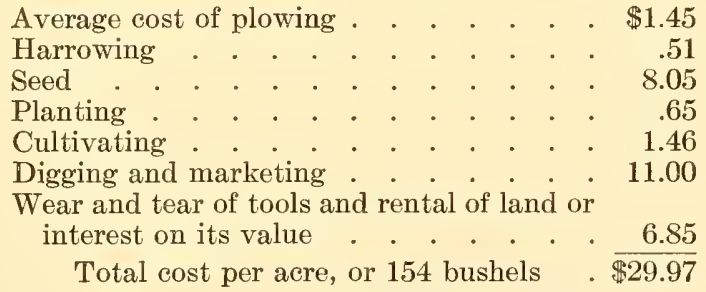

Average number of years each of these ten reporters has raised potatoes in Kansas . . . . . . . . Average number of acres raised by each annually . . 80.0 Average quantity of seed planted per acre (bushels) . 10.4 Average yield per acre (bushels) . . . . . . . . . 153.7 Average value of potato land per acre . . . . . . $\$ 105.00$ 
Place - Ohio.

Authority - Terry, T. B., and Root, A. I., "Potato Culture."

Yield per acre -250 bushels.

Average price -40 cents.

Profit per acre $-\$ 61.06$.

Detailed cost as below :-

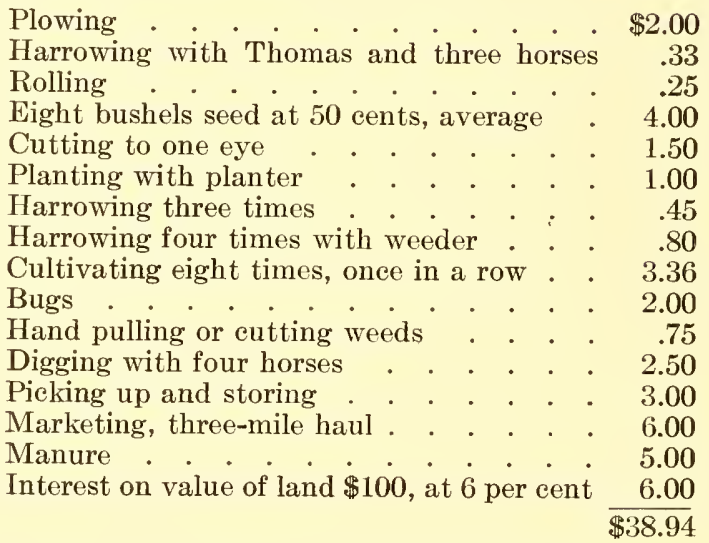

Dodge says: "The more expensive method of growing potatoes usually gives a yield of 275 bushels or more to the acre. Unless an application of barnyard manure is made in addition to the expense estimated at an added cost of from $\$ 5$ to $\$ 10$ per acre, the less expensive method rarely produces more than 125 bushels per acre and in a great many instances decidedly less than 100 bushels per acre. The increase in yield as a result of the more costly method is sufficient to more than pay the difference in cost, supposing potatoes to sell as low as $33 \frac{1}{3}$ cents a bushel. One hundred and twenty-five bushels per acre grown at a cost of $\$ 15$ per acre and sold at $33 \frac{1}{3}$ cents a 
bushel yield a net profit of $\$ 26.66$ per acre. Two hundred and seventy-five bushels per acre grown at a cost of $\$ 60$ per acre and sold at $33 \frac{1}{3}$ cents per bushel yield a net profit of $\$ 31.66$ per acre. The second profit is $\$ 5$ more per acre than the first.

"A farmer in Van Buren County, Michigan, states that his potato crop, mostly marketed in the fall, sold at an average price of 44 cents a bushel for a period of ten years. At the latter price the more expensive method of culture would yield a profit of $\$ 61$ per acre, against $\$ 40$ from the cheaper method. Furthermore, some of the leading potato dealers of the North have stated emphatically that a better quality of potatoes is normally obtained with large yields than with small."

Place - Maine and Wisconsin. Dodge says the Wisconsin figures will represent the expense put into growing the crop in most localities where potato growing is carried on, on a less expensive and thoroughgoing basis. Authority - Dodge, L. G., Farmers' Bul. 465.

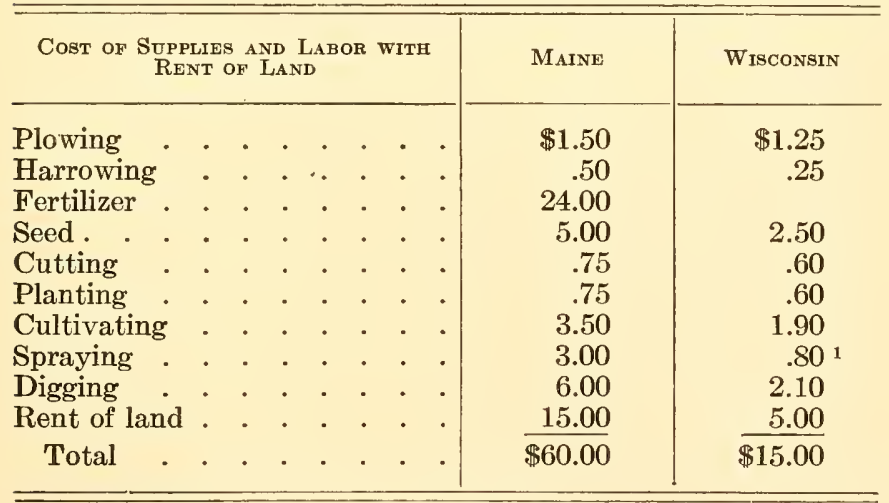

1 For beetles only. 
Place - Maine.

Authority - Bulletin of the Maine Department of Agriculture, March, 1914.

Average cost of one acre of potatoes from records of ten potato growers in different localities in the state:-

Cost of plowing . . . . . . . . . $\$ 2.85$

Harrowing four times . . . . . . . 4.00

Fertilizer . . . . . . . . . . 36.00

Applying . . . . . . . . . . . . 2.00

Seed, 13 bushels at 80 cents . . . . . 10.40

Cutting seed . . . . . . . . . . 1.75

Planting . . . . . . . . . . 4.00

Cultivating four times . . . . . . . 4.00

Hoeing three times . . . . . . . 3.00

Spraying five times at $\$ 1.15$. . . . . 5.75

Harvest . . . . . . . . . . . . 14.00

$\overline{\$ 87.75}$

Place - Maine.

Authority - Cleveland, E. L., Aroostook County, Maine.

Commercial fertilizer 1500 to 2000 pounds $\$ 28.50$ to $\$ 35$

Preparing ground for seed . . . . . 3.00

Seed, 600 pounds . . . . . . . . . . . 7.00

Planting . . . . . . . . . . . . . 2.50

Cultivation . . . . . . . . . . 3.50

Gathering or harvesting . . . . . . 7.50

Preparing for market . . . . . . . . $\quad .50$

Wear and tear on implements . . . . . $\quad .50$

Rent of land (tenant farmer pays) . . . 10.00 to 20

Bordeaux mixture . . . . . . . . . 4.00

Paris green . . . . . . . . . . . $\quad .50$

Hauling to market . . . . . . . . 3.50

Average yield of product per acre . . . 220 bushels

Average value of product per acre . . . . $\$ 88.00$

Average size of fields . . . . . . . . 15 acres

Average value per acre of land growing such crops

$\$ 75.00$ to $\$ 100$

17.00 
"Much depends on the weather conditions as to the cost of applying bordeaux mixture, paris green, cost of cultivation, labor and general net results.

"The above estimates may be regarded the average for a series of years."

Place - Maine.

Authority - Hurd, Prof. W. D., formerly dean of the College of Agriculture, University of Maine.

From records for several years on the college farm at Orono, the cost of growing a ten-acre field of potatoes is about as follows: man and team labor are reckoned at $\$ 3.50$ per day, extra men at $\$ 1.50$ per day.

Plowing at $\$ 2$ per acre

Harrowing five times, $\$ 3.50$ per acre . . . . . . 17.50

Fertilizer (home mixture) $\$ 30$ a ton . . . . . . 225.00

Seed, 130 bushels, 75 cents a bushel . . . . . . 97.50

Disinfecting seed (labor and material) . . . . . . 3.00

Cutting seed (by hand) at 6 cents per bushel . . . 7.80

Planting, team and two men three days, $\$ 5$. . . . $\quad 15.00$

Harrowing or weeding before crop is up, four times . $\quad 10.50$

Cultivating srop eight times at $\$ 3.50$. . . . . . 28.00

Spraying six times (\$1 per acre each application) . . $\quad 60.00$

Hand hoeing and pulling weeds once (if necessary) . 15.00

Digging and hauling to storehouse or station at $\$ 15$ per acre $\dot{0}$. $\dot{5}$ per cent on $\$ 50$ per acre value), 10

acres . . . . . . . . . . . . 25.00

Depreciation of implements (plows, harrows, planter, sprayer, digger, etc.), value $\$ 250$ estimated at 10 per cent .

\subsection{0}

25.00

$\overline{\$ 699.30}$

Value of crop, 225 bushels to acre (2250 bushels at 50 cents)

Value per acre

Cost of growing per acre

Net profit per acre 
Place - New York.

Authority - Results of a survey by the Department of Farm Management, New York State College of Agriculture.

Cost of Growing Potatoes

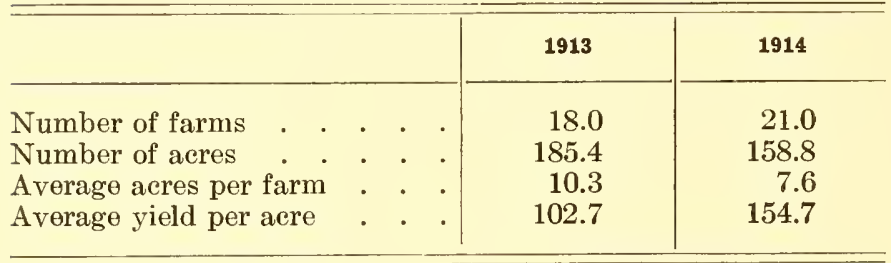

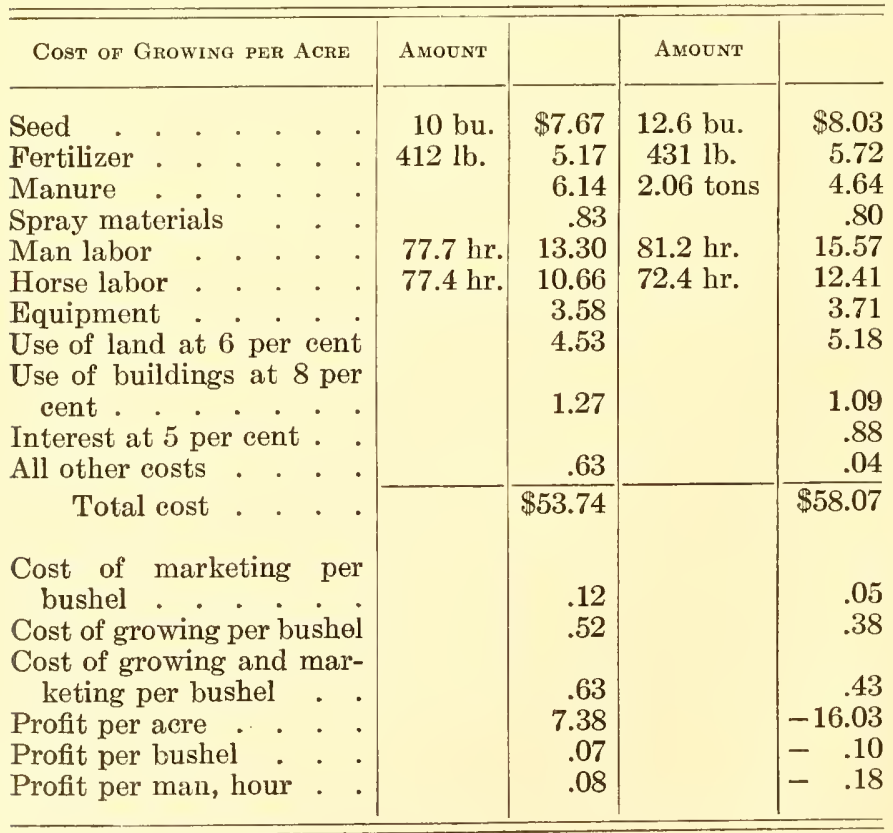




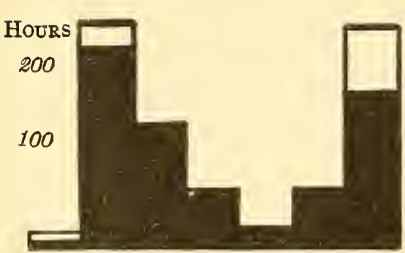

Apr. May June July Aug. Sept. Oct. FIG. 28.

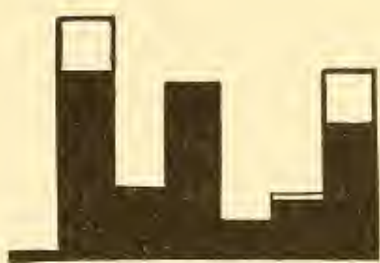

Apr. May June July Aug. Sept. Oot. FIG. 29.

Place - California.

Authority - Shanklin, L. F., Lompoc, California. Quoted from Grubb and Guilford, "The Potato."

L. F. Shanklin of Lompoc, California, estimates the cost of producing an acre of potatoes as follows:-

Use of land (will rent for) . . . . . . . . . . $\$ 30.00$

Seed, 400 pounds at $1 \frac{1}{2}$ cents

Plowing and preparation . . . . . . . . . . . 5.00

Cultivation twice - hoeing once . . . . . . . . 1.00

Digging and picking . . . . . . . . . . . . 3.00

Sacks 5 cents, sacking 5 cents (100 sacks) . . . . . 10.00

Hauling . . . . . . . . . . . . . . . . $\frac{1.00}{85000}$

His average crop is: -

70 sacks first, 115 pounds to sack, at $\$ 1.30$ per 100 . . $\$ 80.00$

30 sacks seconds, 120 pounds to sack, at $\$ 1.00$ per 100 . . $\quad 36.00$

30 sacks cow feed or waste at 10 cents per $100 \cdot \cdot \frac{3.00}{\$ 119.50}$

Place - New York.

Authority - Department of Farm Management, New York State College of Agriculture.

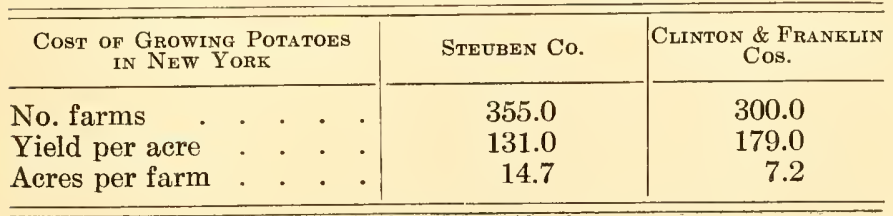




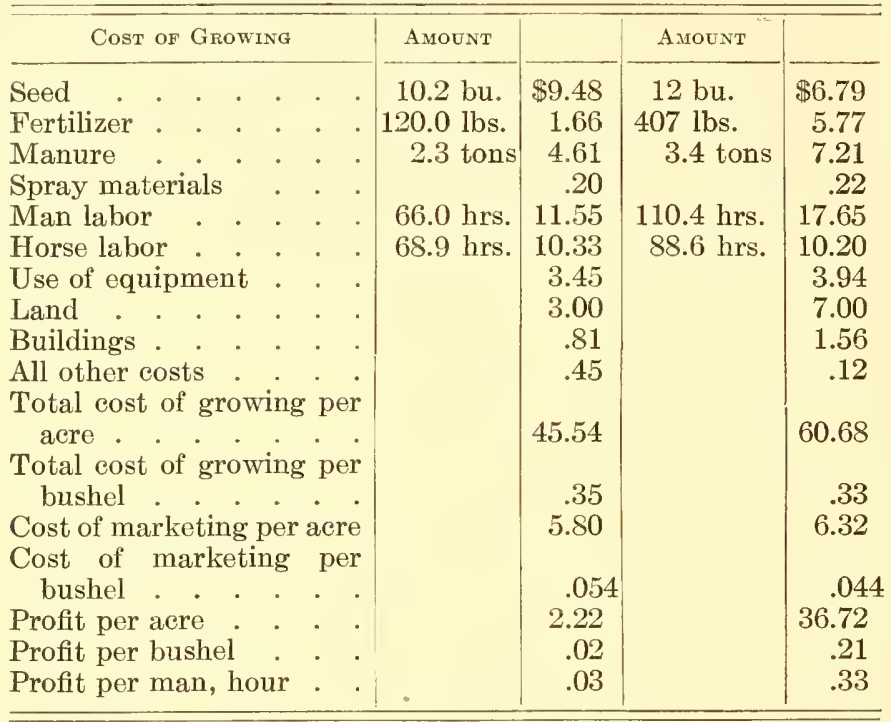

Place - Utah.

Authority - Harper, W. F., Smithfield, Utah. Quoted in Grubb and Guilford, "The Potato."

Plowing, harrowing and leveling the land . . . . . $\$ 5.00$ Fifteen loads of manure at 25 cents per load . . . $\quad 3.75$ Hauling manure at 75 cents per load . . . . . . 11.25 Seed . . . . . . . . . . . . . . . . 10.00 Cutting and planting seed . . . . . . . . . . . . 9.00 Cultivating, weeding and irrigating . . . . . . 5.00 Picking and sacking . . . . . . . . . . . . 10.00 Loading on car . . . . . . . . . . . . 4.50 $\overline{\$ 59.00}$

Results of a survey in New York state

In the agricultural survey of Tompkins County, Warren, Livermore, and others: "The potato crop ranks 
third in value of crops, but the acreage per farm is very small, averaging 1.7 acres. Of 982 farms in four townships, only 33 grew more than 5 acres of potatoes and only 2 grew over 10 acres. Nearly all of the crop is grown in this small way, but the crop is usually a profitable one. "Apparently the larger acreages are profitable. The average labor income of farmers growing more than 5 acres of potatoes is $\$ 853$.

“Of 605 farms operated by owners, 11 sold over $\$ 500$ worth of potatoes. These men made good profits. The lowest labor income was $\$ 724$, and the highest $\$ 2146$; the average was $\$ 1511$. The farms averaged 141 acres. An average of 6.3 acres of potatoes were grown per farm, with an average yield of 219 bushels per acre. The average receipts from the sale of potatoes were $\$ 732$, which constituted 24 per cent of the total sales.

"Of nine of these farms the most important sale was milk, with potatoes second. Each of the farms received some income from hay, grain, eggs, or lambs, etc. The average labor income on these farms was $\$ 1575$.

"One farm of 134 acres was a potato, hay and grain farm, with some sales of eggs, milk, etc. This farm gave a labor income of $\$ 1649$.

"One farm of 71 acres sold potatoes, lambs, hay, grain, eggs, etc., and made a labor income of $\$ 794$. On many farms that have soils adapted to potatoes, it would seem desirable to increase the area of this crop. When the crop can be increased to ten acres per farm, it will justify the purchase of a planter, sprayer and digger. Only by growing a much larger acreage per farm can one afford this labor-saving machinery that will go far toward making the crop pay. It will also pay to try much heavier applications of fertilizer." 


\section{Other survey results}

In a survey of the incomes of 178 New York farms, Burritt $^{1}$ obtained some interesting figures which show comparisons of certain kinds of farms. Unfortunately the number of potato farms in the survey was very small and may not mean very much, but the tables give a suggestive comparison. He says: "All farms were divided into two classes. Mixed or general farms are those on which no one source of income constitutes 40 per cent of the total income. Special farms are those deriving 40 per cent or more of their income from one special crop or industry. This latter class was further divided into dairy, fruit, potato and truck farms."

The seasonal distribution of man and horse labor is one of the factors which determine the feasibility of growing potatoes along with other crops, and represents no small measure of profitableness when considered in the whole farm scheme. The figures 28 and 29 (page 295) are used by Warren to represent the distribution of horse and man labor respectively, on 11 acres of potatoes. Black is work fixed as to time, white is plowing and marketing.

1 Bul. 271, Agri. Expt. Sta., Cornell University. 
Cost of Growing Potatoes

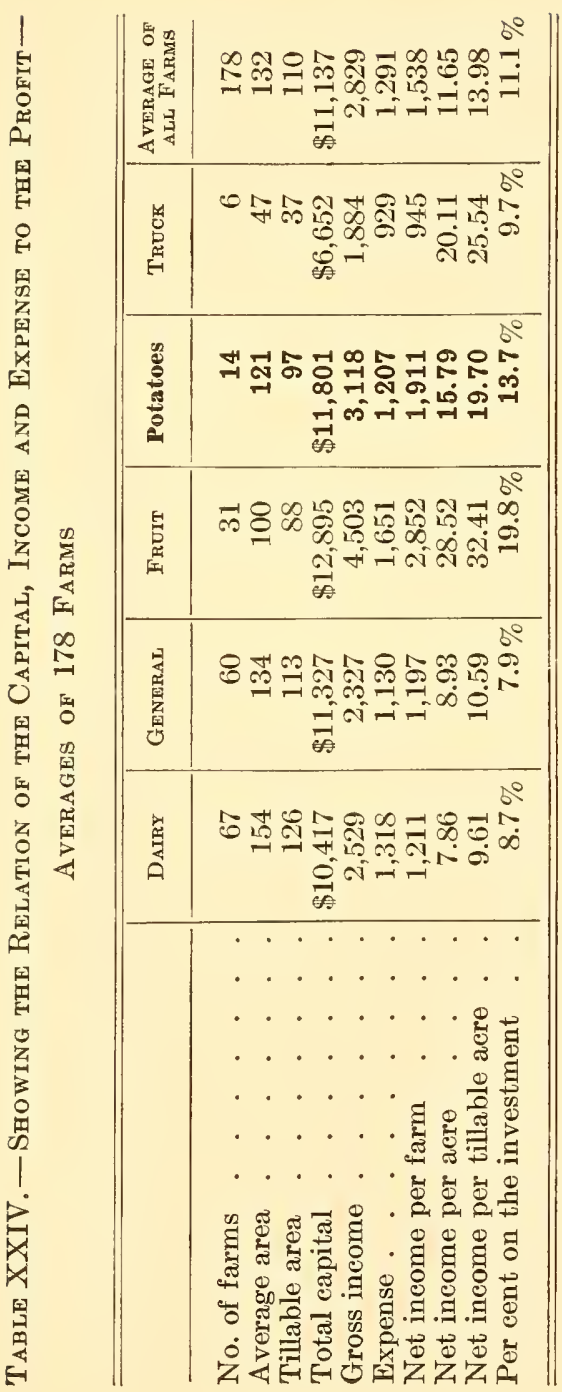




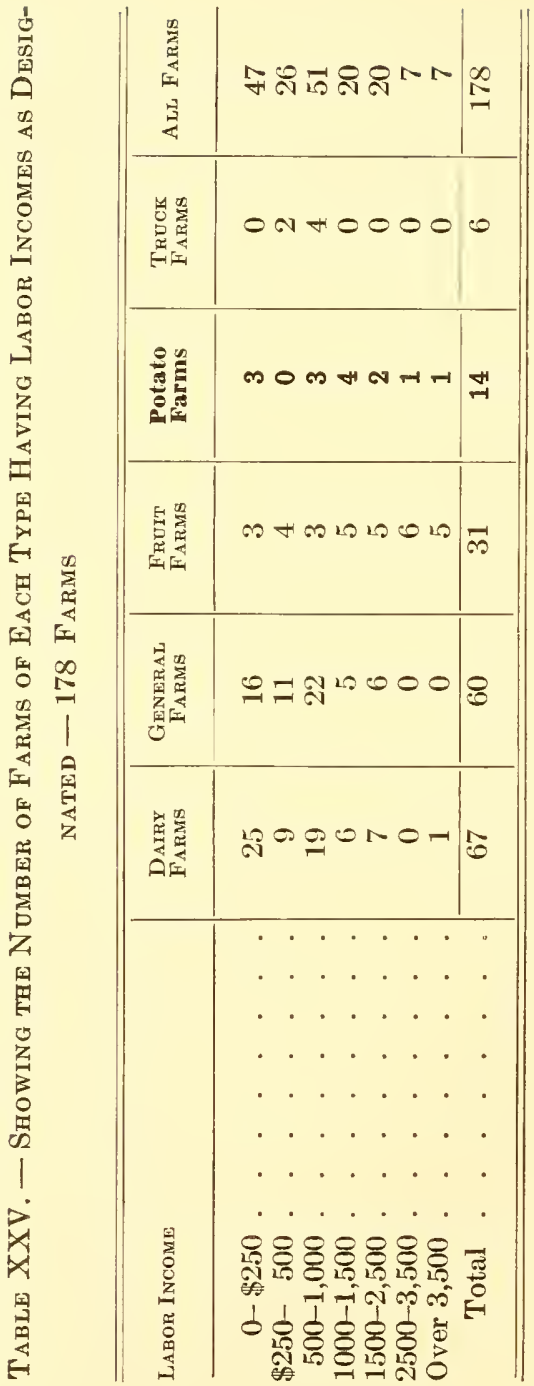


Cost of Growing Potatoes

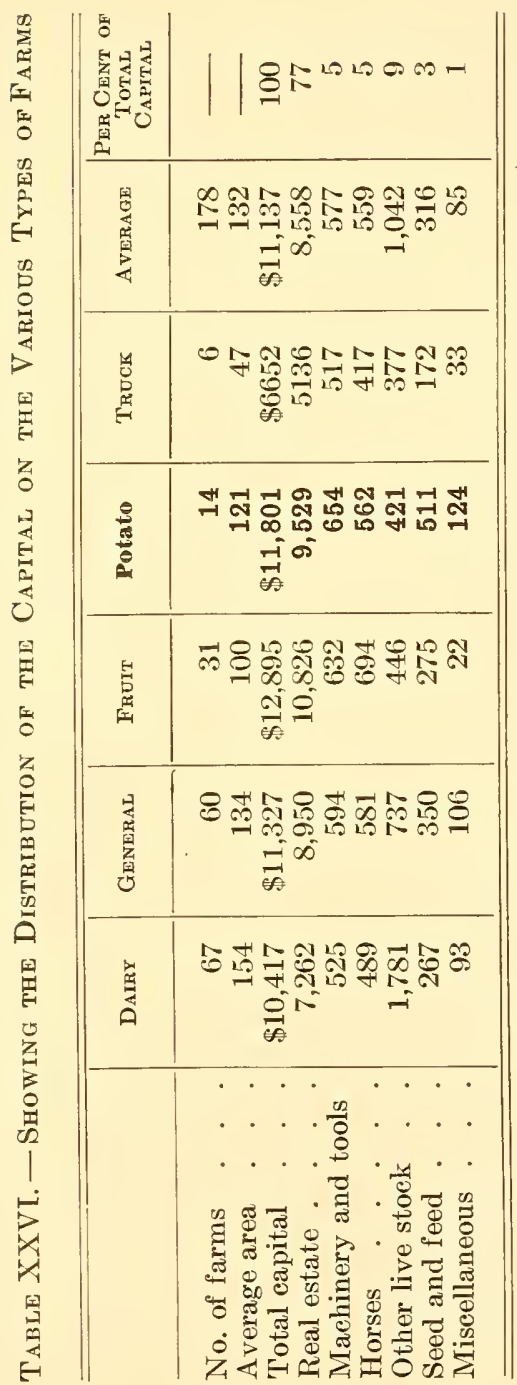




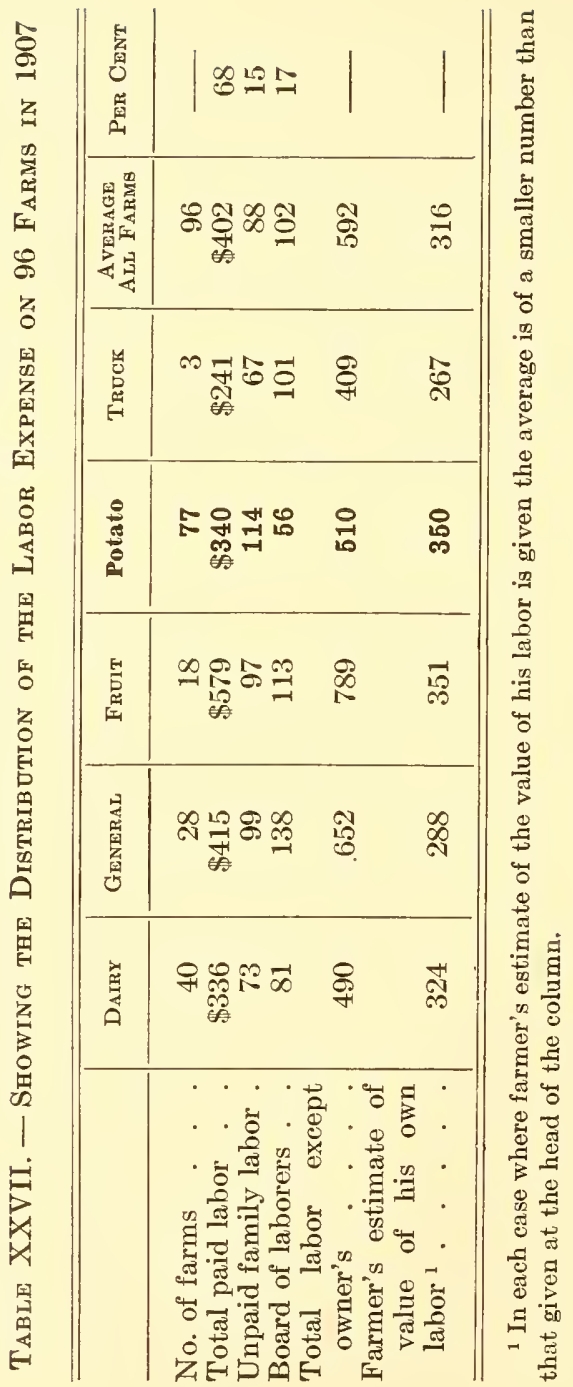


Cost of Growing Potatoes

303

\begin{tabular}{|c|c|}
\hline 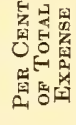 & 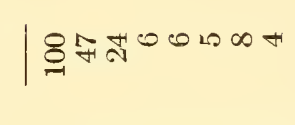 \\
\hline 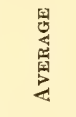 & 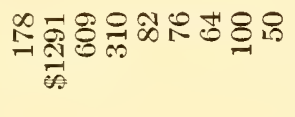 \\
\hline 蜜 & 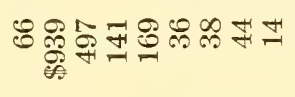 \\
\hline$\stackrel{\circ}{\stackrel{5}{*}}$ & 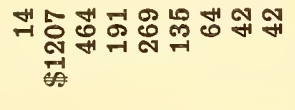 \\
\hline 量 & 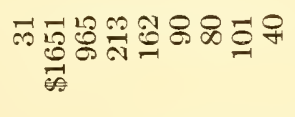 \\
\hline 量 & 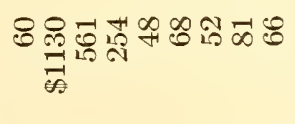 \\
\hline 曾 & 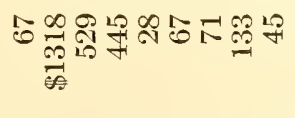 \\
\hline & 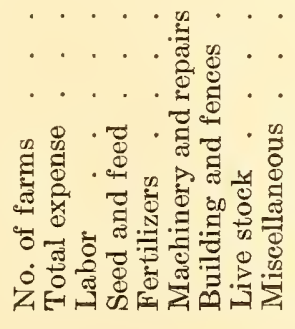 \\
\hline
\end{tabular}


Place - New York (St. Lawrence County).

Authority - Circular of Information of the New York State School of Agriculture at St. Lawrence University, April, 1911.

The detailed cost of growing an acre of early potatoes for the years 1909 and 1910 was as follows :-

Early Potatoes

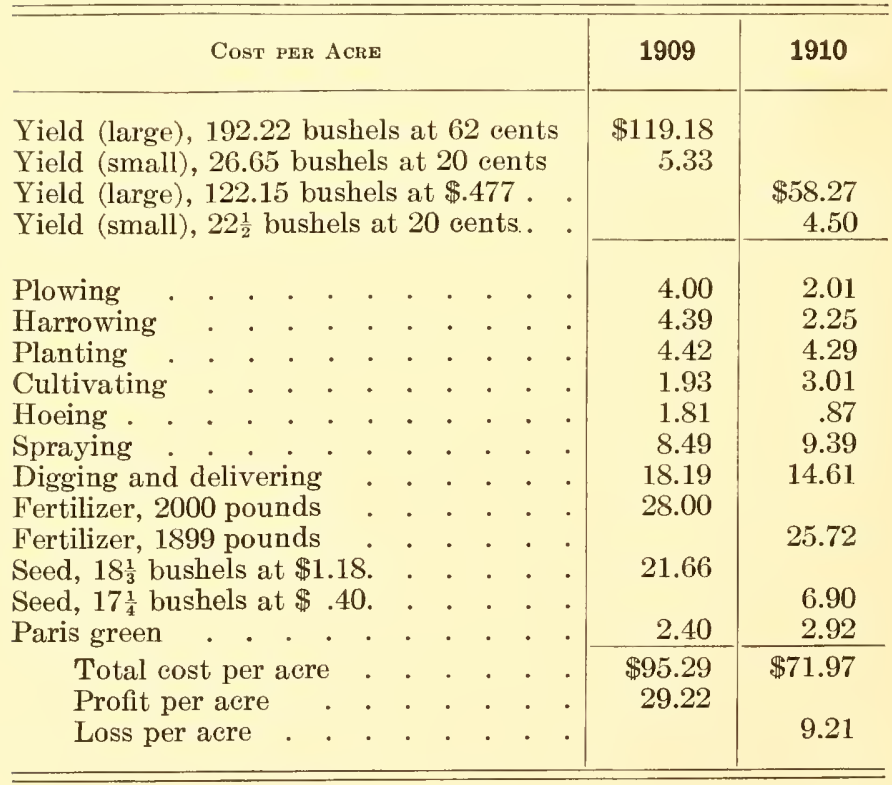

"The soil upon which the main crop of late potatoes was grown is a sandy loam. The field had no clover sod, indeed, no sod of any sort except the quack-grass and weeds. A higher cost for chemicals was necessary to make good this deficiency. Three and one-third acres of the field contained quack-grass and foul seeds. This 
land was plowed twice in the spring with frequent cultivation, which very nearly destroys every trace of quackgrass. The low cost of hand labor on the field warrants the statement that weed growth was practically destroyed by cultivation before the potatoes were planted, and by the weeder after they were planted. It is important that we impress upon the users of weeders and smoothing harrows the absolute necessity of beginning operation at once after the potatoes or seeds have been planted. If the weeds become rooted, even though they may not show very much above ground, the light-fingered tools, which are only safe to use on the growing plants, will have very little effect upon them. Farmers are often disappointed in the effect of weeders, simply because the weeder has given the weed the same encouragement which it gives to the plant under cultivation.

"The seed potatoes which were kept in an outdoor pit during the winter were taken from the pit April 18th, spread thinly on the barn floor and stirred occasionally to prevent long sprouts from growing. They were planted at varying dates from May 28th to June 10th. None of the sprouts were broken in handling or planting. The pieces were cut as nearly cubical as possible, and weighed about $2 \mathrm{oz}$. each. The number of eyes varied from 1 to 5 , the seed ends often containing 5 to 6 eyes. No effort was made to reduce the size of the seed piece from the seed end of the potato, in fact it is a fatal error to do so. Only one or two stalks will develop. The pieces were dropped $14 \frac{1}{2}$ inches by 36 inches."

"The cost by items does not show marked difference for the two years, with the exception of digging and delivering. A part of this saving was due to a lighter yield and a part to more economical methods of handling." 
Four and One-third Acres Potatoes (1910)

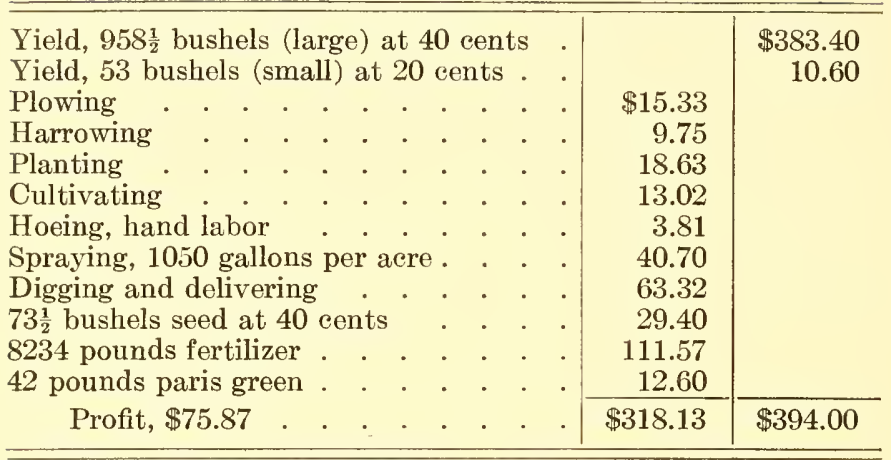

Potatoes

\begin{tabular}{|c|c|c|c|c|c|c|c|}
\hline \multicolumn{6}{|c|}{ COST PER ACRE } & 1909 & 1910 \\
\hline \multirow{4}{*}{\multicolumn{6}{|c|}{$\begin{array}{l}\text { Yield (large), } 289 \frac{4}{5} \text { bushels at } 40 \text { cents } \\
\text { Yield (small), } 27 \text { bushels at } 20 \text { cents . } \\
\text { Yield (large), } 221 \frac{1}{5} \text { bushels at } 40 \text { cents } \\
\text { Yield (small), } 12.2 \text { bushels at } 20 \text { cents }\end{array}$}} & \multirow{4}{*}{$\begin{array}{r}\$ 115.92 \\
5.40\end{array}$} & \multirow{4}{*}{$\begin{array}{r}\$ 88.48 \\
2.44\end{array}$} \\
\hline & & & & & & & \\
\hline & & & & & & & \\
\hline & & & & & & & \\
\hline Plowing . . & & . & . & . & & 4.18 & 3.54 \\
\hline Harrowing & & . & . & . & . & 1.90 & 2.25 \\
\hline Planting . & . & . & . & . & . & 4.30 & 4.30 \\
\hline Cultivating . . . & & . & . & . & . & 1.73 & 3.00 \\
\hline Hoeing (hand labor) & & 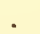 & & & . & .68 & .88 \\
\hline Spraying, 1000 gallons . & . & . & 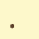 & . & . & 8.49 & \\
\hline Spraying, $1050^{+}$gallons & . & . & & . & . & & 9.39 \\
\hline Digging and delivering & . & . & . & . & . & 24.01 & 14.61 \\
\hline Seed, 16 bushels at 73 ce & $\mathrm{nts}$ & . & . & . & . & 11.68 & \\
\hline Seed, 17 bushels at 40 cer & nts & . & & . & . & & 6.80 \\
\hline Fertilizer, 1800 pounds & . & - & & 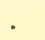 & . & 25.20 & \\
\hline Fertilizer, $1900^{+}$pounds & . & . & & . & . & & 25.75 \\
\hline Paris green, 7 pounds & . & . & 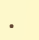 & . & . & 2.10 & \\
\hline Paris green, $9.6^{+}$pounds & . & . & & . & . & & 2.91 \\
\hline Total cost per acre & . & . & • & . & . & $\$ 84.27$ & $\$ 73.43$ \\
\hline Profit per acre & . & . & . & . & . & 37.05 & 17.49 \\
\hline
\end{tabular}




\section{Place - Minnesota.}

Authority - Bulletin 48, Bureau of Statistics, by Hays and Parker.

The cost of producing potatoes, under garden conditions, is given on pages 308 and 309 .

\section{Cost of hauling}

Potatoes are a bulky crop and the cost of hauling is no inconsiderable item. Andrews ${ }^{1}$ says : "In many ways they are hauled under conditions similar to those under which grain is hauled, and the average cost per 100 pounds for hauling potatoes from farms to shipping points is the same as for wheat and 2 cents more than for oats, corn or barley.

"The averages for the United States are affected more by the figures for the north Atlantic and north central states than by the other states and the territories, since about three-fourths of the potato crop of the United States is produced east of the Rocky Mountains and north of the Potomac and Ohio rivers and southern boundaries of Missouri and Kansas.

"The average cost of hauling from farms to shipping points in this region is 9 cents per 100 pounds, or 5.4 cents per bushel. The lowest average cost is for three counties in Rhode Island, where an average of three trips per day is made to and from shipping points, and the highest average cost in the north Atlantic and north central states is in South Dakota, where the average time of round trip between farm and shipping point is longer than one working day."

1 Andrews. Cost of Hauling Crops from Farms to Shipping Points. U. S. D. A., Bureau of Statistics, Bul. 49. 


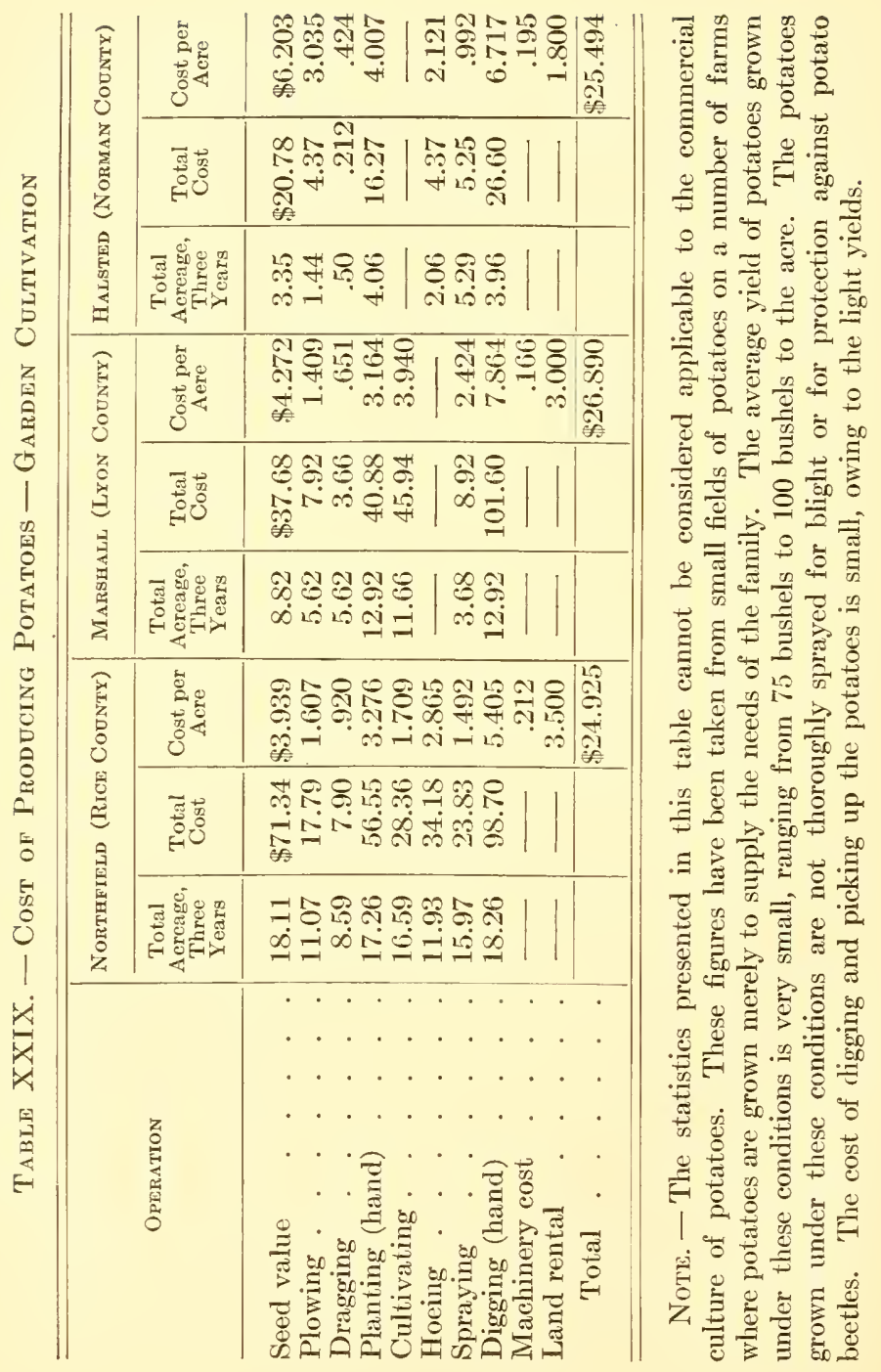




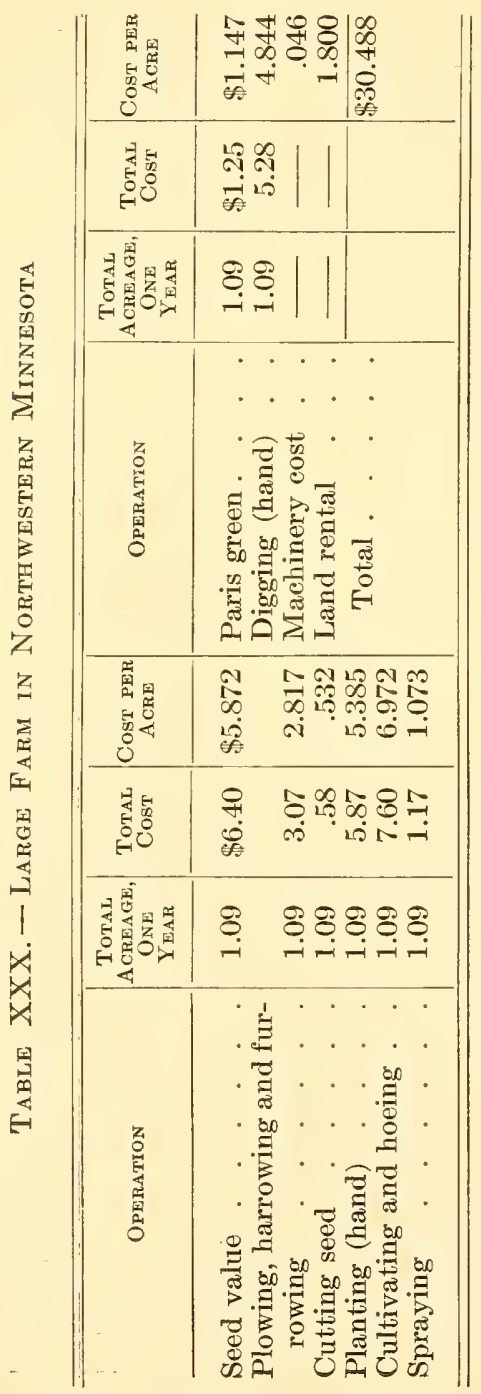


Table XXXI. - Average Cost of Hauling Potatoes from Faris to Shipping Points

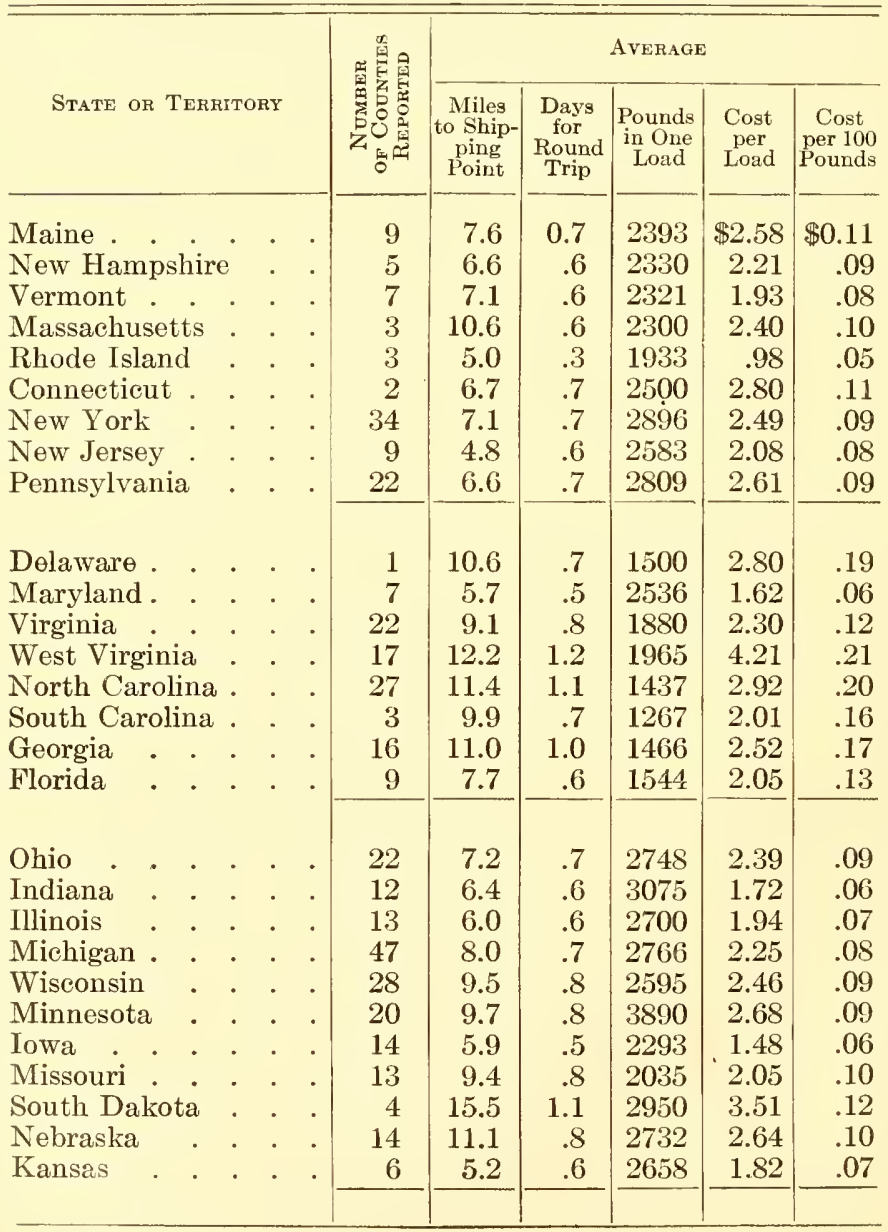




\begin{tabular}{|c|c|c|c|c|c|c|c|c|}
\hline \multirow{2}{*}{\multicolumn{3}{|c|}{ State or Territory }} & \multirow{2}{*}{ 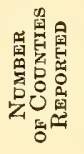 } & \multicolumn{5}{|c|}{ Average } \\
\hline & & & & $\begin{array}{c}\text { Miles } \\
\text { to Ship- } \\
\text { ping } \\
\text { point }\end{array}$ & $\begin{array}{l}\text { Days } \\
\text { for } \\
\text { Round } \\
\text { Trip }\end{array}$ & $\begin{array}{l}\text { Pounds } \\
\text { in One } \\
\text { Load }\end{array}$ & $\begin{array}{l}\text { Cost } \\
\text { per } \\
\text { Load }\end{array}$ & $\begin{array}{c}\text { Cost } \\
\text { per } 100 \\
\text { Pounds }\end{array}$ \\
\hline Kentucky & .. & . & 19 & 12.4 & 1.4 & 1834 & 4.44 & .24 \\
\hline Tennessee & .. & . & 19 & 10.0 & .8 & 1874 & 1.99 & .11 \\
\hline Alabama . & .. & . & 8 & 14.0 & 1.2 & 1450 & 3.14 & .22 \\
\hline Mississippi & . . & . & 11 & 11.9 & 1.1 & 1336 & 2.85 & .21 \\
\hline Louisiana & . & . & 6 & 12.6 & 1.3 & 1400 & 4.00 & .29 \\
\hline Texas . . & . . & . & 26 & 12.4 & 1.1 & 1460 & 2.86 & .20 \\
\hline Indian Territ & tory & . & 3 & 7.9 & .6 & 1867 & 1.65 & .09 \\
\hline Arkansas . & $\cdot \quad \cdot$ & . & 11 & 13.6 & 1.3 & .1523 & 3.04 & .20 \\
\hline Montana . & . & - & 9 & 14.0 & 1.2 & 2811 & 5.47 & .19 \\
\hline Wyoming & . & . & 5 & 25.5 & 2.3 & 2860 & 9.20 & .32 \\
\hline Colorado. & . & . & 20 & 12.2 & 1.1 & 3100 & 4.71 & .15 \\
\hline New Mexico & . & & 3 & 22.7 & 2.1 & 1800 & 9.09 & .50 \\
\hline Utah . . & . & . & 5 & 10.1 & .7 & 3300 & 2.31 & .07 \\
\hline Idaho . . & . & & 4 & 15.5 & 1.4 & 3125 & 5.17 & .17 \\
\hline Washington & . & . & 15 & 7.8 & .8 & 2617 & 3.38 & .13 \\
\hline Oregon . & . & & 9 & 9.7 & .9 & 4028 & 3.15 & .08 \\
\hline California & . $\quad$. & & 7 & 12.0 & 1.1 & 4914 & 4.72 & .10 \\
\hline Geographic & divisic & & & & & & & \\
\hline North Atla & antic & & 94 & 7.0 & .7 & 2717 & 2.55 & .09 \\
\hline South Atla & antic & . & 102 & 9.6 & .9 & 1871 & 2.74 & .15 \\
\hline North Cen & itral & & 193 & 8.1 & .7 & 2651 & 2.30 & .09 \\
\hline South Cen & tral & . & 103 & 12.1 & 1.2 & 1660 & 3.30 & .20 \\
\hline Western & $\cdot \quad \cdot$ & & 77 & 11.3 & 1.0 & 3615 & 4.05 & .11 \\
\hline $\begin{array}{l}\text { States and } \\
\text { represente }\end{array}$ & $\begin{array}{l}\text { Territ } \\
\text { d . }\end{array}$ & ries & 569 & 8.2 & .7 & 2679 & 2.34 & .09 \\
\hline
\end{tabular}


Table XXXil. Cost of Hadling Potatoes from Most Remote Farms to Shipping Points, as Reported

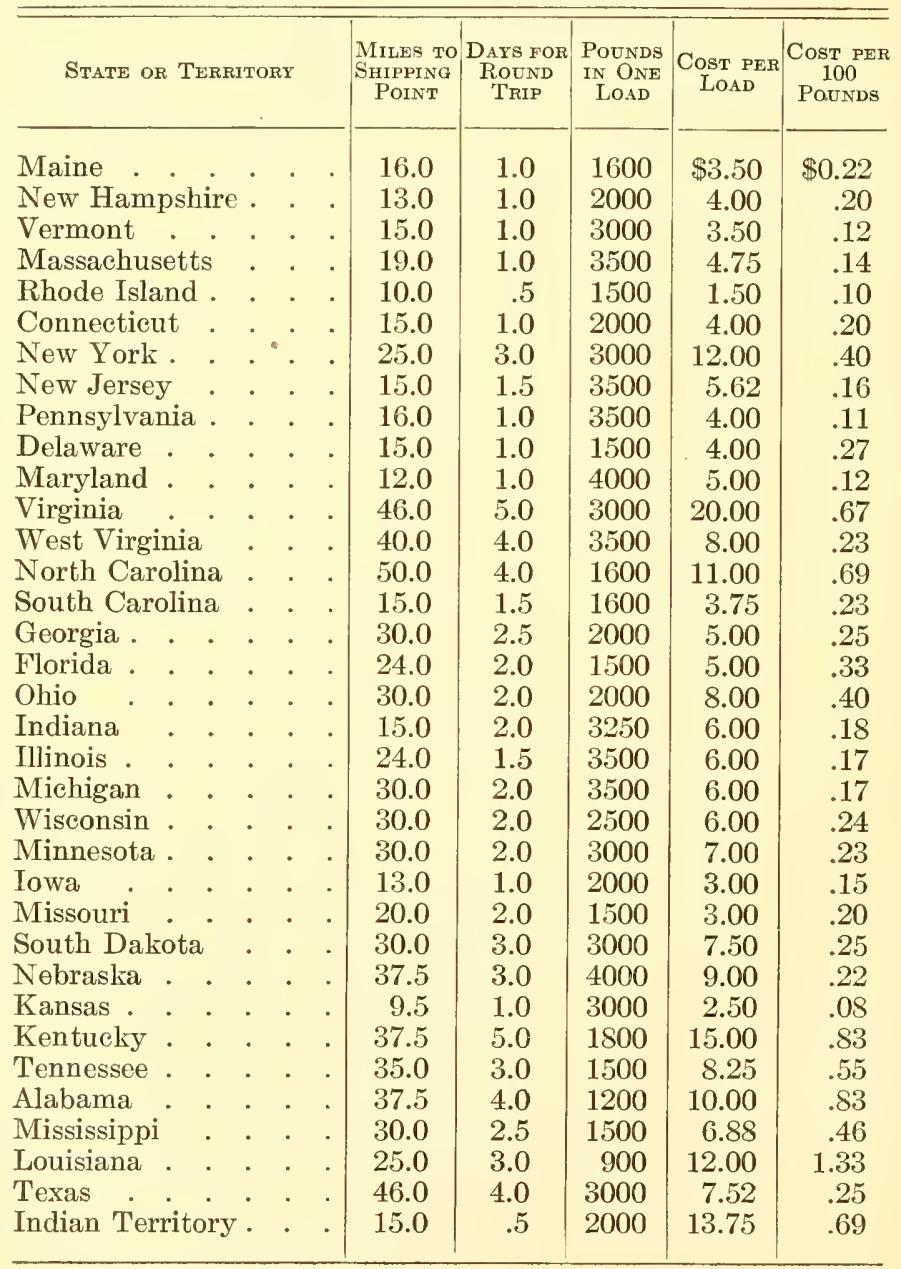




\begin{tabular}{|c|c|c|c|c|c|c|c|c|c|c|}
\hline \multicolumn{5}{|c|}{ State or Territory } & & $\begin{array}{l}\text { MrLes To } \\
\text { SHIPPING } \\
\text { PoINT }\end{array}$ & $\begin{array}{c}\text { DaYs FOR } \\
\text { ROUND } \\
\text { TRIP }\end{array}$ & $\begin{array}{l}\text { POUNDS } \\
\text { IN ONE } \\
\text { LOAD }\end{array}$ & $\begin{array}{c}\text { Cost PEF } \\
\text { LOAD }\end{array}$ & $\begin{array}{c}\text { CosT PER } \\
100 \\
\text { PoUnds }\end{array}$ \\
\hline Arkansas & & . & . & . & & 40.0 & 2.5 & 2250 & 7.50 & .33 \\
\hline Montana & & . & . & . & & 30.0 & 3.0 & 3500 & 13.50 & .39 \\
\hline Wyoming & & . & . & . & & 55.0 & 6.5 & 4500 & 22.75 & .51 \\
\hline Colorado . & & . & . & . & & 70.0 & 7.0 & 2500 & 33.00 & 1.40 \\
\hline New Mexico & & . & - & 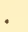 & & 57.5 & 4.0 & 2000 & 22.00 & 1.10 \\
\hline Utah. . & . & . & . & . & & 25.5 & 2.5 & 3000 & 8.75 & .29 \\
\hline Idaho . & & . & . & . & & 25.0 & 3.0 & 2500 & 10.50 & .42 \\
\hline Washington & & . & . & . & & 30.0 & 3.0 & 800 & 12.00 & 1.50 \\
\hline Oregon . & & . & . & . & & 35.0 & 3.0 & 2000 & 13.50 & .68 \\
\hline California & & . & . & . & & 32.0 & 3.0 & 4000 & 12.75 & .32 \\
\hline
\end{tabular}





\section{INDEX}

Africa, production of potatoes in, 3 . alcohol, manufacture of, 274. slops or residue, 282.

use for, 271.

alfalfa in rotation, 111,112 .

alsike clover in rotation, 111 .

Aroostook County, Me., as a potato center, 7, 113.

arsenical injury, 202.

Asia, production of potatoes in, 3 . association of characters in breeding, 75 .

Australia, production of potatoes in, 3 .

Austria-Hungary, production of potatoes in, 2,3 .

bacteria in soils, 102 .

bacterial wilt, 200 .

Baker, 21.

barley, value in United States, 3 . world's crop, 1.

Bauhin, 15.

belladonna, 1 .

black-leg, 199.

blister-beetle, 175 .

bordeaux mixture, 217.

botanical characteristics, 21 .

breeding, 47-85 (chapter IV).

bud-selection, 57 .

bud-sports, 57,76 .

calcium, 124.

Canada, production of potatoes in, $3,13$.

de Candolle, 15.

capsicum, 1.

Carbondale, Colo., as a potato center, 7 .

Cardan, 15.
Chester County, Pa., potatoes consumed on farms, 12.

Cierça de Léon, 14.

classification, 21.

climate, 86 (chapter V).

Clusius, 15.

Colorado potato beetle, 170 .

composition of potatoes, 262.

constitutional degeneracy, 205.

control measures against disease, 206-225 (chapter XI).

corn, value in United States, 3.

world's crop, 1.

cost of growing potatoes, 287-313 (chapter XV).

harvesting, 234 .

hauling, 307.

cotton, value in United States, 3.

cover-crops, 105.

critical period, 89,95 .

crop reporter, 257.

crossing, method of, 78 .

cultivation of potato, 163 .

culture of potato, 89 .

curly dwarf, 203; control, 206.

cutting seed, 156.

cyanimid as fertilizer, $120,121$.

Dala potato, 73 .

Darwin, 76.

description of potato, 22 .

desiccated potatoes, 284 .

digging, methods of, 230 ,

disease, 97.

from organisms in soil, 212.

proof varieties, 50,221 .

diseases of potato, 183-205 (chapter X).

Dodge, 70 .

drainage, 95. 
Early and late potatoes, marketing, |hauling, cost of, 307. 249 .

early blight, 189.

East, 74, 78, 82, 83.

eastern shore of Va. and Md. as potato centers, 7 .

egg-plant, 1.

engines, 165.

England, introduction into, 15.

Europe, production of potatoes in, 3.

European Russia, production of potatoes in, 2.

expense of marketing, 255.

family consumption, statistics, 11 .

farm manures, 130 .

fertilizer practices, 115, 126.

fertilizers, 113 (chapter VI). market forms, 116.

Fischer, 75, 76.

Fitch, 25, 27, 30, 33.

flea-beetles, 173.

flour, potato, 284.

France, production of potatoes in, 2,3 .

freight charges, 253.

Fruwirth, 73, 74.

Funk, 11.

fusarium dry rot, 196. wilt, 195.

Gerard, 16.

Germany, production of potatoes in, 2,3 .

yields to the acre, 12 .

grading, 245.

Great Britain, yields to the acre, 12.

Greeley, Colo., as a potato center, 7. green manures, 105.

growing crop, care of, 160 (chapter VIII).

hand planting, 151 .

harvest, time to, 226.

harvesting cost, 234.

labor, 234.

potatoes, 226-235 (chapter XII). hay-plants, 109.

value of in United States, 3.

heat, 90 .

heated cars, 253.

henbane, 1 .

Herbal, 16.

Heriot, 47.

hill and drill planting, 146.

hill selection, 54 .

history of potato, 14 (chapter II).

human food, uses as, 260.

Humboldt, 15.

hybridization, improvement by, 77-84.

ideals of the potato crop, 48,49 .

improvement, methods of, 56 .

individual selection, 62 .

insects, 170-182 (chapter IX).

Ireland, introduction into, 16.

Irish famine, 20.

Kaw Valley, as a potato center, 7 . Kohler, 31, 33.

late blight, 190 ; treatment, 214.

leaf-hoppers, 129.

leaf roll, 204 ; control, 206.

Livingston County, N. Y., potatoes consumed on farms, 11.

local dealers, marketing through, 243.

McCormick variety, resistant to heat, 91.

Macoun, 12.

Maine, production of potatoes in, 3.

manures and fertilizers, 113 (chapter VI).

marketing through local dealers, 243.

markets, 249.

and marketing, 237-258 (chapter XIII).

mass-selection, 61.

Michigan, production of potatoes in, 3 . 
Milward, 33.

Minnesota, production of potatoes in, 3 .

mosaic, control, 206.

Myers, 59.

net necrosis, 203.

Newman, 73.

New York, production of potatoes in, 3 .

State Potato Ass'n, score card of, 53 .

nitrate of lime, 120.

nitrogen, 119.

Norfolk, Va., as a potato center, 7 .

North America, introduction into, 15.

production of potatoes in, 3 .

oats, value in United States, 3. world's crop, 1.

Orton, 73.

packages, 245.

papas, 16.

Paradisus, 16.

Parkinson, 16.

Parmentier, 18.

pedigree breeding, 62 .

Penn., production of potatoes in, 3 .

Peru, original home of potato, 14.

Phipps, 20.

phosphorus, 122.

picking and sorting, 232.

plant food, 94, 114.

planting, 133-142 (chapter VII).

hill and drill, 146.

tools, 148.

potassium, 123.

potato flour, 284.

plant louse, 177.

pomace, 283.

stalk weevil, 179.

wart, 198.

"Potatoes of Virginia," 18.

value in United States, 3 .

poultry food, 283.

powdery scab, 201.

power for potato fields, 165 . price of potato land, 88 .

prices, 250.

production on farms, statistics, 7 . world, 2 .

in different countries, 2.

pure lines, 58.

quality when cooked, 261.

Raleigh, Sir Walter, 15.

red clover in rotation, 111.

Red River Valley, as a potato center, 7 .

rhizoctoniose, 194.

rice, world's crop, 1 .

Rose, 14.

rotation, 86 (chapter V).

running out of varieties, 72 .

Russia, production of potatoes in, 3.

Sacramento, Cal., as a potato center, 7 .

Salaman, 78, 82, 83, 84.

San Joaquin, Cal., as a potato center, 7.

scab, common, 199.

powdery, 201.

score-card, 152.

seed, cutting, 156.

potatoes, 152 .

treatment for scab, 153, 208.

selection, 55,57 .

shipping, 246.

silver scurf, 196.

soils, 86 (chapter V).

soil texture, 93.

Solanum Cardiophyllum, 21.

Commersonii, 21.

Jamesii, 21.

Maglia, 21.

oxycarpum, 21.

tuberosum, 21.

sorting, 232.

South America, production of potatoes in, 3 .

Spain, introduction into, 15.

Spillman, 12, 70.

spindling sprout, 203. 
stalk borer, 180 .

starch manufacture, 265.

use for, 265, 270.

stock food, use as, 280.

storage, 258.

Stuart, 27, 33, 43, 45.

sulphur, 126.

survey results, growing costs, 296.

texture of cooked potatoes, 263.

three-lined leaf-beetle, 176.

tillage, results of, 137 .

tools, 135 .

tip-burn, 168, 202.

tobaceo, 1.

value in United States, 3.

tomato, 1.

tools, tillage, 35 .

tortoise beetles, 176 .

tractors, 165.

tuber-unit, method of breeding, 62 . types of potato growing, 97 .

United Kingdom, production of potatoes in, 2.

United States, production of potatoes in, 2, 3 .

yields to the acre, 12 .
Uses of potato, 259-286 (chapter XIV).

varieties of Iowa and central west, 25.

verticillium wilt, 196.

Waid's experiments, 72 .

Warren, 11.

water requirements, 92 .

Webber, 62.

weed killing, 140.

wheat value in United States, 3.

world's crop, 1.

white grubs, 180.

wild potatoes, 47 .

Wilson, 81.

wire worms, 181 .

Wiseonsin, production of potatoes in, 3 .

yield, highest recorded in United States, 12.

yields, 12,87 .

Zavitz, 71 . 
THE following pages contain advertisements of a few of the Macmillan books on kindred subjects 

land was plowed twice in the spring with frequent cultivation, which very nearly destroys every trace of quackgrass. The low cost of hand labor on the field warrants the statement that weed growth was practically destroyed by cultivation before the potatoes were planted, and by the weeder after they were planted. It is important that we impress upon the users of weeders and smoothing harrows the absolute necessity of beginning operation at once after the potatoes or seeds have been planted. If the weeds become rooted, even though they may not show very much above ground, the light-fingered tools, which are only safe to use on the growing plants, will have very little effect upon them. Farmers are often disappointed in the effect of weeders, simply because the weeder has given the weed the same encouragement which it gives to the plant under cultivation.

"The seed potatoes which were kept in an outdoor pit during the winter were taken from the pit April 18th, spread thinly on the barn floor and stirred occasionally to prevent long sprouts from growing. They were planted at varying dates from May 28th to June 10th. None of the sprouts were broken in handling or planting. The pieces were cut as nearly cubical as possible, and weighed about $2 \mathrm{oz}$. each. The number of eyes varied from 1 to 5 , the seed ends often containing 5 to 6 eyes. No effort was made to reduce the size of the seed piece from the seed end of the potato, in fact it is a fatal error to do so. Only one or two stalks will develop. The pieces were dropped $14 \frac{1}{2}$ inches by 36 inches."

"The cost by items does not show marked difference for the two years, with the exception of digging and delivering. A part of this saving was due to a lighter yield and a part to more economical methods of handling." 
Four And One-third Acres Potatoes (1910)

Yield, $958 \frac{1}{2}$ bushels (large) at 40 cents. Yield, 53 bushels (small) at 20 cents . . Plowing

Harrowing

Planting

Cultivating

Hoeing, hand labor

Spraying, 1050 gallons per acre .

Digging and delivering

$73 \frac{1}{2}$ bushels seed at 40 cents

8234 pounds fertilizer

42 pounds paris green

Profit, $\$ 75.87$

\begin{tabular}{|r|r} 
& $\$ 383.40$ \\
& 10.60 \\
$\$ 15.33$ & \\
9.75 & \\
18.63 & \\
13.02 & \\
3.81 & \\
40.70 & \\
63.32 & \\
29.40 & \\
111.57 & \\
12.60 & \\
\hline$\$ 318.13$ & $\$ 394.00$ \\
\hline
\end{tabular}

Potatoes

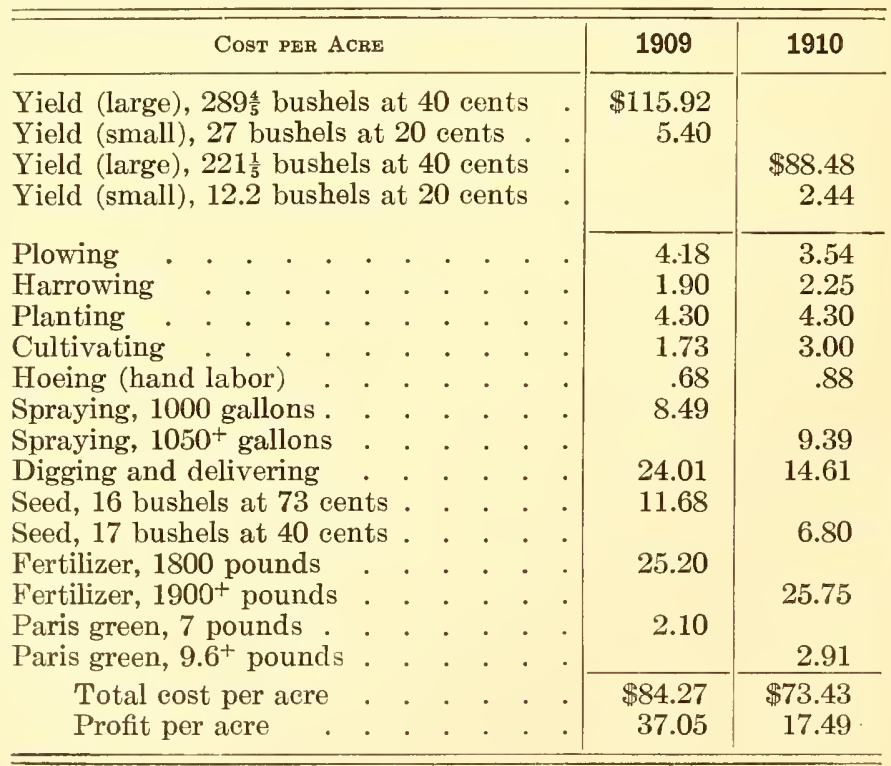


Place - Minnesota.

Authority - Bulletin 48, Bureau of Statistics, by Hays and Parker.

The cost of producing potatoes, under garden conditions, is given on pages 308 and 309 .

\section{Cost of hauling}

Potatoes are a bulky crop and the cost of hauling is no inconsiderable item. Andrews ${ }^{1}$ says: "In many ways they are hauled under conditions similar to those under which grain is hauled, and the average cost per 100 pounds for hauling potatoes from farms to shipping points is the same as for wheat and 2 cents more than for oats, corn or barley.

"The averages for the United States are affected more by the figures for the north Atlantic and north central states than by the other states and the territories, since about three-fourths of the potato crop of the United States is produced east of the Rocky Mountains and north of the Potomac and Ohio rivers and southern boundaries of Missouri and Kansas.

"The average cost of hauling from farms to shipping points in this region is 9 cents per 100 pounds, or 5.4 cents per bushel. The lowest average cost is for three counties in Rhode Island, where an average of three trips per day is made to and from shipping points, and the highest average cost in the north. Atlantic and north central states is in South Dakota, where the average time of round trip between farm and shipping point is longer than one working day."

${ }^{1}$ Andrews. Cost of Hauling Crops from Farms to Shipping Points. U. S. D. A., Bureau of Statistics, Bul. 49. 


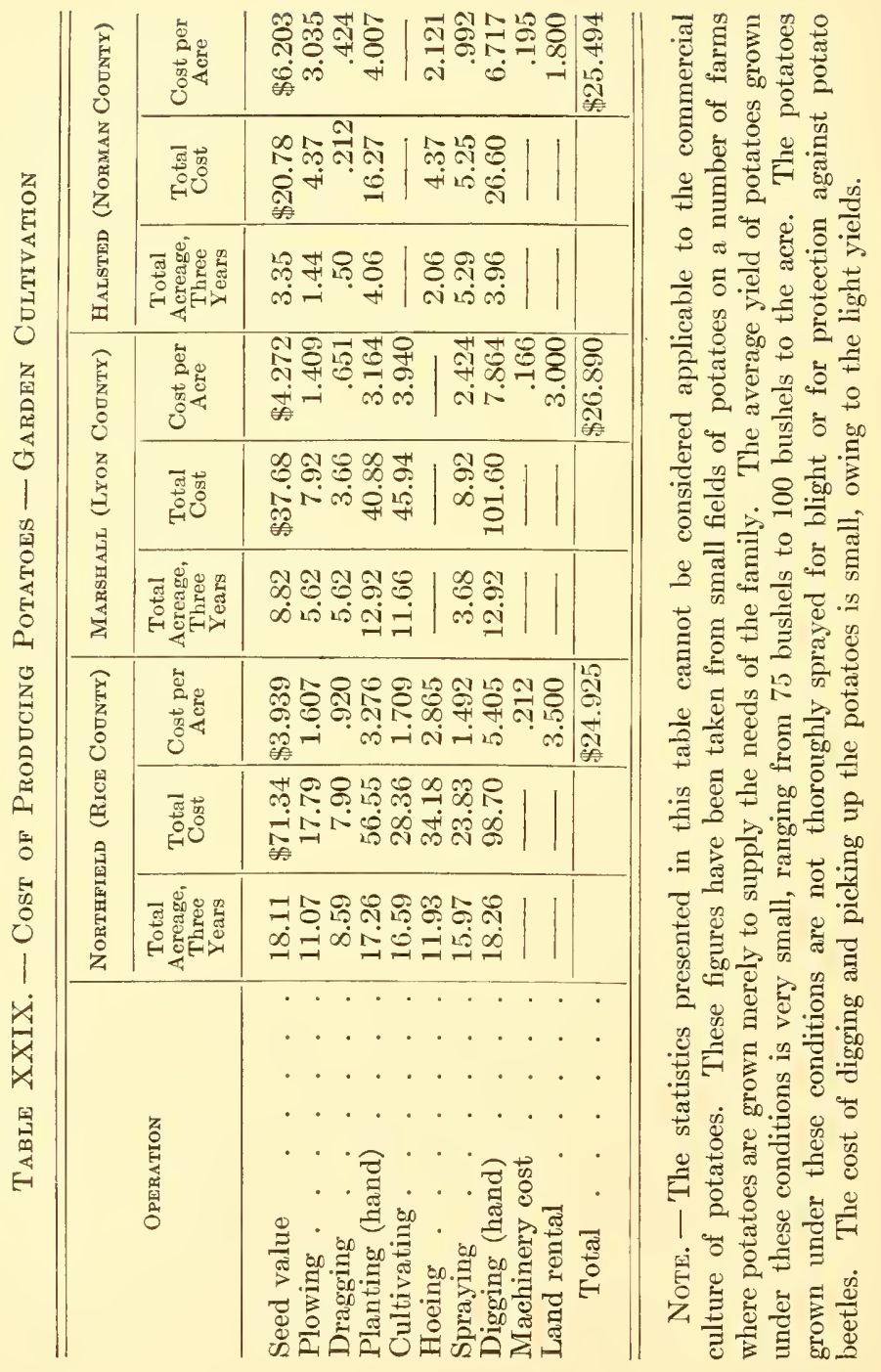


Cost of Growing Potatoes

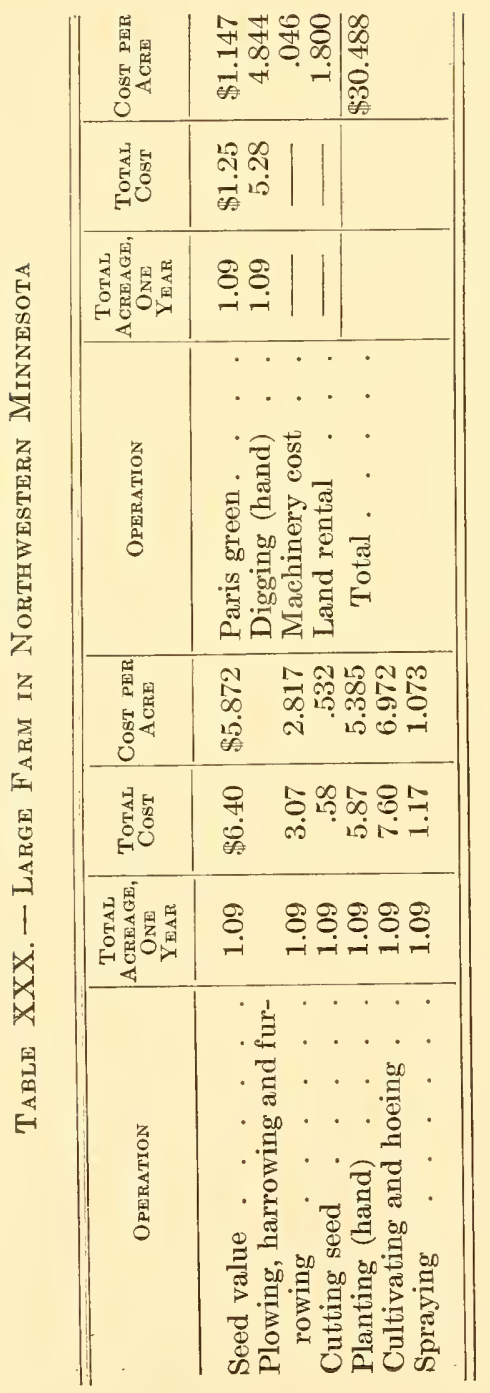


Table XXXi. - Average Cost of Hadling Potatoes from Faris to Shipping Points

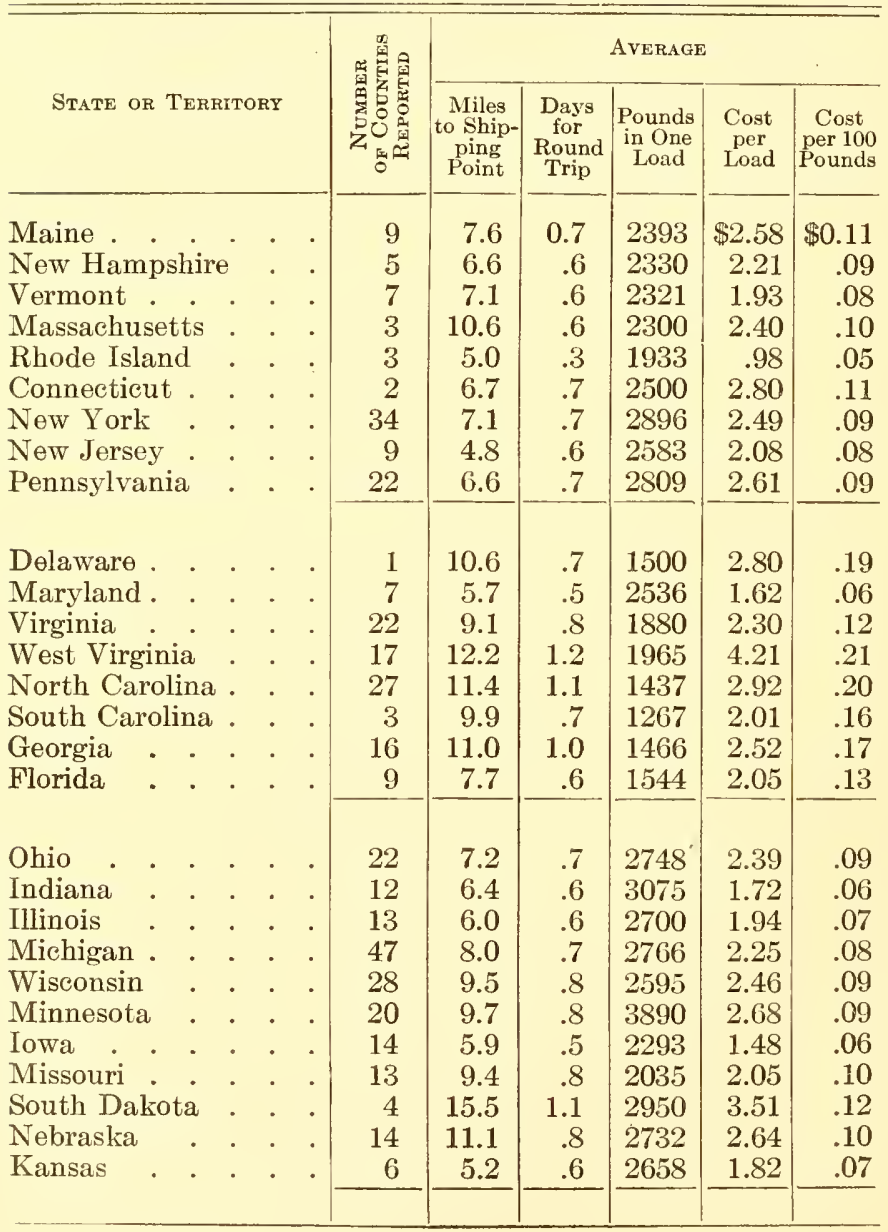




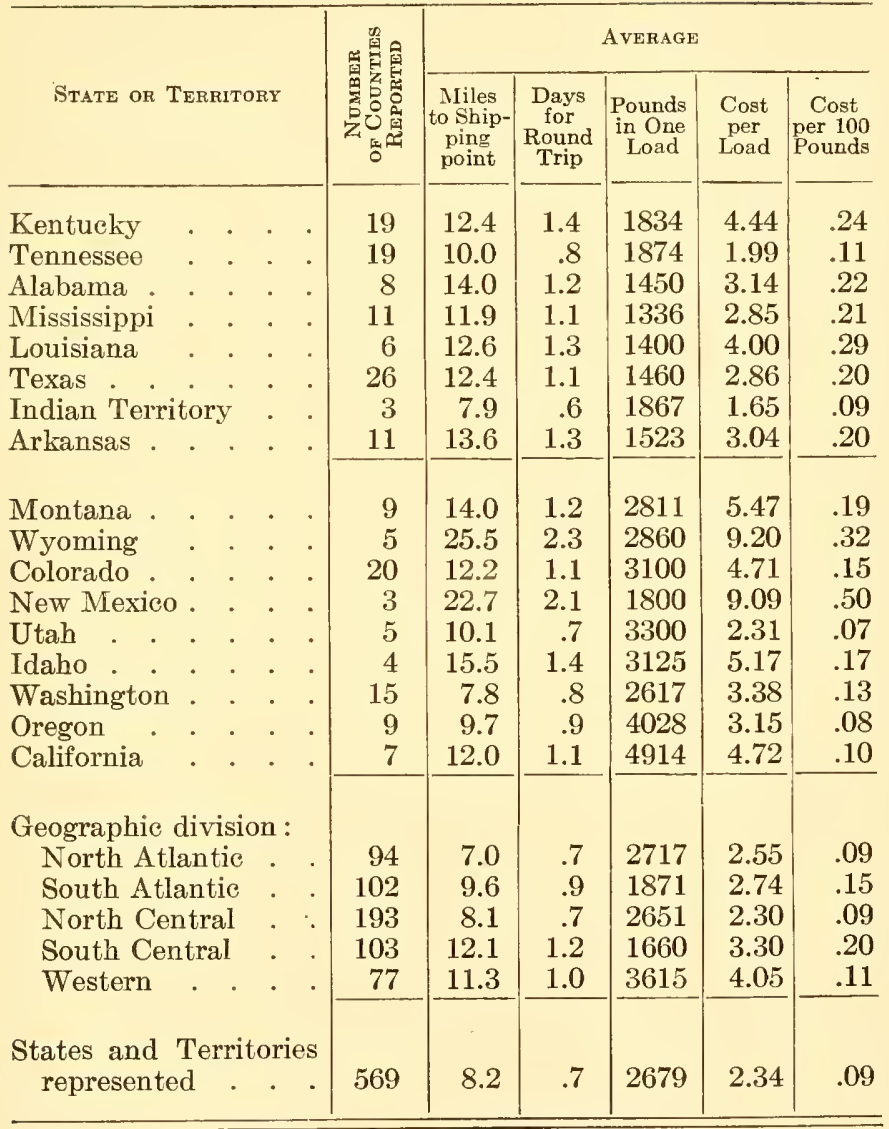


Table XXXII. Cost of Hadling Potatoes from Most Remote Farms to Shipping Points, as Reported

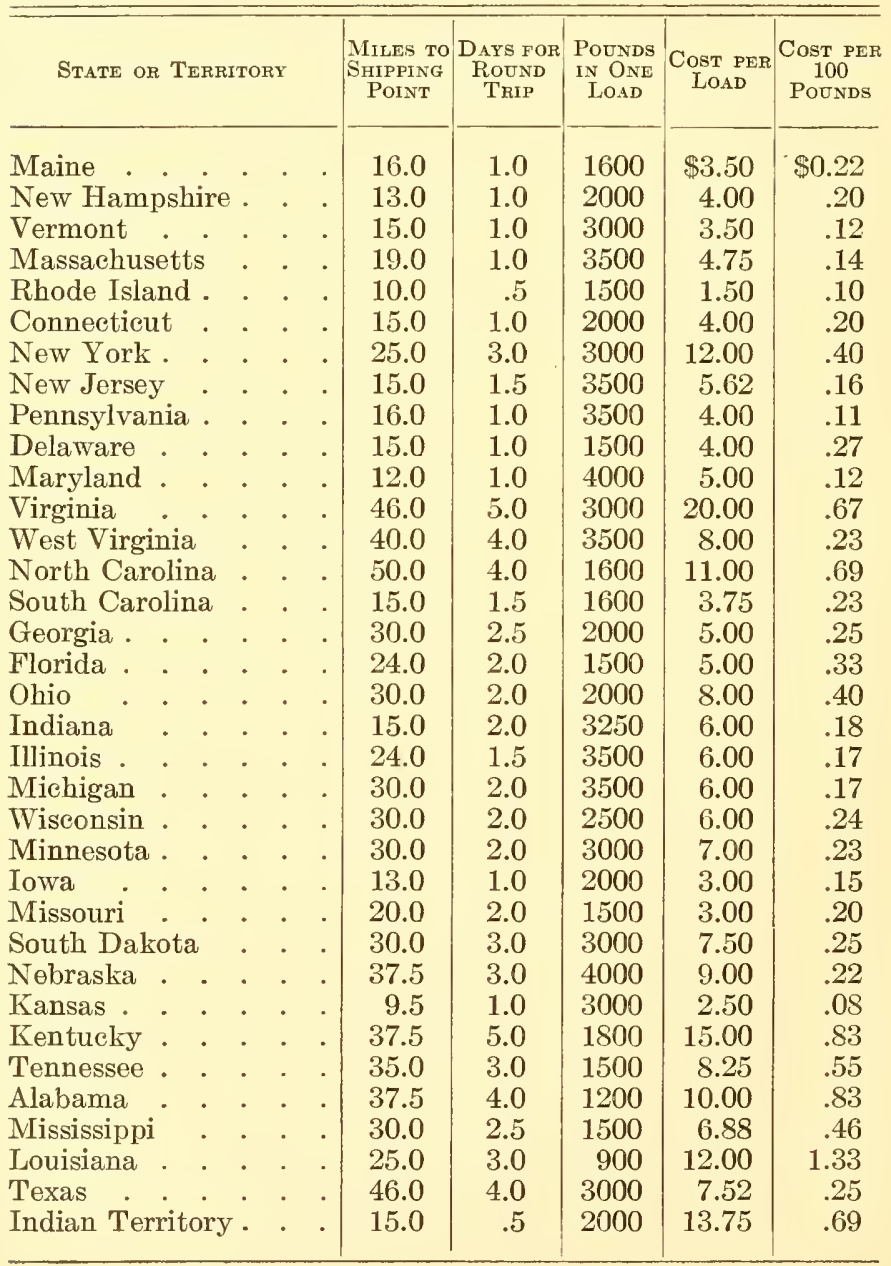




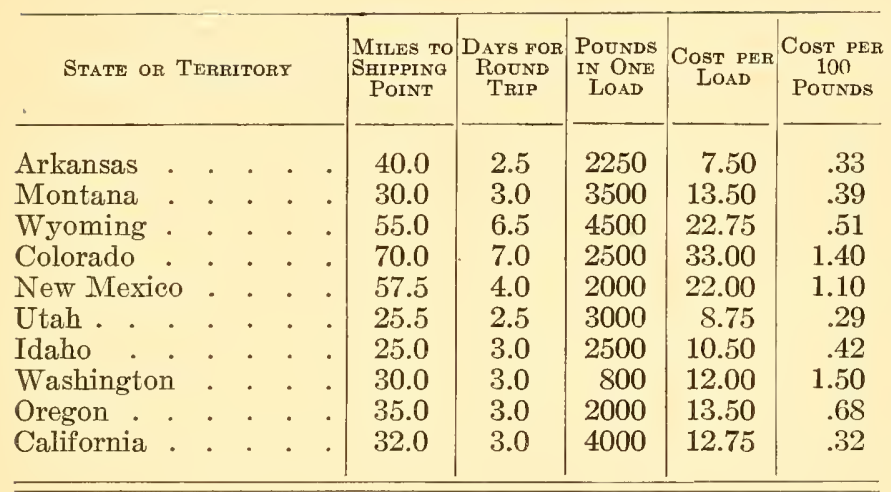





\section{INDEX}

Africa, production of potatoes in, 3 . alcohol, manufacture of, 274 . slops or residue, 282.

use for, 271.

alfalfa in rotation, 111,112 .

alsike clover in rotation, 111.

Aroostook County, Me., as a potato center, 7, 113.

arsenical injury, 202.

Asia, production of potatoes in, 3 . association of characters in breeding, 75 .

Australia, production of potatoes in, 3.

Austria-Hungary, production of potatoes in, 2,3 .

bacteria in soils, 102 .

bacterial wilt, 200 .

Baker, 21.

barley, value in United States, 3 . world's erop, 1.

Bauhin, 15.

belladonna, 1 .

black-leg, 199.

blister-beetle, 175 .

bordeaux mixture, 217.

botanical characteristics, 21 .

breeding, 47-85 (chapter IV).

bud-selection, 57 .

bud-sports, 57, 76 .

calcium, 124.

Canada, production of potatoes in, $3,13$.

de Candolle, 15.

capsicum, 1.

Carbondale, Colo., as a potato center, 7.

Cardan, 15.
Chester County, Pa., potatoes consumed on farms, 12.

Cierça de Léon, 14.

classification, 21.

climate, 86 (chapter V).

Clusius, 15.

Colorado potato beetle, 170 .

composition of potatoes, 262 .

constitutional degeneracy, 205.

control measures against disease, 206-225 (chapter XI).

corn, value in United States, 3.

world's crop, 1.

cost of growing potatoes, 287-313 (chapter XV).

harvesting, 234.

hauling, 307.

cotton, value in United States, 3.

cover-crops, 105.

critical period, $89,95$.

crop reporter, 257.

crossing, method of, 78 .

cultivation of potato, 163 .

culture of potato, 89 .

curly dwarf, 203; control, 206.

cutting seed, 156.

cyanimid as fertilizer, 120, 121.

Dala potato, 73 .

Darwin, 76.

description of potato, 22 .

desiccated potatoes, 284 .

digging, methods of, 230 ,

disease, 97.

from organisms in soil, 212.

proof varieties, $50,221$.

diseases of potato, 183-205 (chapter $\mathrm{X})$.

Dodge, 70 .

drainage, 95. 
Early and late potatoes, marketing, 249.

early blight, 189 .

East, 74, 78, 82, 83.

eastern shore of $\mathrm{Va}$. and $\mathrm{Md}$. as potato centers, 7 .

egg-plant, 1.

engines, 165.

England, introduction into, 15.

Europe, production of potatoes in, 3.

European Russia, production of potatoes in, 2 .

expense of marketing, 255.

family consumption, statistics, 11 .

farm manures, 130.

fertilizer practices, 115, 126.

fertilizers, 113 (chapter VI).

market forms, 116.

Fischer, 75, 76.

Fitch, 25, 27, 30, 33.

flea-beetles, 173.

flour, potato, 284.

France, production of potatoes in, $2,3$.

freight charges, 253.

Fruwirth, 73, 74.

Funk, 11.

fusarium dry rot, 196. wilt, 195.

Gerard, 16.

Germany, production of potatoes in, 2,3 .

yields to the acre, 12 .

grading, 245.

Great Britain, yields to the acre, 12.

Greeley, Colo., as a potato center, 7 . green manures, 105.

growing crop, care of, 160 (chapter VIII).

hand planting, 151.

harvest, time to, 226.

harvesting cost, 234 .

labor, 234.

potatoes, 226-235 (chapter XII). hauling, cost of, 307 .

hay-plants, 109.

value of in United States, 3 .

heat, 90 .

heated cars, 253.

henbane, 1.

Herbal, 16.

Heriot, 47.

hill and clrill planting, 146.

hill selection, 54 .

history of potato, 14 (chapter II).

human food, uses as, 260.

Humboldt, 15.

hybridization, improvement by, 77-84.

ideals of the potato crop, 48,49 .

improvement, methods of, 56 .

individual selection, 62 .

insects, 170-182 (chapter IX).

Ireland, introduction into, 16.

Irish famine, 20.

Kaw Valley, as a potato center, 7 .

Kohler, 31, 33.

late blight, 190; treatment, 214.

leaf-hoppers, 129.

leaf roll, 204; control, 206.

Livingston County, N. Y., potatoes consumed on farms, 11.

local dealers, marketing through, 243.

McCormick variety, resistant to heat, 91 .

Macoun, 12.

Maine, production of potatoes in, 3.

manures and fertilizers, 113 (chapter VI).

marketing through local dealers, 243.

markets, 249.

and marketing, 237-258 (chapter XIII).

mass-selection, 61 .

Michigan, production of potatoes in, 3 . 
Milward, 33.

Minnesota, production of potatoes in, 3 .

mosaic, control, 206.

Myers, 59.

net necrosis, 203.

Newman, 73.

New York, production of potatoes in, 3.

State Potato Ass'n, score card of, 53.

nitrate of lime, 120.

nitrogen, 119.

Norfolk, Va., as a potato center, 7 .

North America, introduction into, 15.

production of potatoes in, 3 .

oats, value in United States, 3. world's crop, 1.

Orton, 73.

packages, 245.

papas, 16.

Paradisus, 16.

Parkinson, 16.

Parmentier, 18.

pedigree breeding, 62 .

Penn., production of potatoes in, 3 .

Peru, original home of potato, 14.

Phipps, 20.

phosphorus, 122.

picking and sorting, 232.

plant food, 94, 114.

planting, 133-142 (chapter VII).

hill and drill, 146.

tools, 148.

potassium, 123.

potato flour, 284.

plant louse, 177.

pomace, 283.

stalk weevil, 179.

wart, 198.

"Potatoes of Virginia," 18. value in United States, 3. poultry food, 283.

powdery scab, 201.

power for potato fields, 165 . price of potato land, 88 .

prices, 250 .

production on farms, statistics, 7 . world, 2.

in different countries, 2.

pure lines, 58 .

quality when cooked, 261.

Raleigh, Sir Walter, 15.

red clover in rotation, 111.

Red River Valley, as a potato center, 7.

rhizoctoniose, 194.

rice, world's crop, 1.

Rose, 14.

rotation, 86 (chapter V).

running out of varieties, 72 .

Russia, production of potatoes in, 3.

Sacramento, Cal., as a potato center, 7 .

Salaman, 78, 82, 83, 84 .

San Joaquin, Cal., as a potato center, 7 .

scab, common, 199.

powdery, 201.

score-card, 152.

seed, cutting, 156.

potatoes, 152.

treatment for scab, 153, 208.

selection, 55,57 .

shipping, 246.

silver scurf, 196.

soils, 86 (chapter V).

soil texture, 93.

Solanum Cardiophyllum, 21.

Commersonii, 21.

Jamesii, 21.

Maglia, 21.

oxycarpum, 21.

tuberosum, 21.

sorting, 232.

South America, production of potatoes in, 3 .

Spain, introduction into, 15.

Spillman, 12, 70 .

spindling sprout, 203. 
stalk borer, 180 .

starch manufacture, 265.

use for, 265,270 .

stock food, use as, 280.

storage, 258.

Stuart, 27, 33, 43, 45 .

sulphur, 126.

survey results, growing costs, 296.

texture of cooked potatoes, 263.

three-lined leaf-beetle, 176.

tillage, results of, 137. tools, 135 .

tip-burn, 168, 202.

tobacco, 1.

value in United States, 3.

tomato, 1.

tools, tillage, 35 .

tortoise beetles, 176 .

tractors, 165 .

tuber-unit, method of breeding, 62 . types of potato growing, 97 .

United Kingdom, production of potatoes in, 2 .

United States, production of potatoes in, 2,3 . yields to the acre, 12 .
Uses of potato, 259-286 (chapter XIV).

varieties of Iowa and central west, 25.

verticillium wilt, 196.

Waid's experiments, 72 .

Warren, 11.

water requirements, 92.

Webber, 62.

weed killing, 140.

wheat value in United States, 3.

world's crop, 1.

white grubs, 180.

wild potatoes, 47 .

Wilson, 81.

wire worms, 181.

Wisconsin, production of potatoes in, 3 .

yield, highest recorded in United States, 12.

yields, 12,87 .

Zavitz, 71. 
THE following pages contain advertisements of a few of the Macmillan books on kindred subjects 



\title{
The Standard Cyclopedia of Horticulture
}

\author{
Edited By L. H. BAILEY
}

\section{WITH THE ASSISTANCE OF OVER 500 COLLABORATORS}

New edition, entirely rewritten and enlarged, with many new features; with

24 plates in color, 96 full-page half tones, and over 4,000 text illustra-

tions. To be complete in six volumes. Volumes I, II, II1,

IV, and $V$ ready. Sold only in sets by subscription.

Each volume, $\$ 6.00$

Set cloth, $\$ 36.00$

Leather, $\$ 60.00$

"The Standard Cyclopedia of Horticulture," pronounced by experts to be an absolute necessity for every horticulturist and of tremendous value to every type of gardener, professional and amateur, is rapidly nearing completion. Only one more volume after this, the sixth, remains to be published. "An indispensable work of reference to every one interested in the land and its products, whether commercially or professionally, as a student or an amateur," is the Boston Transcript's characterization of it, while Horticulture adds that "it is very live literature for any one engaged in any department of the horticultural field."

“This really monumental performance will take rank as a standard in its class. Illustrations and text are admirable. ... Our own conviction is that while the future may bring forth amplified editions of the work, it will probably never be superseded. Recognizing its importance, the publishers have given it faultless form. The typography leaves nothing to be desired, the paper is calculated to stand wear and tear, and the work is at once handsomely and attractively bound." - Nere York Daily Tribune.

\section{THE MACMILLAN COMPANY}

Publishers

64-66 Fifth Avenue

New York 


\title{
THE RURAL MANUALS
}

Edited by L. H. BAILEY

\section{Manual of Milk Products}

By W. A. STOCKING, Jr.

\section{Manual of Fruit Diseases}

By L. R. HESSLER and H. H. WHETZEL

\section{The Pruning Manual}

\author{
By L. H. BAILEY
}

\section{Manual of Fruit Insects}

By MARK VERNON SLINGERLAND and CYRUS R. CROSBY

Of the New York State College of Agriculture, at Cornell University

\section{A Manual of Weeds}

Illustrated, $12 m o, 503$ pages, \$2.00

By ADA E. GEORGIA

Assistant in the Farm Course, New York State College of Agriculture, Cornell University With 385 Illustrations by F. SCHUYLER MATHEws

lllustrated, cloth, 12mo, 593 pages, index, \$2.00

\section{Manual of Farm Animals}

A Practical Guide to the Choosing, Breeding, and Keep of Horses, Cattle, SheEp, AND SWine

By MERRITT W. HARPER

Assistant Professor of Animal Husbandry in the New York State College of Agriculture, at Cornell University

lllustrated, 12mo, 545 pages, index, \$2.00

"A book deserving of close study as well as being handy for reference, and should be in the possession of every farmer interested in stock." - Kural World.

\section{Manual of Gardening}

A Practical Guide to the Making of Home Grounds and the Growing of Flowers, Fruits, and Vegetables for Home Use

By L. H. BAILEY

Illustrated, cloth, $12 m 0,544$ pages, \$2.00

This new work is a combination and revision of the main parts of two other books by the same author, "Garden-Making " and "Practical Garden Book," together with much new material and the result of the experience of ten added years.

\section{The Farm and Garden Rule Book}

\section{By L. H. BAILEY}

Revised and enlarged edition; illustrated, cloth, I2mo, \$2.00

It is essentially a small cyclopedia of ready rules and references packed full from cover to cover of condensed, meaty information and precepts on almost every leading subject connected with country life.

\section{THE MACMILLAN COMPANY}

Publishers

64-66 Fifth Avenue
New York 


\title{
THE RURAL OUTLOOK SET
}

\author{
By L. H. BAILEY
}

Four volumes. Each, cloth, 12mo. Uniform binding, attractively boxed. \$5.00 per set. Each volume also sold separately

In this set are included three of Professor Bailey's most popular books as well as a hitherto unpublished one - "The Country-Life Movement." The long and persistent demand for a uniform edition of these little classics is answered with the publication of this attractive series.

\section{The Country-Life Movement Cloth, Izmo, 220 pages, $\$ 7.25$}

This hitherto unpublished volume deals with the present movement for the redirection of rural civilization, discussing the real country-life problem as distinguished from the city problem, known as the back-to-the-land movement.

\section{The Outlook to Nature (New and Revised Edition)}

Cloth, I2mo, 195 pages, $\$ 1.25$

In this alive and bracing book, full of suggestions and encouragement, Professor Bailey argues the importance of contact with nature, a sympathetic attitude toward which "means greater efficiency, hopefulness, and repose."

\section{The State and the Farmer (New Edition) Cloth, Izmo, $\$ 7.25$}

It is the relation of the farmer to the government that Professor Bailey here discusses in its varying aspects. He deals specifically with the change in agricultural methods, in the shifting of the geographical centers of farming in the United States, and in the growth of agricultural institutions.

\section{The Nature Study Idea (New Edition) Cloth, I2mo, \$1.25}

"It would be well," the critic of The Tribune Farmer once wrote, "if "The Nature Study Idea' were in the hands of every person who favors nature study in the public schools, of every one who is opposed to it. and, most important, of every one who teaches it or thinks he does." It has been Professor Bailey's purpose to interpret the new school movement to put the young into relation and sympathy with nature, - a purpose which he has admirably accomplished.

\section{THE MACMILLAN COMPANY}

Publishers

64-66 Fifth Avenue

New York 


\title{
RURAL SGIENGE SERIES
}

\author{
Edited By L. H. BAILEY
}

\section{Each Volume Illustrated Cloth, 12 mo}

A series of practical books for farmers and gardeners, sold as a set or separately. Each one is the work of a competent specialist, and is suitable for consultation alike by the amateur or professional tiller of the soil, the scientist, or the student. Illustrations of marked beauty are freely used, and the books are clearly printed and well bound.

ON SELECTION OF LAND, ETG.

Isaac P. Roberts' The Farmstead

T. F. Hunt's How to Choose a Farm

ON TILLAGE, ETC.

F. H. King's The Soil

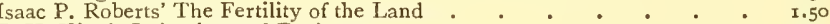

F. H. King's Irrigation and Drainage . . . . . . . . . . 1.50

Edward B. Voorhees' Fertilizers, New Edition : . . . . . . $\quad$ r.50

Edward B. Voorhees' Forage Crops . . . . . . . . . . 1.50

J. A. Widtsoe's Dry Farming . . . . . . . . . . . . . 1.50

L. H. Bailey's Principles of Agriculture . • . . . . . . . . . 1.25

S. M. Tracy's Forage Crops for the South . . . . . . Preparing

ON PLANT DISEASES, ETC.

E. G. Lodeman's The Spraying of Plants . . . . . . . . $\quad$ I.25

ON GARDEN-MAKING

A. W. Gilbert's The Potato D. Lumsden's Greenhouse Construction and Heating : $\quad$ : $\quad$ - . Preparing

L. H. Bailey's Garden-Making . . . . . . . . I.50

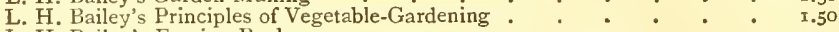

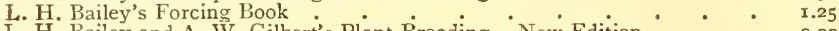

L. H. Bailey and A. W. Gilbert's Plant Breeding. 'New Edition : : : $\quad 2.00$

P. H. Rolf's Subtropical Vegetable-Gardening . . . . . . . I.50

ON FRUIT-GROWING, ETC.

L. H. Bailey's Nursery Book . . . . . . . . . . I.50

L. H. Bailey's Principles of Fruit-Growing. New Edition : $\quad \cdot \quad$ : $\quad$ : $\quad$ I.75

L. H. Bailey's The Pruning Book . . . . . . . . . 1.50

F. W. Card's Bush Fruits . . . . . . . . . 1.50

W. Paddock and O. B. Whipple's Fruit-Growing in Arid Regions : . I.50

J. E. Coit's Citrus Fruits . . . . . . . . . 2.00

S. W. Fletcher's The Strawberry in North America : : : : .

ON THE CARE OF LIVE-STOCK

Nelson S. Mayo's The Diseases of Animals . . . . . . . 1.50

W. H. Jordan's The Feeding of Animals . . . . . . . . . . . 1.50

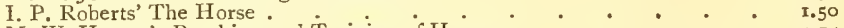

M. W. Harper's Breaking and Training of Horses . . . . . . . $\quad$ r.75

George C. Watson's Farm Poultry. New Edition . . . . . . 1.50

John A. Craig's Sheep Farming . . . . . . . . . . 1.50

E. F. Phillips' Beekeeping . • . . . . . . . . . . 2.00

ON DAIRY WORK, FARM CHEMISTRY, ETC.

Henry H. Wing's Milk and Its Products. New Edition . . . . I.50

J. G. Lipman's Bacteria and Country Life . . . . . . . . . r.50

ON ECONOMICS AND ORGANIZATION

William A. McKeever's Farm Boys and Girls. . . . . . . . I.50

I. P. Roberts' The Farmer's Business Handbook : : . : . . . 1.25

George T. Fairchild's Rural Wealth and Welfare . . . . . . . 1.25

H. N. Ogden's Rural Hygiene. . . . . . . . . . . . . 1.50

J. Green's Law for the American Farmer . . . . . . . . . . 1.50

G. H. Powell's Coöperation in Agriculture . . . . . . . . . . $\quad$ I.50

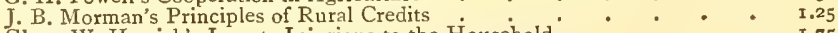

Glenn W. Herrick's Insects Injurious to the Household : . . . $\quad$ I.75

\section{THE MACMILLAN COMPANY}

\section{Publishers \\ 64-66 Fifth Avenue \\ New York}




\title{
RURAL TEXT-BOOK SERIES
}

\author{
Edited by L. H. BAILEY \\ Each volume įllustrated \\ Cloth, I2mo
}

While "The Rural Science Series" is designed primarily for popular reading and for general use, this related new series is designed for classroom work and for special use in consultation and reference. The "Rural Text-Book Series" is planned to cover eventually the entire range of public school and college texts.

Carleton, Mark Alfred. The Small Grains . . . . \$1.75

Duggar, B. M. Physiology of Plant Production . . . . 1.60

Duggar, John Frederick. Southern Field Crops • • • 1.75

Gay, C. Warren. Principles and Practice of Judging Live-Stock r.5O

The Breeds of Live-Stock. By Live-Stock Breeders . • I.75

Goff, E. S. The Principles of Plant Culture . . . . 1.25

Harper, M. W. Animal Husbandry for Schools . . . . I.40

Harris, Franklin S., and Stewakt, Grorge. The Principles of Agronomy . . . . . . . . . $\mathrm{I} .40$

Hiтснсоск, A. S. Grasses . . . . . . . . 1.50

JEFFERY, JosePH A. Text-Book of Land Drainage • • . 1.25

Livingston, George. Field Crop Production . . . . . I.40

Lyon, T. L., Fippin, E. O., and Buckman, H. O. Soils: Their

Properties and Management . . . . . . 1.90

Mann, A. R. Beginnings in Agriculture . , . • $\quad .75$

Montgomery, G. F. Corn Crops . . . . . . . 1.60

Piper, Charles V. Forage Plants and Their Culture . . . 1.75

WARREN, G. F. Elements of Agriculture . . . . . I.1O

Warren, G. F. Farm Management . . . • . 1.75

Wheeler, H. J. Manures and Fertilizers . . . . . 1.60

White, Edward A. Principles of Floriculture . • . . 1.75

Widtsoe, John A. Principles of Irrigation Practice • • . 1.75

\section{THE MACMILLAN COMPANY}

Publishers 64-66 Fifth Avenue New York










\section{LIBRARY OF CONGRESS}

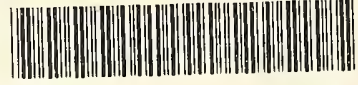

00026854805 